Keywords: Filter Cake, Cake Development, Scouring, Filter Enhancer, Flux Improvement

Retention: Permanent

\title{
Crossflow Filtration: EM-31, WP-2.3.6
}

M.R. Duignan

C.A. Nash

M.R. Poirier

February 2011

Savannah River National Laboratory Savannah River Nuclear Solutions, LLC Aiken, SC 29808

Prepared for the U.S. Department of Energy under contract number DE-AC09-08SR22470.

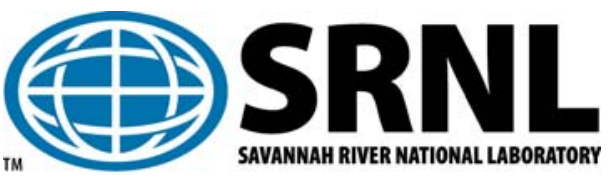


SRNL-STI-2011-00071

Revision 0

\section{DISCLAIMER}

This work was prepared under an agreement with and funded by the U.S. Government. Neither the U.S. Government or its employees, nor any of its contractors, subcontractors or their employees, makes any express or implied:

1. warranty or assumes any legal liability for the accuracy, completeness, or for the use or results of such use of any information, product, or process disclosed; or

2. representation that such use or results of such use would not infringe privately owned rights; or

3. endorsement or recommendation of any specifically identified commercial product, process, or service.

Any views and opinions of authors expressed in this work do not necessarily state or reflect those of the United States Government, or its contractors, or subcontractors.

\section{Printed in the United States of America \\ Prepared for \\ U.S. Department of Energy}




\section{REVIEWS AND APPROVALS}

AUTHORS:

M.R. Duignan, Engineering Develop Laboratory

Date

C.A. Nash, Actinide Characterization \& Processing

Date

M.R. Poirier, Actinide Characterization \& Processing

Date

TECHNICAL REVIEW:

M.E. Stone, Process Technology Programs

Date

APPROVAL:

B.J. Giddings, Manager

Date

Engineering Development Laboratory

S.L. Marra, Manager

Date

Environmental \& Chemical Process Technology Research Programs

W.R. Wilmarth, Advisory Scientist

Date

Environmental Management 


\section{ACKNOWLEDGMENTS}

This first part of EM-31 project WP-2.3.6 dealt with determining ways to improve crossflow filtration operations at both the DOE Savannah River Site and the DOE Hanford Site. It included both a literature review and experimentation. The authors would like to thank the SCUREF intern student, Caroline E. Johnson, for assisting in both tasks. Compiling and reviewing references, interviewing filtration researchers, and writing a summary of the background material was very useful to plan experimentation. Furthermore, Ms. Johnson's initial experimental work with the included dead-end filtration tests was invaluable to proceed with the subsequential crossflow filter tests.

As always, experiments cannot be performed in the Engineering Development Laboratory (EDL) without the assistance of many experienced engineers and specialists. Tim Steeper helped design the filter housings and his engineering input to the overall facility design was very important, Jerry Corbett created the necessary drawings for the flow system and Mike Restivo was very helpful with his knowledge on the valves and electrical equipment, Mike Williams assistance was very important to complete the Hazards Analysis Package paperwork and with the simulant development. Support from Jeff Smoland to analyze the safety aspects of project and his assistance to coordinate all the many individuals to complete the HAP is greatly appreciated. Advice and insight from John Steimke on all aspects of filter operation as well as that of the EDL manager, Bill Giddings, kept the work fundamentally sound.

The crossflow filter tests, which were performed in the EDL could not have been realized with assistance of the laboratory's experienced personnel. Doug Sumpter's technical staff and his planning were fundamental to the successful operation of the experiment. Vernon Bush did a great job with setting up the data acquisition system. We were lucky to have Jimmy Mills perform the instrument calibrations before his retirement in December 2010; we wish him well. Andy Foreman did a great job to support Mike Armstrong when he was unavailable. We are especial grateful to Mr. Armstrong (The Doc) for modifying the existing filtration equipment, operating the test facility, and efficiently address the many problems as they occurred. 


\section{EXECUTIVE SUMMARY}

In the interest of accelerating waste treatment processing, the DOE has funded studies to better understand filtration with the goal of improving filter fluxes in existing crossflow equipment. The Savannah River National Laboratory (SRNL) performed some of those studies, with a focus on start-up techniques, filter cake development, the application of filter aids (cake forming solid precoats), and body feeds (flux enhancing polymers). This paper discusses the progress of those filter studies.

Crossflow filtration is a key process step in many operating and planned waste treatment facilities to separate undissolved solids from supernate solutions. This separation technology generally has the advantage of self-cleaning through the action of wall shear stress created by the flow of waste slurry through the filter tubes. However, the ability of filter wall self-cleaning depends on the slurry being filtered. Many of the alkaline radioactive wastes are extremely challenging to filtration, e.g., those containing compounds of aluminum and iron, which have particles whose size and morphology reduce permeability.

Unfortunately, low filter flux can be a bottleneck in waste processing facilities such as the Savannah River Integrated Salt Disposition Process and the Hanford Waste Treatment Plant. Any improvement to the filtration rate would lead directly to increased throughput of the entire process. To date increased rates are generally realized by either increasing the crossflow filter feed flow rate, limited by pump capacity, or by increasing filter surface area, limited by space and increasing the required pump load.

SRNL set up both dead-end and crossflow filter tests to better understand filter performance based on filter media structure, flow conditions, filter cleaning, and several different types of filter aids and body feeds. Using non-radioactive simulated wastes, both chemically and physically similar to the actual radioactive wastes, the authors performed several tests to evaluate methods to improve filter performance. With the proper use of filter flow conditions and filter enhancers, filter flow rates can be increased over rates currently realized today.

Experiments that use non-radioactive simulants for actual waste always carry the inherent risk of not eliciting prototypic results; however, they will assist in focusing the scope needed to minimize radioactive testing and thus maximize safety. To that end this investigation has determined:

- Waste simulant SB6 was found to be more challenging to filtration than a SRS Tank 8F simulant.

- Higher solids concentration presents a greater challenge to filtration.

- Filter cake is something that should be properly developed in initial filter operation.

- Backpulsing is not necessary to maintain a good filter flux with salt wastes.

- Scouring a filter without cleaning will lead to improved filter performance.

- The presence of a filter cake can improve the solids separation by an order of magnitude as determined by turbidity.

- A well developed cake with periodic scouring may allow a good filter flux to be maintained for long periods of time.

- Filtrate flux decline is reversible when the concentration of the filtering slurry drops and the filter is scoured. 


\section{TABLE OF CONTENTS}

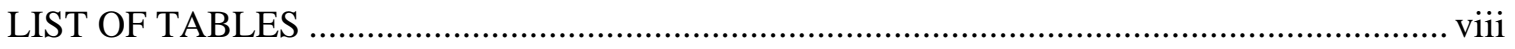

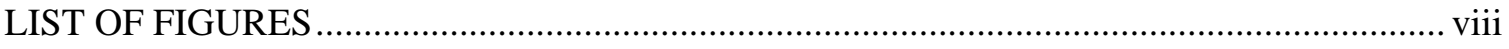

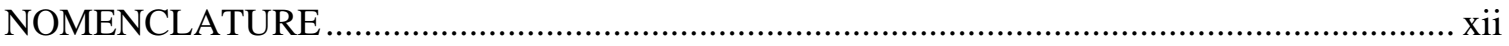

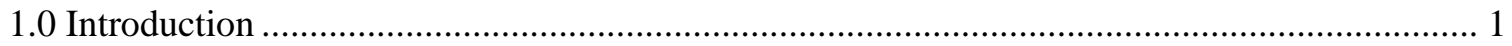

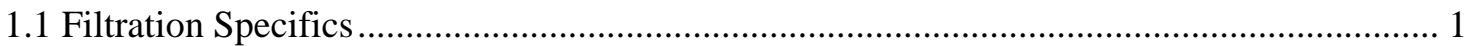

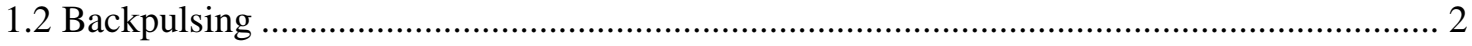

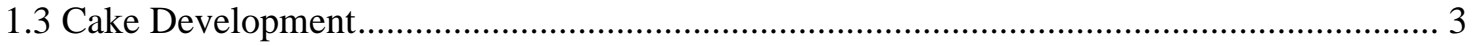

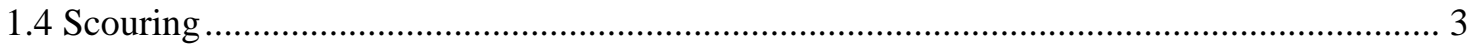

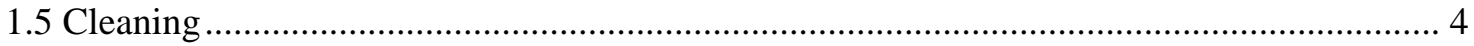

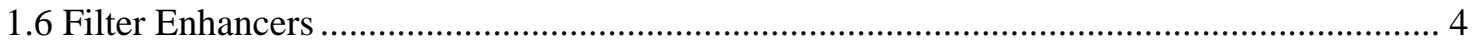

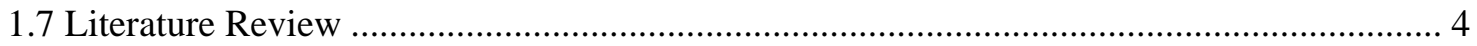

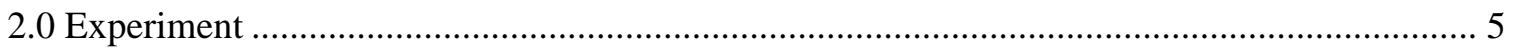

2.1 Filter Enhancers and Dead-End Filter Equipment ............................................................. 5

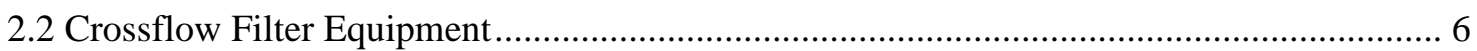

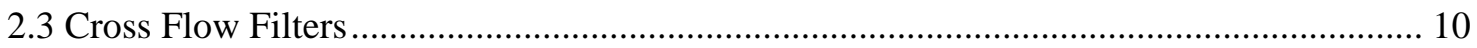

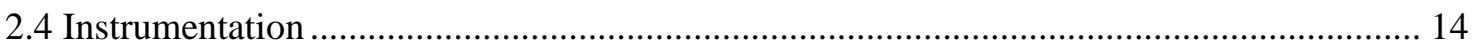

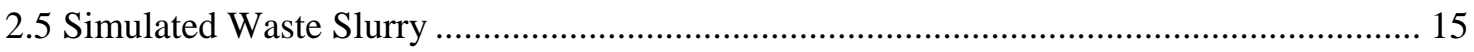

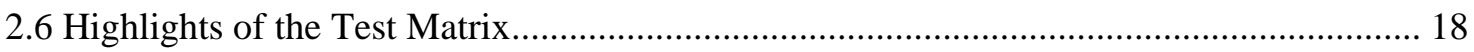

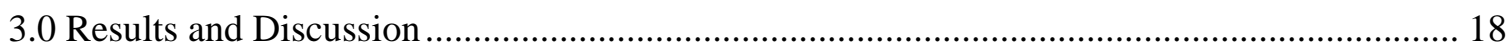

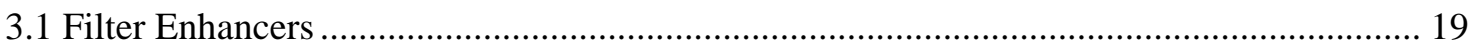

3.2 Crossflow Filtration: Cake Development - Long-Term Slurry Flux and 5 wt\% UDS, and

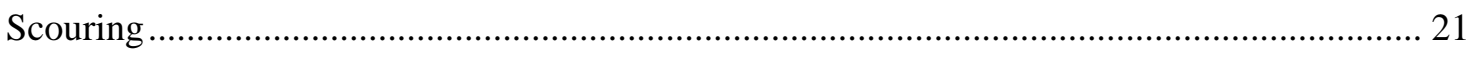

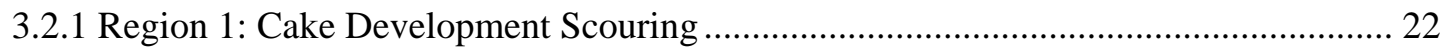

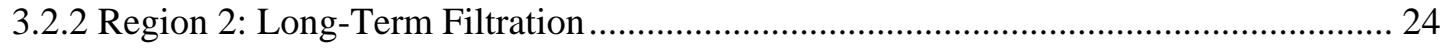

3.2.3 Regions 3, 5, and 6: Higher Flow Conditions ............................................................ 25

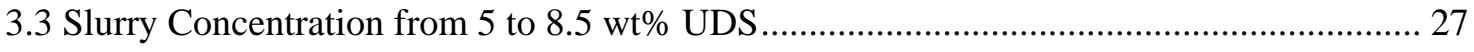

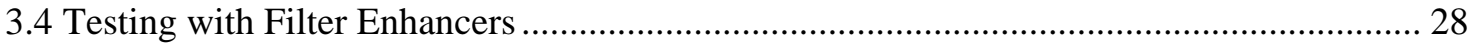

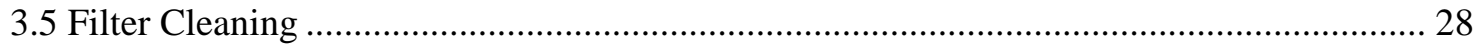

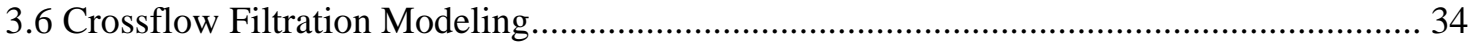

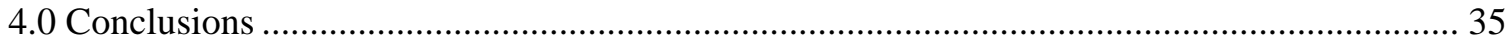

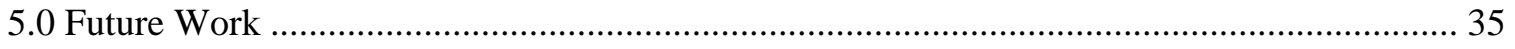

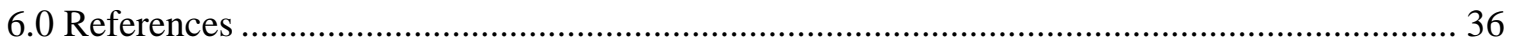


Appendix A: Instrumentation Installed on the Crossflow Filtration Test Facility ........................ 39

Appendix B: Crossflow Model Report by Nicholls State University ............................................ 43 


\section{LIST OF TABLES}

Table 1. Filter Enhancers Compared for Effect on Filtration.................................................. 6

Table 2. Error in Solids Due to Slurry Stream Split.......................................................... 10

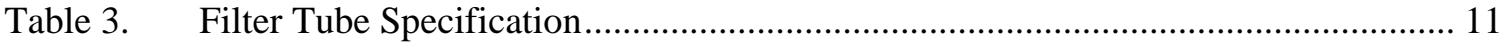

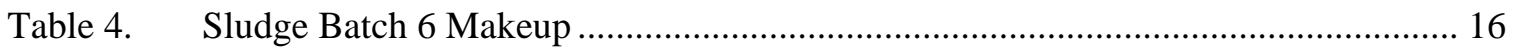

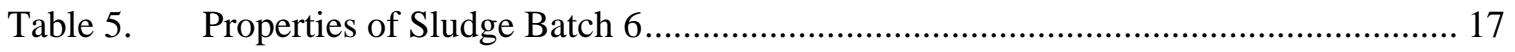

Table 6. Solids Concentrations of SB6 Slurry during the Concentration Test........................ 28

Table 7. Measure and Test Equipment on the Crossflow Filtration Test Facility................... 40

Table 8. Instument Location and Name used on the Test Facility (The first two columns correspond to the columns in the preceding table.)................................................. 41

Table 9. Calibration of Data Acquisiton Channels used by Equipment in Preceding Table... 42

\section{LIST OF FIGURES}

Figure 1. Crossflow Filtration - Liquid Separated from Flowing Slurry Tangentially through a Porous Wall and Filter Cake ...................................................................................... 1

Figure 2. Four Nalgene Dead-End Filter with 0.45-micron Nylon Filters Connected to the same Vacuum Source and Vacuum Gauge .............................................................. 6

Figure 3. Partial Drawing of the Pilot-Scale Crossflow Ultrafiltration Test Facility ................. 7

Figure 4. Schematic of the Pilot-Scale Crossflow Ultrafiltration Test Facility.......................... 8

Figure 5. Three Filters Studied, all are 24 inches Long. From Left to Right: 3/8-inch I.D. Pall, 0.1 micron Absolute Rated; 3/8 inch I.D. Mott, and 1/2-inch Mott, both 0.1 micron Nominal Rated Filters

Figure 6. Three Filters Shown Side by Side before Being Trimmed to 24 inches in length and placed in the Filter Housings and Having 22.5 inches of active length .................... 11

Figure 7. Installed Filter Tubes: (a) Side By Side, (b) Close Up........................................... 12

Figure 8. Operational Side of the Test Facility and Visible are the Computer, Two 10-hp Pumps, Slurry Reservoir to the Right and the Secondary Containment Pan at the Bottom.

Figure 9. Looking Down from the 2nd Level the Slurry Reservoir is Visible and Filled with Slurry, the Equipment Visible at Mid-Height Is some of the Measurement Equipment 
Figure 10. Slurry Reservoir Filled with the 5 wt\% SB6 Slurry with the Filtrate Exiting to the Top of the Slurry

Figure 11. The Cleaning Loop Reservoir and Solutions Were Located on the Top Level and filling was done with the Peristaltic Pump Seen in the Center of the Picture........... 14

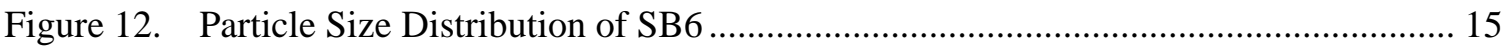

Figure 13. Sludge Batch 6 (batch 2) was Used for this Test. Note that 10 dyne/cm2 = $1 \mathrm{~Pa}$.... 15

Figure 14. Shown is the Range of Yield Stress of the Waste Stored in SRS Tanks (This Figure Indicates that SB6 Waste Shown in Preceding Figure has a Yield Stress Equivalent of Waste Tanks with the Highest Yield Stresses)

Figure 15. SB6 Sludge at $10.4 \mathrm{wt} \%$ solids loading before being mixing with the $5.6 \mathrm{M}$ supernate to attain a concentration of $5 \mathrm{wt} \%$

Figure 16. Dead End Test: $\mathrm{T}=21^{\circ} \mathrm{C}$, Transmembrane Pressure $=10$ psid.

Figure 17. Filters Coated with Filter Aids: (a) New, (b) SiC, (c) $\mathrm{TIO}_{2}$, (d) S-51HF, (e) S-51FF (See Table 1).

Figure 18. Dead End Test Comparison of Some of the Filter Aids in SB6 Slurry at a 5 wt\% Solids Loading: $\mathrm{T}=21^{\circ} \mathrm{C}$, Transmembrane Pressure $=10$ psid, Duration 200 to 300 minutes

Figure 19. Long Term 12-Day Filtration Test was Done at the Several Conditions Listed for the Three Filter Tubes at $25^{\circ} \mathrm{C} \pm 2^{\circ} \mathrm{C}$

Figure 20. Filter Performance at a Single Set of Flow Conditions at 5 wt\% Solids Loading .... 24

Figure 21. Filter Performances at a Single Set of Flow Conditions at 5 wt\% Solids Loading... 26

Figure 22. Regions 5 and 6 are Expanded to Be Seen Better ................................................ 26

Figure 23. Filtrate Flux as the Solids Loading Increasing through 4.5 hours of Filtration ........ 27

Figure 24. Filter Performance and Rinsing with Water and during the Circulation of $0.5 \mathrm{M}$ Oxalic Acid for 85 minutes

Figure 25. Filter Performance during the Circulation of $0.5 \mathrm{M}$ Oxalic Acid After the Filter Soaked in the Acid for more than 2 days

Figure 26. Filter Performance at the Start of Cleaning with Two Water Rinses, followed by 0.5 M Oxalic Acid on the first day, Indicated by (a) 30

Figure 27. Filter Performance on the $2^{\text {nd }}$ day of Cleaning with $0.5 \mathrm{M}$ Oxalic Acid, as Indicated by (b).

Figure 28. Filter Performance on the $3^{\text {rd }}$ day of Cleaning $0.5 \mathrm{M}$ Oxalic Acid after the Filter Soaked in the Acid for 3 days, then followed by Two Water Rinses.

Figure 29. Filter Performance on the $4^{\text {th }}$ day of Cleaning that Started with a Water Rinse after the Filter Sat in Water for 24 hours, Followed by a $2^{\text {nd }}$ Acid Cleaning. 33 
Figure 30. Filter Performance on the $5^{\text {th }}$ day of Cleaning after the Filter Soaked in Acid for Approximately 15 hours, which was then Rinsed Twice with Deionized Water...... 33

Figure 31. Filter Performance on the $6^{\text {th }}$ and Last day of Cleaning with a Final Water Rinse to

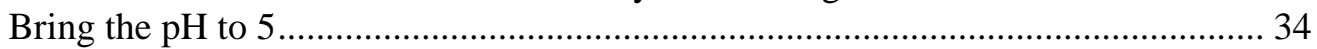




\section{NOMENCLATURE}

\begin{tabular}{|c|c|}
\hline SRNL & Savannah River National Laboratory \\
\hline${ }^{\circ} \mathrm{C}$ & Degree Centigrade \\
\hline cP & Centipoise \\
\hline COLIWASA & Composite Liquid Waste Sampler \\
\hline CUF & $\begin{array}{l}\text { Cells Ultrafiltration Facility (bench-top crossflow filter used with both } \\
\text { radioactively cold and hot wastes) }\end{array}$ \\
\hline DAS & Data Acquisition System \\
\hline DOE & United States Department of Energy \\
\hline EDL & Engineering Development Laboratory (part of SRNS/SRNL) \\
\hline $\mathrm{ft}$ & Foot \\
\hline$\gamma$ & Shear Rate, sec ${ }^{-1}$ (Rheology Parameter) \\
\hline gpm & Gallons Per Minute \\
\hline $\mathrm{h}$ & Hour (Time) \\
\hline I.D. & Inside Diameter \\
\hline in & inch \\
\hline $\mathrm{L}$ & Liter \\
\hline M & Molar $=$ Moles / Liter \\
\hline$\mu$ & Dynamic Viscosity, cP, (Rheology Parameter) \\
\hline$\mu_{0}$ & Consistency or Plastic Viscosity, cP, (Rheology Parameter) \\
\hline nominal & $\begin{array}{l}\text { The word "nominal" for a filter rating is a vague term because its } \\
\text { meaning is manufacturer dependent. Further, a "nominal" rating does not } \\
\text { give an exact size to a filter medium, but rather an approximation to the } \\
\text { expected performance of a filter. In the case of Mott, a nominal rated } \\
0.1-\mu \text { m filter means that approximately } 95 \% \text { of particles greater than } 0.1 \\
\mu \mathrm{m} \text { will not pass the filter }\end{array}$ \\
\hline O.D. & Outside diameter \\
\hline $\mathrm{Pa}$ & Pascal - Unit of Force \\
\hline PNNL & Pacific Northwest National Laboratory \\
\hline PSD & Particle Size Distribution \\
\hline psi & Pounds Per Square Inch \\
\hline psid & Pounds Per Square Inch Differential \\
\hline psig & Pounds Per Square Inch Gauge \\
\hline RPP-WTP & $\begin{array}{l}\text { River Protection Project - Waste Treatment and Immobilization Plant } \\
\text { (Hanford DOE) }\end{array}$ \\
\hline $\mathrm{s}$ & Second (Time) \\
\hline SRNS & Savannah River Nuclear Solutions - Principal Contractor managing SRS \\
\hline SRS & Savannah River Site \\
\hline
\end{tabular}


$\tau$

$\tau_{0}$

TMP

UDS

AV
Shear Stress, dynes $/ \mathrm{cm}^{2}$, (Rheology Parameter)

Yield Stress (Shear Stress at Shear Rate $=0$ ), dynes $/ \mathrm{cm}^{2}$, (Rheology

Parameter)

Transmembrane Pressure (the average pressure drop across the thickness of the filter medium - perpendicular to the slurry flow.)

Undissolved solids

Axial velocity - average velocity axially through a filter tube 


\subsection{Introduction}

Crossflow filtration is a widely used technology to separate liquids from solids, and the world market is projected to grow to ten billion dollars by 2015 [Flow Control, 2010]. While it is a well established technology, the method of use varies widely, and the efficiency of its separation varies for each different industrial application, especially within production-end product categories, from pharmaceutical to water treatment, hazardous waste treatment, etc. For the DOE Complex the stored radioactive wastes are being prepared for long-term storage and disposal with many technologies, but treatment of much of that waste begins with the separation of suspended solids from the liquid by filtration, including crossflow filtration. Filtration of these wastes can be very challenging. Such poor performance would be a bottleneck for an entire processing cycle. A better understanding of crossflow filtration with such wastes may help to increase filter performance and thus overall waste treatment throughput. This study finds that filter performance of existing hardware can be improved through refined operational methods.

\subsection{Filtration Specifics}

The two items of focus for crossflow filtration at the Savannah River and Hanford Sites are the filters themselves and the waste to be treated. Details of each are given later, but highlights are described here. Figure 1 is a diagram of a typical crossflow filter arrangement in a horizontal orientation but could be vertical or at some other inclination. The arrows in the center, parallel to the tube, represent the slurry flow or the axial velocity (AV) of the slurry. The arrow perpendicular, and outside the tube wall, represents the liquid, called the filtrate or permeate. The motive force that drives the liquid through the filter wall is the difference in pressure from the slurry to the filtrate and is referred to as the transmembrane pressure (TMP).

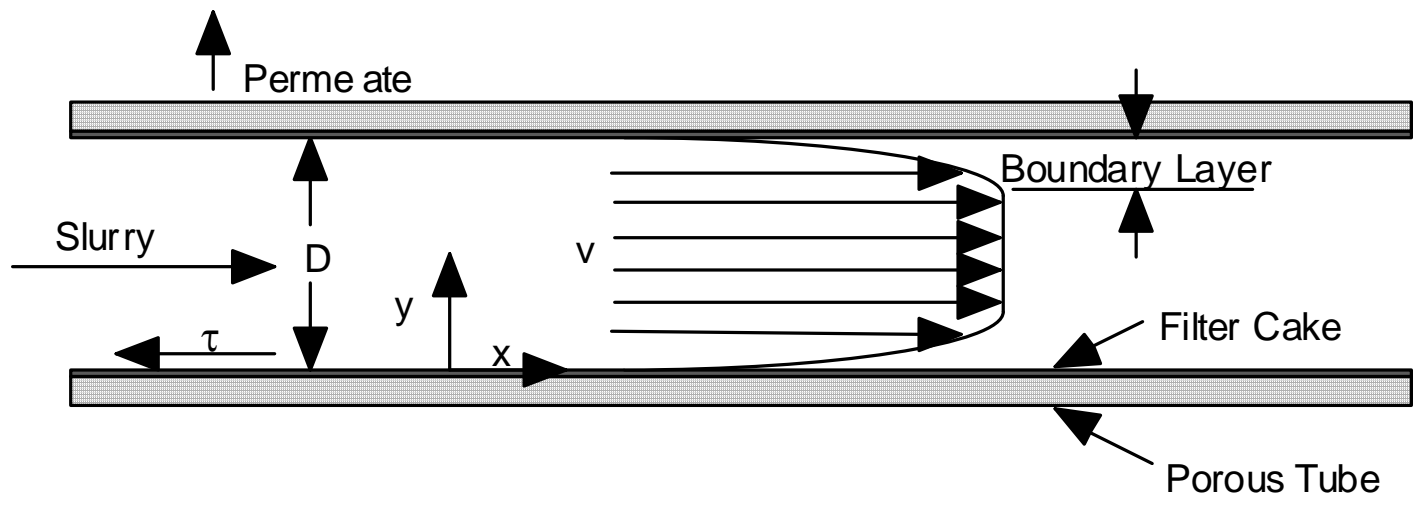

\section{Figure 1. Crossflow Filtration - Liquid Separated from Flowing ${ }^{\dagger}$ Slurry Tangentially through a Porous Wall and Filter Cake}

In the past many different filter media have been used at waste treatment facilities. Currently, two large treatment plants are under construction, the Waste Treatment Plant (WTP) at Hanford and the Salt Waste Processing Facility (SWPF) at Savannah River. For the former, the crossflow

\footnotetext{
${ }^{\dagger}$ Figure 1 depicts turbulent flow through a tube, i.e., see Fig. 5.4 in Tennekes and Lumley (1972)
} 
filters are 1/2-inch inside diameter stainless steel tubes, and for the latter, 3/8-inch inside diameter stainless steel tubes. This study determines differing performances between these filters. Both of these filters are made with a 0.1 micron nominal pore rating and of a symmetric sintered metal design. Because the only difference between these two filters is geometry, another tube design was added for comparison. This third tube has an asymmetric design, a 3/8-inch inside diameter, and a 0.1 micron absolute pore rating. While this last tube is still made primarily of sintered stainless steel, the inner tube surface is coated with a 10-micron thick layer of zirconia and it is this multilayer construction that is referred to as asymmetric [Mann et al., 2004]. To elicit a side-by-side performance of all three filter tubes they were placed in parallel in a test facility such that the same test simulant would flow through each at the same time. Because the properties of wastes to be treated can change with time, it is important to remove the issue of aging, which could confound results.

The range of wastes to be treated is large [Shimskey et al., 2011], but in general they usually have high soluble ionic strength, are basic, have small particles, i.e., $~ 1$ micron, and are radioactive. Due to the risk and costs of radioactivity, testing was done with a non-radioactive simulant; however, actual waste testing will be necessary in the future. The selected simulant was made so the chemical and physical properties were both similar to the actual waste. It was important to choose a waste that would be difficult to filter. The waste should contain components that make filtration difficult [Nash et al., 2000], e.g., iron and aluminum oxides and small particle size, and should have some past history of filtration so a comparison could be made. Two candidates that represent SRS wastes were initially selected, Sludge Batch 6 and Tank 8F. Due to limited resources, only one could be tested; therefore, they were both tested in a dead-end filter to make a final selection of one simulant.

\subsection{Backpulsing}

When dealing with micro or ultra-filtration, one operational issue often considered is how to maintain a filter surface free of cake. The rationale is that a cake-free surface will allow the solid-liquid separation to occur faster. To maintain a surface cake-free or minimize cake buildup, the predominant method is backpulsing. In many cases such as the water treatment industry, backpulsing is absolutely necessary to maintain a high permeate flux [Ramirez et al., 1998]. Some backpulsing frequencies can be quite high; for instance, it could be as high as $1 \mathrm{~Hz}$ used by some in the biochemical industry [Levesley and Hoare, 1998] where the backpulse duration lasts only fractions of a second. Some [Mores et al., 2000] state that "one method of reducing membrane fouling is rapid backpulsing" where backpulsing involves the reversal of the permeate flow through the filter membrane for very short periods, and that this "can provide in situ cleaning by removing some of the foulants from the membrane surface or pores." Up to a 30-fold increase with backpulsing over no backpulsing has been realized.

At issue is an ongoing need to keep the filter surface clean, i.e., free of cake. Is this the approach method for all slurries? When waste processing plants were designed to treat stored salt wastes at the Hanford and Savannah River sites, backpulsing was included to help maintain filter fluxes high. Unfortunately, after more than a decade of filter tests with salt wastes backpulsing has not been very effective [Duignan et al., 2002; Duignan, 2003; Daniel et al., 2009]. While much time and effort were invested to design robust flow-reversing systems, results have not been promising.

Along with backpulsing, another method to keep the filter surface clean, or to minimize cake buildup, was to flow the suspension fluid very fast past the filter surface, so the shear stress would strip the cake from the wall (Van Brunt et al., 2000). However, typical axial flowrates 
used in operation, e.g., 12-15 ft/s, may not suffice for some suspensions that are viscous or have a strong affinity for the filtering surface. However, if it were possible to increase wall shear beyond what is possible solely from the flow of slurry, a shear rate may be attainable to keep the filter wall clean.

A higher wall shear stress was created with the concept of a rotary microfilter [Herman et al., 2010]. This rotary process spins the filtering surface at a rate such that the filter outer surface moves at more than $60 \mathrm{ft} / \mathrm{s}$. In fact, approximately $70 \%$ of the filtering surface is kept completely free of cake. Having a clean filtering surface leads to high filtering fluxes, but a cake-free surface leads to other problems. When the filter is keep clean, either by backpulsing or high shear rate, the surface is always exposed to the smallest particles in a slurry. Specifically, for backpulsing it has been shown that once a cake is lifted off a filter surface the smallest particles are the first to return to the surface, which accelerates depth fouling [Fischer and Raasch, 1986; Lu and Ju, 1989]. Because of this fact, backpulsing was recommended to be kept at a minimum [Duignan, 2003].

\subsection{Cake Development}

Because of poor filter performances and the ineffectiveness of backpulsing with stored salt wastes [Nash et al., 2000; Duignan, 2003] SRNL test plans were developed to filter without any backpulses. Furthermore, instead of trying to avoid cake buildup, the desire was to actively establish a cake, but one that would be more permeable and lead to better filter fluxes. Of course, the filter membrane itself is a filter, but by the forming of a filter cake on the surface a secondary filter is established [Murkes and Carlsson, 1988]. When forming a cake, it is always important to take into account the nature of the slurries and sludges being filtered [Defrance and Jaffrin, 1999]. From past work [Duignan, 2003] it appeared that waste solids adhered well to the filter surface based on the loss of the backpulse effectiveness in a very short time (hours). In this short time period filter depth fouling was probably unlikely. Unfortunately, there is no direct evidence of surface adhesion or fast depth fouling; therefore, an assumption of good adhesion led to the method of cake development used in this study. In the past, the procedure to start and maintain filtration was to fill the filtration and slurry systems, start filtration with an immediate backpulse, and then periodically backpulse when the filtrate flux became unacceptably low [Duignan, 2003, Duignan et al., 2002, Daniel, 2009]. Depending on the waste stream, the effectiveness of backpulsing dropped at different rates and eventually filtration had to be stopped to chemically clean the filter membrane to remove the depth fouling.

The intention of the present study was to not avoid cake buildup, but to actively establish a cake that would be permeable and act to filter even smaller particles than what the filter membrane was capable of handling. If successful then the developed cake would allow a high filtrate flux. Furthermore, to maintain the high flux, a mechanism of what will be called "scouring" was tried. This is an action of stripping off some of the established cake to remove the smallest particles [Ripperger and Altmann, 2002] by increasing the slurry axial velocity for a short period while no filtration is occurring.

\subsection{Scouring}

During the test many trials were performed to observe if filtrate flux could be improved while filtering without the need of cleaning. A method that seemed to work the best the authors termed 
"scouring." The intention was that when the filter is operating with an established filter cake, the filter flux would be stopped for a few minutes while slurry flow continued. Then axial velocity of the slurry would be increased by 50 to $80 \%$ above the operational velocity. After being held at this higher velocity, the velocity is then returned to the original value while filtrate flow is reestablished very slowly over an approximate 15-minute period. The hope was that scouring would leave a base filter cake, free of the smallest particles, which would return the filter rate to what was initially established at start-up. If successful the further hope was this process of scouring and reestablishing of a high filter flow could be repeated indefinitely.

\subsection{Cleaning}

Due to depth fouling, eventually the filter performance will drop to a non-productive level or the transmembrane pressure increases beyond what is sustainable. When a filter reaches this point, generally mechanical methods, e.g., backpulsing or high shear rates, become ineffective to recover filtration. Filtration needs to stop and the filters need to be cleaned chemically. Cleaning is obviously dependent on the material causing the fouling.

For salt wastes stored at SRS and Hanford, a series of different chemicals have been used, but the most common is $2 \mathrm{M}$ to $4 \mathrm{M}$ nitric acid or $0.5 \mathrm{M}$ oxalic acid. A benchtop study was performed [Poirier and Fink, 2002] using actual radioactive wastes that included both of these acids and concentrations and found these acids did a similar job of cleaning. The oxalic acid was more effective at dissolving iron, titanium, and silicon, while the nitric did better with aluminum; however, both continued to dissolve all the compounds during the 8-hours of contact time. While both nitric and oxalic acids have been used for years to dissolve waste compounds, the general consensus is that oxalic does a slightly better job [Daniel, 2009; Nash, 1995; Poirier et al., 2003a; Mann et al., 2004] and was used for this test.

\subsection{Filter Enhancers}

In an attempt to seek other methods to improve filter performance, several filter aids and body feeds were evaluated in a dead-end filter to obtain a good potential filter enhancer for crossflow filtration. Filter aids are substances that coat a filter to improve overall permeability. Body feeds are compounds made to react with a slurry to flocculate solids to hopefully create a more permeable cake. Unfortunately, the enhancer could not be tested in the crossflow due to the lack of time; therefore, it will be tested in the future.

\subsection{Literature Review}

Before performing work on the experimental work a review was done on past work to better plan the tests. Due to the large amount of work done on filtration at both sites, SRNL (Johnson and Duignan, 2011) and PNNL (Daniel et al., 2010), did separate reviews. The information is lengthy and will not be repeated here but the SRNL findings are:

- The rheology and particle size of the substance being filtered affects the rate of filtration, as shown by the various optimum operating conditions.

- Smaller particles can clog the pores or form a tight cake layer and thus significantly reduce the filtration rate. 
- High solids concentrations can reduce the overall filtrate flux, as well as the time it takes for the flux to reach a pseudo-steady-state value.

- The formation of the cake is dependent on several conditions, the most important of which is either a critical filtrate flux or transmembrane pressure. Once that critical state is reached, particle deposition can begin to form the layer.

- The thickness of the cake is determined by the shearing forces of the bulk flow across the filter surface.

- Increasing the axial velocity will increase the filtrate flux.

- Reducing slurry viscosity through diluting, e.g., washing, or increasing temperature, e.g., during leaching, increases the filter flux.

- Increasing the transmembrane pressure will increase filtrate flux, but only until a critical TMP value is reached. That critical value is different for different feed materials and different solids concentrations.

- Filter aids were often found to increase average filter flux for many slurries processed in crossflow filtration.

- Filter coatings were also tested and the hydrophilic polymer membranes seem to provide an improvement.

- Backpulsing produced mixed results. While it was often used successfully to clear (or partially clear) the filter cake from the surface of the membrane, it generally cannot remove the particles trapped in the pores of the filter, and worse, it seems to accelerate depth fouling.

- The volume of filtrate used by backpulsing dislodges a filter cake and the frequency of use reduces a filters effectiveness.

- After irreversible filter fouling from slurry containing metal oxide and hydroxide solids chemically cleaning with acid is necessary. Many chemicals were tested but the best results came with the nitric acid or the oxalic acid.

Considering the findings from the review the planned crossflow filtration tests:

- Determine an optimum set of operating conditions that will lead to a more permeable cake that will sustain a good filtrate flux for long periods of operation and result in a relatively clean filtrate stream.

- Reevaluate the need to backpulse by balancing its positive effect to maintain good filtrate flux and its negative effect of accelerating the irreversible situation of depth fouling.

- Determine if there is another method to maintain a good filtrate flux besides backpulsing.

- Evaluate the effectiveness of filter aids to improve filter performance.

\subsection{Experiment}

\subsection{Filter Enhancers and Dead-End Filter Equipment}

Six different substances were tested in the hope that at least one would help to enhance filtration by creating a more permeable filter cake, or filter surface, than without their use. The enhancers can be grouped as Filter Aids, which coat a porous filter surface, or Body Feeds, which flocculate slurry solids. Table 1 lists the filter enhancers tested.

To choose the most promising filter enhancer among the candidates in Table 1 a dead-end filter test was set up, as has been done in the past (Poirier, 2001). The dead-end filter test served two purposes: 1 . To choose a challenging slurry waste simulant from two available, which are described later, and 2. to evaluate the effectiveness of the filter enhancers. Figure 2 shows the dead-end filter set up with multiple filters in parallel so that a side by side comparison could be 
made with the different simulants at two different solids loadings, e.g., $0.1 \mathrm{wt} \%$ or $5 \mathrm{wt} \%$, and with the various filter enhancers.

Table 1. Filter Enhancers Compared for Effect on Filtration

\begin{tabular}{|c|c|c|c|c|c|}
\hline Enhancer Type & Enhancer Symbol & Location & Manufacturer & $\begin{array}{c}\text { Particle Size } \\
\left(\mathrm{d}_{50}, \text { micron }\right)\end{array}$ & $\begin{array}{c}\text { Bulk Density } \\
(\mathrm{g} / \mathrm{ml})\end{array}$ \\
\hline Silicon Cabide & $\mathrm{SiC}$ & Filter Aid & Many & 20 & 3.1 \\
\hline Titanium Oxide & $\mathrm{TiO}_{2}$ & Filter Aid & Many & 1 to 2 & 4.2 \\
\hline Activated Carbon & DARCO $^{\circledR}$ S-51HF & Filter Aid & Norit Americas, Inc. & 40 to 55 & 0.51 \\
\hline Activated Carbon & DARCO $^{\circledR}$ S-51FF & Filter Aid & Norit Americas, Inc. & 30 to 50 & 0.51 \\
\hline Flocculant & SUPERFLOC ${ }^{\circledR} \mathrm{HX}-200$ & Body Feed & Cytec Industries, Inc. & $\mathrm{NA}$ & $\mathrm{NA}$ \\
\hline Flocculant & PEO-Antiscalant & Body Feed & Cytec Industries, Inc. & $\mathrm{NA}$ & $\mathrm{NA}$ \\
\hline Note: NA = Not Applicable & & & \\
\hline
\end{tabular}

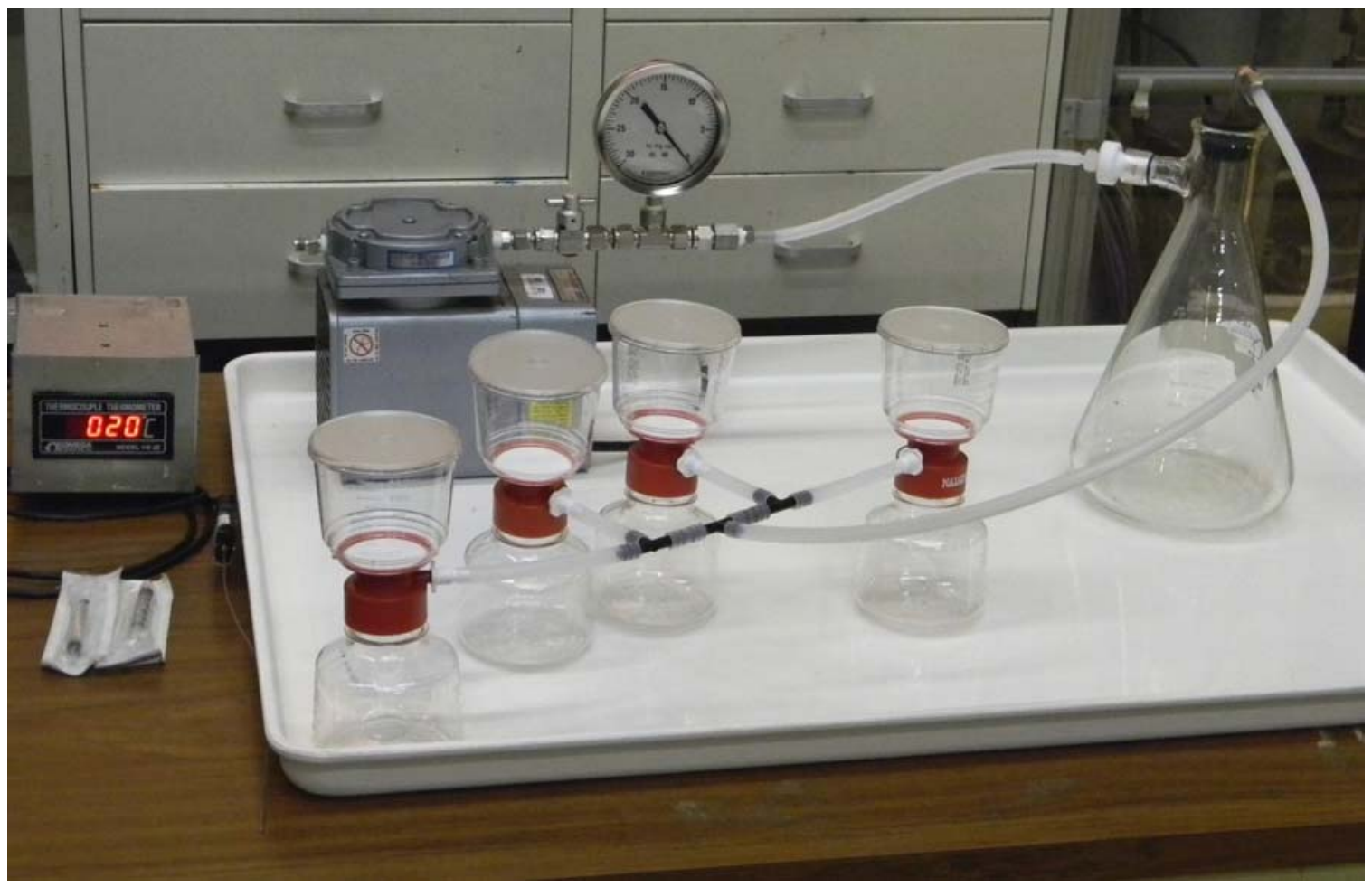

Figure 2. Four Nalgene Dead-End Filter with 0.45-micron Nylon Filters Connected to the same Vacuum Source and Vacuum Gauge

\subsection{Crossflow Filter Equipment}

Figure 3 is a partial drawing of the as-built test rig and Fig. 4 is a simplified schematic of the test rig that highlights key features. The facility stands approximately 25 -feet tall and is serviced by a two-level mezzanine. The test rig is taller than the 24-inch tall filter elements because it originally was used to test a 10 -foot tall filter (Steimke, 1994). Several modifications were made in order to install the current three crossflow filters. Most of the test rig was made of 300 series 
stainless steel with the majority being 304 stainless steel; however, filter tube housings and the tube runs to and from the housings were made of PVC.

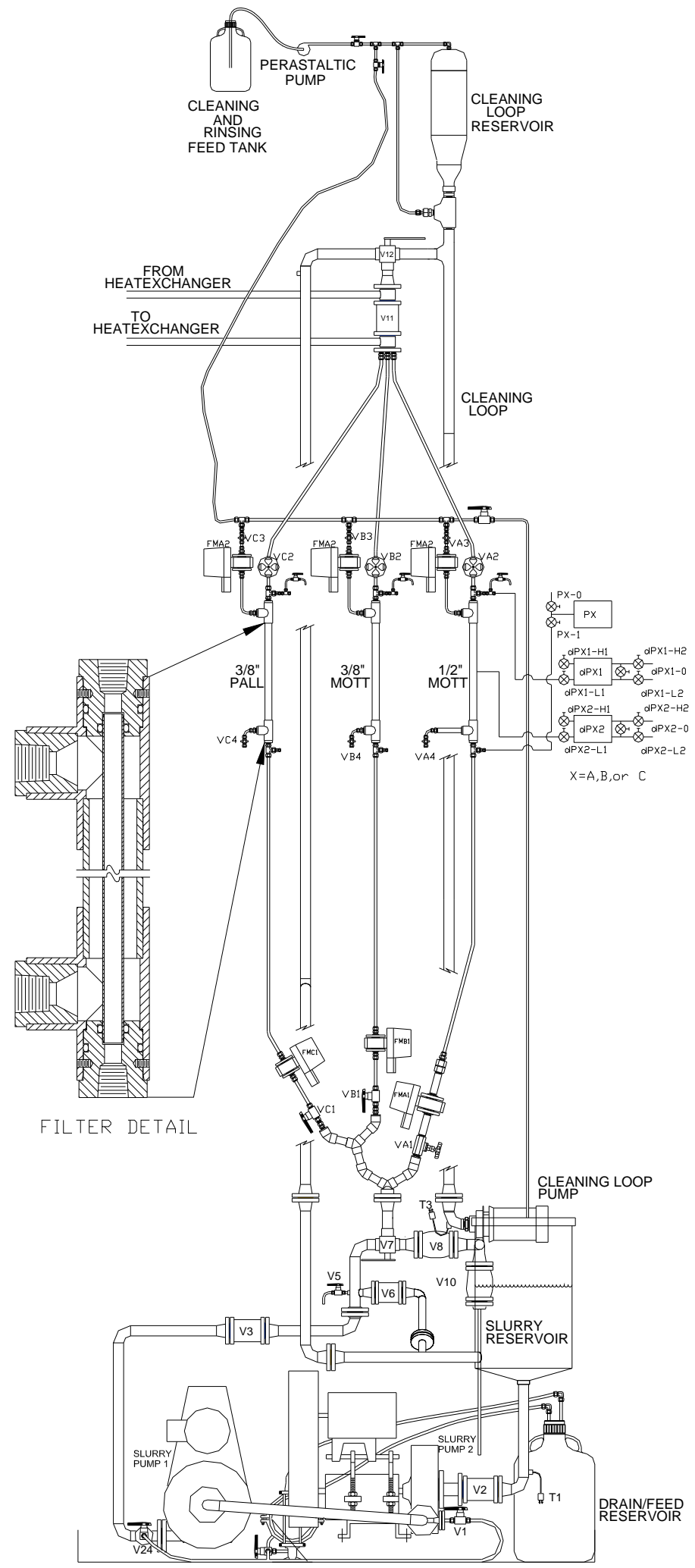

Figure 3. Partial Drawing of the Pilot-Scale Crossflow Ultrafiltration Test Facility 


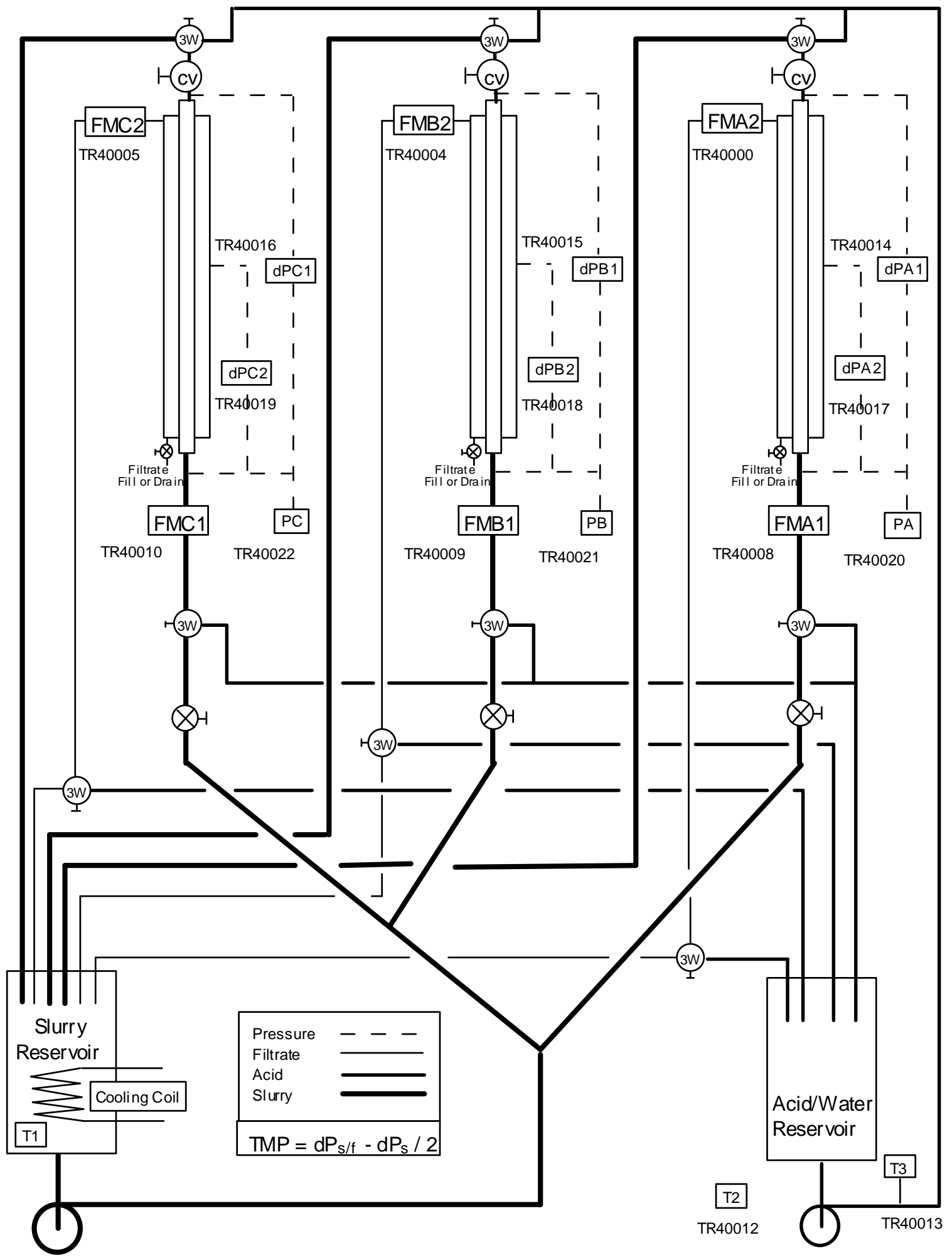

Figure 4. Schematic of the Pilot-Scale Crossflow Ultrafiltration Test Facility 
The test rig was made up of three basic flow loops:

1. Slurry loop - contains three 24-in long filters (22.5 in. active length) and their housings, which serve as the primary flow path for circulating slurry. This "loop” was really made of three sub-loops so that the three filters could be controlled separated in order to maintain the same flow conditions in each despite their geometric differences.

2. Filtrate loop - begins at the filter housing, allows the filtrate liquid from each filter to flow to a common header that was directed back to the slurry tank.

3. Cleaning loop - allows the three filters to be cleaned without removing most of the test slurry that remained in the lower portion of the test rig during cleaning.

To circulate slurries in the test rig, two $10 \mathrm{hp}$ Galigher centrifugal pumps were used. The impeller and impeller housing were lined with EPDM to be compatible with both the $\mathrm{pH}>14$ slurry that was tested and the $\mathrm{pH}<1$ acid cleaning solutions. The two pumps were used in series for the slurry loop to attain a pressure of greater than $65 \mathrm{psig}$ at $60 \mathrm{gpm}$.

Two other flow circuits are the recirculation and the backpulse loops:

1. The recirculation loop is part of the slurry loop (by using valve V6) and is used to better control the slurry flow. The recirculation loop helps to increase mixing and to maintain a well mixed slurry.

2. The backpulse loop is normally part of the facility but it was dismantled and therefore not shown. It is mentioned here because backpulse has always been a part of crossflow filtration. However, one goal of this task was to purposely develop a filter cake that would be more permeable than what was possible in the past. The purpose of a backpulse is to remove an established cake to clean the filter surface; therefore, it use was discontinued for this experiment.

Note, that when flowing slurry is split into different streams there is always the question whether all the streams will contain the same slurry. That is, the undissolved solids in the stream may not equally divide when the main stream is split. Both Figs. 3 and 4 show that the main stream is initially split into two streams and then one of those streams is further divided into two more streams. This is done so the 0.5-inch I.D. filter and the two 0.375-inch I.D. filters will all receive the same slurry and can be controlled to have the same axial velocity and transmembrane pressure. Based on the small sizes of the particles of SB6 slurry, being on the average less than 10 microns, a large variance in undissolved solids was not expected among the three streams. The slurry specifications will be further detailed later. Despite this expectation of similar stream makeup, slurry samples were taken before the stream splitters and then immediately downstream of each of the three filter tubes. Table 2 shows that within measurement uncertainty the streams were the same.

The other question to answer is whether slurry flowing from a sample valve accurately represented the slurry contained within the flow loops. Table 2 also compares sample results taken from sampling port V5, which is just before the slurry stream is split, to a sample taken directly from the slurry reservoir, Fig. 3. The results are identical and this means that samples take from a sample port, which are much easier to collect than with a COLIWASA, are accurate representations of the slurry within the flow loop. 
Table 2. Error in Solids Due to Slurry Stream Split

\begin{tabular}{|c|c|c|c|}
\hline \multicolumn{2}{|c|}{ Sample Port } & \multirow[b]{2}{*}{$\mathrm{w} t \%$} & \multirow[b]{2}{*}{$\%$} \\
\hline Number & Location & & \\
\hline \multicolumn{2}{|c|}{ Is the slurry in all three loops the same? } & UDS (1) & Error (2) \\
\hline V5 & Before Stream Split & 3.20 & \pm 12 \\
\hline VA2 & Downstream 1/2-Mott Filter & 3.05 & \pm 12 \\
\hline VB2 & Downstream 3/8-Mott Filter & 3.06 & \pm 12 \\
\hline VC2 & Downstream 3/8-Pall Filter & 3.27 & \pm 12 \\
\hline \multicolumn{2}{|c|}{ Is slurry in samples the same as the flow loop? } & TS (3) & Error \\
\hline $\begin{array}{c}\text { V5 } \\
\text { COLIWASA (4) }\end{array}$ & $\begin{array}{l}\text { Before Stream Split } \\
\text { Slurry Reservoir }\end{array}$ & $\begin{array}{l}21.33 \\
21.23\end{array}$ & \\
\hline \multicolumn{4}{|c|}{$\begin{array}{l}\text { (1) UDS = Undissolved or Suspended Solids } \\
\text { (2) The Analytical claimed uncertainty is } \pm 10 \% \text { but since UDS is } \\
\text { determined from two other measurements, i.e., Total Solids and } \\
\text { Dissolved Solids, which both have an accuracy of } \pm 10 \% \text { then UDS } \\
\text { uncertainty is slightly higher. } \\
\text { (3) TS = Total Solids }\end{array}$} \\
\hline
\end{tabular}

\subsection{Cross Flow Filters}

The main goal of this experimental task was to test and improve the productivity of various crossflow filter elements, including media currently in use at both SRS and Hanford. Their performance characteristics were tested with a challenging simulated waste slurry. The filter units received from the manufacturers are partially shown in Figs. 5 and 6. Once the 24-inch long tubes were installed in their housing the active filter surface length was 22.5 inches. The specifications for the filters are listed in Table 3.

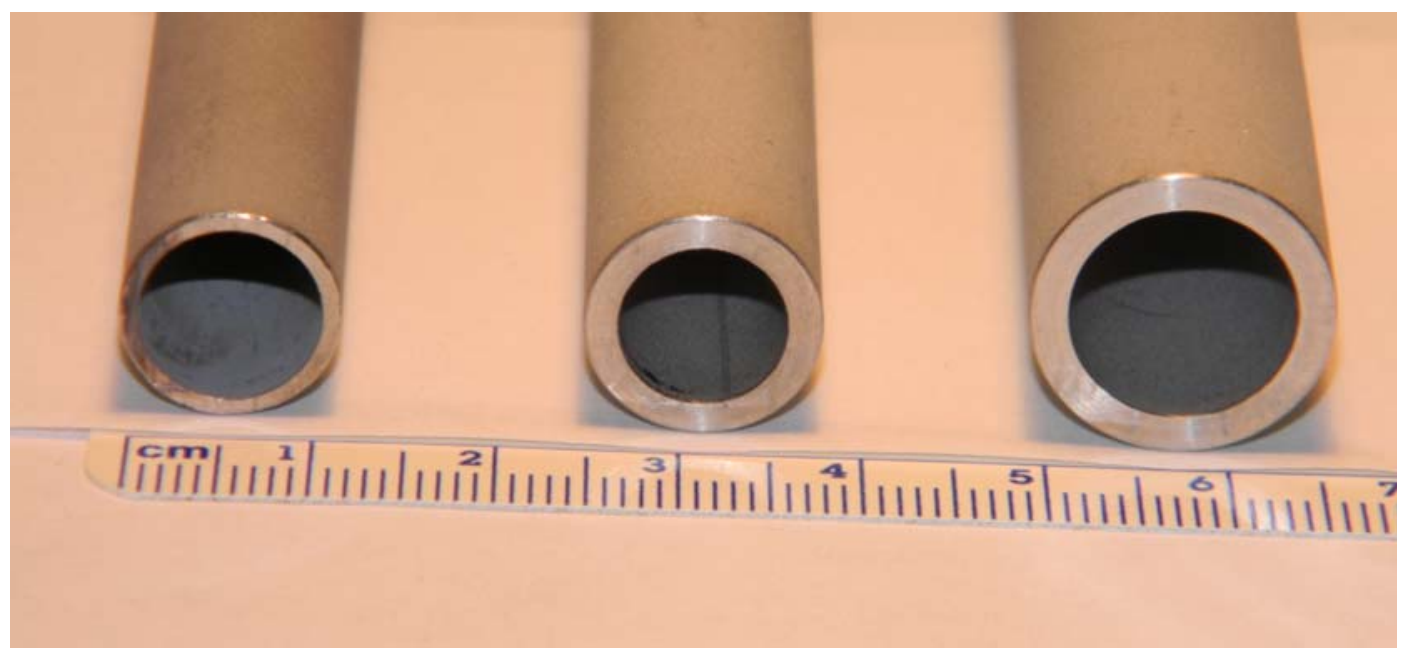

Figure 5. Three Filters Studied, all are 24 inches Long. From Left to Right: 3/8-inch I.D. Pall, 0.1 micron Absolute Rated; 3/8 inch I.D. Mott, and 1/2-inch Mott, both 0.1 micron Nominal Rated Filters 


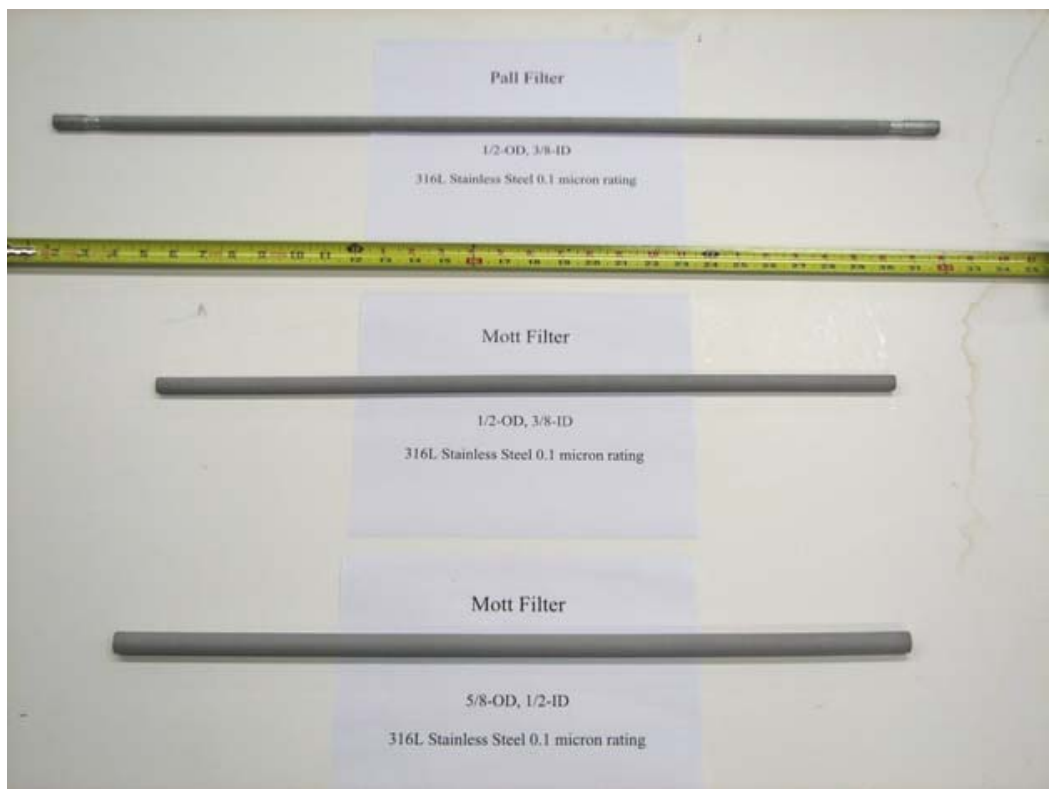

Figure 6. Three Filters Shown Side by Side before Being Trimmed to 24 inches in length and placed in the Filter Housings and Having 22.5 inches of active length

Table 3. Filter Tube Specification

\begin{tabular}{|c|c|c|c|c|c|c|c|}
\hline $\begin{array}{c}\text { Filter } \\
\text { (a) }\end{array}$ & $\begin{array}{c}\text { Actual } \\
\text { Inside } \\
\text { Diameter } \\
\text { inch }\end{array}$ & $\begin{array}{c}1 \times \\
\text { Standard } \\
\text { Deviation } \\
\text { inch }\end{array}$ & $\begin{array}{c}\text { Actual } \\
\text { Outside } \\
\text { Diameter } \\
\text { inch }\end{array}$ & $\begin{array}{c}\text { Medium Design } \\
\text { (b) }\end{array}$ & $\begin{array}{c}\text { Primary } \\
\text { Material }\end{array}$ & $\begin{array}{c}\text { Active } \\
\text { Length } \\
\text { in }\end{array}$ & $\begin{array}{c}\text { Filter Surface } \\
\text { Pore Rating (d) }\end{array}$ \\
\hline $\begin{array}{c}\text { 1/2-inch } \\
\text { Mott }\end{array}$ & 0.487 & 0.0026 & 0.653 & Symmetric & $\begin{array}{c}316 \mathrm{~L} \text { Stainless } \\
\text { Steel }\end{array}$ & 22.5 & 0.1 micron nominal \\
\hline $\begin{array}{c}\text { 3/8-inch } \\
\text { Mott }\end{array}$ & 0.363 & 0.0027 & 0.512 & Symmetric & $\begin{array}{c}316 \mathrm{~L} \text { Stainless } \\
\text { Steel }\end{array}$ & 22.5 & 0.1 micron nominal \\
\hline $\begin{array}{c}3 / 8 \text {-inch } \\
\text { Pall }\end{array}$ & $0.391)$ & 0.0033 & 0.480 & Asymmetric (c) & $\begin{array}{c}316 \text { L Stainless } \\
\text { Steel }\end{array}$ & 22.5 & 0.1 micron absolute \\
\hline
\end{tabular}

Notes:

(a) Mott, refers to the Mott Corporation; Pall, to the Pall Corporation.

(b) Symmetric = filter has same material and pore rating throughout, Asymmetric $=$ filter has two or more materials and pore ratings.

(c) Pall filter consists of 10 micron thick inner surface made of Ziconia and stainless steel substrate has a much larger pore rating.

(d) "Nominal" for a filter rating is vague because its meaning is manufacturer dependent. A "nominal" rating does not give an exact size to a filter medium, but rather an approximation to the expected performance of a filter. In the case of Mott, a nominal rated 0.1-micron filter means approximately $95 \%$ of particles greater than 0.1 micron will not pass the filter. For the 0.1 micron absolute rating $100 \%$ of particles greater than 0.1 micron will not pass the filter. A rough approximation between of the ratings is a 0.1 micron nominal has been equated to 0.7 micron nominal rating (Mann et al., 2004)

Figure 7 shows the tube installed in their housing that directed the separated liquid, filtrate, back to a centralized collection point that either returned to the slurry reservoir tank, when steady-state solids concentration was being used, or into a separate container, when the slurry was to be concentrated. Several aspects of the overall test facility are shown in Figs. 8 to 11. 


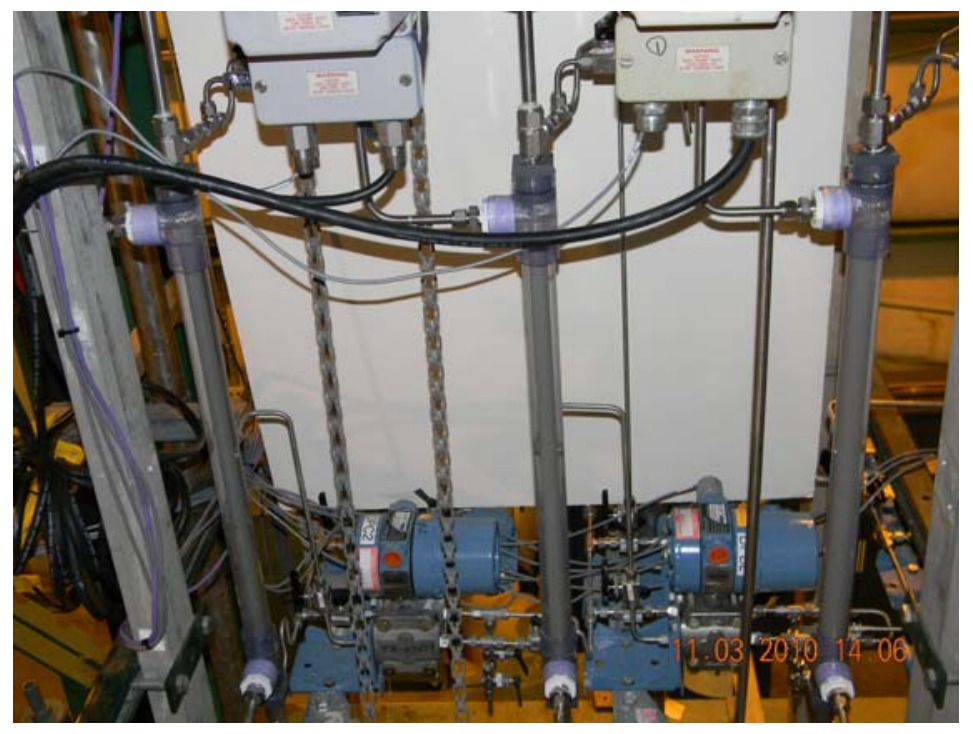

(a)

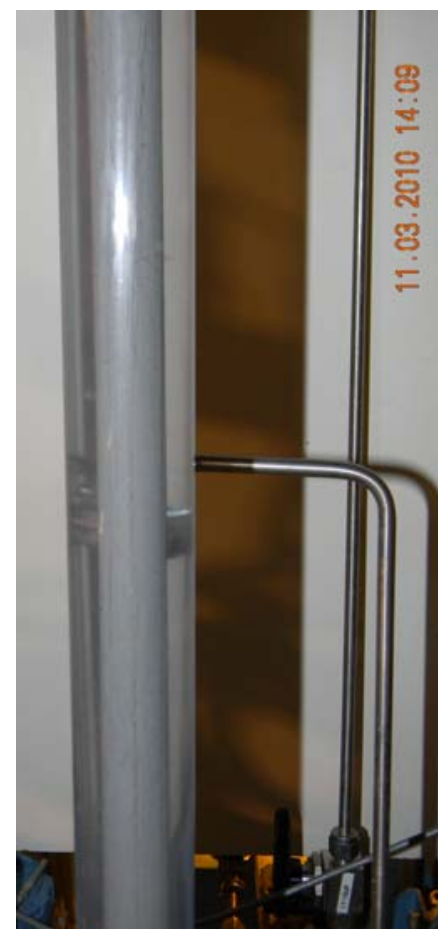

(b)

Figure 7. Installed Filter Tubes: (a) Side By Side, (b) Close Up

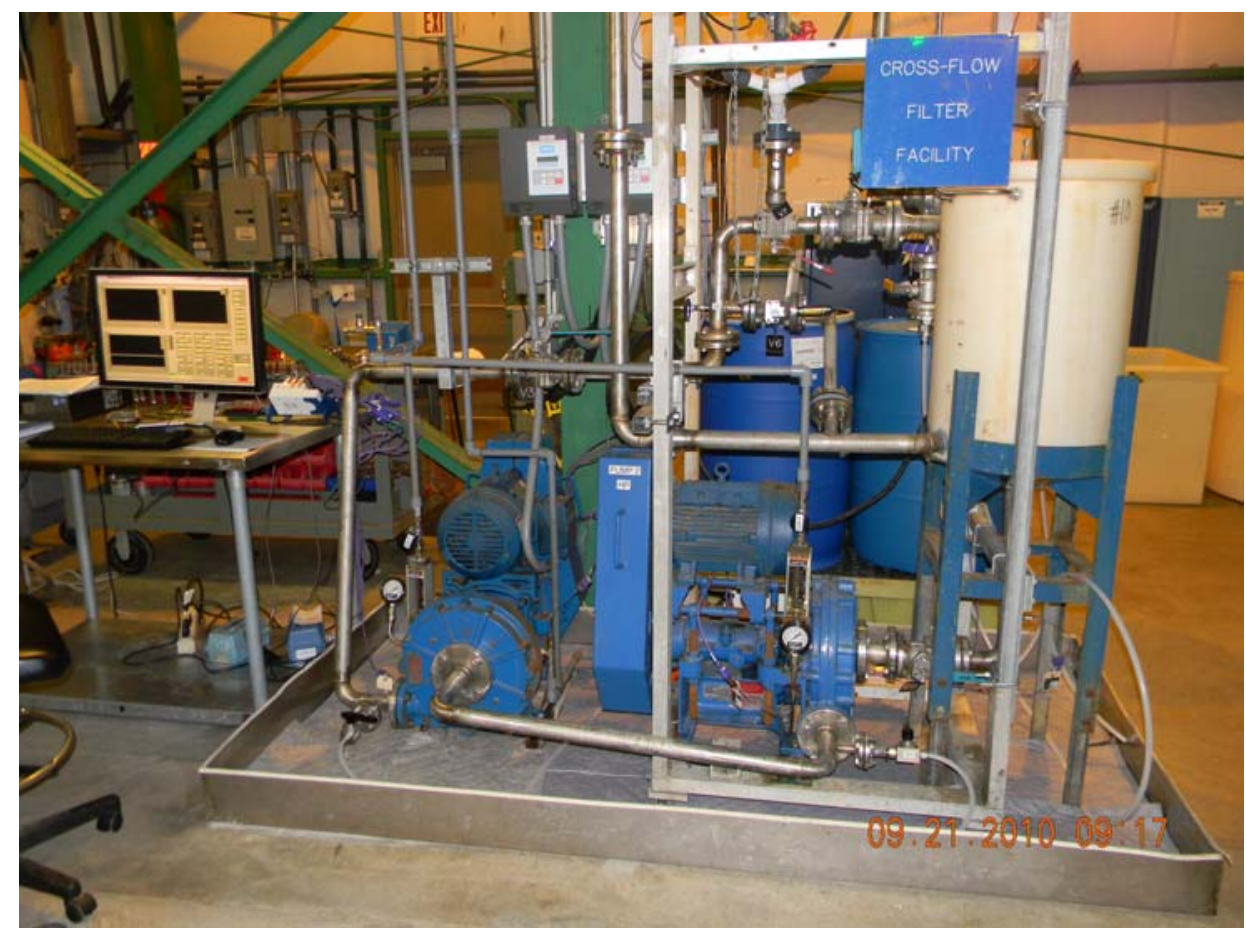

Figure 8. Operational Side of the Test Facility and Visible are the Computer, Two 10-hp Pumps, Slurry Reservoir to the Right and the Secondary Containment Pan at the Bottom 


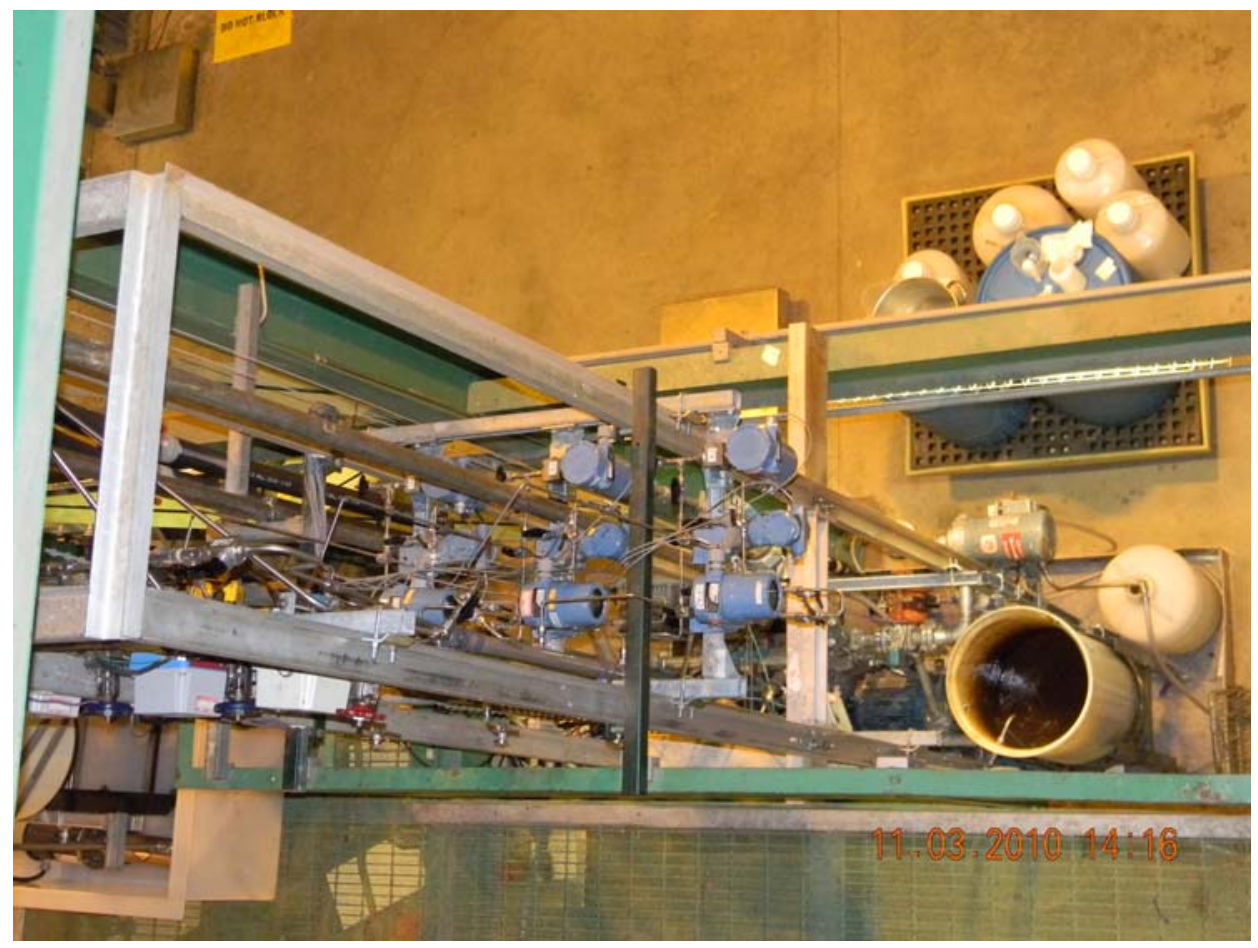

Figure 9. Looking Down from the 2nd Level the Slurry Reservoir is Visible and Filled with Slurry, the Equipment Visible at Mid-Height Is some of the Measurement Equipment

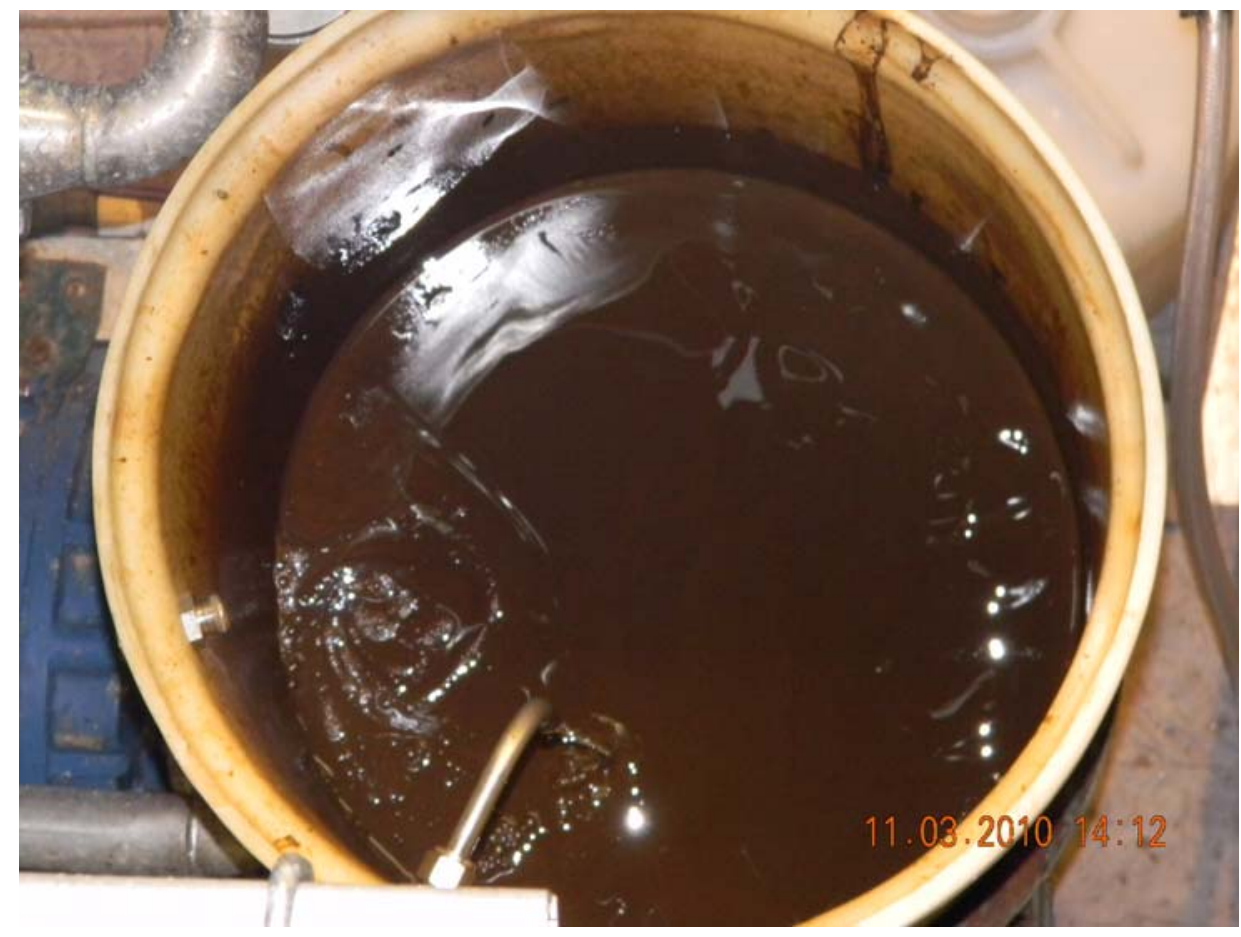

Figure 10. Slurry Reservoir Filled with the 5 wt\% SB6 Slurry with the Filtrate Exiting to the Top of the Slurry 


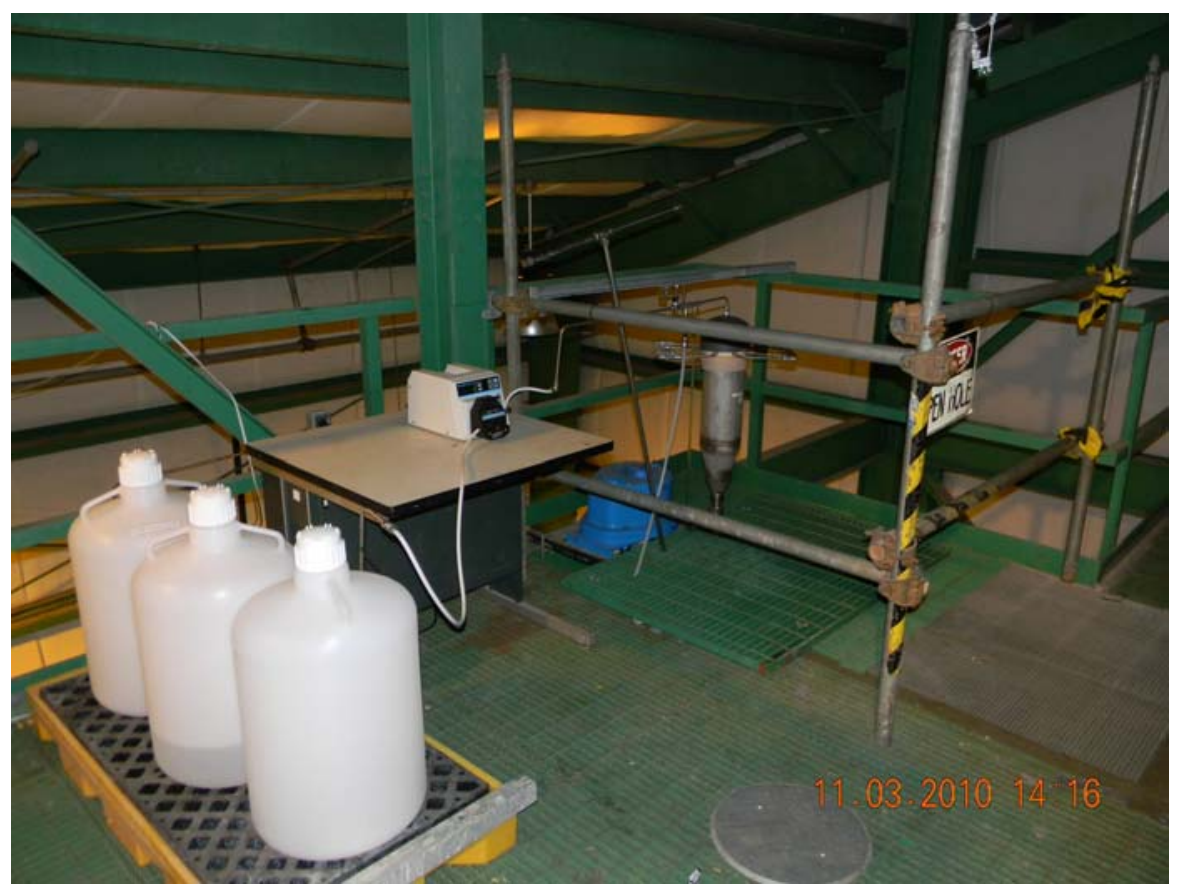

Figure 11. The Cleaning Loop Reservoir and Solutions Were Located on the Top Level and filling was done with the Peristaltic Pump Seen in the Center of the Picture

\subsection{Instrumentation}

The measurement equipment (see also Appendix A) used for this experiment was:

3 Type $\mathrm{E}$ thermocouples with accuracies*: 0.6 to $1.1^{\circ} \mathrm{C}$,

6 Differential pressure transducers with accuracies*: 0.02 to $0.12 \mathrm{psid}$

3 Gauge pressure transducers with accuracies*: 0.04 to 0.06 psig

3 Magnetic flow meters (filtrate) with accuracies*: 0.0005 to $0.0016 \mathrm{gpm}$

3 Magnetic flow meters for slurry with accuracies*: 0.03 to $0.06 \mathrm{gpm}$

1 Turbidity meter: $\pm 2 \%$ Reading or 0.01 NTU, whichever is greater

*accuracies are a function of the instrument and calibration. The uncertainty introduced through the use of the 16-bit data acquisition system was insignificant $(<0.1 \%$ reading) and was not included in the values above.

\section{Measurement Uncertainty}

The measurement uncertainties (95\% confidence level), for the important calculated quantities were estimated to be:

Slurry Velocity in a Filter Tube: $\pm 9 \%$

Transmembrane Pressure: $\quad \pm 1 \%$

Filtrate Flux: $\quad \pm 12 \%$ 


\subsection{Simulated Waste Slurry}

Two waste simulants were obtained for this test: a HM Waste Sludge - Sludge Batch 6 (SB6) and a Purex Waste Sludge - SRS Tank 8F.

In a separate dead-end filter test, for which the results will be described later, the SB6 was found to filter significantly slower than the Tank 8F waste. Therefore, the SB6 was chosen for the crossflow filter test and the properties of the SB6 sludge properties are shown below in Figs. 1214 and Tables 4-5.

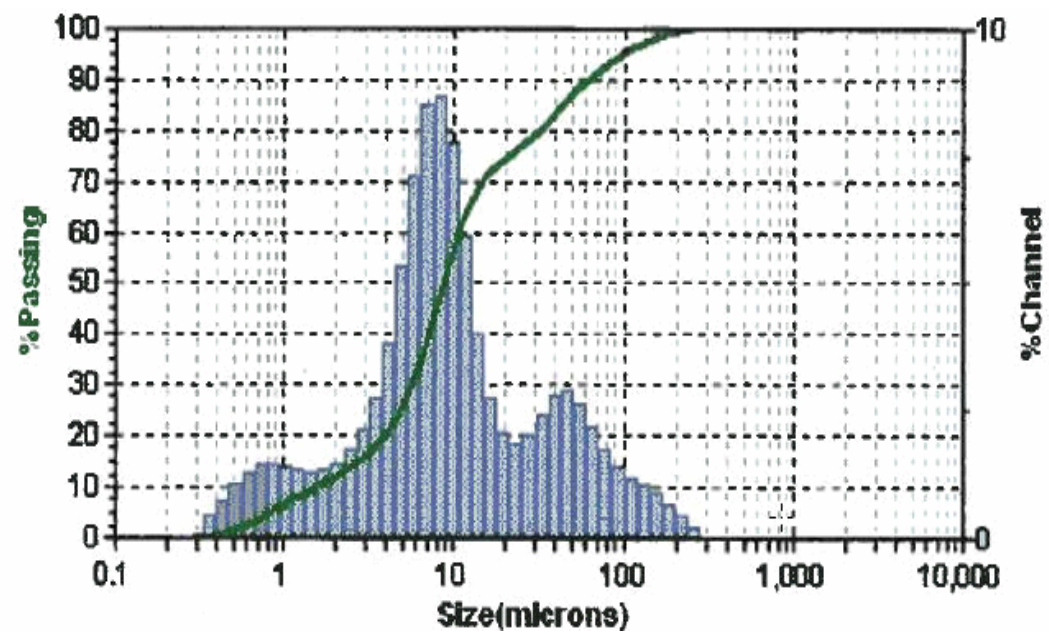

Figure 12. Particle Size Distribution of SB6

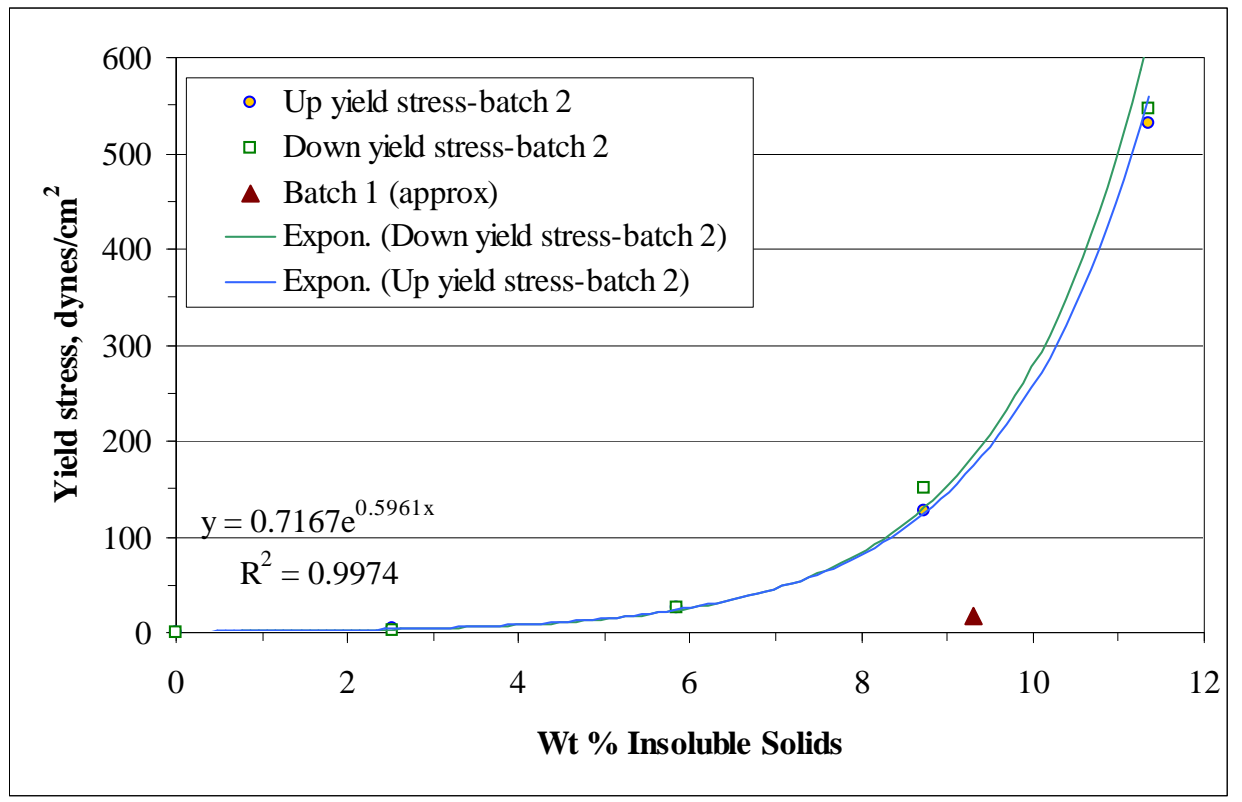

Figure 13. Sludge Batch 6 (Batch 2) was Used for this Test. Note that 10 dyne/cm2 $=1$ Pa 
Sludge Yield Stress Dependence on Insoluble Solids

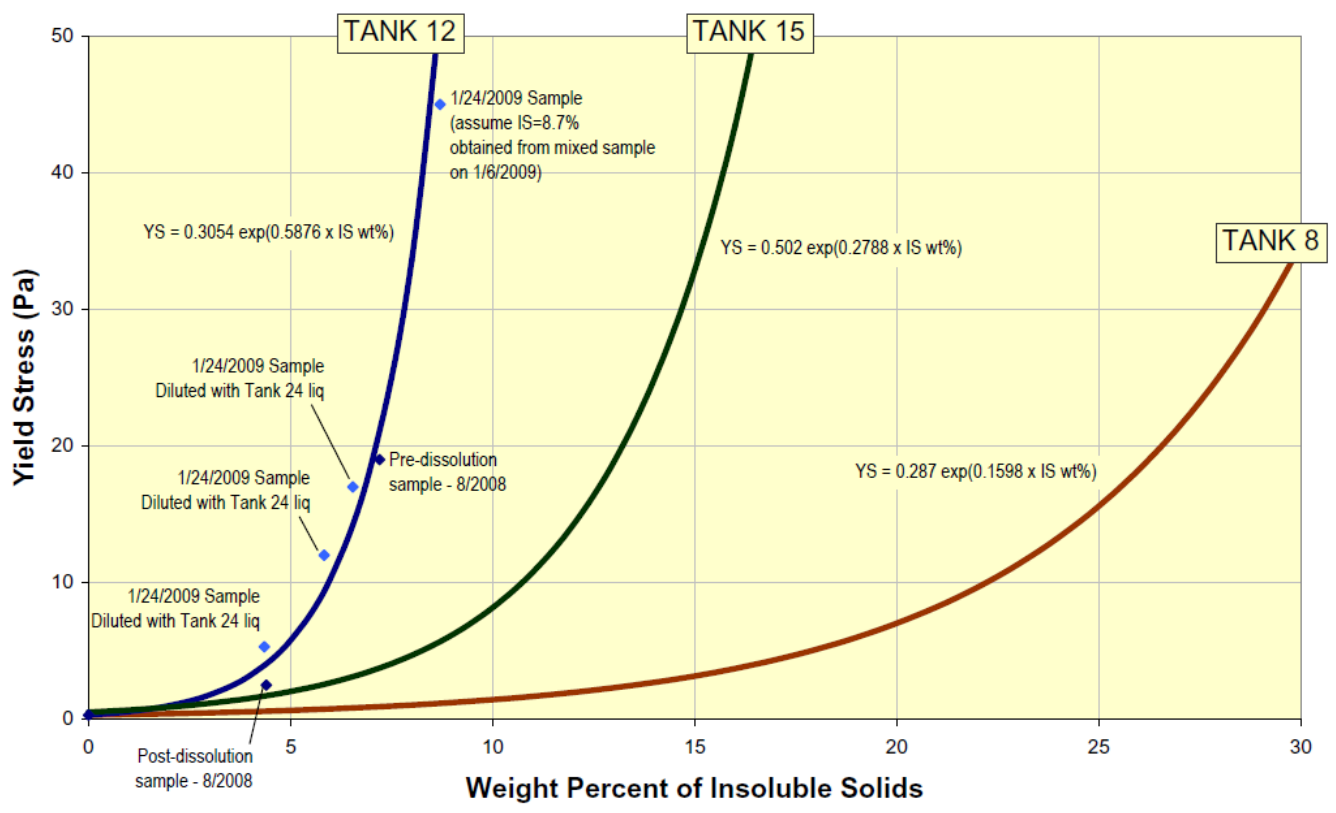

Figure 14. Shown is the Range of Yield Stress of the Waste Stored in SRS Tanks

Note that Fig. 14 indicates the SB6 waste shown in Fig. 13 has a yield stress representative of waste tanks with the highest yield stresses.

Table 4. Sludge Batch 6 Makeup

\begin{tabular}{|c|c|c|}
\hline Component & \multicolumn{2}{|c|}{ Calcined Solids, wt\% } \\
\hline & Target & Actual \\
\hline $\mathrm{Al}$ & 16.181 & 15.80 \\
\hline $\mathrm{Ca}$ & 1.147 & 1.08 \\
\hline $\mathrm{Ce}$ & 0.085 & 0.08 \\
\hline $\mathrm{Cu}$ & 0.085 & 0.10 \\
\hline $\mathrm{Fe}$ & 17.743 & 18.02 \\
\hline $\mathrm{K}$ & 0.021 & 0.24 \\
\hline $\mathrm{La}$ & 0.074 & 0.08 \\
\hline $\mathrm{Mg}$ & 0.552 & 0.55 \\
\hline $\mathrm{Mn}$ & 5.982 & 6.31 \\
\hline $\mathrm{Na}$ & 19.305 & 17.77 \\
\hline $\mathrm{Ni}$ & 2.231 & 2.30 \\
\hline $\mathrm{S}$ & 0.712 & 0.28 \\
\hline $\mathrm{Si}$ & 1.232 & 1.52 \\
\hline $\mathrm{Zn}$ & 0.053 & 0.06 \\
\hline $\mathrm{Zr}$ & 0.234 & 0.22 \\
\hline $\mathrm{Sum}$ & $\mathbf{6 6 . 0}$ & $\mathbf{6 4 . 4}$ \\
\hline
\end{tabular}


Table 5. Properties of Sludge Batch 6

\begin{tabular}{|l|l|l|}
\hline & \multicolumn{1}{|c|}{ Target } & \multicolumn{1}{|c|}{ Actual } \\
\hline Slurry density g/mL & $1.12 \pm 0.05$ & 1.12 \\
\hline Total Solids, wt \% & $18.17 \pm 2 \%$ & 16.7 \\
\hline Insoluble Solids, wt \% & $14 \pm 1 \%$ & 10.4 \\
\hline & & \\
\hline Anions & & \\
\hline Nitrite, NO$_{2-}$ & $8807 \pm 10 \%$ & 11100 \\
\hline Nitrate, $\mathrm{NO}_{3-}$ & $6096 \pm 10 \%$ & 6470 \\
\hline Phosphate, $\mathrm{PO}_{43-}$ & $27 \pm 25 \%$ & $<100$ \\
\hline Sulfate, $\mathrm{SO}_{42-}$ & $904 \pm 25 \%$ & 1060 \\
\hline
\end{tabular}

Notes:

Simulant properties "as-received” were:

Bingham Yield Stress 54.6 Pa

Bingham Consistency $=17.8 \mathrm{cP}$

The SB6 was mixed with a 5.6 M supernatant to obtain the desired solids loading before testing. Figure 15 shows the viscous sludge before supernate was added to obtain a solids loading of 5 wt $\%$.

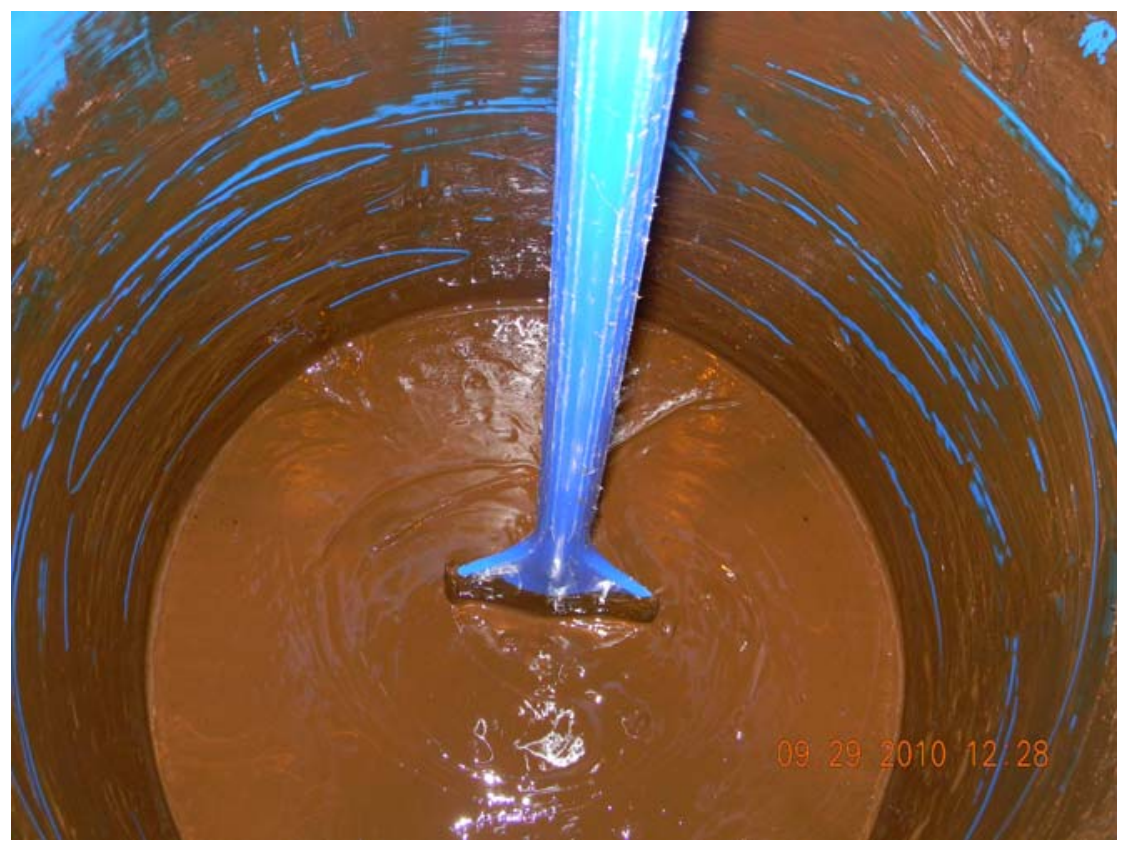

Figure 15. SB6 Sludge at $10.4 \mathrm{wt} \%$ solids loading before being mixing with the $5.6 \mathrm{M}$ supernate to attain a concentration of $5 \mathrm{wt} \%$ 
The particle size for the SB6 simulant had a large variation, i.e., from 0.3 to 300 microns, which captured well the ranges expected in the actual wastes [Poirier et al., 2003b; Wells et al., 2007]. In fact, particle size distribution was tri-modal with peaks at approximately 0.8 , 8, and 50 microns. It was assumed this range would be very challenging to the filters.

\subsection{Highlights of the Test Matrix}

The following list shows highlights of the intended test sequence when testing began, or as those that were developed while testing was progressing. The discussion that follows will provide more detail.

- $\quad$ Prepare filter media by soaking in deionized and filtered water

- Determine filter flux with water

- Precondition filters with SB6 slurry to put in used condition

- Clean filters with following sequence:

o Flush filters with solely water

o Clean filters with $0.5 \mathrm{M}$ oxalic acid

o Rinse filter with water until $\mathrm{pH} \sim 5$

- Try several techniques to develop a filter cake with slurry

- Filter slurry at an axial velocity (AV) of (12 ft/s) and a transmembrane pressure (TMP) of (40 psid) at $5 \mathrm{wt} \%$ UDS*

- Extended cleaning of filters to understand effectiveness of just using water and longer periods of acid cleaning.

- Filter slurry at an axial velocity of (15 ft/s) and a TMP of (50 psid) at $5 \mathrm{wt} \%$ UDS

- Concentrate slurry at an axial velocity of (12 ft/s) and a TMP of (40 psid) from $5 \mathrm{wt} \% 10$ wt\% UDS (or to the maximum concentration possible with available slurry).

- Filter slurry at an axial velocity of (12 ft/s) and a TMP of (40 psid) at $10 \mathrm{wt} \%$ UDS

- Return slurry back to 5 wt\% UDS

- Filter slurry at an axial velocity of (12 ft/s) and a TMP of (40 psid) at $10 \mathrm{wt} \%$ UDS

- Clean filters

- Using a filter aid - filter slurry at an axial velocity of (12 ft/s) and a TMP of (40 psid) at 5 wt\% UDS

- Clean filters

*UDS = undissolved solids, also referred to a suspended solids

\subsection{Results and Discussion}

Before the crossflow filtration began two sludge simulants, Sludge Batch 6 (SB6) and SRS Tank $8 \mathrm{~F}$, were tested against each other in a dead-end filter for filterability and at two different solids loadings. To these sludges 5.6 M sodium supernatant was added to attain a solids loadings of 0.1 $\mathrm{wt} \%$ and $5 \mathrm{wt} \%$. Equal amounts of the resulting slurries were placed in four Nalgene dead-end filters, which had 0.45-micron nylon filters. A vacuum was applied to all four filters and when the first filter cup was emptied, which turned out to be the Tank 8F slurry at a solids loading of $0.1 \mathrm{wt} \%$, the test was stopped and each cup was measured for its filtered volume. In normalizing each filtered volume to the fastest Fig. 16 shows a clear distinction between the two slurries. The 
SB6 simulant was the most challenging to filtration, as well as the higher solids loading. Therefore, the SB6 slurry was selected at a $5 \mathrm{wt} \%$ solids loading.

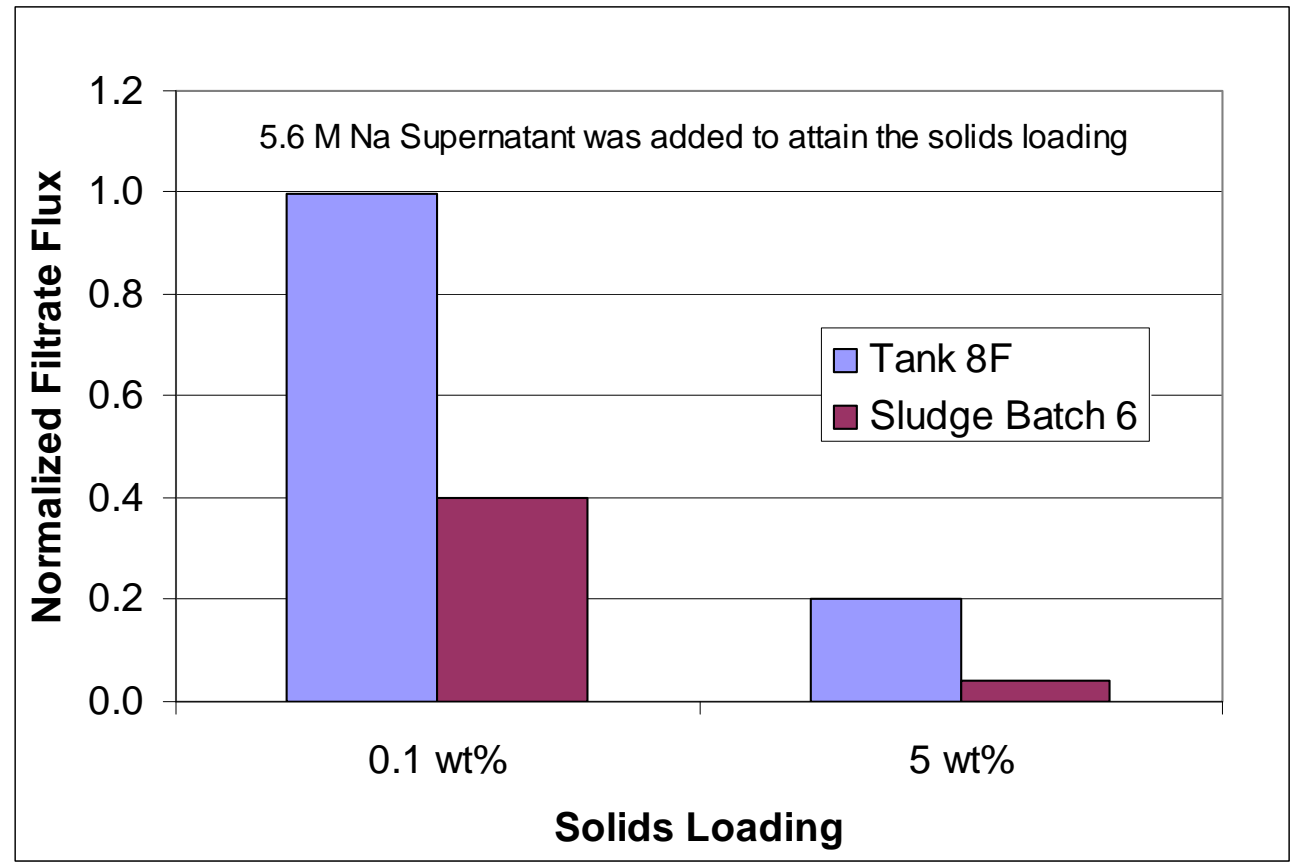

Figure 16. Dead End Test: $\mathrm{T}=21^{\circ} \mathrm{C}$, Transmembrane Pressure $=10 \mathrm{psid}$

\subsection{Filter Enhancers}

The dead-filter testing was also useful to select the best filter enhancer. The enhancers can be classified into two groups: Filter Aid and Body Feed. A filter aid is generally made of solid particles used to precoat the filter surface to produce a more permeable cake. Starting with new filter, Fig. 17(a), each filter aid was mixed with deionized water and filtered in order to evenly coat a filter surface. Figures 17(b-e) show the Nalgene filter surfaces coated with the filter aids just before adding the slurry to be filtered: Figure 17(b) is silicon carbide, Fig. 17(c) is titanium oxide, Fig. 17(c) is one activated carbon (DARCO ${ }^{\circledR}$ S-51HF), and Fig. 17(e) is the other activated carbon (DARCO ${ }^{\circledR}$ S-51FF). Finally, the slurry was very gently added to each filter cup so as to not disturb the settled filter aid. In general, the aids appeared to adhere well to the nylon filter surface and were not disturbed by the action of slurry introduction. Once all four slurry cups were filled with equal amount of slurry the vacuum was applied and the filter rate measured. 


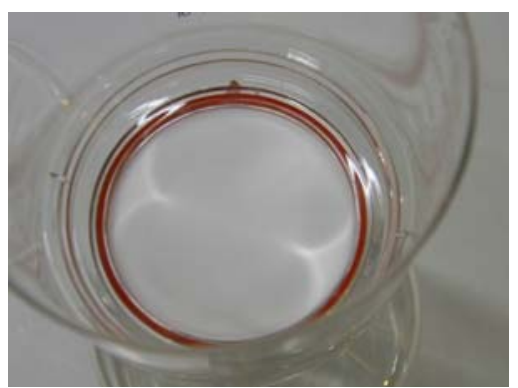

(a)

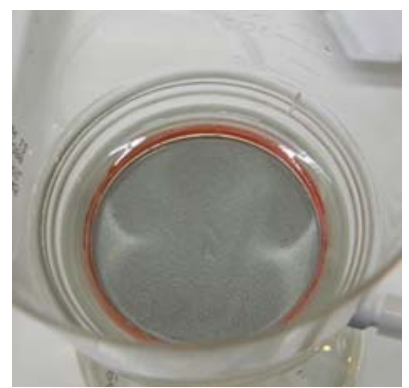

(b)

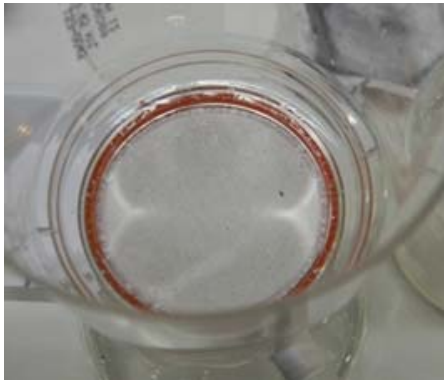

(c)

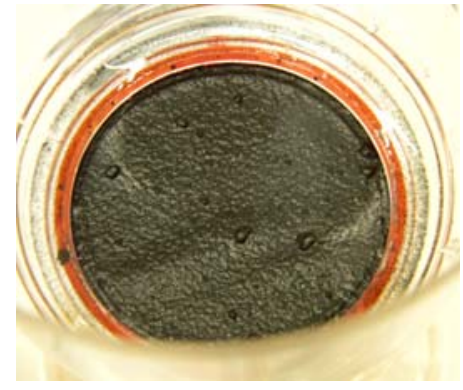

(d)

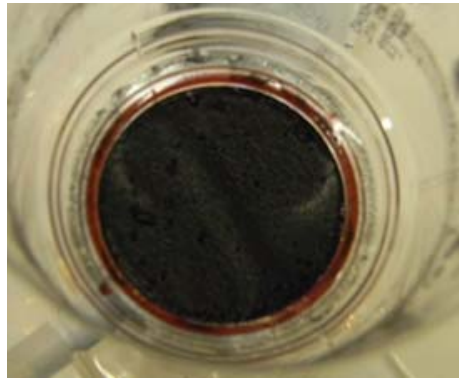

(e)

Figure 17. Filters Coated with Filter Aids: (a) New, (b) SiC, (c) $\mathrm{TIO}_{2}$, (d) S-51HF, (e) S51FF (See Table 1)

For the body feeds, PEO and Supefloc HX200 (Saito et al., 1999; Martino et al., 2001; Poirier, 2001) which are chemicals that flocculate the slurry solids, they were added directly to the slurry and then poured into the filter cups to measure filter flux. However, the same vacuum was used as that for the filter aid tests

Several dead-end test combinations were tried, i.e., slurry solid loading combinations, filter aid and body feed concentrations, etc, and the results are shown in Fig. 18. These combinations were also tried with the other slurry, i.e., Tank 8F, and the other solids loading, i.e., $0.1 \mathrm{wt} \%$, but since the slurry SB6 at 5 wt\% filtered significantly slower, i.e., the most challenging; therefore, only those results are shown in Fig. 18. Note, that all the results were normalized to the filtration rate of SB6 at $5 \mathrm{wt} \%$ with no filter enhancer, which is referred to as SB6-Control. The results indicate that 3 of the 4 filter aids helped to filter faster and that both of the body feeds and the $\mathrm{TiO}_{2}$ filter aid led to no improvement. Also note that difference concentrations of the filter enhancers were tried. For the filter aids, which are particulates, initially a layer of particles with an arbitrary thickness of three particle diameters was tried. For the activated carbon it was clear during the test the layer did not cover the entire surface; therefore, the thickness was increased by a factor of 10. This is the reason why the last two columns are labeled 10XHf and 10XFF in Fig. 18. The thicker layer was very successful in increasing the filtering rates and for S-51FF the increase was close to $50 \%$. From these tests S-51FF was chosen to be the candidate to try during the filter enhancer phase of crossflow filter testing. 


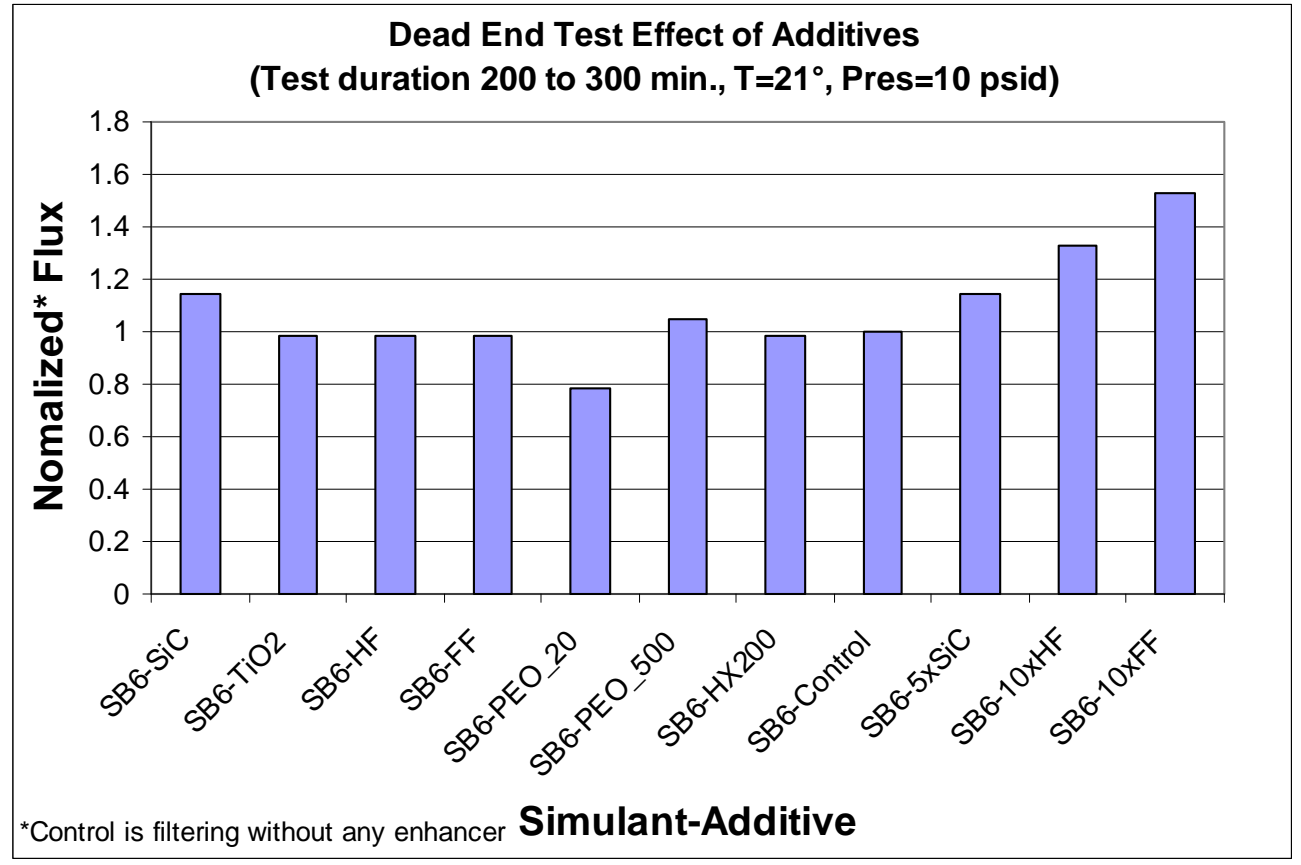

Figure 18. Dead End Test Comparison of Some of the Filter Aids in SB6 Slurry at a 5 wt\% Solids Loading: $\mathrm{T}=21^{\circ} \mathrm{C}$, Transmembrane Pressure $=10$ psid, Duration 200 to 300 minutes

\subsection{Crossflow Filtration: Cake Development - Long-Term Slurry Flux and 5 wt\% UDS, and Scouring}

Crossflow testing began with facility shakedown on 9/13/2010 and completed on 11/29/2010. However, the principal test results were obtained over a 12-day period shown in Fig. 19 beginning on $10 / 29 / 2010$. Prior to this period the three filters were pre-conditioned with the test slurry, which was followed by a pre-acid water rinsing, an acid cleaning, and a post-acid water rinsing. The cleaning was done until the water flux returned to what it was before filtering with slurry. This preconditioning was to try to put the filters in a 'used' condition to avoid the anomaly of new filter performance. Once the three filters were preconditioned with the SB6 slurry and thoroughly cleaned, the test began. 


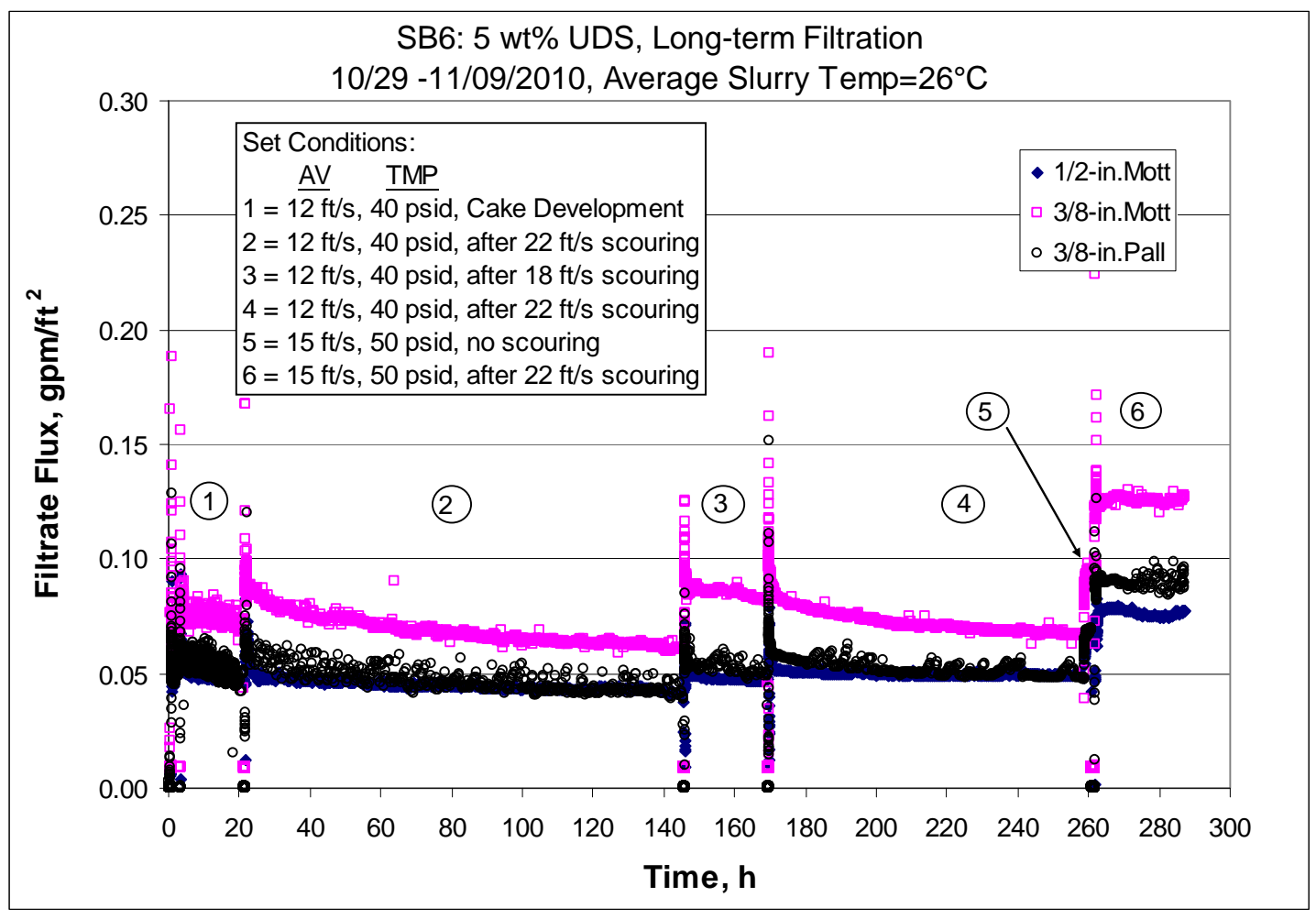

Figure 19. Long Term 12-Day Filtration Test was Done at the Several Conditions Listed for the Three Filter Tubes at $25^{\circ} \mathrm{C} \pm 2^{\circ} \mathrm{C}$

\subsubsection{Region 1: Cake Development Scouring}

To begin the test, the slurry loop was very slowly filled with the test slurry and the filtrate loop shut so the filters would not become challenged prematurely. However, the filter housings did slowly partially fill as liquid separated from the slurry across the porous membranes. This was possible because the air in the filtrate housing was drawn into the slurry, which then percolated through the slurry loop until it was released to the atmosphere from the slurry reservoir. Once the slurry was circulating at a constant, but very slow rate, i.e., the axial filter velocity was less than $0.5 \mathrm{~m} / \mathrm{s}$, and air stop leaving the system, then the filtrate valves were opened very slowly over approximately a 15-minute period. Once both the filtrate and slurry loops were filled, the filtrate flow was again stopped. Now the flow conditions to be used for filtering, i.e., axial velocity (AV) $=12 \mathrm{ft} / \mathrm{s}$ and a transmembrane pressure $(\mathrm{TMP})=40 \mathrm{psid}$, were established. (These conditions were used because they had been selected from previous work [Duignan, 2003] as the best for filtration.) Once established and stable, then the filtrate flow was very slowly engaged over an approximate 15-minute period. With the filtrate flow established, the system was allowed to run about 2 hours to allow the filter cake to develop, as noticed by a slight drop in filtration rate. After the cake was established, the filters received the initial 'scouring' for 15 to 20 minutes. The process used to develop the filter cake is listed below [Duignan, 2010]. Refer to Figs 3 and 4 for valve locations. 


\section{Direction for Filter Cake Development Start-Up}

1. Circulate rinse water through cleaning loop, then flush out any sample valve of debris, purge the pressure transducer tubes of any solids, finally do a zero check of all pressure transducers and log the zeros.

2. Drain water thoroughly.

3. Set test rig for slurry operation.

4. Filtrate valves, VA3, VB3, and VC3 MUST be closed.

5. Close upstream slurry valves VA1, VB1, and VC1.

6. Open slurry recirculation valve, V6, and turn on pumps to $<20 \mathrm{~Hz}$ to allow the slurry to circulate only in the bottom of the test rig and mix it thorough. The slurry should have a smooth uniform appearance when fully mixed.

7. Fully open upstream slurry valves: VA1, VB1, and VC1.

8. Fully open downstream slurry valves: VA2, VB2, and VC2.

9. Slowly begin filling the test rig with slurry by slowly closing valve V6. Move it to $25 \%$ closed, $50 \%$ closed, $75 \%$ closed, then $100 \%$ closed.

10. Once slurry and air are not noticeably exiting into the slurry reservoir tank or the slurry flowmeters do not register fluid movement, then increase the slurry pumps just enough to establish a slurry circulation. The filter velocities shall not exceed $5 \mathrm{ft} / \mathrm{s}$.

11. Wait for the slurry circulation to be become steady and air no longer is bubbling through the slurry reservoir.

12. Complete the filling of the filtrate system by very slowly open the filtrate valves, VA3, VB3, and VC3, over a period of 15 minutes to full open.

13. If the filtrate housings are filling too slow or stops filling, then slowly close the downstream slurry valves, VA2, VB2, and VC2 to reduce the axial velocity to below $1 \mathrm{ft} / \mathrm{s}$ in order to increase the TMP.

14. After both the filtrate and slurry loops are full shut the filtrate valves.

15. Bring the filter flow conditions to the chosen values, e.g., Axial Velocity of $12 \mathrm{ft} / \mathrm{s}$ and TMP $=40$ psid. (Note, since there is no filtrate flow there cannot be any significant TMP; however, the system (slurry) pressure should be close to what it would be when the filter is operational. What was used was approximately $10 \%$ over TMP; therefore, for 40 psid, then a system pressure of 44 psig was set before opening the filtrate valves.)

16. Now, reopen the filtrate valves, VA3, VB3, and VC3, very slowly over a period of approximately 15 minutes to full open. While opening note the increasing TMP and do not allow the TMP to increase sharply, that is, the pressure should be increased slowly and smoothly during the 15 minutes.

17. Readjust the slurry valves to obtain the chosen flow conditions, e.g., Axial Velocity of 12 $\mathrm{ft} / \mathrm{s}$ and TMP $=40 \mathrm{psid}$.

18. Allow the filters to operate for approximately 2 hours and then perform the first scouring.

Scouring is the process of shutting the filtrate flow valve, increasing the slurry axial velocity to $50 \%$ to $80 \%$ above the original set velocity, allowing the high velocity slurry to flow for approximately 15 to 20 minutes, then returning the velocity back to the original setting, and finally reestablishing filtrate flow over a 15-minute period. This scouring, which was done after two hours, is hard to see in Fig. 19 but it is exactly what was done between Region 1 and Region 2. In fact, it is what was done between Regions 2 and 3, 3 and 4, 5 and 6, noted by the jump in filtrate flux. That is, at no time were the filters cleaned or backpulsed, but only scoured. It can be seen that after each scouring the filtration flux return to approximately the same value, implying that no significant depth fouling had occurred. In fact, over the entire 290 hours (12 days) of continuous filtering the filters never were backpulsed nor cleaned and after each scouring the filter flux always returned to its initial value at time zero. The steps used to perform a scouring are listed below: 
Direction for Scour Filters while Running in Steady State

1. Close the filtrate valves, VA3, VB3, and VC3

2. Turn the slurry axial velocity up to $50 \%$ to $80 \%$ above the standard operating velocity by fully open downstream slurry valves: VA2, VB2, and VC2 and increase the slurry pump speed. (Note, the velocities tried were $18 \mathrm{ft} / \mathrm{s}$ and $22 \mathrm{ft} / \mathrm{s}$. The value of $22 \mathrm{ft} / \mathrm{s}$ was initially used because this was the highest velocity attainable with the available equipment. The lower value of $18 \mathrm{ft} / \mathrm{s}$ was tried to see is it would be just as effective. It was.)

3. Allow the higher axial velocity to scour the filter cake for 15 to 20 minutes.

4. After the scouring period return the slurry axial velocity to its set operating value, e.g., 12 $\mathrm{ft} / \mathrm{s}$, by first return the slurry pumps to its original steady-state setting, reopen the downstream slurry valves: VA2, VB2, and VC2 to their original settings.

5. Reopen the filtrate valves, VA3, VB3, and VC3, very slowly over a period of approximately 15 minutes to full open. While opening note the increasing TMP and do not allow the TMP to increase sharply, that is, the pressure should be increased slowly and smoothly during the 15 minutes.

6. Readjust the slurry valves to obtain the chosen flow conditions, e.g., Axial Velocity of 12 $\mathrm{ft} / \mathrm{s}$ and $\mathrm{TMP}=40 \mathrm{psid}$.

\subsubsection{Region 2: Long-Term Filtration}

Figure 20 is an excerpt of Region 2 from Figure 19. It depicts the better performance of the 0.375-in Mott filter over the 1/2-in Mott and the 0.375-in Pall.

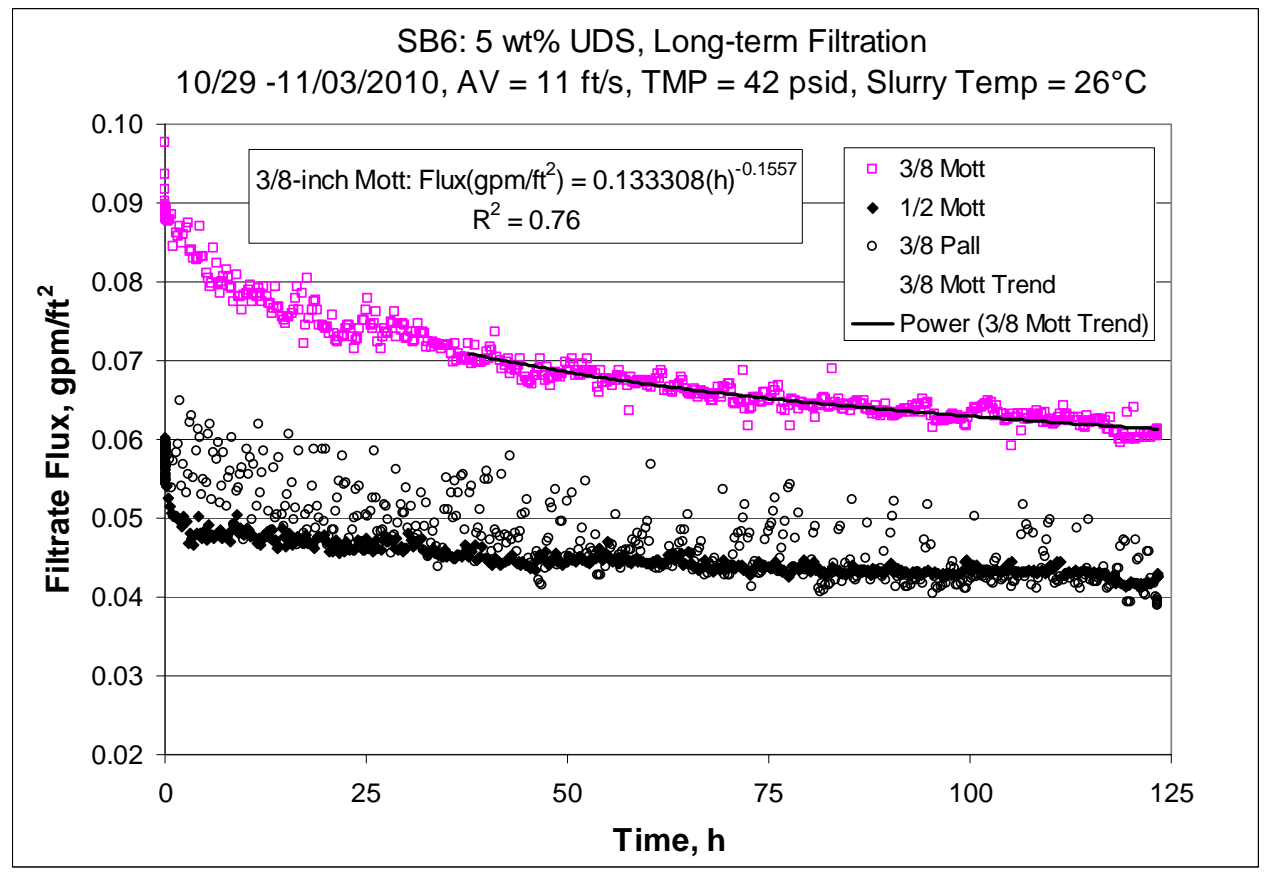

Figure 20. Filter Performance at a Single Set of Flow Conditions at 5 wt\% Solids Loading

An interesting feature from the test results was the higher flux of the smaller diameter filter tube. The 30 to $40 \%$ higher flux of the small Mott tube over the larger Mott tube was not a surprise as this has been studied previously [Duignan and Lee, 2006] but it was never observed with the same slurry at the same time; this evidence was reassuring. The higher flux is directly related to 
the higher wall shear stress for the small tube at the same axial velocity, which can be related to the ratio of filter surface area to flow volume. The 0.375-in I.D. tube has 33\% more area to volume than the 0.5 -in I.D. tube.

The other interesting aspect of the data in Fig 20 is the very slow rate of decline in the filter flux. The drop in flux is approximately $30 \%$ over 5 days, which is a significant improvement to the 80\% drops experienced from past works [Duignan, 2003, Daniel, 2009].

Finally, the large difference in flux between the two tubes with the same insider diameter of 0.375 in must be related to the different pore structure. The Mott filter is listed as a 0.1 micron nominal pore and the Pall is a 0.1 micron absolute pore. As mentioned earlier the $0.1-\mathrm{m}$ Mott has been estimated [Poirier et al., 2003a] to be an approximately 0.7 micron absolute; therefore, the Pall had a much tighter pore structure. The smaller pores do a much better job to separate the smallest solid particles, but also result in a lower flux because of a much higher base membrane flow resistance. The question then is: is the much tighter pore needed for these types of wastes? One way to determine this would be to measure the turbidity of the filtrate. Unfortunately, the turbidity of the filtrate of each filter could not be measured because all three streams were joined in a common header, as the filtrate was returned to the slurry reservoir. However, the turbidity of the joined stream was measured and that would tell at least the separation efficiency for the tube with the largest pore openings:

Turbidity ( $\pm 0.01 \mathrm{NTU})$

For Deionized water used throughout testing:

$0.26 \mathrm{NTU}$

From filters using only water:

$0.25 \mathrm{NTU}$

From filter using the $5 \mathrm{wt} \%$ SB6 slurry:

$0.03 \mathrm{NTU}$

These data imply that not only does the filter cake act as a secondary filter but it prevents even the smaller particles from passing through the filter than a cake-free filter. Therefore, this means that the more open pore structure is more efficient. Of course, the pore size cannot be allowed to become too big because eventually depth fouling would confound operation.

\subsubsection{Regions 3, 5, and 6: Higher Flow Conditions}

Figure 21 is an excerpt of Regions 3 and 6 from Figure 19 of only the 0.375-in Mott data. Because of the success of a much higher, and longer sustained, filter flow rate than expected, it was of interest to see if higher flow conditions would result in even higher filtrate flux. After several scourings and a return to the same axial velocity and TMP, those values were increased.

At the end of a successful long term run, shown as Region 4 in Fig. 19, and Fig. 22, the flow conditions were increased to an axial velocity of $15 \mathrm{ft} / \mathrm{s}$ and a TMP of $50 \mathrm{psid}$, without scouring. Indeed the filter fluxes increased by about $50 \%$, but this is only about $15 \%$ above the starting flux of Region 4. However, after a scouring was done and then a return to the conditions of $15 \mathrm{ft} / \mathrm{s}$ and 50 psid, the increase was $100 \%$ or about $43 \%$ above the starting point of Region 4 . 


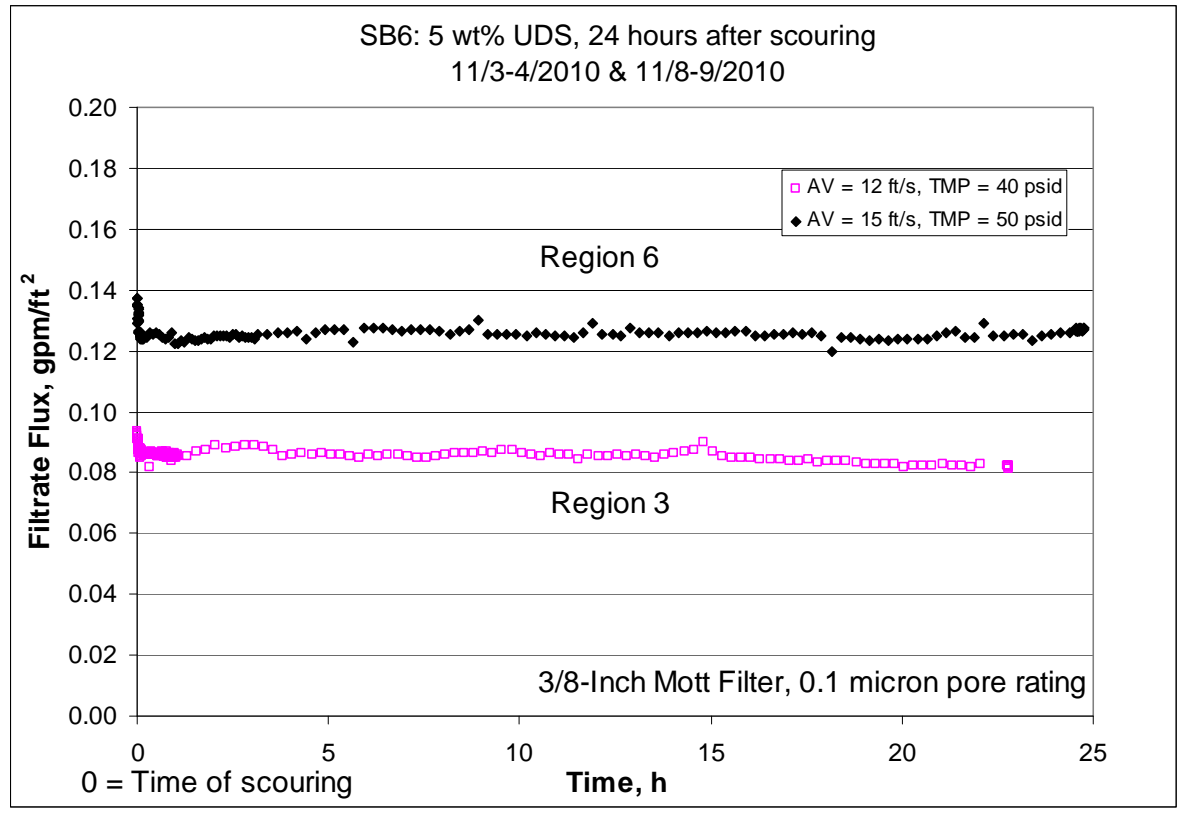

Figure 21. Filter Performances at a Single Set of Flow Conditions at 5 wt \% Solids Loading

This $43 \%$ can be seen better in Fig. 21 which illustrates the 20+ hours of operation after a scouring that started Regions 3 and 6 with the 0.375-in-m Mott filter. The filtrate flux at an AV of $15 \mathrm{ft} / \mathrm{s}$ and a TMP of 50 psid was surprising high (better than $0.12 \mathrm{gpm} / \mathrm{ft}^{2}$ ) and remained high for a full 24 hours. With continual scouring this flux may be maintained for a very long time.

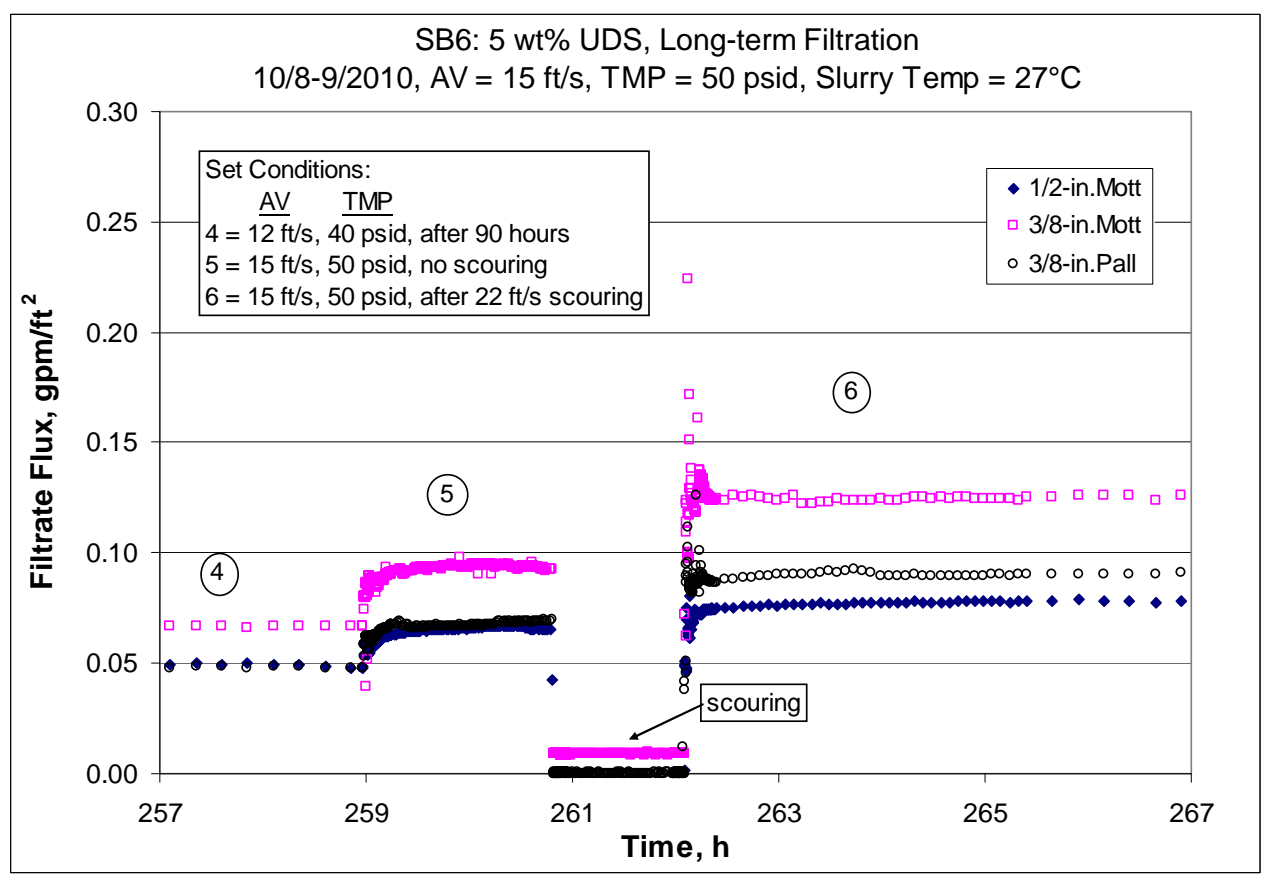

Figure 22. Regions 5 and 6 are Expanded to Be Seen Better 


\subsection{Slurry Concentration from 5 to $8.5 \mathrm{wt} \%$ UDS}

During actual waste processing the waste solids concentration will not remain constant. Filtration will be a batch operation and liquid removal from the slurry will cause the solids concentration to increase. Because of the limited simulant for this test and the large volume needed to keep the filter facility full, the amount of material available to concentrate was limited. However, some concentration was possible and did reveal filter performance. Figure 23 is limited to only the 0.375-in Mott filter because it demonstrated the best performance, but the two other filters performed similarly except for being lower in filtrate fluxes.

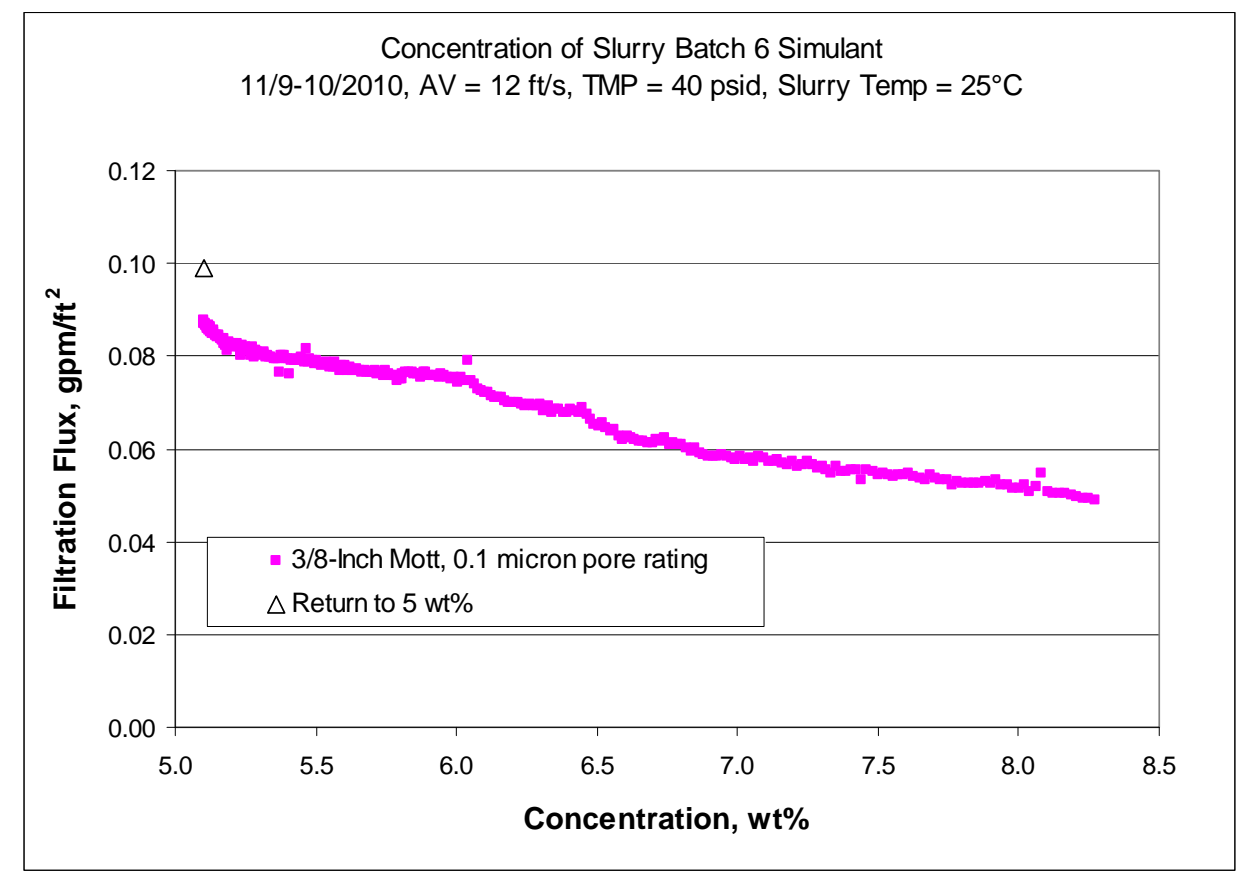

Figure 23 Filtrate Flux as the Solids Loading Increasing through 4.5 hours of Filtration

The drop in flux shown in Fig. 23 was expected from the increase in slurry viscosity. What was not known was the effect on the formed filter cake and if a good filter flux would return once the solids concentration was reduced to its starting point. Over a 4.5-hour period the SB6 simulant was filtered and allowed to concentrate by redirecting the filtrate to a separate container. Once the limit of the simulant volume was reached filtration stopped; the concentration subsequently was determined to have reached $8.3 \mathrm{wt} \%$. Without cleaning the filters the removed filtrate was returned to the simulant to attain the starting concentration of $5.1 \mathrm{wt} \%$ and then the filters were scoured and filtering commenced. The open diamond on Fig. 23 shows that a good flux rate was obtained again, thus indicating that the base filter cake was still intact and doing its job well. The solids loading data in Fig. 23 were estimated from solids measurements made on three samples taken during the concentration test. The samples were taken at the start of the test and after 2 and 4.6 hours of slurry concentration. The results of those measurements and uncertainties are listed in Table 6. 
Table 6. Solids Concentrations of SB6 Slurry during the Concentration Test

\begin{tabular}{|c|c|c|c|c|c|c|}
\hline $\begin{array}{c}\text { Concentration } \\
\text { Time }\end{array}$ & $\begin{array}{c}\text { TS (a) } \\
\text { Slurry }\end{array}$ & $\begin{array}{c}\text { Measurement } \\
\text { Error }\end{array}$ & $\begin{array}{c}\text { FS (b) } \\
\text { Filtrate }\end{array}$ & $\begin{array}{c}\text { Measurement } \\
\text { Error }\end{array}$ & $\begin{array}{c}\text { UDS (c) } \\
\text { Slurry }\end{array}$ & $\begin{array}{c}\text { Measurement } \\
\text { Error }\end{array}$ \\
\hline hours & wt $\%$ & $\%$ & & $\%$ & wt $\%$ & $\%$ \\
\hline 0 & 19.93 & \pm 10 & 15.64 & \pm 10 & 5.09 & \pm 12 \\
\hline 2 & 20.74 & \pm 10 & 15.84 & \pm 10 & 5.82 & \pm 12 \\
\hline 4.6 & 22.76 & \pm 10 & 15.80 & \pm 10 & 8.27 & \pm 12 \\
\hline
\end{tabular}

\subsection{Testing with Filter Enhancers}

While the dead-end filter results imply that filter enhancers may lead to even more filter performance improvement, failure with the test equipment and the lack of time prevented testing. This test phase was left for future work.

\subsection{Filter Cleaning}

Before any slurry filter testing was performed the filters were preconditioned with the SB6 slurry and then the filters were cleaned by first rising with water and then circulating $0.5 \mathrm{M}$ oxalic acid. Initially, the filters were cleaned with just water, but there was no improvement in filtrate flux. However, water flushing was useful to remove the bulk of the simulant solids that accumulated on the walls of the flow loops. The water was then followed with acid. During the 85-minute acid cleaning, Fig. 24, the filtrate fluxes remained relatively constant but still only on the order of slurry flux; it was expected to be at least a factor of two higher. Past studies either used nitric acid or oxalic acid to clean, but only for short periods of time, from 1 to 12 hours, but rarely were filters returned to a clean condition.

Note, the acid filtrate fluxes could have been higher with higher flow rates and TMP, but those conditions for cleaning, shown in Fig. 24 of an axial velocity of $11 \mathrm{ft} / \mathrm{s}$ and $21 \mathrm{psid}$, were set at these values because of the limit of the filtrate flowmeters. The meters were calibrated a maximum flux of $0.35 \mathrm{gpm} / \mathrm{ft}^{2}$ because the expected waste filter fluxes were on the order of 0.02 $\mathrm{gpm} / \mathrm{ft}^{2}$. To keep the flux within the calibrated range, once acid began to flow, the flow conditions were set to obtain initial acid filtrate fluxes of approximately one half the maximum range of the calibrated range.

Because the acid filtrate fluxes did not show any improvement during the 85-minute cleaning and because the cleaning came at the end of a week, the facility was shut down. The filters were allowed to soak in the acid over the weekend. Figure 26 shows that the after approximately 60 hours over the weekend of acid soaking the flux to more than doubled. Clearly acid needs time to dissolve the solids. 


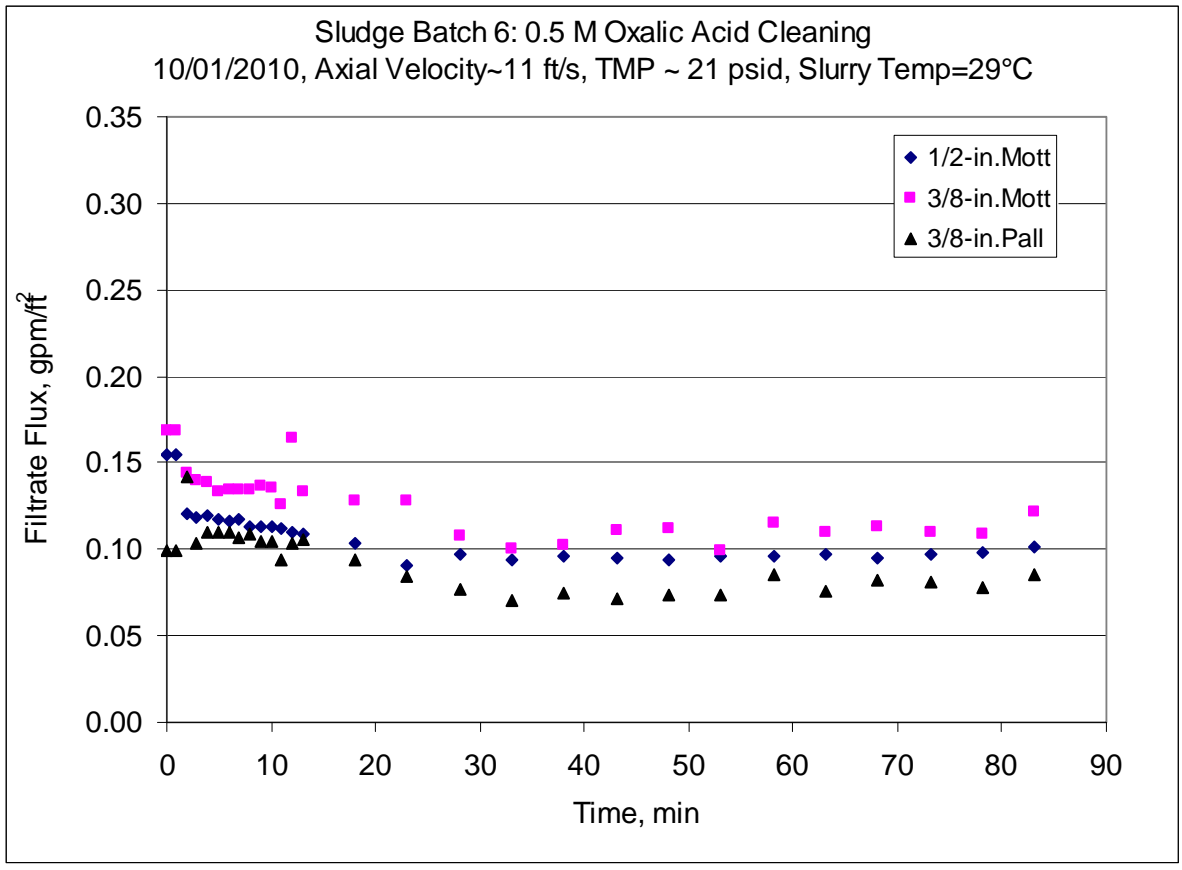

Figure 24. Filter Performance and Rinsing with Water and during the Circulation of $0.5 \mathrm{M}$ Oxalic Acid for 85 minutes

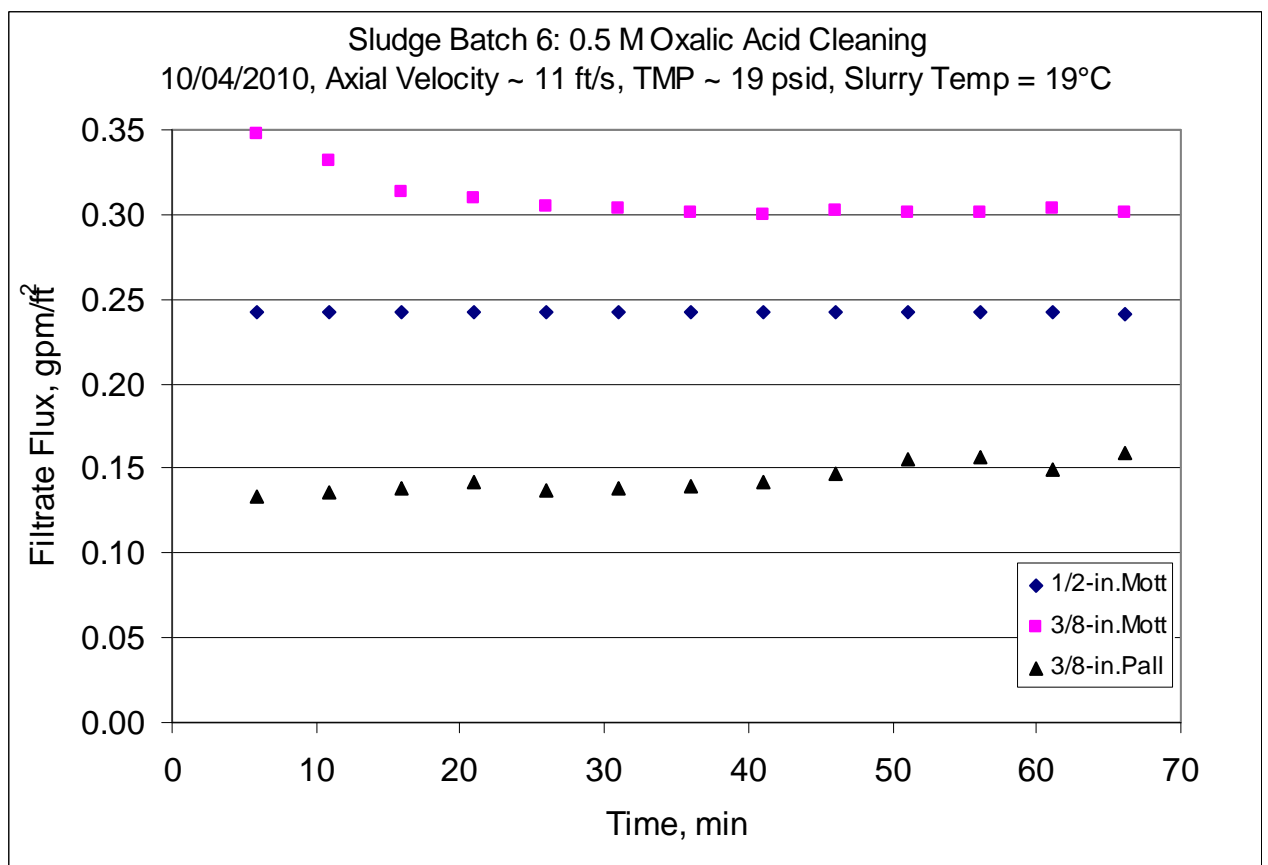

Figure 25. Filter Performance during the Circulation of $0.5 \mathrm{M}$ Oxalic Acid After the Filter Soaked in the Acid for more than 2 days

Based on filter flux improvement from Fig. 24 to Fig. 25 it was clear that the filters needed more contact time with the acid and cleaning protocols needed to be studied further. After the next slurry campaign, 10/11-19/2010, a more detailed cleaning test began. Over an 8-day period the 
filters were rinsed with water, cleaned with acid, followed by more rinsing and a second acid cleaning and then a final rinse. The results are shown in the next seven graphs, e.g., Figs. 26 to 31, and to better see the trends, only data from the 0.375-in Mott filter are illustrated. The other two filters gave similar data except that the filtrate fluxes were slightly lower.

Once a slurry test was done and the filter loops were drained of slurry; however, the tubing walls still contained a lot of simulant due to having finite yield stress and its viscous nature. So that acid was more efficiently used, and to see the effect of a simple water rinse, most of the simulant remnants were removed with two water rinses. In Fig. 26 the first two groupings of data points, during the first hour and at the 2-hour mark, are from the water flushes. Most of the slurry solids were removed with the first water flush. The second water flush further removed solids, but the filter flux did not improve; definitely not to the acid values shown in Fig. 25

The next step was to begin acid cleaning; therefore, at the 3-hour mark from starting the water rinse, Fig. 26, $0.5 \mathrm{M}$ oxalic acid was introduced into the filter loops. Notice the filtrate flux immediate drops from $\sim 0.2$ to $0.10 \mathrm{gpm} / \mathrm{ft}^{2}$ as shown as " $1^{\text {st }}$ Acid Cleaning (a)." This was not unexpected because the remaining solids begin to dissolve to an amorphous state effect the filter porous surface.

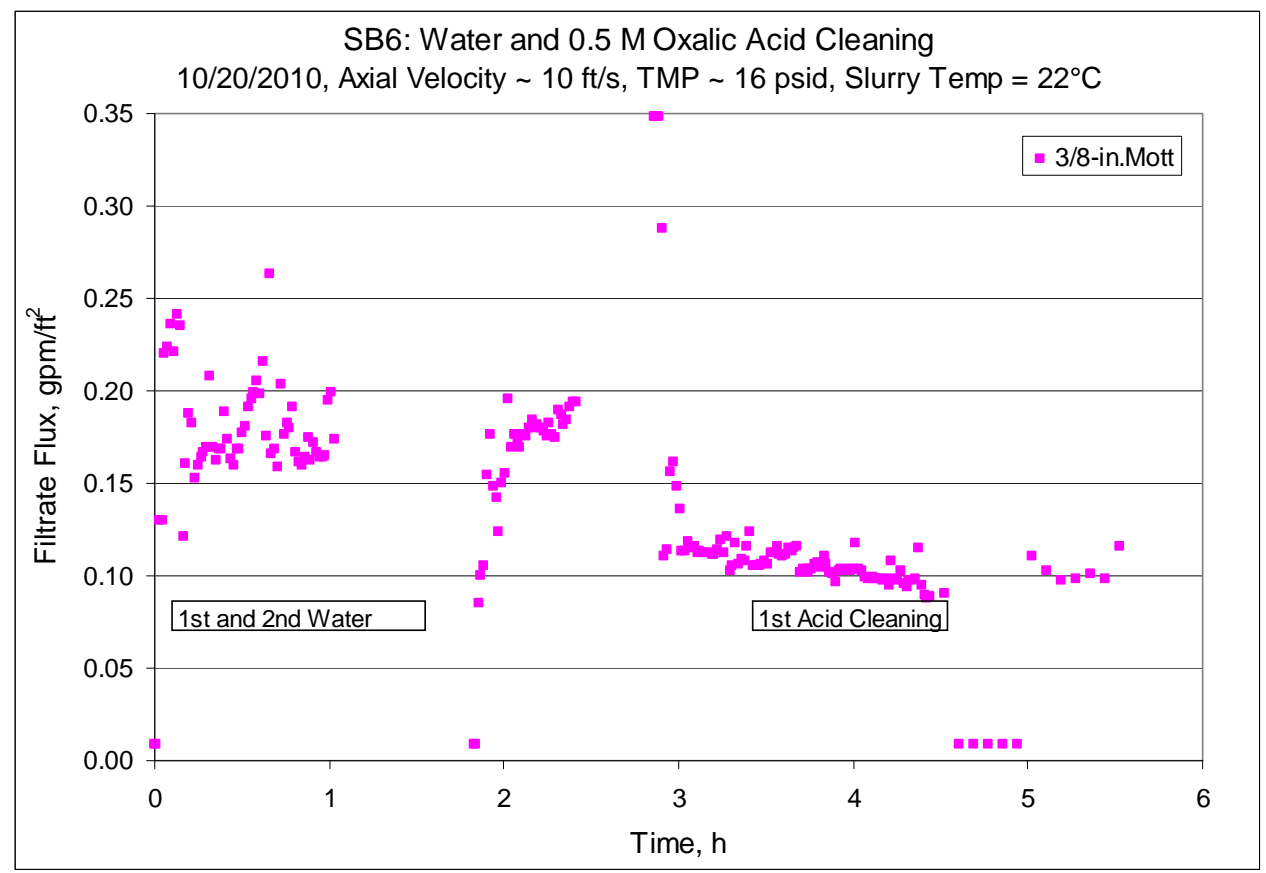

Figure 26. Filter Performance at the Start of Cleaning with Two Water Rinses, followed by 0.5 M Oxalic Acid on the first day, Indicated by (a)

On allowing the filters to soak, the acid filter flux was checked after 24 hours, Fig. 27. The data set listed as " 1 st Acid Cleaning (b)" shows that even at around 30 hours the acid filter flux jumped above and below the to $0.1 \mathrm{gpm} / \mathrm{ft}^{2}$ level. Only after approximately 31 hours do the data seem to steadily increase. At this point the test facility was shut down for a long weekend and the filters were allowed to soak in the acid.

After 5 days of soaking the acid was once again circulated and the acid filter flux more than doubled, to above $0.25 \mathrm{gpm} / \mathrm{ft}^{2}$, as seen as the first grouping of data in Fig. 28. Note, that when 
the acid was first applied it turns almost immediately yellow in color indicating that iron is dissolved very fast but some other oxides and hydroxides take longer to dissolve (Poirier and Fink, 2002) and is probably the reason for the better fluxes after several days of soaking.

Figure 28 also shows the subsequent three water rinses after the acid is drained from the filter loops. The reason that three rinses were done was to dilute the acid before receiving the next batch of sludge waste simulant, which is alkaline. The water rinses use water that was deionized and filtered with a 0.2 micron rated dead-end filter. The first rinse shows a continued improvement of filtrate flux from 0.25 to above $0.30 \mathrm{gpm} / \mathrm{ft}^{2}$, but then the flux drops. The drop is thought to occur because as the $\mathrm{pH}$ begins to increase remnants of dissolved compounds in the diluted acid begin to precipitate. After the first rinse the $\mathrm{pH}$ increased to approximately 2, after the second rinse it increased to approximate 3 , and after the third the $\mathrm{pH}$ was approximately 5 . Normally a $\mathrm{pH}=5$ was the stopping point for rinses because it was approximately the value of the $\mathrm{pH}$ of the house water; therefore, no significant benefit would be realized with further rinses. However, for this cleaning test two more rinses were tried to see the effect.

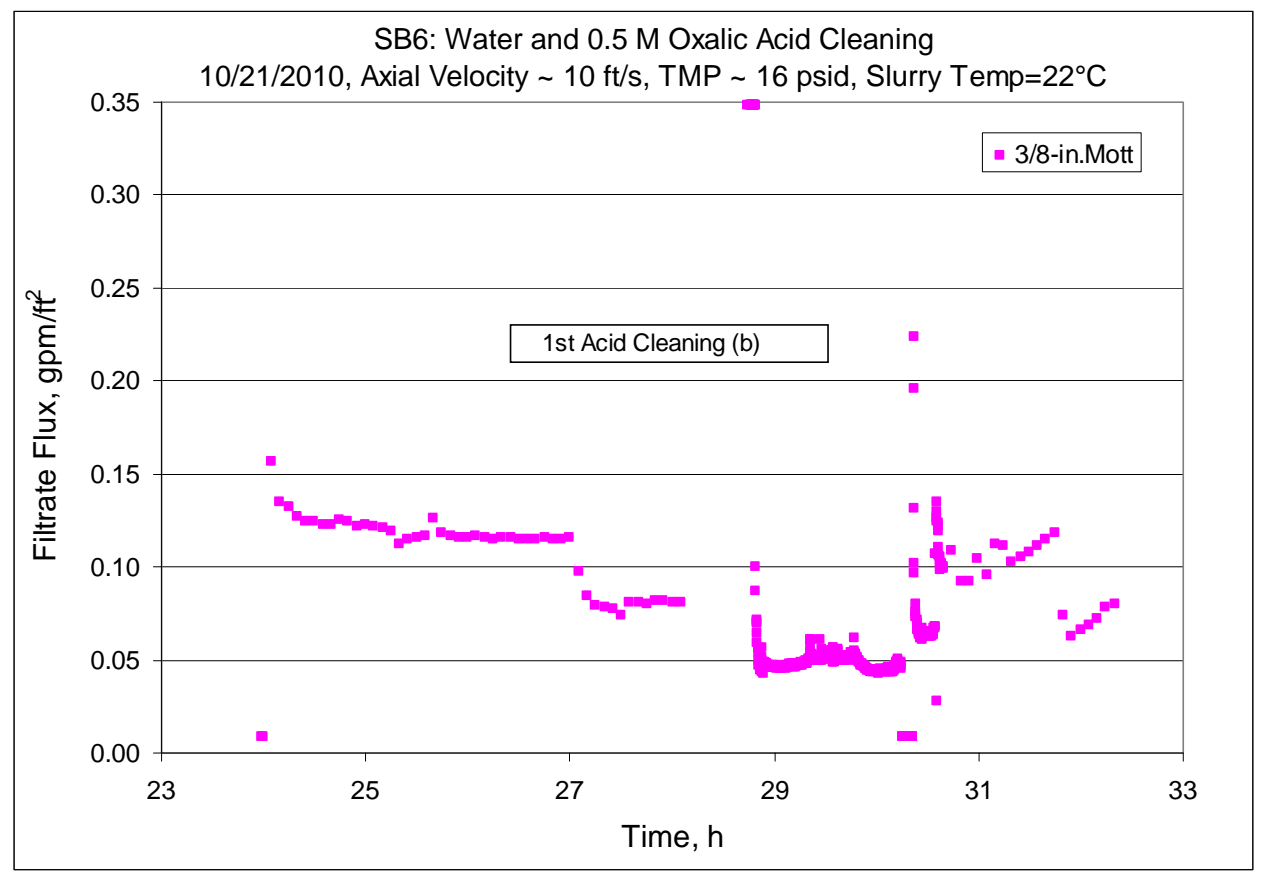

Figure 27. Filter Performance on the $2^{\text {nd }}$ day of Cleaning with 0.5 M Oxalic Acid, as Indicated by (b) 


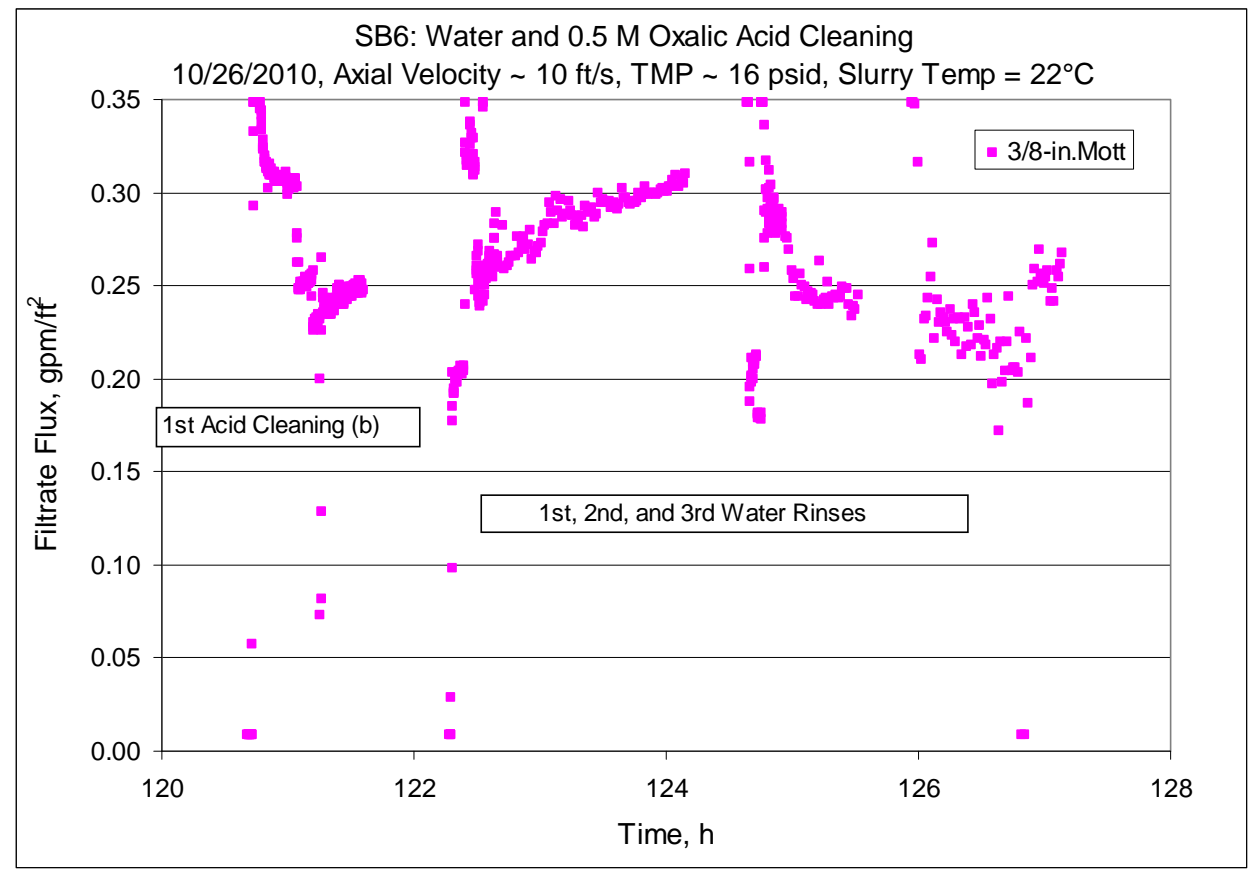

\section{Figure 28. Filter Performance on the $3^{\text {rd }}$ day of Cleaning $0.5 \mathrm{M}$ Oxalic Acid after the Filter Soaked in the Acid for 3 days, then followed by Two Water Rinses}

Indeed, little was gained with the $4^{\text {th }}$ and $5^{\text {th }}$ rinses shown in Fig. 29 and in fact the data scatter is much larger for those data sets due to the fact that the fraction of acid is extremely small, especially on the fifth dilution That is, the ionic strength of the cleaning solution is lower than needed for the proper operation of the flowmeters. The flowmeters used for the project were magnetic flowmeters that detect the flow of ions to measure the flow. In other words, the measurement equipment could only detect the flow sporadically causing the large data spread. However, near the end of the $5^{\text {th }}$ rinse the filtrate flow seemed to be below $0.20 \mathrm{gpm} / \mathrm{ft}^{2}$, so a second cleaning with acid began to determine if any further improvement could be realized. As will be seen no improvement was obtained beginning with the $2^{\text {nd }}$ acid introduction, Fig. 29.

Figure 29 shows the data set, " $2^{\text {nd }}$ Acid Cleaning (a)," which began at the $147^{\text {th }}$ hour of the cleaning test and that the acid filter flux began just above $0.20 \mathrm{gpm} / \mathrm{ft}^{2}$. After 4 hours of cleaning the flux improved to just above $0.25 \mathrm{gpm} / \mathrm{ft}^{2}$. Note, that with ions from the acid the filtrate flux measurement was once again stable. Subsequently, the filters were allowed to soak in the $0.5 \mathrm{M}$ oxalic acid overnight, After about 18 hours of soaking in acid the filters were started one last time, as shown in Fig. 30 as " 2 nd Acid Cleaning (b)." The filtrate flux was good and close to that obtained during the first acid cleaning of $0.30 \mathrm{gpm} / \mathrm{ft}^{2}$, but there was no improvement; therefore rinsing began. The $1^{\text {st }}, 2^{\text {nd }}$, and $3^{\text {rd }}$ rinsing shown in Figs. 30 and 31 are similar to the initial series of rinses and clearly shows that the water fluxes to be slightly lower than that acid fluxes; therefore, the cleaning test was terminated. 


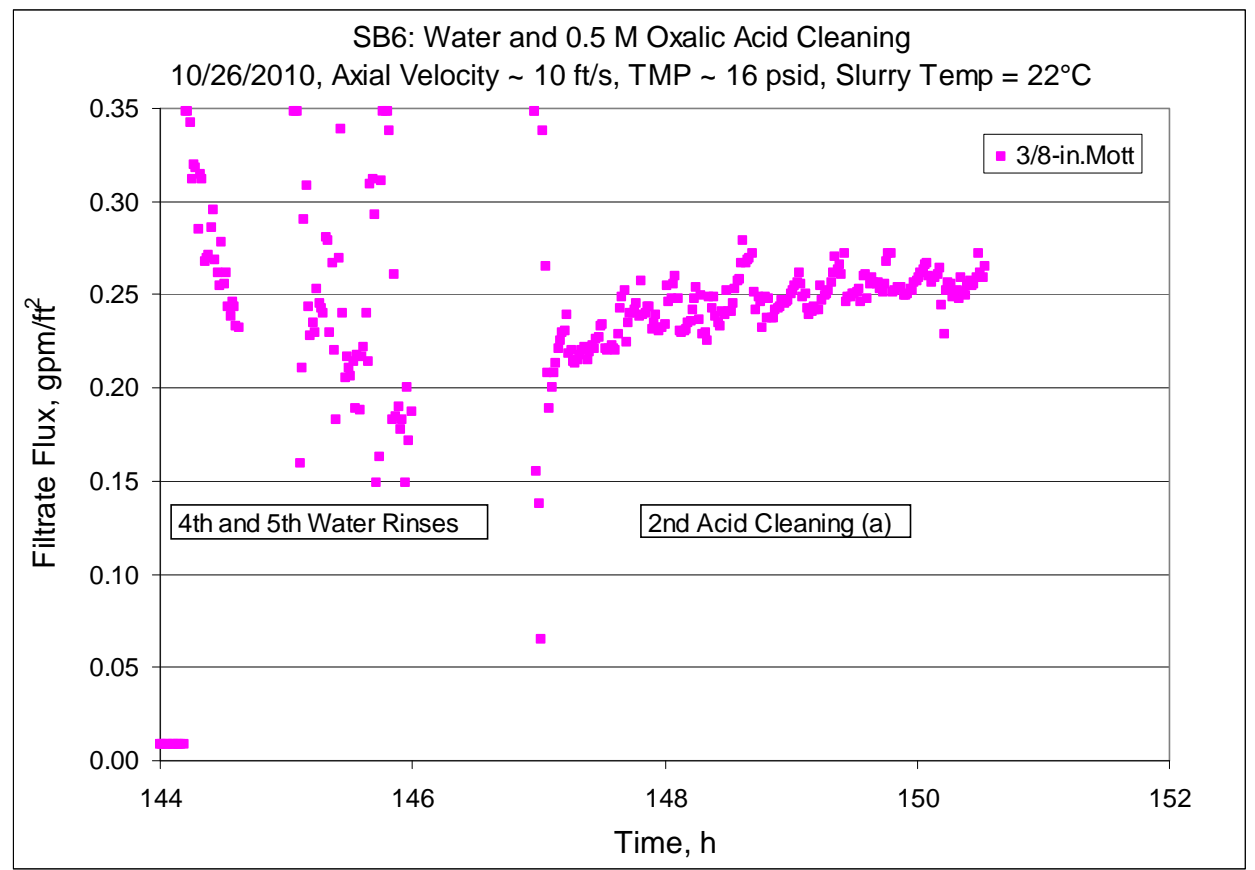

Figure 29. Filter Performance on the $4^{\text {th }}$ day of Cleaning that Started with a Water Rinse after the Filter Sat in Water for 24 hours, Followed by a $2^{\text {nd }}$ Acid Cleaning

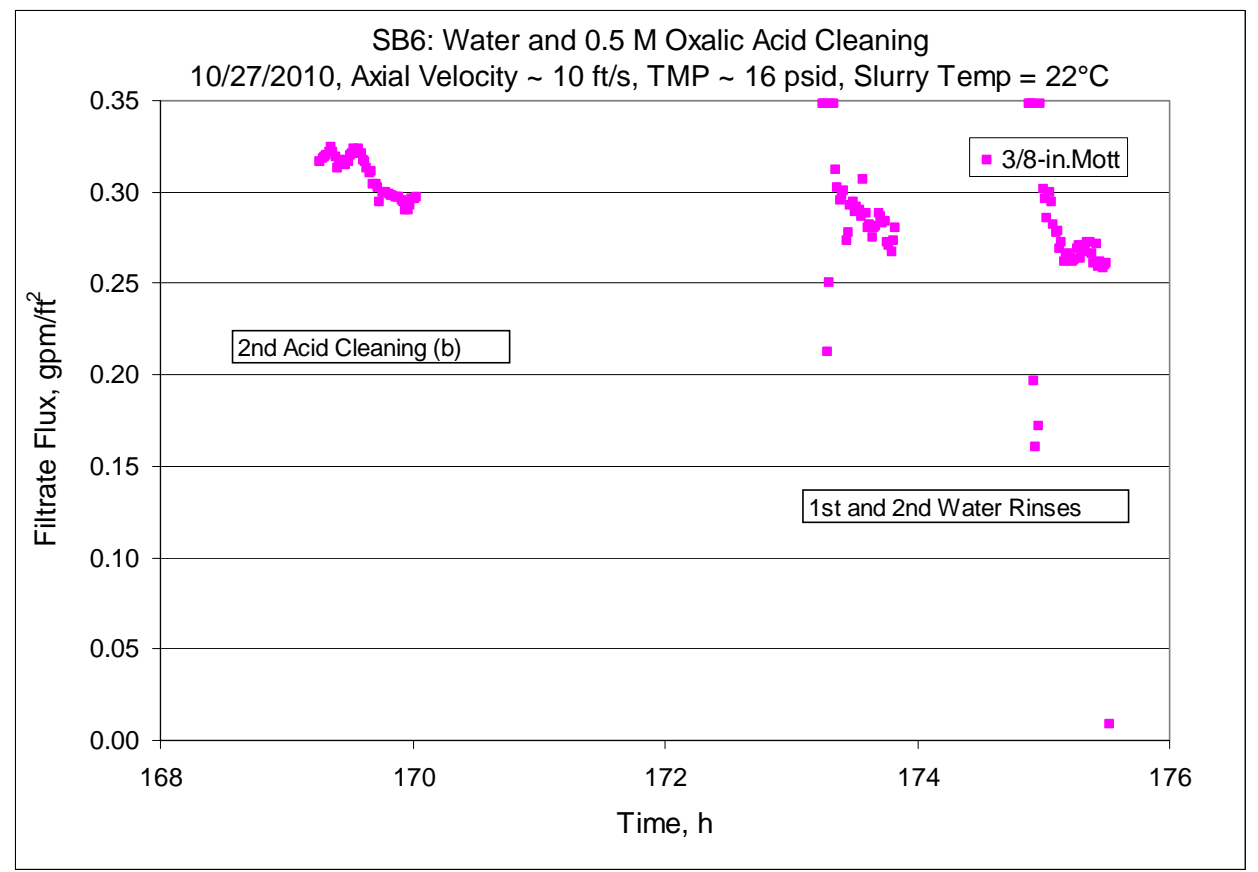

Figure 30. Filter Performance on the $5^{\text {th }}$ day of Cleaning after the Filter Soaked in Acid for Approximately 15 hours, which was then Rinsed Twice with Deionized Water 


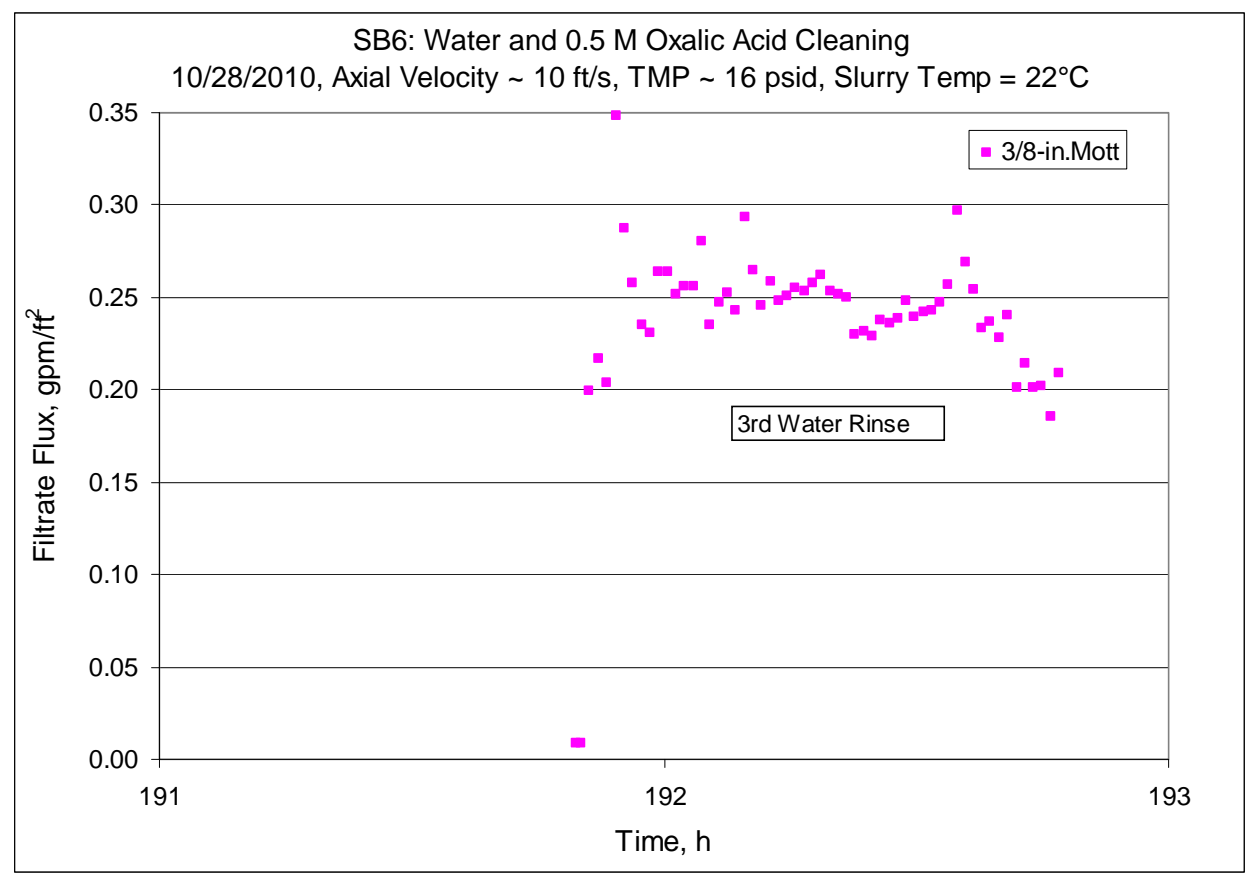

Figure 31. Filter Performance on the $6^{\text {th }}$ and Last day of Cleaning with a Final Water Rinse to Bring the $\mathrm{pH}$ to 5

\subsection{Crossflow Filtration Modeling}

A subtask was done by Nicholls State University, Appendix B, in an attempt to better understand crossflow filtration by studying what needs to be known to better model the phenomena. Specifically, aspects of the cake development were studied with respect to it being affected by fluid conditions, particle size distribution, and surface morphology of either the membrane surface or developing cake layer. As indicated in the Literature Background discussed in the Introduction of this report and in the one done for the subtask, the dynamics of filtration at the filter surface and within the cake are complex, challenging any effort to adequately model the phenomena. To date, most models are limited to empirical relationships that model well a very specific situation under specific conditions, but generally cannot be used beyond those specific cases; the models do not capture the underlying physicals. Unfortunately, the modeling effort in Appendix B is no exception; however, the discussion therein may lead to more insight to the physics behind crossflow filtration and to more accurate models. 


\subsection{Conclusions}

Experiments that use non-radioactive simulants for actual waste always carry the inherent risk of not eliciting prototypic results; however, they will assist in focusing the scope needed to minimize radioactive testing and thus maximize safety. To that end this investigation has determined:

- SB6 was found to be more challenging to filtration than SRS Tank 8F simulant.

- With the best performing filter tube, i.e., 3/8-in Mott, good sustainable filter fluxes were obtained:

0 Better than $0.08 \mathrm{gpm} / \mathrm{ft}^{2}$ at $\mathrm{AV}=12 \mathrm{ft} / \mathrm{s}$ and TMP $-=40 \mathrm{psid}$

0 Better than $0.12 \mathrm{gpm} / \mathrm{ft}^{2}$ at $\mathrm{AV}=15 \mathrm{ft} / \mathrm{s}$ and $\mathrm{TMP}=50 \mathrm{psid}$

- Higher solids concentration presents a greater challenge to filtration.

- Filter cake is something that should be properly developed in initial filter operation.

- Backpulsing is not necessary to maintain a good filter flux with sludge wastes.

- Scouring a filter without cleaning will lead to improved filter performance.

- The presence of a filter cake can improve the solids separation by an order of magnitude as determined by turbidity, i.e., 0.03 NTU with cake and 0.2 NTU without cake.

- A well developed cake with periodic scouring may allow a good filter flux to be maintained for long periods of time. Data show 75\% of the original flux after 125 hours of continuous filtering.

- Filtrate flux decline is reversible when the concentration of the filtering slurry drops and the filter is scoured.

\subsection{Future Work}

The results from this study imply that crossflow filtration performance can be improved versus previous testing, but the data base is small and limited. To better understand the applicability of the cake development / scouring techniques discussed in this report further research would be very beneficial. Specifically, what needs to be investigated are:

- If the test process works with other salt waste streams and sludge waste streams, besides SB6.

- If the results are applicable to multi-tube operation and tube inclination.

- If scouring can maintain a good filter flux indefinitely.

- If different waste streams can be processed without cleaning the filters or removing a cake.

- If the cleaning protocol can be improved by using an acid rinse before a water rinse to remove soluble species so that dissolved material does not precipitate in the filter system during rinsing. 


\subsection{References}

Daniel, R.C., J.M. Billing, J.R. Bontha, C.F. Brown, P.W. Eslinger, B.D. Hanson, J.L. Huckaby, N.K. Karri, M.L. Kimura, D.E. Kurath, and M.J. Minette, "EFRT M-12 Issue Resolution: Comparison of Filter Performance at PEP and CUF Scale,” PNNL-18498 (and WTP-RPT-185), Pacific Northwest National Laboratory (2009)

Daniel, R.C., P.P. Schonewill, R.W. Shimskey, R.A. Peterson, "A Brief Review of Filtration Studies for Waste Treatment at the Hanford Site,” PNNL-20023, Pacific Northwest National Laboratory (2010)

Defrance, L. and M.Y. Jaffrin, "Reversibility of fouling formed in activated sludge filtration,” J. Membrane Science, No. 157, pp. 73-84 (1999).

Duignan, M.R., C.A. Nash, and P.S. Townson, "Cross-flow filtration with a shear-thinning organic-based slurry,” Experimental Thermal and Fluid Science, No. 26, pp. 683-691 (2002)

Duignan, M.R., "Final Report: Pilot-scale cross-flow ultrafiltration test using a Hanford Site Tank 241-AN-102 Waste Simulant,” WSRC-TR-2003-00204 (and SRT-RPP-00087) Savannah River National Laboratory (2003)

Duignan, M.R. and S.Y. Lee, “Cross-flow ultrafiltration scaling considerations,” Proc. ASME Fluids Engineering Division Summer Meeting and Exhibition, FEDSM2006-98492 (2006).

Duignan, M.R., “EM-31 Cross-Flow Filtration,” Task Notebook No. SRNL-NB-2010-00073 (2010)

Fischer, E. and J. Raasch, "Model tests of the particle disposition at the filter-medium in crossflow filtration,” Proc. $4^{\text {th }}$ World Filtration Congress, Part II, pp. 9.9 - 9.16 (1986)

Flow Control, “Cross-flow membrane market to reach \$10 Bil. In 2015,” November (2010).

Herman*, D.T., W. Greene**, J. Gilmour**, T. Ho**, "Rotary Microfilter 1000-hour test," SRNL-L3100-2010-00229, *Sannavah River National Laboratory \& **SpinTekfiltration (Presented as paper S04-08 at the EM Waste Processing Technical Exchange, Atlanta, Georgia) (2010)

Johnson, C.E. and M.R. Duignan, “Cross-Flow Filtration: Literature Reviewt,” SRNL-STI-201100013, Savannah River National Laboratory (2011)

Levesley, J.A. and M. Hoare, "The effect of high frequency backbulsing on microfiltration of yeast homogenate suspensions for the recovery of soluble proteins," J. Membrane Science, No. 158, pp. 29-39, (1999).

Lu, W.M., S.C. Ju, "Selective particle deposition in crossflow filtration,” Sep. Sci. Technol., No. 24, pp. 517-540 (1989). 
Mann, N.R., R.S. Herbst, T.G. Garn, M.R. Poirier, and S.D. Fink, "Alternative Ultrfiltration Membrane Testing for the SRS Baseline Process,” INEEL/EXT-04-01933, Idaho National Engineering and Environmental Laboratory (2004).

Martino, C.J., M.R. Poirier, F.F. Fondeur, and S.D. Fink, "Flocculating, Settling, and Decanting for the Removal of Monosodium Titanate and Simulated High-Level Waste Sludge from Simulated Salt Supernate,” WRSC-TR-2001-00413, Savannah River National Laboratory (2001)

Mores, W.D., C.N. Bowman, and R.H. Davis, “Theoretical and experimental flux maximization by optimization of backpulsing,” J. Membrane Science, No. 165, pp. 225-236 (2000)

Murkes, J. and C.G. Carlsson, Crossflow Filtration, John Wiley \& Sons, Ltd. (1988).

Nash, C.A., "Filtration of Tank 48H Contents with a Cells Unit Filter," WSRX_TR-95-0483, Savannah River National Laboratory (1995)

Nash, C.A., S.W. Rosencrance, W.W. Walker, W.R. Wilmarth, "Investigate of Varied StrontiumTransuranic Precipitation Chemistries of Crossflow Filtration,” BNF-003-98-0171, Savannah River National Laboratory (2000)

Poirier, M.R., "Improving the Filtration of Sludge/Monosodium Titanate Slurries by the Addition of Flocculants,” WSRC-TR-2001-00175, Savannah River National Laboratory (2001)

Poirier, M.R. and S.D. Fink, "Investigation of Alternative Approaches for Cleaning Mott Porous Metal Filters,” WSRC-TR-2002-00526, Savannah River National Laboratory (2002)

Poirier, M.R., P.R. Burket, and J.L. Siler, "Filtration, Washing, and Leaching of a Hanford AY102/C-106 Sample,” WSRC-TR-2003-00240 (and SRT-RPP-2003-00110) Savannah River National Laboratory (2003a)

Poirier, M.R., F.F. Fondeur, D.P. Lambert, D.R. Hobbs, and S.D. Fink, "Particle Size of Simulated SRS Sludge, Actual SRS Sludge, and Monosodium Titanate,” WSRC-TR-2003-00221, Savannah River National Laboratory (2003b)

Ramirez, J.A. and R.H. Davis, “Application of cross-flow microfiltration with rapid backpulsing to wastewater treatment,” J. Hazardous Materials B, No. 63, pp. 179-197, (1998)

Ripperger, S. and J Altmann, "Crossflow microfiltration - state of the art," Separation and Purification Technology, No. 26, pp. 19-31 (2002)

Saito, H.H., M.R. Poirier, S.W. Rosencrance, and J.L. Siler, "Improving Filtration Rates of Mono-sodium Titanate (MST) - Treated Sludge Slurry with Chemical Additives,: WSRC-TR-9900343 (1999)

Shimskey, R.W., P.P. Shonewill, R.C. Daniel, R.A. Peterson, “Complex Microfiltration Behavior of Metal Hydroxide Slurries,” Proc. Waste Management 2011, Paper No. 11376 (2011)

Steimke, J.L., C.M. Hart, and S.E. Sponseller, "Results from Tests of Du Pont Crossflow Filter," Technical Report WSRC-TR-94-0332, Savannah River Technology Center, Aiken, SC (1994) 
Tennekes, H. and J.L. Lumley, A First Course in Turbulence, The MIT Press, Cambridge, MA (1972).

Van Brunt, V., C. Stork, T. Deal, and R. Haggard, "Final Report on the Crossflow Filter Optimization with 506 M Sodium Solution,” University of South Carolina Report No. USCFRED-PSP-RPT-09-0-0015 (2000) [Report has a cover letter by M.R. Poirier No. WSRC-TR2001-00035, Savannah River National Laboratory (Jan. 11, 2001)]

Wells, B.E., M.A. Knight, E.C. Buck, R.C. Daniel, S.K. Cooley, L.A. Mahoney, P.A. Meyer, A.P. Poloski, J.M. Tingey, W.S. Callaway, G.A. Cooke, M.E. Johnson, M.G. Thien, D.J. Washenfelder, J.J. Davis, M.N. Hall, G. Smith, S.L. Thomson, and Y. Onishi, "Estimate of Hanford Waste Insoluble Solid Particle Size and Density Distribution,” PNWD-3824, Battelle Pacific Northwest Division (2007) 
SRNL-STI-2011-00071

Revision 0

\section{Appendix A}

Instrumentation Installed on the Crossflow Filtration Test Facility 
Table 7. Measure and Test Equipment on the Crossflow Filtration Test Facility

\begin{tabular}{|c|c|c|c|c|c|}
\hline \multirow{2}{*}{\multicolumn{5}{|c|}{ Cross-Flow Filtration M\&TE, Revision 4, September 16, 2010}} & \multirow[b]{2}{*}{ Pre-Cal Unc } \\
\hline & & & & & \\
\hline Flow & DAS \# & M\&TE No. & Device & Range & (gpm) \\
\hline 1 & 11 & TR-40004 & Fischer-Porter Magnetic & $0-0.059 \mathrm{gpm}$ & 0.0016 \\
\hline 2 & 9 & TR-40005 & Fischer-Porter Magnetic & $0-0.052 \mathrm{gpm}$ & 0.0007 \\
\hline 3 & 13 & TR-40006 & Fischer-Porter Magnetic & $0-0.052 \mathrm{gpm}$ & 0.0005 \\
\hline 4 & 12 & TR-40008 & Fischer-Porter Magnetic & $0-10 \mathrm{gpm}$ & 0.048 \\
\hline 5 & 10 & TR-40009 & Fischer-Porter Magnetic & $0-10 \mathrm{gpm}$ & 0.027 \\
\hline 6 & 8 & TR-40010 & Fischer-Porter Magnetic & $0-20 \mathrm{gpm}$ & 0.056 \\
\hline Pressure & & M\&TE No. & & Range & (psid/psig) \\
\hline 1 & 14 & TR-40014 & Rosemount Transducer & $0-5$ psid & 0.020 \\
\hline 2 & 18 & TR-40015 & Rosemount Transducer & $0-5$ psid & 0.020 \\
\hline 3 & 16 & TR-40016 & Rosemount Transducer & $0-5$ psid & 0.021 \\
\hline 4 & 17 & TR-40017 & Rosemount Transducer & $0-50$ psid & 0.055 \\
\hline 5 & 15 & TR-40018 & Rosemount Transducer & $0-50$ psid & 0.124 \\
\hline 6 & 19 & TR-40019 & Rosemount Transducer & $0-50$ psid & 0.037 \\
\hline 7 & 21 & TR-40020 & Rosemount Transducer & $0-50$ psig & 0.035 \\
\hline 8 & 22 & TR-40021 & Rosemount Transducer & $0-50$ psig & 0.055 \\
\hline 9 & 20 & TR-40022 & Rosemount Transducer & $0-50$ psig & 0.058 \\
\hline Temp. & & M\&TE No. & Device & Range & $\left({ }^{\circ} \mathrm{C}\right)$ \\
\hline 1 & 0 & TR-40011 & Type E-TC & $0-100^{\circ} \mathrm{C}$ & 0.83 \\
\hline 2 & 1 & TR-40012 & Type E-TC & $0-100^{\circ} \mathrm{C}$ & 1.05 \\
\hline 3 & 2 & TR-40013 & Type E-TC & $0-100^{\circ} \mathrm{C}$ & 0.64 \\
\hline 4 & 4 & TR-02964 & Type E-TC & $0-100^{\circ} \mathrm{C}$ & 1.7 \\
\hline 5 & 3 & TR-02957 & Type E-TC & $0-100^{\circ} \mathrm{C}$ & 1.7 \\
\hline 6 & 6 & TR-02956 & Type E-TC & $0-100^{\circ} \mathrm{C}$ & 1.7 \\
\hline 7 & 5 & TR-02971 & Type E-TC & $0-100^{\circ} \mathrm{C}$ & 1.7 \\
\hline
\end{tabular}

Note: Temperature instruments numbers 4-7 were used on the cooling system for the pump seals and therefore not used in experimental, but on for safety concerns. The measurement uncertainties listed are for off-the-shelf type E thermocouple, but they were checked for operational accuracies at selected points. 
Table 8. Instument Location and Name used on the Test Facility (The first two columns correspond to the columns in the preceding table.)

\begin{tabular}{|c|c|c|c|}
\hline Flow & DAS \# & Instrument Location & Name \\
\hline 1 & 11 & Mott 0.375-inch Filtrate & FMB2 \\
\hline 2 & $\overline{9}$ & Mott 0.5-inch Filtrate & FMA2 \\
\hline 3 & 13 & Pall 0.375-inch Filtrate & FMC2 \\
\hline 4 & 12 & Pall 0.375-inch Slurry & FMC1 \\
\hline 5 & 10 & Mott 0.375-inch Slurry & FMB1 \\
\hline 6 & 8 & Mott 0.5-inch Slurry & FMA1 \\
\hline \multicolumn{4}{|l|}{ Pressure } \\
\hline 1 & 14 & Mott 0.5-inch Axial dP & dPA1 \\
\hline 2 & 18 & Pall 0.375-inch Axial dP & $\mathrm{dPC1}$ \\
\hline 3 & 16 & Mott 0.375-inch Axial dP & dPB1 \\
\hline 4 & 17 & Mott 0.375-inch TMP & dPB2 \\
\hline 5 & 15 & Mott 0.5-inch TMP & dPA2 \\
\hline 6 & 19 & Pall 0.375-inch TMP & $\mathrm{dPC2}$ \\
\hline 7 & 21 & Mott 0.375-inch Slurry Gauge & $\mathrm{PB}$ \\
\hline 8 & 22 & Pall 0.375-inch Slurry Gauge & $\mathrm{PC}$ \\
\hline 9 & 20 & Mott 0.5-inch Slurry Gauge & PA \\
\hline \multicolumn{4}{|l|}{ Temp. } \\
\hline 1 & 0 & Slurry & $\mathrm{T} 1$ \\
\hline 2 & 1 & Room Temperature & $\mathrm{T} 2$ \\
\hline 3 & 2 & Cleaning Loop & T3 \\
\hline 4 & 4 & Pump 1 Seal Water In & SWTC2 \\
\hline 5 & 3 & Pump 1 Seal Water Out & SWTC1 \\
\hline 6 & 6 & Pump 2 Seal Water Out & SWTC4 \\
\hline 7 & 5 & Pump 2 Seal Water In & SWTC3 \\
\hline
\end{tabular}


SRNL-STI-2011-00071

Revision 0

Table 9. Calibration of Data Acquisiton Channels used by Equipment in Preceding Table

\begin{tabular}{|c|c|c|c|c|c|c|c|c|c|c|}
\hline \multicolumn{11}{|c|}{ Calibration check of all DAS channels was done on 23 August 2010} \\
\hline & & & & & & & & & & \\
\hline & \multicolumn{2}{|c|}{ Thermocouples } & & & & & & & & \\
\hline Temperature & Channel 0 & Channel 0 & Channel 1 & Channel 1 & Channel 2 & Channel 2 & Channel 3 & Channel 3 & Channel 4 & Channel 4 \\
\hline Name & \multicolumn{2}{|c|}{ Slurry Discharge } & \multicolumn{2}{|c|}{ Room Temperature } & \multicolumn{2}{|c|}{ Cleaning Loop } & \multicolumn{2}{|c|}{ Seal Water 1 (SW1) } & \multicolumn{2}{|c|}{ Seal Water 2 (SW2) } \\
\hline${ }^{\circ} \mathrm{C}$ & T, applied & $T$, reading & $\mathrm{T}$, applied & $T$, reading & T, applied & $T$, reading & $\mathrm{T}$, applied & $T$, reading & $\mathrm{T}$, applied & $T$, reading \\
\hline 0 & 0.0 & 0.0 & 0.0 & 0.0 & 0.0 & 0.0 & 0.0 & 0.0 & 0.0 & 0.0 \\
\hline 25 & 25.0 & 25.0 & 25.0 & 25.0 & 25.0 & 25.0 & 25.0 & 25.0 & 25.0 & 24.9 \\
\hline 50 & 50.0 & 50.1 & 50.0 & 50.0 & 50.0 & 50.0 & 50.0 & 49.9 & 50.0 & 49.9 \\
\hline 75 & 75.0 & 75.1 & 75.0 & 75.0 & 75.0 & 75.0 & 75.0 & 75.0 & 75.0 & 74.9 \\
\hline 100 & 100.0 & 100.1 & 100.0 & 100.0 & 100.0 & 100.0 & 100.0 & $\begin{array}{l}100.0 \\
\end{array}$ & 100.0 & 99.9 \\
\hline & & & & & & & & & & \\
\hline \multirow[t]{2}{*}{ Temperature } & Channel 5 & Channel 5 & Channel 6 & Channel 6 & Channel 7 & & & & & \\
\hline & \multicolumn{2}{|c|}{ Seal Water 3 (SW3) } & \multicolumn{2}{|c|}{ Seal Water 4 (SW4) } & Not Used & & & & & \\
\hline${ }^{\circ} \mathrm{C}$ & T, applied & $T$, reading & $\mathrm{T}$, applied & $T$, reading & & & & & & \\
\hline 0 & 0.0 & -0.1 & 0.0 & -0.2 & & & & & & \\
\hline 25 & 25.0 & 24.9 & 25.0 & 24.8 & & & & & & \\
\hline 50 & 50.0 & 49.9 & 50.0 & 49.8 & & & & & & \\
\hline 75 & 75.0 & 74.9 & 75.0 & 74.9 & & & & & & \\
\hline \multirow[t]{4}{*}{100} & 100.0 & 99.9 & 100.0 & 99.9 & & & & & & \\
\hline & & & & & & & & & & \\
\hline & & & & & & & & & & \\
\hline & \multicolumn{4}{|c|}{ Flow Meters and Pressure Transducers } & & & & & & \\
\hline Current & Channel 8 & & Channel 9 & & Channel 10 & & Channel 11 & & Channel 12 & \\
\hline Name & \multicolumn{2}{|c|}{ Flow Meter A1 (FMA1) } & \multicolumn{2}{|c|}{ Flow Meter A2 (FMA2) } & \multicolumn{2}{|c|}{ Flow Meter B1 (FMB1) } & \multicolumn{2}{|c|}{ Flow Meter B2 (FMB2) } & \multicolumn{2}{|c|}{ Flow Meter C1 (FMC1) } \\
\hline $\mathrm{mA}$ & $\mathrm{V}$, meas. & $\mathrm{V}$, calc. & mA, applied & $\mathrm{V}$, calc. & mA, applied & V, calc. & mA, applied & V, calc. & mA, applied & \\
\hline 4 & 2.00 & 2.00 & 1.99 & 1.99 & 2.00 & 2.00 & 1.99 & 1.99 & 2.00 & 2.00 \\
\hline 8 & 3.99 & 3.99 & 3.98 & 3.98 & 3.99 & 3.99 & 3.98 & 3.98 & 4.00 & 4.00 \\
\hline 12 & 5.98 & 5.98 & 5.98 & 5.98 & 5.99 & \begin{tabular}{|l|l}
5.99 \\
\end{tabular} & 5.97 & \begin{tabular}{|l|l|}
5.97 \\
\end{tabular} & 6.00 & 6.00 \\
\hline 16 & 7.98 & 7.98 & 7.97 & 7.97 & 7.98 & \begin{tabular}{l|l|}
7.98 \\
\end{tabular} & 7.97 & $\begin{array}{l}7.97 \\
\end{array}$ & 8.00 & 8.00 \\
\hline 20 & 9.97 & 9.97 & 9.97 & 9.97 & 9.97 & 9.97 & 9.96 & $\begin{array}{l}9.96 \\
\end{array}$ & 10.00 & 10.00 \\
\hline & & & & & & & & & & \\
\hline Current & \begin{tabular}{|l|} 
Channel 13 \\
\end{tabular} & Channel 13 & \begin{tabular}{|l|} 
Channel 14 \\
\end{tabular} & \begin{tabular}{|l|} 
Channel 14 \\
\end{tabular} & Channel 15 & Channel 15 & Channel 16 & Channel 16 & Channel 17 & Channel 17 \\
\hline Name & Flow Meter & r C2 (FMC2) & Slurry dP Fi & Iter A (dPA1) & - TMP dP Filt & ter A (dPA2) & \begin{tabular}{|l|l|l} 
Slurry Filt \\
\end{tabular} & ter B (dPB1) & -TMP dP Filt & ter B (dPB2) \\
\hline $\mathrm{mA}$ & $\mathrm{V}$, meas. & V, calc. & $\mathrm{V}$, meas. & $\mathrm{V}$, calc. & $\mathrm{V}$, meas. & V, calc. & $\mathrm{V}$, meas. & V, calc. & mA, applied & V, calc. \\
\hline 4 & 2.00 & 2.00 & 2.00 & 2.00 & 2.00 & 2.00 & 2.00 & 2.00 & 1.99 & 1.99 \\
\hline 8 & 4.00 & 4.00 & 4.01 & 4.01 & 3.99 & \begin{tabular}{l|l|}
3.99 \\
\end{tabular} & 3.99 & 3.99 & 3.98 & 3.98 \\
\hline 12 & 6.00 & 6.00 & 6.01 & 6.01 & 5.99 & $\begin{array}{l}5.99 \\
\end{array}$ & 5.99 & \begin{tabular}{l|l|}
5.99 \\
\end{tabular} & 5.98 & 5.98 \\
\hline 16 & 8.00 & 8.00 & 8.01 & 8.01 & 7.98 & \begin{tabular}{l|l|}
7.98 \\
\end{tabular} & 7.98 & \begin{tabular}{l|l|}
7.99 \\
\end{tabular} & 7.97 & 7.97 \\
\hline 20 & 10.00 & 10.00 & 10.01 & 10.01 & 9.98 & 9.98 & 9.99 & 9.99 & 9.96 & 9.96 \\
\hline & & & & & & & & & & \\
\hline Current & Channel 18 & Channel 18 & Channel 19 & Channel 19 & Channel 20 & Channel 20 & Channel 21 & Channel 21 & Channel 22 & Channel 22 \\
\hline Name & Slurry dP Fil & $\operatorname{ter} \mathrm{C}(\mathrm{dPC} 1)$ & - TMP dP Fil & $\operatorname{ter} \mathrm{C}(\mathrm{dPC} 2)$ & Gauge Pres. & Filter $\mathrm{A}(\mathrm{PA})$ & Gauge Pres. & Filter B (PB) & Gauge Pres. & Filter $\mathrm{C}(\mathrm{PC}$ \\
\hline $\mathrm{mA}$ & mA, applied & $\mathrm{V}$, calc. & mA, applied & $\mathrm{V}$, calc. & mA, applied & V, calc. & mA, applied & V, calc. & mA, applied & V, calc. \\
\hline 4 & 1.99 & 2.00 & 1.99 & 1.99 & 2.00 & 2.00 & 2.00 & 2.00 & 2.00 & 2.00 \\
\hline 8 & 3.99 & 3.99 & 4.00 & 3.99 & 4.00 & \begin{tabular}{l|l}
4.00 \\
\end{tabular} & 3.99 & \begin{tabular}{l|l|}
3.99 \\
\end{tabular} & 3.99 & 3.99 \\
\hline 12 & 5.99 & 5.98 & 5.99 & 5.99 & 6.00 & 6.00 & 5.99 & 5.99 & 5.99 & 5.99 \\
\hline 16 & 7.97 & 7.97 & 7.99 & 7.99 & 8.00 & 8.00 & 7.99 & 7.99 & 7.98 & 7.98 \\
\hline 20 & 9.96 & 9.96 & 9.99 & 9.99 & 10.01 & 10.01 & 9.99 & 9.99 & 9.98 & 9.98 \\
\hline
\end{tabular}


SRNL-STI-2011-00071

Revision 0

\section{Appendix B}

\section{Crossflow Model Report by Nicholls State University}




\title{
Utilizing Particle Capture Models to Understand how to Maximize Permeate Volumes
}

\author{
Henry Foust \\ Nicholls State University \\ Thibodaux, LA \\ Malay Ghosehajra \\ PSI \\ New Orleans, LA \\ Firat Sever \\ Ft. Myers, FL \\ January 2011
}




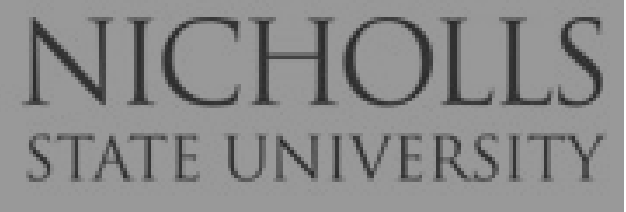




\section{ACKNOWLEDGEMENTS}

We'd like to thank the financial support of SRNL, especially Mark R.Duignan, and technical assistance from K.J. Hwang of Tamkang University, Tamsui, Taiwan. We would also like to thank the help of the following students at Nicholls State University - Bijeta Prasai, Britney Hebert, and Jake Rodrigue. 


\section{EXECUTIVE SUMMARY}

This research provides theoretical insight on experimental results that have shown there is some benefit to allowing the set-point of a cross-flow filtration system to vary in order to maximize permeate volumes and does this in several parts. Firstly, a literature review is provided on particle size capture associated with cross-flow filtration; secondly, presentation of a model that relates the moment balance of a solid captured on the membrane surface to Darcy's law that includes considerations of changing cake properties with each subsequent cake layer; and how these changes are dictated by three integral systems - fluid conditions, particle size distribution of solids within the slurry, and surface morphology of either the membrane surface or developing cake outer layer. Next, a method to experimentally validate the model is conducted and lastly a discussion of where the research is currently headed.

It will be shown that a model was developed that incorporates the three systems - fluid flow, solid-membrane interactions, and particle size distribution of the solids within the slurry. The model was then benchmarked in three progressive steps. The first step was simply to validate moment balance of a solid captured on the membrane surface against experimental results from the literature; the second step was to validate the model that includes cake properties against experimental results from the literature; and, the final step was to validate the model against experimental results conducted as part of the scope of this work. The first two steps were fairly successful, but the third step failed.

There are several reasons why our model could not be benchmarked to our experimental results. The experimental apparatus did not perform as intended. Results were not isothermal. The heat exchanger did not work well enough. No rheological study was conducted and the DI/microsphere slurry was assumed to have the behavior of water, which may or may not been a reasonable assumption. No analysis of the particle size distribution was conducted. Several parameters that were critical to the model are inherently difficult to measure.

The model itself only considered hydrodynamic forces and the model for the mechanism of mass transfer between the bulk phase and cake phase was simplistic. It is the consideration of these researchers that particle capture models are qualitative tools and not quantative tools. But the developed model is still adequate to answer the following question - is there any benefit to allowing the set-point to vary to maximize permeate volumes per a unit time? This question and its answer are beyond the scope of this project, but partial answer is discussed herein. 


\section{TABLE OF CONTENTS}

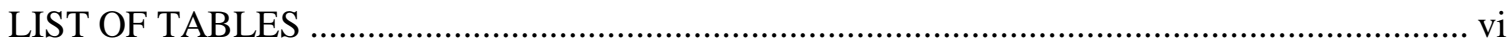

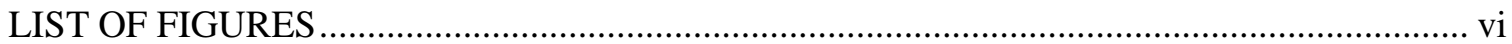

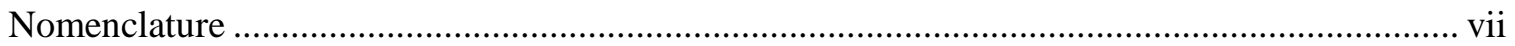

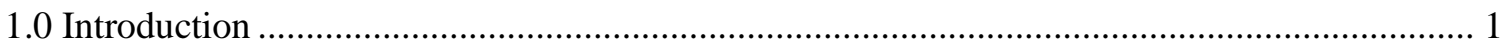

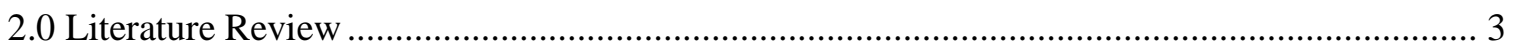

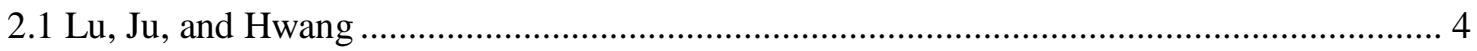

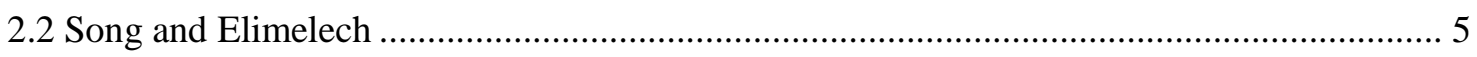

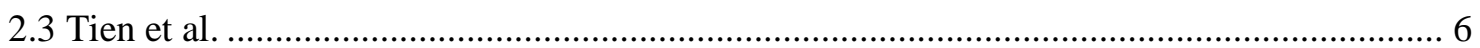

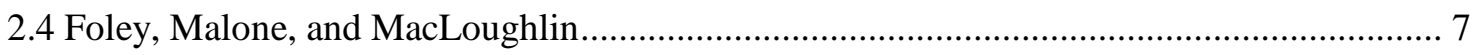

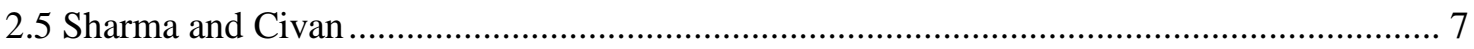

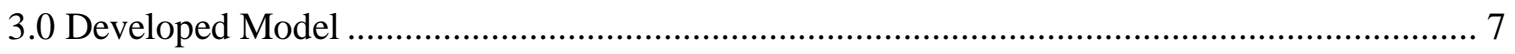

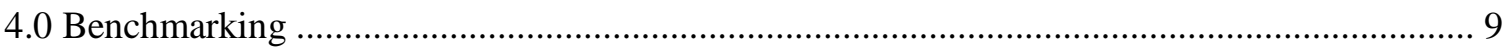

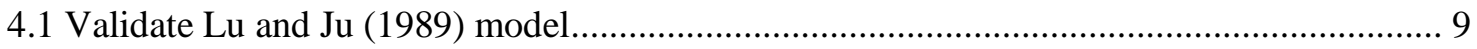

4.2 Validate developed model against Lu, Hwang and Ju (1993) experimental work .............. 10

4.3 Validate developed model against our experimental work ............................................. 11

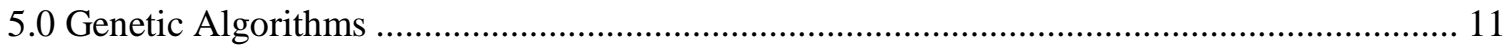

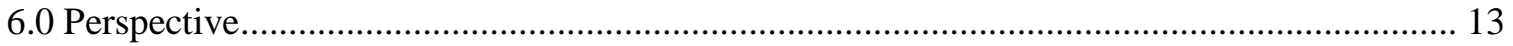

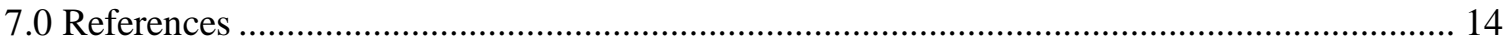

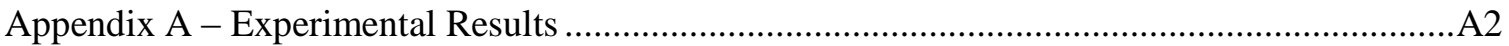

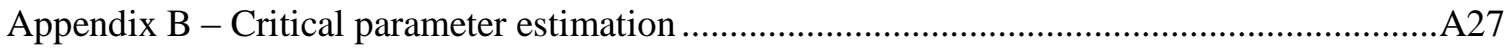

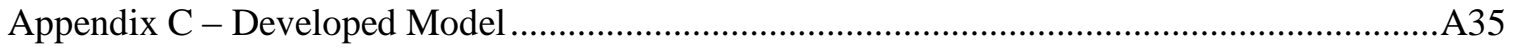

Appendix D - Filtration Drawings and Equipment Specifications .............................................A61

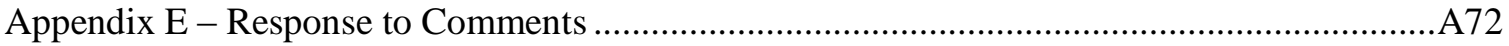




\section{LIST OF TABLES}

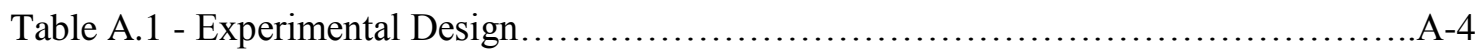

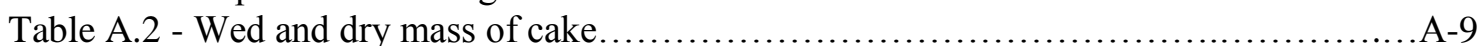

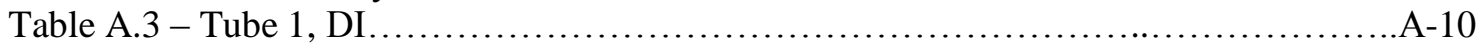

Table A.4 - Tube 1, Slurry .........................................................

Table A.5 - Tube 2, Slurry ........................................................

Table A.6 - Tube 3, Slurry .......................................................

Table A.7 - Tube 4, Slurry .....................................................

Table D.1 - Filter Unit Specifications..............................................

Table D.2 - Pump Specifications................................................ 66

Table D.3 - Flow Meter Specifications................................................

TableD.4 - Pressure Gauge Specifications ......................................... 66

\section{LIST OF FIGURES}

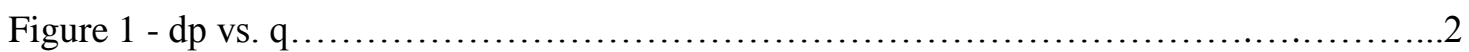

Figure 2 - dp vs. q (Benchmarking)............................................... 10

Figure 3 - time vs. permeate flux (Benchmarking) ....................................... 11

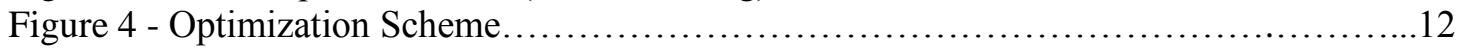

Figure A.1 - dp vs. Qp for clean filter.................................................

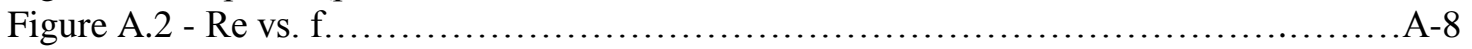

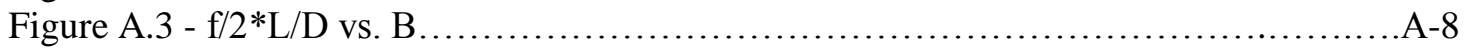

Figure A.4 - Determination of Angle of Repose .....................................

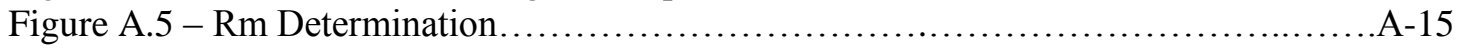

Figure A.6 - Tube 1, Slurry, Time vs. Permeate Flux..............................

Figure A.7 - Tube 1, Slurry, TMP vs. Permeate Flux................................ 17

Figure A.8 - Tube 1, Slurry, Axial Velocity vs. Permeate Flux..........................A-18

Figure A.9 - Tube 2, Slurry, Time vs. Permeate Flux...............................A-19

Figure A.10 - Tube 2, Slurry, TMP vs. Permeate Flux.............................. 20

Figure A.11 - Tube 2, Slurry, Axial Velocity vs. Permeate Flux...........................A-21

Figure A.12 - Tube 3, Slurry, Time vs. Permeate Flux................................. 22

Figure A.13 - Tube 3, Slurry, TMP vs. Permeate Flux...............................

Figure A.14 - Tube 4, Slurry, Time vs. Permeate Flux.................................

Figure A.15 - Tube 4, Slurry, TMP vs. Permeate Flux............................... 25

Figure A.16 - Tube 4, Slurry, Axial Velocity vs. Permeate Flux..........................A-26

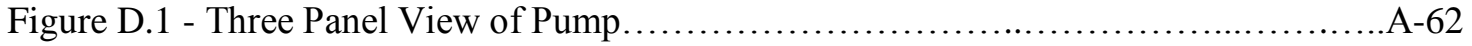

Figure D.2 - Front View of Filtration System.......................................... 63

Figure D.3 - Back View of Filtration System......................................... 64

Figure D.4 - Side View of Filtration System........................................ 65 


\section{Nomenclature}

$\mathrm{a}_{1}, \mathrm{a}_{2}$, and $\mathrm{a}_{3}$ : Adjustment parameter, mean, and standard deviation, respectively (used in the model developed in this study)

$\mathrm{a}_{\mathrm{p}}$ : Particle size diameter in Sherwood's number ( $\left.\mathrm{mm}\right)$

$\mathrm{c}_{1}, \mathrm{c}_{2}, \mathrm{c}_{3}$ : Coefficients associated with the forces that act on a solid of cut-off diameter size

$\mathrm{C}_{0}$ : Particle number concentration of the channel inlet (Sherwood's number)

$\mathrm{d}_{\mathrm{p}}$ : Cut-off diameter $(\mu \mathrm{m})$

DI : Deionized Water

$\mathrm{D}_{\infty}$ : Diffusion coefficient $\left(\mathrm{m}^{2} / \mathrm{s}\right)$

$\mathrm{f}$ : Friction factor

$\mathrm{F}_{\mathrm{n}}, \mathrm{F}_{\mathrm{t}}, \mathrm{F}_{\mathrm{l}}, \mathrm{F}_{\mathrm{w}}$ : Normal, tangential, drag, Inertial lift, and gravitational force exerted on a particle $(\mathrm{N})$

g: Gravitational acceleration $\left(\mathrm{m} / \mathrm{s}^{2}\right)$

J: Permeate flux in Sherwood's number $(\mathrm{mm} / \mathrm{s})$

k: Critical permeability $(\mathrm{m} / \mathrm{s})$

$\mathrm{K}^{*}$ : Non-dimensional number to define the ratio of diffusive and convective transport of particles

$\mathrm{P}\left(\mathrm{d}_{\mathrm{p}}\right)$ : Probability Density Function $\mathrm{q}_{\mathrm{p}}$ : Permeate flux $(\mathrm{mm} / \mathrm{s})$

PMMA: Poly(methyl methacrylate)

PSD: Particle Size Distribution

Qp: Permeate Rate

Qp(max): Permeate Rate with clean filter

$\mathrm{R}_{\max }$ : Maximum size particle captured (Civan and Sharma) $(\mu \mathrm{m})$

Sh: Sherwood's number (ratio of convective and diffusive transport)

$\mathrm{Sh}_{\mathrm{D}}, \mathrm{Sh}_{\mathrm{P}}, \mathrm{Sh}_{\mathrm{L}}$, and $\mathrm{Sh}_{\mathrm{EX}}$ : Particle flux components due to diffusion, permeation, inertial lift, and external forces

t: time

u: Axial velocity $(\mathrm{m} / \mathrm{s})$

$\mathrm{V}_{\mathrm{p}}$ : Permeate volume $\left(\mathrm{m}^{3}\right)$

$\alpha$ : Average specific resistance $[1 / \mathrm{m}-\mathrm{kg}]$

$\beta_{\mathrm{c}}$ : Critical friction angle (between a loose particle and cake layer)

$\delta$ : Cake thickness (mm)

$\Delta \mathrm{P}$ : Trans-membrane pressure differential $\left(\mathrm{N} / \mathrm{m}^{2}\right)$

$\theta$ : Angle of repose between the membrane surface feature and particle of concern

$\mu$ :Dynamic viscosity $(\mathrm{Pa} \cdot \mathrm{s})$

$v$ : Kinematic viscosity $\left(\mathrm{m}^{2} / \mathrm{s}\right)$

$\rho_{\mathrm{p}}$; Density of the solids $\left(\mathrm{kg} / \mathrm{m}^{3}\right)$

$\rho_{\mathrm{s}}$; Density of the slurry $\left(\mathrm{kg} / \mathrm{m}^{3}\right)$

$\varphi$ : Correction factor for stokes flow

$\varphi_{\mathrm{b}}$ : volumetric concentration of solids in bulk phase

$\varphi_{\mathrm{c}}$ : volumetric concentration of solids in cake phase 


\subsection{Introduction}

This investigation attempts to understand how changing the set-point of a cross-flow filtration process can improve the performance. Set-point is defined as the axial velocity (u) and transmembrane pressure differential (TMP) of the system; improved performance is here defined as increasing permeate volumes per a unit time.

In on-going experimentation, SRNL [1] have shown that starting a cross-flow filtration system by ramping up to the prescribed axial velocity and pressure drop across the porous tube and slowly allowing the permeate valve to open, which slowly increases the TMP, has provided higher than previous seen permeate fluxes and consequently, permeate volumes. A partial explanation for these phenomena is the following.

The main thesis of this sub-task, a thesis that supports the above observation, is that there is an integral relationship between flow conditions, surface morphology of the membrane surface/developing cake surface, and particle size distribution (PSD) of solids within the slurry that is being treated. Understanding this relationship and how the set-point dictates a certain portion of the PSD is captured can help in dictating what structure (morphology) each layer of the cake has. To increase production, there are likely better ways to layer the cake in the sense that it may be better to have smaller particles toward the membrane surface and larger particles away from the membrane surface.

A practical example of this idea is that to address pooling of water on a property a french drain is built. This is done by digging up a hole in the area of pooling and filling the bottom of the hole with a porous pipe and around the pipe putting in different size material. There are preferential ways of grading the material to improve the performance; one example is that it's better to include construction fill toward the surface, which is fairly small with a low permeability. Even though this seems counter intuitive - it actually improves the performance in the long run due to issues of clogging that occurs when using larger size particles at the surface.

Lu and Ju [2] have shown the following relationship exists between permeate flux (q) and particle size cut-off diameter

(Equation 1)

$q=c_{1} d_{p}-c_{2} d_{p}^{2}+c_{3} d_{p}^{3}$

Where $\mathrm{q}$ is the permeate flux $[\mathrm{cm} / \mathrm{s}], \mathrm{d}_{\mathrm{p}}$ is the cut-off diameter [microns], and $\left\{\mathrm{c}_{1}, \mathrm{c}_{2}, \mathrm{c}_{3}\right\}$ are coefficients associated with the forces that act on a solid of size $d_{p}$. This work has assumed all solids have $\mathrm{d}_{\mathrm{p}}$ greater than 1 micron and thus only hydrodynamic forces are considered.

A partial explanation of the SRNL observations is as follows (see Figure 1). Typically, the axial velocity and TMP begin at a full run; this is represented by Path A. What SRNL has done is shown by Path B. Each path is explained.

In Path $\mathbf{A}$, the system begins to run at $\mathrm{Q}_{\mathrm{p}}(\max )$ associated with a clean filter, high axial velocity, and high TMP. The permeate flux, $\mathrm{Q}_{\mathrm{p}}$, then slowly decays with time as the cake builds capturing large particles to smaller. Eventually, there are no smaller particles to capture and a quasi-steady state permeate flux is reached. Various cleaning methods can recover some of the initial performance, but there is likely some internal fouling of fines that are hard to remove. 
On the other hand, in Path $\mathbf{B}$, the smallest size particles are captured first, the permeate fluxes slowly increase to some level below $\mathrm{Q}_{\mathrm{p}}(\max )$, and slowly decays. Again, with time the cake builds, smaller and smaller particles are captured past time, $\mathrm{t}_{1}$, and eventually a quasi-steady state is reached.

The sequence of particles captured along Path $\mathbf{A}$ is as follows - largest to smallest - and so the inner layer of the cake is composed of larger particles and probably more poly-dispersed. Subsequent layers, on average, have smaller size particles. For Path B, the sequence of particles captured is as follows - smallest to larger and then slowly back to smallest - and so the inner layer of the cake is composed of smaller particles, the middle layers larger particles, and the outer layer is again smaller particles.

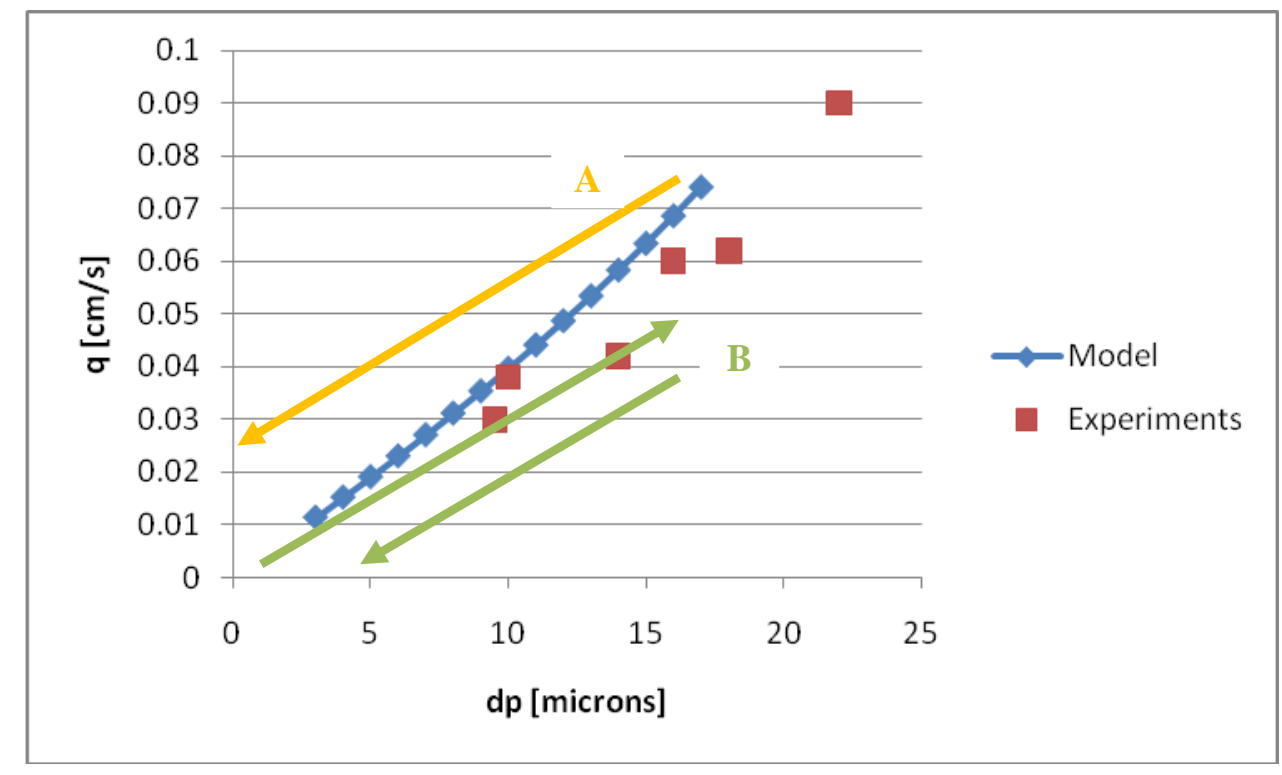

Axial Velocity $=.57 \mathrm{~m} / \mathrm{s}, \mathrm{TMP}=152 \mathrm{kPa}, .5 \mathrm{wt} \% \mathrm{CaCO} 3$

Figure 1 - dp vs. q [2]

It is possible that starting along Path $\mathbf{B}$ results in a mono-dispersed cake with smaller particles and a looser packing structure, which has been shown in Hwang and Wang [3] to have a large porosity when compared with larger sized particles. Further, by the time the filtration process gets to the larger particle sizes the cake is again roughly mono-dispersed, because the smaller size particles have possibly been utilized in previous cake layers. In [3], it has also been shown for a binary solution the lowest packing porosities are when the \% volume of larger particles is $75 \%$ and this may roughly correspond to the starting point for Path A.

This sub-task provides theoretical insight on what is discussed above and does this in several parts. Firstly, a literature review is provided on particle size capture associated with cross-flow filtration; second, presentation of a model that relates Equation 1 to Darcy's law that includes considerations of changing cake properties with each subsequent cake layer; and how these changes are dictated by three integral systems - fluid conditions, particle size distribution of solids within the slurry, and surface morphology of either the membrane surface or developing cake outer layer. Next, a method to experimentally validate the model is conducted and lastly a discussion of where the research is currently headed. 
It will be shown that a model was developed that incorporates the three systems - fluid flow, solid-membrane interactions, and particle size distribution of the solids within the slurry. The model was then benchmarked in three progressive steps. The first step was simply to validate Equation 1 against experimental results from the literature; the second step was to validate the model that includes cake properties against experimental results from the literature; and, the final step was to validate the model against experimental results conducted as part of the scope of this work. The first two steps were fairly successful, but the third step failed.

There are several reasons for this. The experimental apparatus did not perform as intended. Results were not isothermal. The heat exchanger did not work well enough. No rheological study was conducted and the DI/micro-sphere slurry was assumed to have the behavior of water, which may or may not been a reasonable assumption. No analysis of the particle size distribution was conducted. Several parameters that were critical to the model are inherently difficult to measure.

The model itself only considered hydrodynamic forces and the model for the mechanism of mass transfer between the bulk phase and cake phase was simplistic. It is the consideration of these researchers that particle capture models are qualitative tools and not quantative tools. But the developed model is still adequate to answer the following question - is there any benefit to allowing the set-point to vary to maximize permeate volumes per a unit time? This question and its answer are beyond the scope of this project, but we see a partial answer in the figure above and what SRNL has done.

The scope of this project was the development of a dynamic model adequate to form the basis to an optimization scheme to ask the question given above about maximizing permeate volumes by allowing the set-point to vary. It was also hoped that the dynamic model would be representative of cross-flow systems similar to what is envisioned to treat radioactive waste at SRNL and the Hanford Department of Energy facility.

\subsection{Literature Review}

Frank Tiller who is considered the "father of modern filtration", as acknowledged by the American Filtration Society, was one of the first to consider how the particle size distribution (PSD) of solids within solid/liquid slurry can affect the performance of filtration. Much of these effects are due to changes in morphology of the cake that result from changes in the segment of the PSD captured by the developing cake. The segment captured is an artifact of the process conditions that includes axial velocity and TMP, surface roughness and surface morphology of solid boundary, and the size of the particle itself.

Many of the studies in the area of how PSD affects filtration performance are based on applying Newton's second Law to each particle as it approaches the interface between the membrane surface (cake surface) and bulk phase. The main difference between the papers to be discussed below is what forces were included and what mechanism was utilized to distinguish between particles captured and particles not captured. One exception is Song and Elimelech [4], who treated the slurry/membrane system as a diffusion/convection process, in which convective diffusion equation was formulated with the inclusion of lateral transport due to permeation drag and inertial lift, and transport due to gravitational, double layer, and Van der Waals forces.

According to Hwang et. al. [5], the forces that are important for a particular slurry/membrane system are largely governed by the size of particles of solids within the slurry where particles above one (1) micron are likely governed by hydrodynamic forces (physical system) and particles below one (1) micron can be predominantly controlled by inter-particle forces (where chemistry 
plays more of a hand). It is also seen that above 10 micron the inertial lift becomes the dominate force and there is much less retention of these size particles in the outer layer of the cake.

It should be noted that a proper understanding of membrane separation needs to include three interlocking mechanisms - fluid dynamics (process conditions), interaction between particles and membrane/cake surface, and particle-particle interactions. The following factors were not considered in the proposed research:

- Membrane cake surface morphology (pore size, roughness, area of peaks and valleys, etc.)

- Compressibility of the cake

- Changing bulk phase concentration of solids

- Changes in the rheology of the cake

This review has grouped the research by either research group or area of application. An example of this is that Civan and Sharma [6,7 and 13] are petroleum engineers interested in cakes that form within wells extracting petroleum.

\section{1 $\mathrm{Lu}, \mathrm{Ju}$, and Hwang}

$\mathrm{Lu}$, Ju, and Hwang [2, 3, 5, 9, 10 and 11] have worked consistently in this area for over 20 years. In [2], they showed that permeate rates are related to a third order polynomial of $\mathrm{d}(\mathrm{pc})$, which is the largest size particle retained in the outer cake layer. This analysis was based on a momentum balance of the forces, which included drag forces, gravitational forces, and lateral lift forces. One benefit of the developed model is that a steady-state filtration rate equation was derived. The experimental validation was a rectangular cross-flow system with one permeable wall and a .5 wt $\%$ dilute light calcium carbonate slurry with an average $d(\mathrm{pc})$ of 10 micron, which tends to have one believe that most or all particles where above 1 micron. This study also showed that as the permeate flux decreases with time so does $\mathrm{d}(\mathrm{pc})$, which is in agreement with results of several other researchers $[9,13]$.

In [3], a hydrodynamic model along with bulk phase concentration of solids within a turbulent system were considered. A "cut-off" diameter was utilized from [2]. This paper largely looks at the model developed in [2] and how process conditions affect permeate rates. One observation is the following "it has been shown that the increase in the shear stress exerted on the cake surface seems to be more significant in improving the rate of cross-flow filtration than is the increase in the bulk velocity of the main stream."

In "Cake formation in 2-D Cross-Flow Filtration" by Lu and Hwang [4], a critical friction angle, $\beta_{c}$, is determined for a given situation based on a force balance of a particle with radius a. Particles that are entrained in the outer cake layer with an angle less than $\beta_{\mathrm{c}}$ are deposited and particle with an angle greater than $\beta_{\mathrm{c}}$ are swept away. The forces considered are 1) tangential drag parallel to the filter medium, 2) net drag normal to the filter medium, 3) net gravity force, and 4) inter-particle forces (i.e., Van der Waal's forces, electrostatic forces). Particle deposition was determined using a probability function defined as 
(Equation 2)

$P\left(d_{p}\right)=\frac{\beta_{c}}{\pi / 2}$

This equation agrees with a filtration model given by Tiller and Cooper [14], Carmen-Kozeny's equation for average specific resistance $(\alpha)$, and an equation by Happel and Brenner [15] for Kozeny's constant. The Happel and Brenner model and Carmen-Kozeny equation both determine specific resistance but assume the domain is made up of either unit cells or bundles of parallel tubes. Essentially, the same experimental set-up was utilized in $[2,10]$ where the particle size distribution went from 1 to 20 micron. Results indicate that values of $\beta_{\mathrm{c}}$ were smaller for larger particles, which imply, all else being constant, they're more likely to be swept away. This indicates that there is a critical "cut-off" diameter; and that the upper layer of the cake has smaller particles than lower layers, which is consistent with [2, 9, 10, 13, 16 and 17]. This observation can be seen in Figure 1, that is, as a filtration run continues, the permeate flux decreases and the $\mathrm{d}_{\mathrm{p}}$ decreases also.

Both references 3 and 11 provide the basis to the permeate models for cake filtration that includes sub-micron particles and the forces appropriate to these size particles that is utilized in [5]. In [3], the forces considered are frictional drag force, net gravity, inertial lift, net inter-particle forces, and Brownian forces. A particle was deposited when the drag force was larger than inter-particle forces and the binary mixture was 0.25 and 0.8 micron (mean).

The experimental apparatus was a rectangular channel, which treated Poly(methyl methacrylate) or simply PMMA spheres and had a laminar flow condition for the axial velocity. Results from the experiments indicate that mono-dispersed, smaller diameter slurry had a larger packing porosity than mono-dispersed, larger diameter slurry and that a mixture of mostly large diameter particles with significant $(25 \%)$ small particles had the lowest packing porosity. In addition, higher filtration rates result in lower packing porosities. Utilizing Kozeny's equation for spherical particles and a given average size of particles within the cake, a higher packing porosity results in a lower specific resistance.

The "Effects of particle size on the performance of cross-flow microfiltration" [5] provides one of the first studies of the effects of a poly-dispersed (sub-micron and micron) solids and their effect on cake formation. A rectangular cross-flow filtration system was utilized to treat a PMMA/DI slurry with a particle size distribution that ranged from 0.5 to 10 microns. It was concluded that the particle size distribution become finer as the cross-flow velocity increased and became coarser as filtration pressure increased. An increase in transmembrane pressure differential (TMP) led to a decrease in cake porosity and an increase in the average filtration resistance of the cake.

Results for sub-micron particles include the following forces - net inter-particle force and drag forces, both tangential and normal. As particle size increases, both inertial lift and gravitational forces become more important and for the axial velocities shown $(0.2$ to $0.6 \mathrm{~m} / \mathrm{s})$, above 10 micron no deposition occurs. Further, different segments of the particle size distribution have different trends in terms of percentage of capture, $\mathrm{P}\left(\mathrm{d}_{\mathrm{p}}\right)$. Below 0.5 micron, $\mathrm{P}\left(\mathrm{d}_{\mathrm{p}}\right)$ increases, from 0.5 to 2 micron $P\left(d_{p}\right)$ increases, and beyond 2 micron $P\left(d_{p}\right)$ drastically tapers off to zero. Lastly, higher axial velocities tended to reduce the average particle size of capture.

\subsection{Song and Elimelech}

Song and Elimelech [4] were interested in particle deposition on a parallel plate cross-flow system that mimics hyper-filtration and reverse osmosis. Naturally the approach they took was 
based more on chemical considerations and is the diffusion-convection approach mentioned earlier in the document. The components of this model included diffusion, permeation, inertial lift, and external forces, which were colloidal and gravitational. The developed equation was nondimensionalized into the following form

(Equation 3)

$S h=S h_{D}+S h_{P}+S h_{L}+S h_{E X}$

Where Sh is Sherwood's number (ratio of convective and diffusive transport) and is defined as

(Equation 4)

$\operatorname{Sh}=\frac{a_{p} J}{D_{\infty} C_{0}}$

Where $a_{p}$ is the particle size diameter, $J$ is permeate flux, $D_{\infty}$ is the diffusion coefficient, and $C_{0}$ is the particle number concentration of the channel inlet. Further, $\mathrm{Sh}_{\mathrm{D}}, \mathrm{Sh}_{\mathrm{P}}, \mathrm{Sh}_{\mathrm{L}}$, and $\mathrm{Sh}_{\mathrm{Ex}}$ are the particle flux components due to diffusion, permeation, inertial lift, and external forces. A more appropriate non-dimensional number $\mathrm{K}^{*}$ is utilized, which is defined as

(Equation 5)

$K^{*}=\frac{S h^{*} D_{\infty}}{a_{p}}$

A numerically analysis was carried out with neutrally buoyant particles ranging from $10 \mathrm{~nm}$ to 3 microns. Results include "Gravitational settling of particles may influence the dependence of particle deposition rate on particle size." It was seen that the density of the solid and particles above 1 micron $\mathrm{K}^{*}$ varied a great deal. Further, it was seen that for Brownian particles axial velocity had little effect on particle deposition rate and for micron size particles it has a large effect.

\subsection{Tien et al.}

Tien $[12,16$, and 18] has done a great deal of work in the broad area of cake filtration. He's even wrote a book on this topic, Introduction to Cake Filtration: Analysis, Experiments, and Applications [18]. He has proposed a model to explain particle deposition within a cross-flow filtration system based on a theory of friction. His theory is called particle adhesion [16]. In his research, he established a criterion based on the interplay of the geometry of the cake-suspension interface and various forces acting on a particle as it moves toward the interface. An expression of the adhesion probability of impacting particles was also developed, which was found to display behavior consistent with the observed phenomena of crossflow filtration and capable of representing experimental results.

In 2006, Tien and Ramarao [12] performed a state of the art review on analysis of cake formation and growth in cake filtration. According to them, most of the studies on cake filtration conducted so far assume that the local state of a filter cake is uniquely determined by the constitutive relationship, or in other words, a state of mechanical equilibrium is maintained. This condition under which the assumption is valid, however, has not been examined systematically. It was documented that although the equations describing the macro and micro compaction can be formulated with little difficulty, there are multiple issues which must be investigated further, such as the relationship between the compressive stress of the filter cake and the liquid pressure and 
compressive stress with the aggregate. The selection of the expression for liquid exchange between particle aggregates and suspending liquid should also be investigated further.

\subsection{Foley, Malone, and MacLoughlin}

A "cut-off" diameter, $d_{p}(i)$, was determined for a critical force balance of normal fluid drag and tangential fluid drag [16]. A new $d_{p}(i)$ is computed for each new layer of the cake. Knowing $d_{p}(i)$ along with information about the particle size distribution allows us to determine the \% capture and average $d_{p}(i)$, dpi_bar, for the $i^{\text {th }}$ cake layer. Once, dpi bar is determined, then $\alpha(i)$ can be determined, which represents the specific resistance of the ith layer of the cake. Knowing $\alpha(i)$ and $\alpha$ bar allows us to determine $\delta(t)$ and $J(t)$ where $\delta(t)$ is the cake thickness and $J(t)$ is the permeate flux at time $t$.

The numerical analysis is based on a symmetric particle size distribution with a $\mathrm{d}(\mathrm{min})$ of 0 micron and a d(max) of 10 microns. Results showed that the initial "cut-off" diameter, $d_{p}(0)$, had an immense effect on $\alpha$ in terms of when $\alpha$ began to increase and the slope of the curve where a larger $d_{p}(0)$ resulted in a longer time before inception and lower slopes. The interpretation is that $\mathrm{d}_{\mathrm{p}}(0)$ is directly related to $\Delta \mathrm{P}$ and inversely related to $\mathrm{u}_{\mathrm{x}}$ where $\Delta \mathrm{P}$ is trans-membrane pressure differential and $u_{x}$ is axial velocity. A larger $\Delta P$ or lower $u_{x}$ reduces the value of $\alpha$. Controlling $\delta(\mathrm{t})$ is best done by a lower $\Delta \mathrm{P}$ and higher $\mathrm{u}_{\mathrm{x}}$.

One nice feature of this work was the incorporation of several parameters of the particle size distribution (PSD) that include $\mathrm{d}(\min ), \mathrm{d}(\max )$, standard deviation, mean, and ability to skew the PSD. This was done by utilizing the work described in [18].

\subsection{Sharma and Civan}

In [13], Jiao and Sharma looked at two mechanisms for solid capture - rolling and sliding. The developed equations associated with each mechanism were of the form

(Equation 6)

$q=k R_{\max }$

where $\mathrm{R}_{\max }$ is the maximum size particle captured. Equation 6 is based on a moment balance for drag and shear forces. This model was then used to develop a model for cake thickness based on the slope $\mathrm{k}$, a critical permeability, shear stress, and $\Delta \mathrm{P}$. These equations were then used to show that a cake will not form below a critical permeability of the membrane.

\subsection{Developed Model}

If we assume all particles are at or above 1 micron, then the only forces to consider are hydrodynamic and namely [2 and 17]

1. Normal drag force $\left(F_{n}\right)$

2. Tangental drag force $\left(\mathrm{F}_{\mathrm{t}}\right)$

3. Inertial lift $\left(\mathrm{F}_{1}\right)$

4. Gravitational $\left(\mathrm{F}_{\mathrm{w}}\right)$

These forces act about a contact point and when the moment is zero, which designates the critical diameter, then 
(Equation 7)

$F_{t}=\left(F_{n}+F_{w}\right) \tan \theta$

And

(Equation 8)

$q_{p}=\frac{.425 f u^{2}}{\phi v \tan \theta} d_{p}-\frac{\left(\rho_{p}-\rho_{s}\right)}{18 \mu \phi} g d_{p}^{2}+\frac{15.25 f^{2} u^{4}}{4608 v^{3}} d_{p}^{3}$

Where $q_{p}$ is the permeate flux, $f$ is the friction factor, $u$ is the axial velocity, $d_{p}$ is the "cut-off" diameter, $\rho_{\mathrm{p}}$ is the density of the solids, $\rho_{\mathrm{s}}$ is the density of the slurry, $\varphi$ is a correction factor for stokes flow, $\nu$ is the kinematic viscosity, $\mu$ is the dynamic viscosity, $g$ is the gravity constant, and $\theta$ is the angle of repose between the membrane surface feature and particle of concern.

And

(Equation 9)

$Q_{p}=\frac{\Delta \mathbf{P}}{\mu\left(R_{m}+R_{c}\right)}=c_{1} d_{p}-c_{2} d_{p}^{2}+c_{3} d_{p}^{3}$

Where $\mathrm{C}_{1}, \mathrm{C}_{2}$, and $\mathrm{C}_{3}$ are defined in Equation 8

The procedure for solution to Equation 9 is as follows.

1. Determine $\mathrm{Qp}(0)$ from initial conditions with clean membrane.

2. Determine $\mathrm{dp}(0)$ from Equation 8.

3. Determine \% capture, $\mathrm{f}(0)$, from

(Equation 10)

$f=\frac{\int_{d m i n}^{d p} x^{3} p(x) d x}{\int_{d m i n}^{d m a x} x^{3} p(x) d x}$

Where

(Equation 11)

$p(x)=\frac{\frac{d \max * x-x^{2}}{d \max * x-x^{2}+a_{1}} \exp \left(-\left(\frac{x-a_{2}}{a_{3}}\right)^{2}\right)}{\int_{0}^{d m a x} \frac{d \max * x-x^{2}}{d \max * x-x^{2}+a_{1}} \exp \left(-\left(\frac{x-a_{2}}{a_{3}}\right)^{2}\right)}$

4. Determine dpi_bar from

(Equation 12)

$\overline{d p}(i)=\frac{\int_{d m i n}^{d p \omega} x^{3} p(x) d x}{\int_{d m i n}^{d p \omega} x^{2} p(x) d x}$ 
5. Determine $\alpha(i)$ from

(Equation 13)

$\alpha(i)=\frac{180}{d p(i)^{2}} \frac{\varphi_{c}^{2}}{\left(1-\varphi_{c}\right)^{a}}$

Which assumes spherical solids

6. Determine $\alpha$ from

(Equation 14)

$\alpha=\sum_{i=1}^{n-1} \frac{\alpha_{i} d \delta_{i}}{\delta}$

Where

(Equation 15)

$\frac{d \delta}{d t}=\frac{\varphi_{b}}{\varphi_{c}} f J$

Where $\phi_{\mathrm{b}}$ is the volume fraction of solids in the bulk phase and it is noted this model could allow for changes in $\mathrm{C}_{\mathrm{b}}(\mathrm{t})$, rheology, and set-points.

It is noted that the particle size distribution is specified through $d_{\min }, d_{\max }, a_{1}, a_{2}$, and $a_{3}$ where $a_{1}$ is an adjustment parameter, $\mathrm{a}_{2}$ is the mean, and $\mathrm{a}_{3}$ is the standard deviation.

\subsection{Benchmarking}

To validate the developed model, a sequence of steps was considered. These steps are

1. Validate Lu and Ju model [2]

2. Validate developed model against Lu, Hwang and Ju [9] experimental work [9]

3. Validate developed model against experimental work

\subsection{Validate Lu and Ju (1989) model}

The first step in validation the theoretical work against an empirical study was to validate Equation 8 and 9 against experimental work by Lu and Ju [2], which was done and shown as Figure 2. As can be seen in the figure, a fair agreement exists between the model and experimental results. We then proceeded to step 2 . 


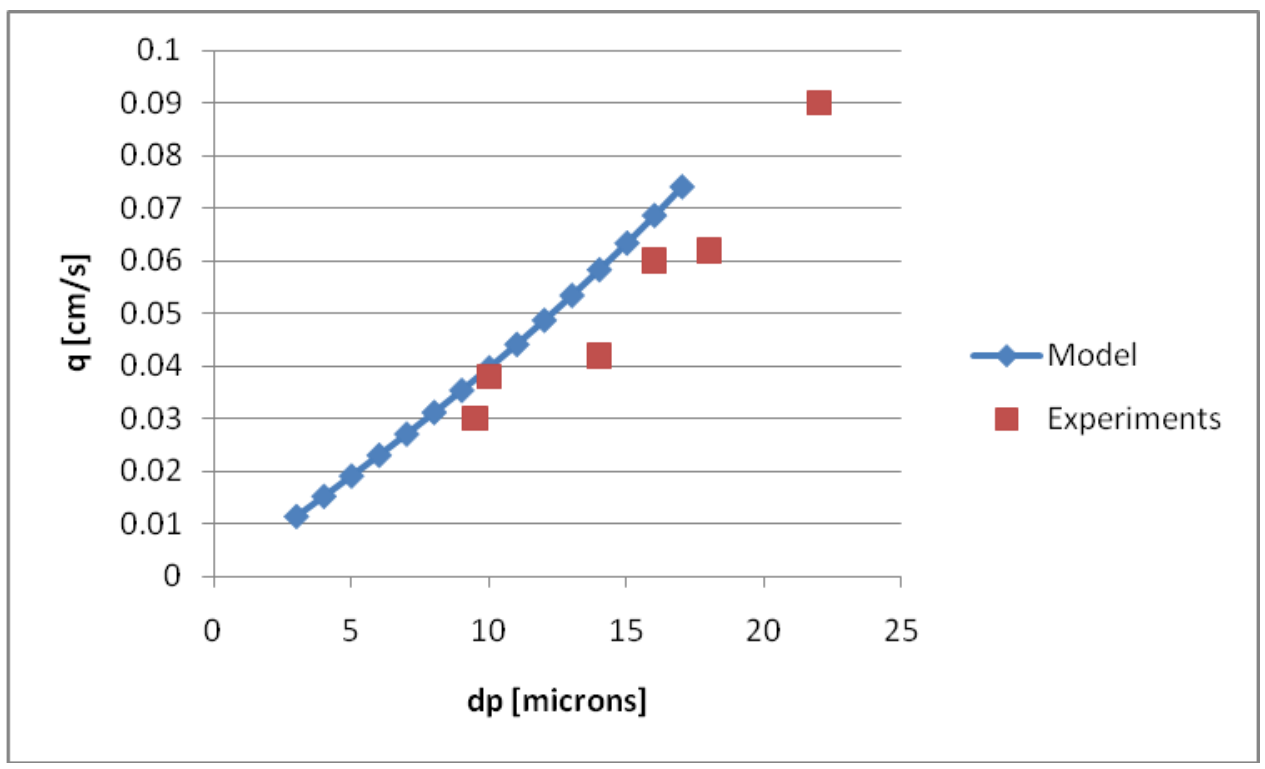

Axial Velocity $=.57 \mathrm{~m} / \mathrm{s}, \mathrm{TMP}=152 \mathrm{kPa}, .5 \mathrm{wt} \% \mathrm{CaCO} 3$

Figure 2 - Permeate flux versus cut-off diameter.

4.2 Validate developed model against $\mathrm{Lu}$, Hwang and Ju (1993) experimental work

The next step was to validate the developed model against Lu, Hwang and Ju [9] and this became more problematic. The key issue was how to estimate critical parameters such as $\varphi_{\mathrm{c}}$ and $\varphi_{\mathrm{b}}$. Other parameters, which are hard to estimate, were determined during the course of the research. Some criteria were established to determine when the model fits the data adequately

1. Match $\mathrm{Qp}(0)$ between model and experiment

2. When $\mathrm{Qp}(\mathrm{t}) / \mathrm{Qp}(0)=1 / 2$ and match $\mathrm{t}$ between model and experiment

3. Use reasonable parameters determined through experimentation

A good agreement was established (see Figure 3), but several parameters were altered to allow for this agreement. $R_{m}$ was reported as $2 \mathrm{e} 101 / \mathrm{m}$, but was not physically possible from a knowledge of $\mathrm{Q}_{\mathrm{p}}(0)$ and a viscosity for water. Also, the values determined for $\varphi_{\mathrm{c}}$ and $\varphi_{\mathrm{b}}$ resulted in unrealistic permeate fluxes and so other values were determined through a search method. This brings up a concern about the quantitative reliability of the particle capture model developed. See PERSPECTIVE for more details.

The model is provided as APPENDIX C2.

Needless to say, a good agreement between the model and experimental data was established. 


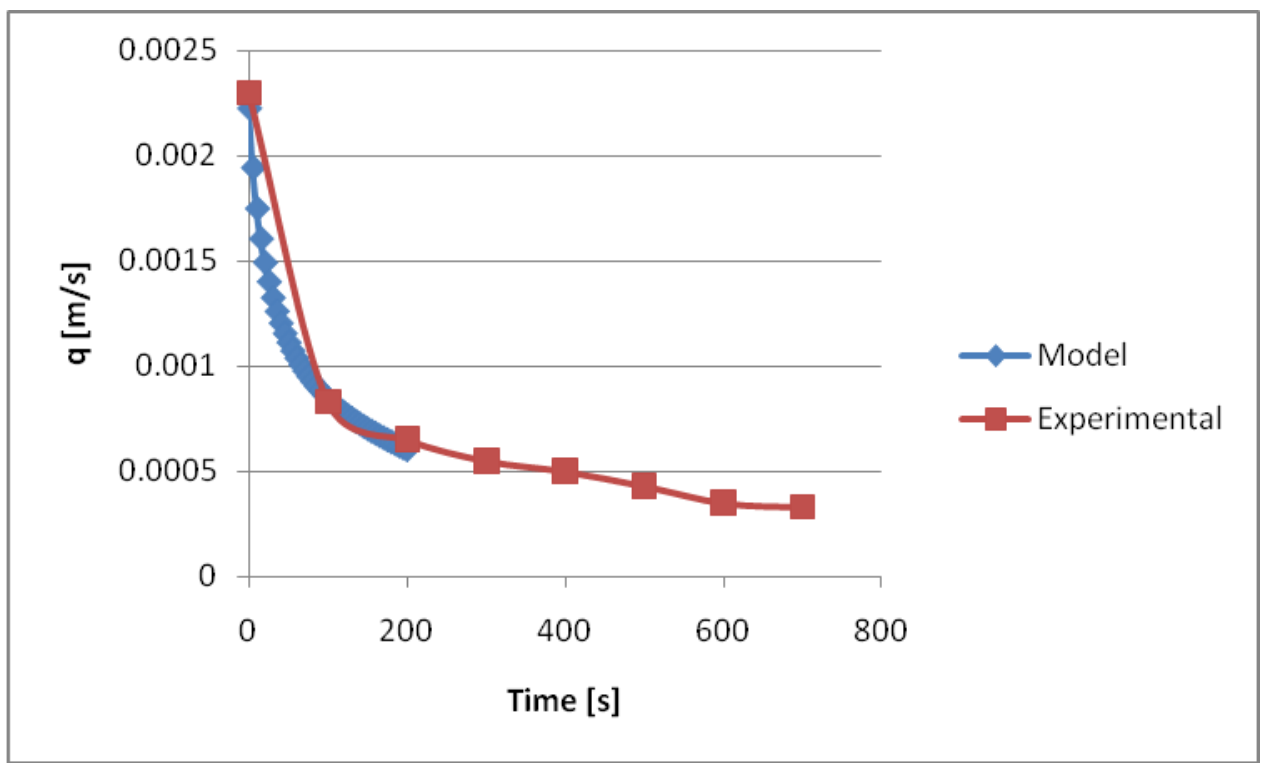

Axial Velocity $=.61 \mathrm{~m} / \mathrm{s}, \mathrm{TMP}=26.7 \mathrm{kPa}, .5 \mathrm{wt} \% \mathrm{CaCO} 3$

Figure 3 - Permeate flux versus time

\subsection{Validate developed model against our experimental work}

The next step was to validate the developed model against an experimental data set (See APPENDIX A) that is representative of cross-flow filtration systems currently being utilized by SRNL in their experimental work. One caution is that our bench-scale system (see APPENDIX D for filtration drawings and equipment specifications) is at a different physical scale to the SRNL cross-flow filtration system. As part of this sub-task, experimental work was conducted and part of this effort was to estimate these parameters. Unfortunately, this effort was not fruitful. Another effort based on Civan [7] is discussed below.

Several reasons are given for this. The first issue associated with the experimental apparatus was that the heat exchange system built was not properly designed and the cross-flow filtration was not isothermal and temperatures varied significantly between the beginning of a run and the end of the run. The next issue was that the various experimental methods utilized to estimate $\varphi_{\mathrm{c}}$ and $\theta$ did not work. Further, our filtration run times and often varying the set-point may have created cakes that are not representative of what SRNL is seeing in their cake's properties.

Experimental and model results were not given. The reason for this is that the model claims for the conditions associated with Tube 3 that the first "cut-off" diameter is essential at the $\mathrm{d}(\mathrm{min})$ and no cake would have formed. It's not obvious why this is and so no results are presented.

The model is provided as APPENDIX C3.

\subsection{Genetic Algorithms}

The next step in the research will be to utilize the model calibrated to $\mathrm{Lu}$ and Ju [2] and ask the following question: Can allowing the set-point to vary maximize the volume of permeate per a unit time? An answered will be provided by utilizing the developed model and genetic algorithms.

Set-point is defined as a particular trans-membrane pressure differential (TMP) and axial velocity, which corresponds to a given pressure drop across the length of the porous tube. It is generally 
the case that the set-point is a constant and large TMP and axial velocity. SRNL has shown that utilizing a "ramping" set-point improves the performance in terms of permeate volume per a unit time. There method involved starting at a very low TMP and slowly allowing the TMP to increase to the complete, prescribed value.

It is noted that the use of genetic algorithms in conjunction with the developed dynamic model for cake formation based on particle capture was beyond the scope of this project, but a description of genetic algorithms is given. After this brief introduction to genetic algorithms, a description of how GA(s) will be used in the up-coming work will be mentioned.

Genetic algorithms are a form of evolutionary optimization scheme, and evolutionary optimization schemes provide a seemingly random search method that transition from several points at once when compared against calculus based search schemes. Each individual of the generation, which is the sum points currently evaluated, is a string of ones and zeros. This binary string represents the value of parameters from a base 10 system.

The rules for transition are based on three operators:

- Reproduction

- Crossover

- Mutation

This parallel computing scheme finds through "fitness" better points within the solution domain and converges to an optima. This optimization tool will be utilized in an up-coming project in the following manner (see Figure 4).

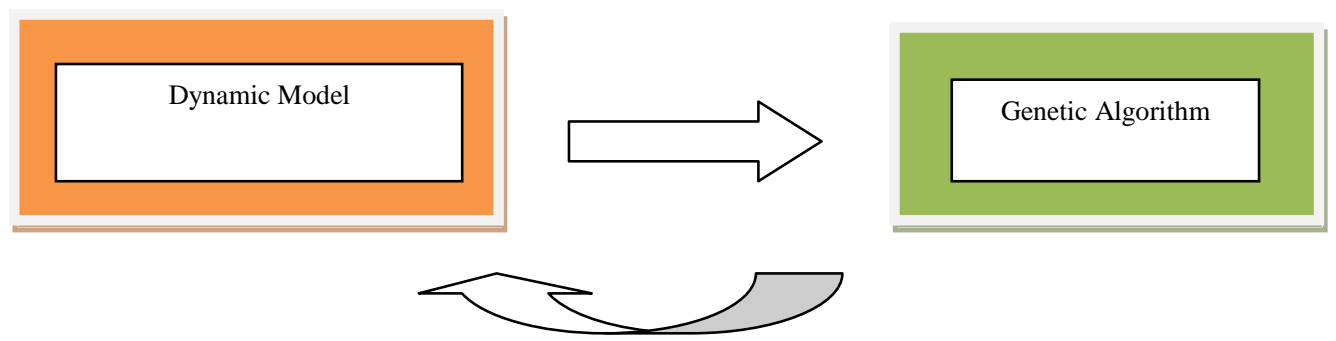

Figure 4 - Optimization Scheme

The dynamic model will conveniently be taken to have a filtration run of 400 seconds broken into 5 second internals, which results in 80 time intervals. At each time interval, the axial velocity and trans-membrane pressure differential will both be allowed to vary between eight values. All 80 time intervals and the range of set-points constitute one individual and will be encoded into a binary form. The population size will be between 30 and 50 with an acceptable mutation rate. The number of generations will be determined as part of the research. There could be issues associated with the number of computations involved and utilizing a PC to crunch these numbers.

Associated with each individual is a "fitness", which in this case is a volume of permeate. If there's value to allowing the set-point to vary, there will be a significant difference between the worst permeate volume and best permeate volume on the solution domain. 


\subsection{Perspective}

What worked and what didn't work? What was learned from this experience?

A dynamic model that represents a cross-flow filtration system was developed and validated against experimental results. This dynamic model is adequate to explore the optimization problem posed above.

The following were issues that were not resolved.

- Effect of fines on filtration performance

- Non-Isothermal system

- Larger sized micro-sphere slurry tended to foam excessively

- Slurry was very unclear and this made determining the volumetric flow rate difficult

- Ignored changes in viscosity due to solids within the slurry

It's obvious that more experimentation is needed and some experimental methods need to be revisited. We felt we have a fair handle on $\mathrm{R}_{\mathrm{m}}, \varphi$ (bulk), but not $\theta$ and $\varphi($ cake).

The filtration system had a heat exchanger, but this didn't work well and the temperature changed over the course of the run. Only permeate fluxes for Tube 3 were corrected for temperature and utilized in Bench Marking. The correction was to $20 \mathrm{C}$.

There were four porous tubes utilized during the experimentation and labeled Tubes 1 to 4 . Tube 1 was utilized to determine $\mathrm{Rm}$, friction factors, and estimate porosity of the cake. Tube 2 was utilized to measure porosity of the cake; Tube 3 was used to establish at a constant axial velocity the permeate rates with time and determine porosity of cake for larger particle size microspheres; Tube 4 was utilized much as Tube 3 but with a smaller particle size microspheres. The slurry was either deionized (DI) water or DI and microspheres.

The model, APPENDIX $\mathbf{C}$, is the combination of two well-established models and the physics associated with the momentum balance seems reasonable. What needs to be addressed is the fact that little of the chemistry of the system has been addressed and this fact during the course of the research became apparent. One limitation is that the mass transfer rate, as expressed by Equation $\mathbf{1 5}$, is overly simplistic and there are likely particle-particle and particle-membrane interactions of a chemical nature that need to be included and possibly by altering the value of measure parameters we're addressing this issue, but not in a proper fashion. Also, the angle of repose changes during the course of filtration, but for the modeling is assumed constant. Angle of repose is a misnomer in that its an angle of contact between features on the membrane surface and a captured solid, but is affected by flow conditions the size of solids within the slurry and these interactions with the membrane surface. The model would still be useful for the intended us of finding out if there's any benefit to allowing the set-point to varying in order to maximize permeate volumes.

What, in particular, was learned from the Bench Marking? Some of what was learned has just been mentioned. But, in general, the main issue that came up was the mechanism for mass transfer from the bulk phase to the cake currently utilizes is simplistic, simplistic in the sense that the chemistry of this system is largely ignored, and would require more research to develop a 
more realistic model for the mass transfer from these two phases. Also, as previously mentioned, several parameters are difficult to estimate and in particular $\varphi$ and $\varphi_{\text {c }}$. Attempts were made to estimate these parameters (see APPENDIX A), but generally provided poor estimates.

Our path forward is to utilize the model calibrated against experimental results given in Lu, and $\mathrm{Lu}[2]$ and begin the work on the development of an optimization scheme to ask the question, is there a benefit to production by allowing the set-point to vary with time. This will be done to validate the results and ideas expressed by Figure 1.

\subsection{References}

[1] Mark Duignan (2010). Personal Communications.

[2] Lu and Ju (1989). "Selective particle deposition in cross-flow filtration", Separation Science and Technology, v. 24, n. 7/8, pp. 517 to 540.

[3] Hwang and Wang (2001). "Numerical simulation of particle deposition in cross-flow microfiltration of binary particles." Tamkang Journal of Science and Engineering, v. 4, n. 2, pp. 119 to 125.

[4] Song and Elimelech (1995). "Particle deposition onto a permeable surface in laminar flow." Journal of Colloid and Interface Science, 173, pp. 165 to 180.

[5] Hwang, Hsu, and Tung (2006). "Effect of particle size on the performance of cross-flow filtration." Advanced Powder Technology, v. 17, n. 2, pp. 189 to 206.

[6] Civan (1998). "Incompressible cake filtration: mechanism, parameters, and modeling." AIChE Journal, v. 44, n. 11, pp. 2379 to 2387.

[7] Civan (1998). "Practical model for compressive cake filtration including fine particle invasion." AIChE Journal, v. 44, n. 11, pp. 2388 to 2398.

[8] Poirier and Fink (2003). Axial Pressure Drop Measurements during Pilot-Scale Testing ofa Mott Crossflow Filter, Savannah River Technology Center, WSRC-TR-3003-00051, Rev. 0.

[9] Lu, Hwang, and Ju (1993). "Studies on the mechanism of crossflow filtration." Chemical Engineering Science, v. 48, n. 5, pp. 863 to 872.

[10] Lu and Hwang (1995). "Cake formation in 2-D cross-flow filtration." AIChE Journal, v. 41, n. 6 , pp. 1443 to 1455 .

[11] Hwang, Hu, and $\mathrm{Lu}$ (2001). "Crossflow microfiltration of submicron microbial suspensions." Journal of Membrane Science, 194, pp. 229 to 243.

[12] Tien and Ramarao (2006). "On analysis of cake formation and growth in cake filtration." Journal of China Institute of Chemical Engineers, v. 37, n. 1, pp. 81 to 94.

[13] Jiao and Sharma (1994). "Mechanism of cake buildup in crossflow filtration of colloidal suspensions." Journal of Colloid and Interface Science, v. 164, pp. 454 to 462. 
[14] Tiller and Cooper (1960). "The role of porosity in filtration: IV Constant Pressure Filtration". AIChE Journal, v. 6, pp 595.

[15] Happel and Brenner (1965). Low Reynolds number hydrodynamics: With special applications to particulate media; Prentice-Hall Englewood Cliffs, N.J.

[16] Tien et al. (1993). "A simple model of cross-flow filtration based on particle adhesion", AIChE Journal, v. 39, pp. 1292 to 1302.

[17] Foley, Malone and MacLoughlin (1995). "Modeling the effects of particle polydispersity in crossflow filtration.” Journal of Membrane Science, v. 99, pp. 77 to 88.

[18] Tien, Chi (2006). Introduction to Cake Filtration: Analysis, Experiments, and Applications Elsevier Science, Amsterdam, The Netherlands.

[19] Peleg, Normad, and Rosenau (1986). "A distribution function for particle populations having a finite size range and a mode independent of the spread." Powder Technology, v. 46, pp. 209 to 214. 


$$
\text { A-1 }
$$


Appendix A - Experimental Results

Appendix A1 - Experimental Procedure

Appendix A2- Experimental Results 


\section{Appendix A1 - Experimental Work}

\section{Experimental Procedure}

This experimental procedure includes the following five parts.

1. Operating Procedure

2. Experimental Design

3. Solids collection procedure

4. Membrane cleaning procedure

5. QA/QC

\section{Operating Procedure}

See APPENDICIES D1 and D2 for equipment diagrams with equipment specifications.

1. Visually inspect the system and check the following conditions:

a. The outer valve must remain closed and that the choke valve must be partially closed.

b. The slurry holding tank must be in-place and with fluid in it.

c. The pressure gauges must be "on."

d. Correct mixing ratios must be used for slurry

e. Holding tank must be constantly stirred.

2. Slurry mixture: Using 2 liters of DI water and 200 grams of solids means a concentration of solids equal to $100 \mathrm{~g} / \mathrm{L}$. We'll likely need to determine the viscosity of this liquid/solid slurry, which will be significantly different from water.

3. Turn on the pump and adjust the choke valve so the flow is set to the desired level.

4. As permeate is drawn off into the permeate collection vessel, an equal amount of DI water needs to be added to the slurry holding tank.

5. At a prescribed time interval, take the following measurements. Pressure at pressure gauge 1, pressure at pressure gauge 2, volumetric discharge, volume (mass) in permeate collection vessel, and add DI water to slurry holding vessel.

6. At the end of the run, remove the membrane and collect solids. Weigh solids wet, dry in drying oven, and weigh solids dry. Record these values.

7. Provide tube drying procedure - tubes were air dried for 1 week.

8. Provide coolant system procedure - coolant water was checked and periodically replaced with cooler water. 
9. Provide any observations of the experiment and date/time experiment and sign.

\section{Experimental Design}

The following four modules of experiments were conducted. Experiments to calibrate and validate friction factor model, experiments to determine angle of repose between solids and membrane surface, experiments to validate model for concentration of solids within cake, and experimental validation of particle capture model for permeate rates as a function of time. Each experimental module is discussed below.

In order to run the four experimental modules, four porous tubes were utilized. Details are given below in Table A1 and more details can be found within APPENDIX A2, Experimental Results. More details of the micro-spheres are given in APPENDIX D2. It is noted that spherical solid particles were utilized for several reasons and the main reason is that the shape factor for a sphere is know and this simplifies the form of the Carmen-Kozeny equation utilized.

\begin{tabular}{|c|c|c|}
\hline Tube \# & Slurries Utilized & Experiments Run \\
\hline 1 & $\begin{array}{c}\text { DI, DI + Large } \\
\text { Microspheres }\end{array}$ & Determined $R_{m}$, Determined f for DI, Determined f for DI+MS, porosity \\
\hline 2 & DI + Large Microspheres & Determined porosity \\
\hline 3 & $\mathrm{DI}+$ Large Microspheres & Determined t vs. $\mathrm{Q}_{\mathrm{p}}$, porosity for Larger MS \\
\hline 4 & $\mathrm{DI}+$ Small Microspheres & Determined t vs. $\mathrm{Q}_{\mathrm{p}}$, porosity for Smaller MS, angle of repose \\
\hline
\end{tabular}

\section{Table A1 - Experimental Design}

\section{Friction factor experiments}

A proposed model for friction factors is

$$
\begin{aligned}
& \text { (Equation A1) } \\
& \frac{1}{\sqrt{f}}=2 \log (\operatorname{Re} \sqrt{f})+B
\end{aligned}
$$

Where $\mathrm{f}$ is friction factor, Re is Reynold's number, and B is a parameter to be determined.

Two sets of experiments will be conducted. The first using DI and running at the following values $2 \mathrm{gpm}, 4 \mathrm{gpm}, 6 \mathrm{gpm}, 8$, gpm and $10 \mathrm{gpm}$. Associated with each Q will be a pressure drop between the pressure gauges.

The second set of experiments will include the addition of 200 grams of the larger spheres and conducting the above sequence of volumetric discharges over a sequence of 10 minute intervals. The following parameters will be measured:

- $\quad$ Pressure Gauge Inlet

- Pressure Gauge Outlet

- Volumetric Flow Rate

- Mass/Volume of Permeate 
- Temperature in slurry holding vessel

\section{Determination of angle of repose}

The angle of reposed between the solids and membrane surface will be determined by running the 20 grams of smaller particles in 2 liters of DI water. The flow rate will start low enough to capture the .5 micron particles, which have a narrow PSD, and increased to keep the permeate rate constant. For these conditions, the following equation applies

(Equation A2)

$Q_{p}=\frac{.425 f u^{2}}{\emptyset v \tan (\theta)} d_{p}$

Or

(Equation A3)

$Q_{p}=k f u^{2}$

Where $f$ is friction factor, $u$ is axial velocity, $d_{p}$ is the particle size of capture, $\varphi$ is a correction factor, $Q_{p}$ is the permeate rate, and $v$ is the viscosity. A plot of $\mathrm{fu}^{2} \mathrm{vs}$. $\mathrm{Q}_{\mathrm{p}}$ will provide the value for $\mathrm{k}$ and we can back-out $\operatorname{Tan}(\theta)$.

\section{Determination of concentration of solids in cake}

Given below are three methods to measure the mass of solids in the cake, but each system is fraught with problems. It may be best to use all three methods. All three methods determine the mass of solids, w, for a given time and relate this to permeate rates, $Q_{p}$. As will be shown below, a graph of $1 / \mathrm{Q}_{\mathrm{p}}$ vs. w can determine porosity.

\section{Method 1}

Experiments will be run where the filtration system is run to a certain ratio of $Q p(0) / Q p(t)$ and the tared filter tubes weight is measure. This will be done using 4 filters. These four data points will be utilized in the following manner

Darcy's law states

(Equation A4)

$Q_{p}=\frac{\Delta P A}{\mu\left(R_{m}+R_{c}\right)}$

which can be shown to also have the form

(Equation A5)

$R_{c}=\frac{\Delta P}{\mu} \frac{A}{Q_{p}}-R_{m}$

Or

(Equation A6) 
$w=\frac{\Delta P A}{\mu \bar{\alpha}} \frac{1}{Q_{p}}-\frac{R_{m}}{\bar{\alpha}}$

A plot of $1 / Q_{p}$ vs. w will provide the slope, which allows us to back out $\alpha$ and for spherical solids

(Equation A7)

$\bar{\alpha}=\frac{180}{d p^{2}} \frac{\phi_{c}^{2}}{\left(1-\phi_{c}\right)^{3}}$

\section{Method 2}

Tare the weight of a dry porous tube, run the experiment, determine the wet mass of cake + porous tube, dry the tube and cake, re-weigh.

\section{Method 3}

Measure the weight of holding tank, measure weight of permeate, and estimate the mass of solids in the system. The discrepancy is the mass of solids in the cake.

Experimental validation of particle capture model for permeate rates

The experiments run for the friction factor experiment with solids present will be the same experimental data utilized to validate the particle capture model.

\section{Filter Cleaning}

Using the given sodium hydroxide solution, which will be in a bath, submerge the dirty filter tube for at least 24 hours and drip dry.

\section{QA/QC Procedures}

QA/QC will be performed in three steps.

1. All data will be record using experimental forms.

2. Two senior investigators were always present during experimentation and determined from how the experiments were conducted and visual inspection the validity of experimental results.

\section{Experimental Results}

The following experiments were run:

1. Determination of $R_{m}$

2. Determination of friction factor for filter system + DI

3. Determination of friction factors for filter system + DI/Larger Sized Microspheres

4. Determination of porosity for larger microspheres and smaller microspheres

5. Determination of angle of repose

More details of the micro-spheres are given in APPENDIX D2. 


\section{Determination of $\mathrm{R}_{\underline{m}}$}

As mentioned above, the value of $\mathrm{R}_{\mathrm{m}}$ was determined by running the filtration system with a clean filter and DI at various pressure drops. This results in a graph of dP vs. Qp (see Figure A1) and the slope of the line provides an estimate of $R_{m}$, which was found to be $1 / \mathrm{m}$ (see APPENDIX B for more details).

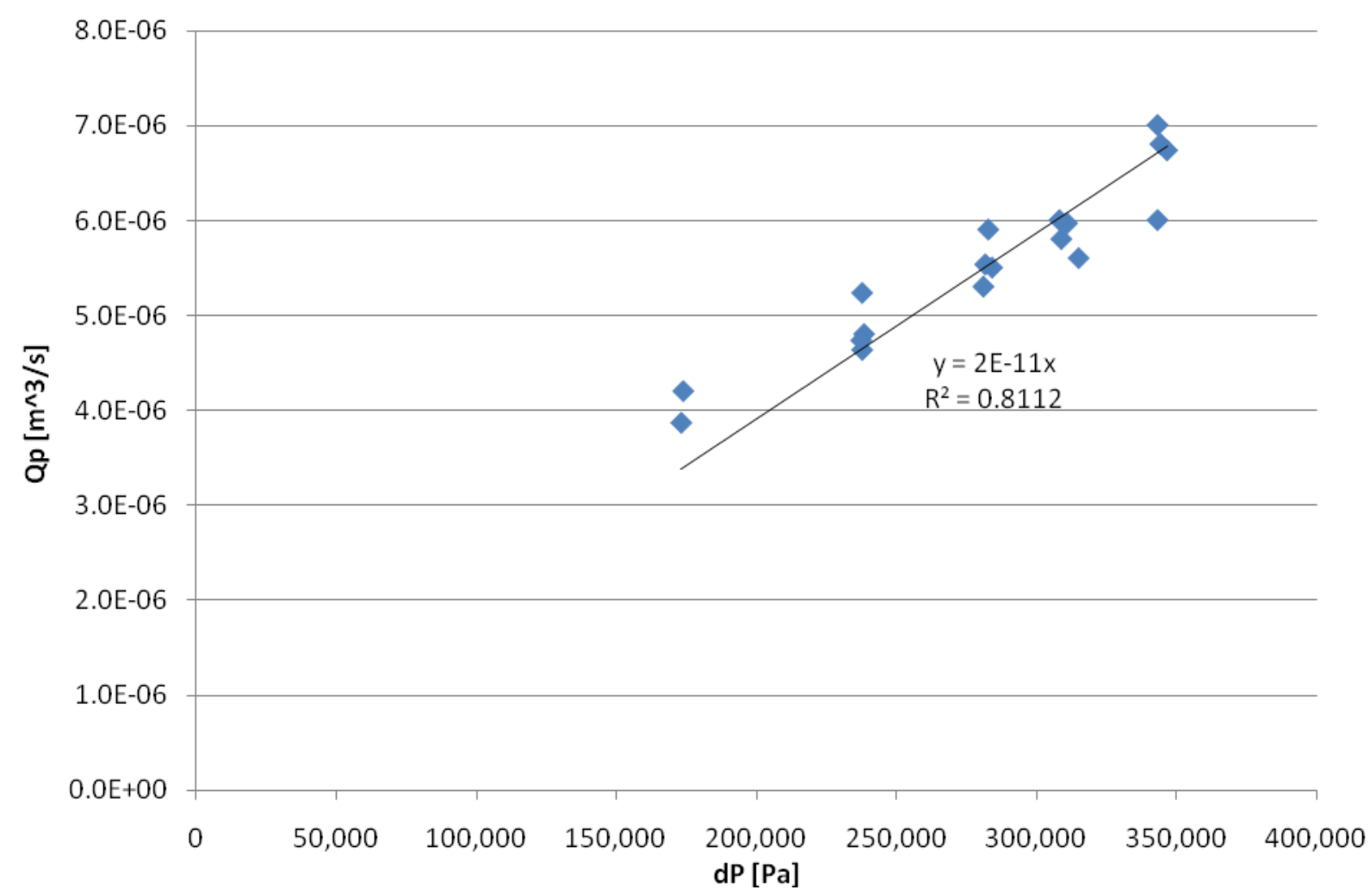

Figure A1 - Permeate flow rate versus pressure differential for Clean Filter

Determination of friction factor for filter system + Various Slurries

Given in Figure A2 are curves for Re vs. $\mathrm{f}$ for Tubes 1, 4, and DI. The model proposed for friction factors is

(Equation A8)

$\frac{1}{\sqrt{f}}=2 \log (\operatorname{Re} \sqrt{f})+B$

Where $\mathbf{B}$ is determined from Figure $\mathbf{A 3}$ to be

(Equation A9)

$B=-4.23\left(\frac{f}{2} \frac{L}{D}\right)+2$ 


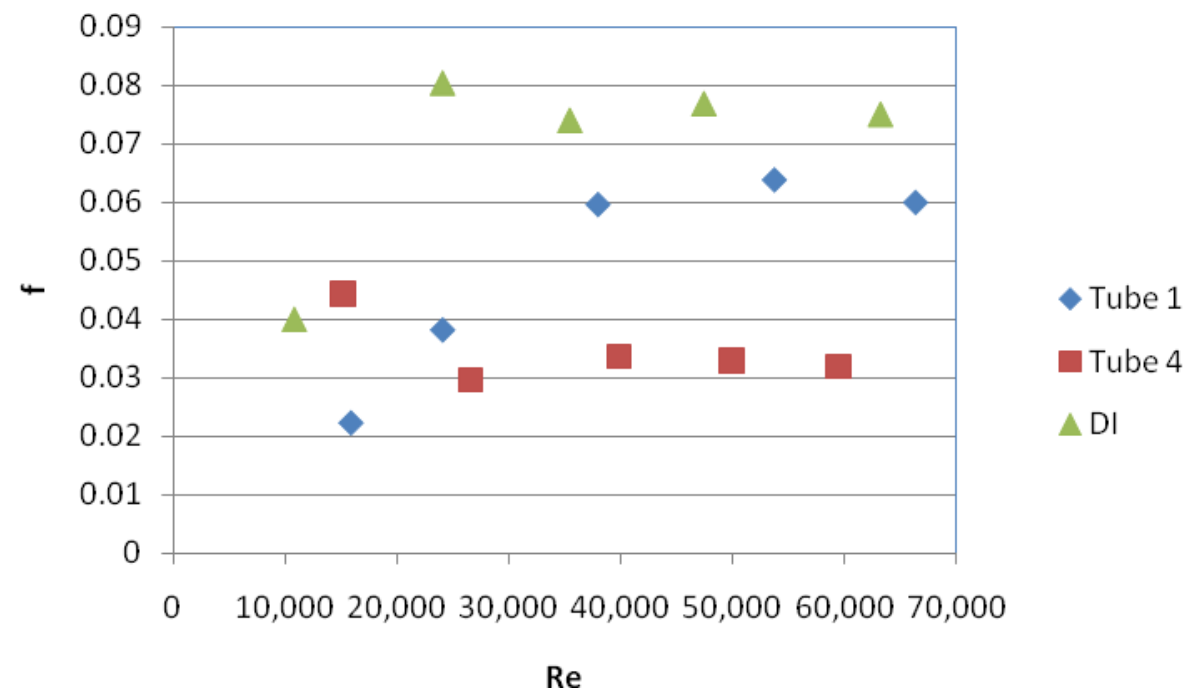

Figure A2 - Friction factor versus Reynolds number

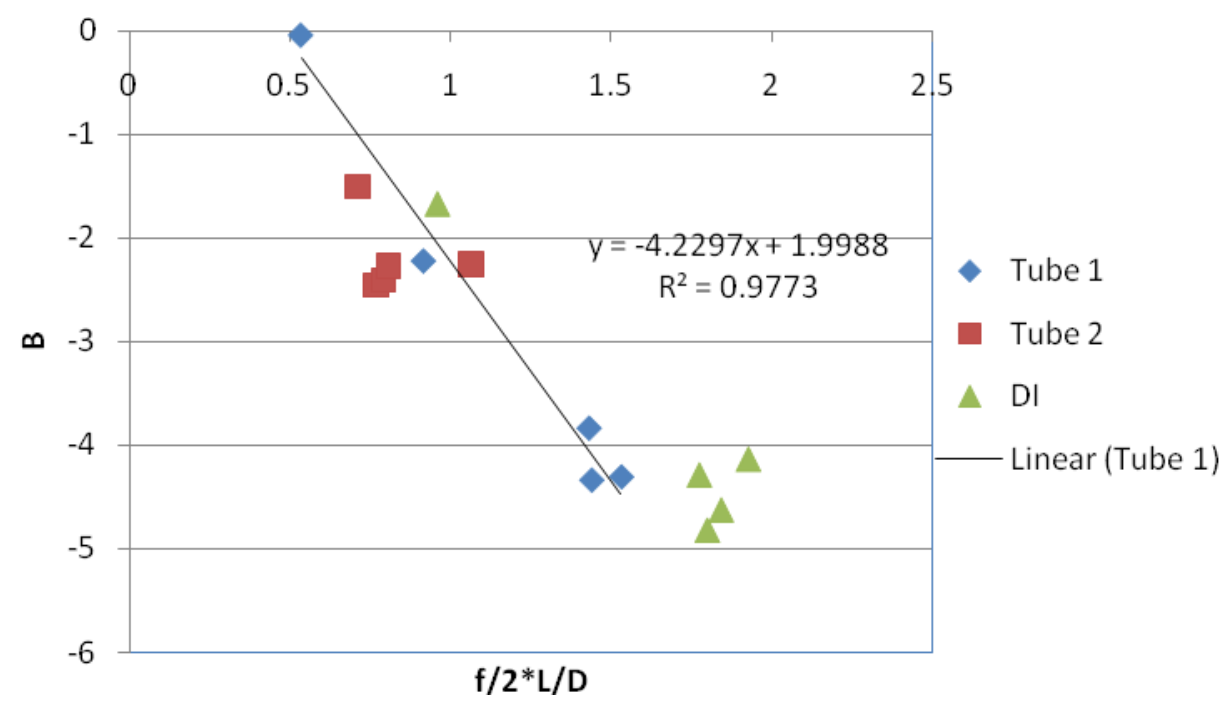

Figure A3 - Friction factor parameters B versus f/2*L/D

Determination of porosity of larger microspheres and smaller microspheres

The porosity associated with cake on the four tubes was determined by measuring the dry wet of each tube, running to various end-point Qp, measuring the wet weight of the tube + cake, letting the tube + cake dry, and measuring the dry weight of the tube + cake. These values for Tubes 1 to 3 are given in Table A2. An average value of $\mathrm{m}$ was determined and using a standard filtration equation (see APPENDIX B), the value for $\theta$ (cake) was determined to be $8.8 \mathrm{e}-3$. 


\begin{tabular}{|r|c|c|r|r|r|r|}
\hline Tube \# & $\begin{array}{c}\text { Tube } \\
\text { Dry }\end{array}$ & $\begin{array}{c}\text { Tube+Solids } \\
\text { Wet }\end{array}$ & $\begin{array}{c}\text { Tube+Solids } \\
\text { Dry }\end{array}$ & $\begin{array}{c}\text { Wet } \\
\text { Mass }\end{array}$ & \multicolumn{1}{c|}{$\begin{array}{c}\text { Dry } \\
\text { Mass }\end{array}$} & \multicolumn{1}{c|}{ m } \\
\hline & [gms.] & [gms.] & [gms.] & & & \\
\hline 1 & 432.59 & 441.15 & 432.68 & 8.56 & 0.09 & 95 \\
\hline 2 & 431.52 & 441.82 & 431.62 & 10.3 & 0.1 & 103 \\
\hline 3 & 437.72 & 449.15 & 437.85 & 11.43 & 0.13 & 88 \\
\hline 4 & 437 & 461.05 & n/a & n/a & n/a & n/a \\
\hline
\end{tabular}

Table A2 - Wet and Dry mass of cake

Determination of angle of repose

Tube 4 was utilized to find the angle of repose utilizing the smaller MS where the idea was to plot $\mathrm{dP}$ vs. Qp and the slope of this line would be equal to $\mathrm{C}_{1}$ within Equation A8. The only unknown within $\mathrm{C}_{1}$ is $\tan (\theta)$ and can be solved for. However the relationship between $\mathrm{dP}$ and Qp values obtained was rather polynomial with two extrema. Hence, the slope of the dP versus Qp plot or the angle of repose could not be determined. This unexpected relationship between $\mathrm{dP}$ and $\mathrm{Qp}$ could be attributed to erroneous data and experimental flaws.

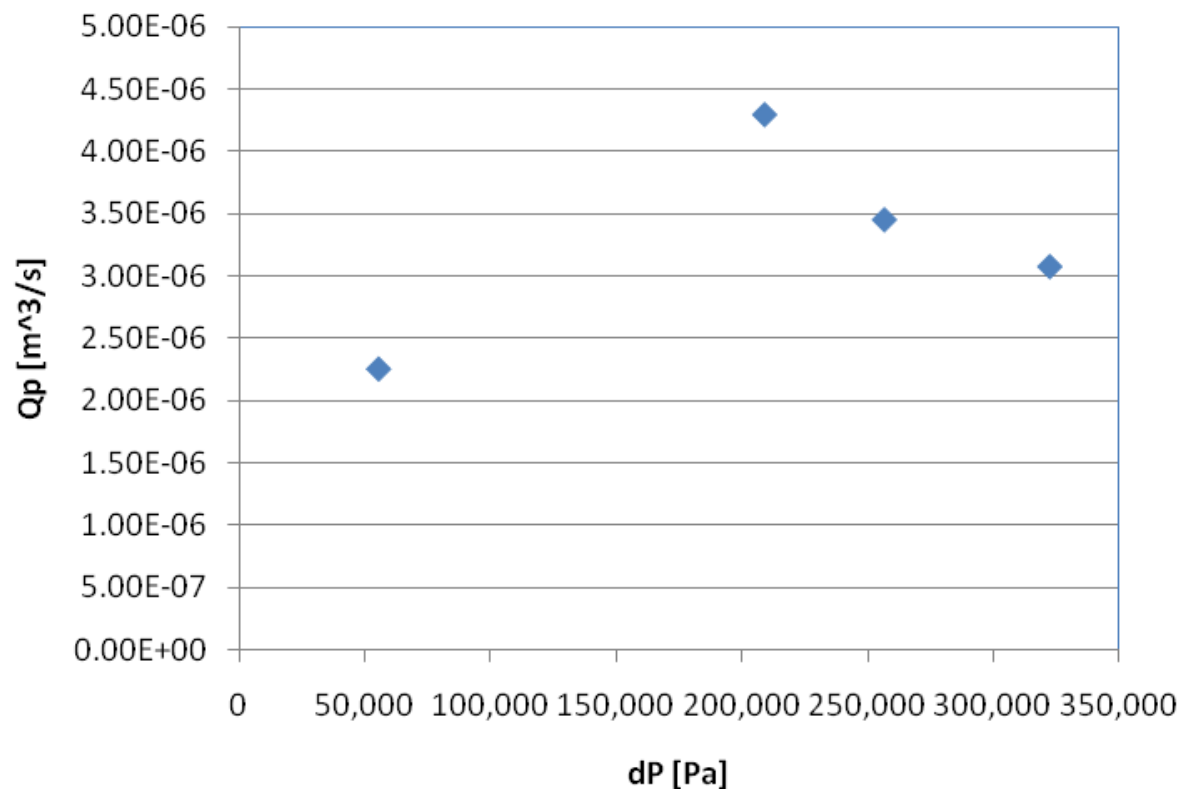

Figure A4 - Determination of Angle of Repose ( $\theta$ )

Another method was to utilize experimental results for the steady-state permeate rates for Tube 3 and Equation A8 with the minimum particle size and conditions to back-out $\operatorname{Tan}(\theta)$. This method is provided in APPENDIX $\mathbf{B}$ and the value was determined to be .55 .

\section{Experimental Validation of Permeate Rates}

Experimental and model results were not given. The reason for this is that the model claims for the conditions associated with Tube 3 that the first "cut-off" diameter is essential at the $\mathrm{d}(\mathrm{min})$ and no cake would have formed. It's not obvious why this is and so no results are presented.

The model is provided as APPENDIX C3 


\begin{tabular}{|c|c|c|c|c|c|c|c|c|c|c|c|c|c|c|c|}
\hline Time & Flow & P1 & P2 & Mass & Temperature & $\mathbf{Q}$ & dP & v & v & $\operatorname{Re}$ & $f$ & dP & Qp & dP & Qp \\
\hline [minutes] & [gpm] & [psig] & [psig] & [grams] & {$[\mathrm{C}]$} & [gpm] & [psig] & [fps] & {$[\mathrm{m} / \mathrm{s}]$} & & & [psig] & {$[\mathrm{ml} / \mathrm{s}]$} & {$[\mathrm{Pa}]$} & {$\left[\mathrm{m}^{\wedge} 3 / \mathrm{s}\right]$} \\
\hline 0 & 10 & & & & 28 & & & & & & & & & & \\
\hline 0.5 & 10 & 28.9 & 22.3 & 164 & & 10 & 6.6 & 16.34 & 4.98 & 63255.37 & 0.076526 & 25.6 & 5.47 & 175891.2 & $5.46667 \mathrm{E}-06$ \\
\hline 1 & 10 & 28.5 & 22.1 & 290 & & 10 & 6.4 & 16.34 & 4.98 & 63255.37 & 0.074207 & 25.3 & 4.20 & 173829.9 & 0.0000042 \\
\hline 1.5 & 10 & 28.4 & 22 & 406 & & 10 & 6.4 & 16.34 & 4.98 & 63255.37 & 0.074207 & 25.2 & 3.87 & 173142.9 & 3.86667E-06 \\
\hline 2 & 7.5 & 36.6 & 32.8 & 550 & & 7.5 & 3.8 & 12.26 & 3.74 & 47441.53 & 0.07833 & 34.7 & 4.80 & 238415 & 0.0000048 \\
\hline 2.5 & 7.5 & 36.4 & 32.8 & 707 & & 7.5 & 3.6 & 12.26 & 3.74 & 47441.53 & 0.074207 & 34.6 & 5.23 & 237727.9 & $5.23333 \mathrm{E}-06$ \\
\hline 3 & 7.5 & 36.5 & 32.7 & 846 & & 7.5 & 3.8 & 12.26 & 3.74 & 47441.53 & 0.07833 & 34.6 & 4.63 & 237727.9 & 4.63333E-06 \\
\hline 3.5 & 7.5 & 36.4 & 32.7 & 988 & & 7.5 & 3.7 & 12.26 & 3.74 & 47441.53 & 0.076268 & 34.55 & 4.73 & 237384.4 & $4.73333 \mathrm{E}-06$ \\
\hline 4 & 5.6 & 42.4 & 40.3 & 1153 & & 5.6 & 2.1 & 9.15 & 2.79 & 35423.01 & 0.077644 & 41.35 & 5.50 & 284105.4 & 0.0000055 \\
\hline 4.5 & 5.6 & 42.1 & 40.2 & 1330 & & 5.6 & 1.9 & 9.15 & 2.79 & 35423.01 & 0.070249 & 41.15 & 5.90 & 282731.3 & 0.0000059 \\
\hline 5 & 5.6 & 41.9 & 39.9 & 1489 & 30 & 5.6 & 2 & 9.15 & 2.79 & 35423.01 & 0.073947 & 40.9 & 5.30 & 281013.6 & 0.0000053 \\
\hline 5.5 & 5.6 & 42 & 40 & 1655 & & 5.6 & 2 & 9.15 & 2.79 & 35423.01 & 0.073947 & 41 & 5.53 & 281700.7 & $5.53333 \mathrm{E}-06$ \\
\hline 6 & 3.8 & 46.4 & 45.3 & 1823 & & 3.8 & 1.1 & 6.21 & 1.89 & 24037.04 & 0.088326 & 45.85 & 5.60 & 315023.8 & 0.0000056 \\
\hline 6.5 & 3.8 & 45.7 & 44.8 & 2002 & & 3.8 & 0.9 & 6.21 & 1.89 & 24037.04 & 0.072267 & 45.25 & 5.97 & 310901.4 & 5.96667E-06 \\
\hline 7 & 3.8 & 45.4 & 44.5 & 2176 & & 3.8 & 0.9 & 6.21 & 1.89 & 24037.04 & 0.072267 & 44.95 & 5.80 & 308840.1 & 0.0000058 \\
\hline 7.5 & 3.8 & 45.4 & 44.3 & 2356 & & 3.8 & 1.1 & 6.21 & 1.89 & 24037.04 & 0.088326 & 44.85 & 6.00 & 308153.1 & 0.000006 \\
\hline 8 & 1.7 & 50 & 50.2 & 2560 & & 1.7 & -0.2 & 2.78 & 0.85 & 10753.41 & -0.08024 & 50.1 & 6.80 & 344224.5 & 0.0000068 \\
\hline 8.5 & 1.7 & 50.1 & 49.8 & 2770 & & 1.7 & 0.3 & 2.78 & 0.85 & 10753.41 & 0.120362 & 49.95 & 7.00 & 343193.9 & 0.000007 \\
\hline 9 & 1.7 & 50 & 49.9 & 2950 & & 1.7 & 0.1 & 2.78 & 0.85 & 10753.41 & 0.040121 & 49.95 & 6.00 & 343193.9 & 0.000006 \\
\hline 9.5 & 1.7 & 50.2 & 50.1 & 3048 & & 1.7 & 0.1 & 2.78 & 0.85 & 10753.41 & 0.040121 & 50.15 & 3.27 & 344568 & $3.26667 \mathrm{E}-06$ \\
\hline 10 & 1.7 & 50.5 & 50.4 & 3250 & 34 & 1.7 & 0.1 & 2.78 & 0.85 & 10753.41 & 0.040121 & 50.45 & 6.73 & 346629.3 & $6.73333 \mathrm{E}-06$ \\
\hline
\end{tabular}

Table A.3 - Tube 1, DI 


\begin{tabular}{|c|c|c|c|c|c|c|c|c|c|c|c|c|c|c|c|c|}
\hline Time & Flow & Flux & $q p[20 \mathrm{C}]$ & P1 & P2 & Mass & Temperature & $\mathbf{Q}$ & $d P$ & v & v & $\operatorname{Re}$ & $f$ & $d P$ & Qp & TMP \\
\hline [minutes] & [gpm] & {$[\mathrm{m} / \mathrm{sec}]$} & {$[\mathrm{m} / \mathrm{s}]$} & [psig] & [psig] & [grams] & {$[C]$} & [gpm] & [psig] & [fps] & {$[\mathrm{m} / \mathrm{s}]$} & & & [psig] & {$[\mathrm{ml} / \mathrm{s}]$} & {$[\mathrm{Pa}]$} \\
\hline 0 & 10.5 & & & 28 & 21.4 & 0 & & 10.5 & 6.6 & & & & & & & \\
\hline 0.5 & 10.5 & $1.84088 \mathrm{E}-05$ & & 25.7 & 20.2 & 13.42 & & 10.5 & 5.5 & 17.16 & 5.23 & 66418.14 & 0.058 & 22.95 & 0.45 & 157683.7 \\
\hline 1 & 10.5 & $1.58848 \mathrm{E}-05$ & & 26.7 & 21 & 25 & & 10.5 & 5.7 & 17.16 & 5.23 & 66418.14 & 0.060 & 23.85 & 0.39 & 163867.3 \\
\hline 1.5 & 10.5 & $1.92044 \mathrm{E}-05$ & & 26.9 & 21 & 39 & & 10.5 & 5.9 & 17.16 & 5.23 & 66418.14 & 0.062 & 23.95 & 0.47 & 164554.4 \\
\hline 2 & 8.5 & 2.23594E-05 & & 33.1 & 29.2 & 55.3 & & 8.5 & 3.9 & 13.89 & 4.23 & 53767.07 & 0.063 & 31.15 & 0.54 & 214023.8 \\
\hline 2.5 & 8.5 & $2.23594 \mathrm{E}-05$ & & 33.1 & 29.1 & 71.6 & & 8.5 & 4 & 13.89 & 4.23 & 53767.07 & 0.064 & 31.1 & 0.54 & 213680.3 \\
\hline 3 & 8.5 & $1.99588 \mathrm{E}-05$ & & 33.1 & 29.1 & 86.15 & & 8.5 & 4 & 13.89 & 4.23 & 53767.07 & 0.064 & 31.1 & 0.49 & 213680.3 \\
\hline 3.5 & 8.5 & 2.95336E-05 & & 33.2 & 29.2 & 107.68 & & 8.5 & 4 & 13.89 & 4.23 & 53767.07 & 0.064 & 31.2 & 0.72 & 214367.3 \\
\hline 4 & 6 & $2.40329 \mathrm{E}-05$ & & 39.1 & 37.6 & 125.2 & & 6 & 1.5 & 9.80 & 2.99 & 37953.22 & 0.048 & 38.35 & 0.58 & 263493.2 \\
\hline 4.5 & 6 & $2.82579 \mathrm{E}-05$ & & 40.1 & 38 & 145.8 & & 6 & 2.1 & 9.80 & 2.99 & 37953.22 & 0.068 & 39.05 & 0.69 & 268302.7 \\
\hline 5 & 6 & $3.31962 \mathrm{E}-05$ & & 39.7 & 37.8 & 170 & & 6 & 1.9 & 9.80 & 2.99 & 37953.22 & 0.061 & 38.75 & 0.81 & 266241.5 \\
\hline 5.5 & 6 & 2.9904E-05 & & 40.1 & 38.2 & 191.8 & & 6 & 1.9 & 9.80 & 2.99 & 37953.22 & 0.061 & 39.15 & 0.73 & 268989.8 \\
\hline 6 & 3.8 & 3.99177E-05 & & 47 & 46.7 & 220.9 & & 3.8 & 0.3 & 6.21 & 1.89 & 24037.04 & 0.024 & 46.85 & 0.97 & 321894.6 \\
\hline 6.5 & 3.8 & 3.3059E-05 & & 47.3 & 46.8 & 245 & & 3.8 & 0.5 & 6.21 & 1.89 & 24037.04 & 0.040 & 47.05 & 0.80 & 323268.7 \\
\hline 7 & 3.8 & $3.84088 \mathrm{E}-05$ & & 47.3 & 46.7 & 273 & & 3.8 & 0.6 & 6.21 & 1.89 & 24037.04 & 0.048 & 47 & 0.93 & 322925.2 \\
\hline 7.5 & 3.8 & $3.78601 \mathrm{E}-05$ & & 47.4 & 46.9 & 300.6 & & 3.8 & 0.5 & 6.21 & 1.89 & 24037.04 & 0.040 & 47.15 & 0.92 & 323955.8 \\
\hline 8 & 2.5 & $3.60768 \mathrm{E}-05$ & & 50 & 49.8 & 326.9 & & 2.5 & 0.2 & 4.09 & 1.25 & 15813.84 & 0.037 & 49.9 & 0.88 & 342850.3 \\
\hline 8.5 & 2.5 & $5.22634 \mathrm{E}-05$ & & 50.1 & 49.9 & 365 & & 2.5 & 0.2 & 4.09 & 1.25 & 15813.84 & 0.037 & 50 & 1.27 & 343537.4 \\
\hline 9 & 2.5 & 0 & & 50 & 50 & 396.4 & & 2.5 & 0 & 4.09 & 1.25 & 15813.84 & 0.000 & 50 & 1.05 & 343537.4 \\
\hline 9.5 & 2.5 & $4.33471 \mathrm{E}-05$ & & 50.2 & 50.1 & 428 & & 2.5 & 0.1 & 4.09 & 1.25 & 15813.84 & 0.019 & 50.15 & 1.05 & 344568 \\
\hline 10 & 2.5 & $4.2524 \mathrm{E}-05$ & & 50.2 & 50.1 & 459 & & 2.5 & 0.1 & 4.09 & 1.25 & 15813.84 & 0.019 & 50.15 & 1.03 & 344568 \\
\hline
\end{tabular}

Table A.4 - Tube 1, Slurry 


\begin{tabular}{|c|c|c|c|c|c|c|c|c|c|c|c|c|c|c|c|c|}
\hline Time & Flow & Flux & P1 & P2 & Mass & Temperature & Q & dP & v & v & $\operatorname{Re}$ & f & dP & Qp & TMP & Qp \\
\hline [minutes] & [gpm] & {$[\mathrm{m} / \mathrm{sec}]$} & [psig] & [psig] & [grams] & {$[C]$} & [gpm] & [psig] & [fps] & {$[\mathrm{m} / \mathrm{s}]$} & & & [psig] & {$[\mathrm{ml} / \mathrm{s}]$} & {$[\mathrm{Pa}]$} & {$\left[\mathrm{m}^{\wedge} 3 / \mathrm{s}\right]$} \\
\hline 0 & 9.5 & & 30.2 & 27.5 & 0 & & 9.5 & 2.7 & & & & & & & & \\
\hline 0.5 & 9.5 & 0.000156379 & 30.4 & 26.9 & 114 & & 9.5 & 3.5 & 15.52 & 4.73 & 60092.60 & 0.044966 & 28.65 & 3.80 & 196846.9 & 0.0000038 \\
\hline 1 & 9.5 & 0.00011797 & 29.5 & 26.9 & 200 & 19.8 & 9.5 & 2.6 & 15.52 & 4.73 & 60092.60 & 0.033403 & 28.2 & 2.87 & 193755.1 & $2.86667 \mathrm{E}-06$ \\
\hline 1.5 & 9.5 & 9.60219E-05 & 29.7 & 26.9 & 270 & & 9.5 & 2.8 & 15.52 & 4.73 & 60092.60 & 0.035973 & 28.3 & 2.33 & 194442.2 & 2.33333E-06 \\
\hline 2 & 9.5 & $8.77915 \mathrm{E}-05$ & 29.7 & 27.1 & 334 & 19.5 & 9.5 & 2.6 & 15.52 & 4.73 & 60092.60 & 0.033403 & 28.4 & 2.13 & 195129.3 & 2.13333E-06 \\
\hline 2.5 & 9.5 & $7.54458 \mathrm{E}-05$ & 29.6 & 27 & 389 & & 9.5 & 2.6 & 15.52 & 4.73 & 60092.60 & 0.033403 & 28.3 & 1.83 & 194442.2 & $1.83333 \mathrm{E}-06$ \\
\hline 3 & 9.5 & $6.72154 \mathrm{E}-05$ & 29.5 & 26.9 & 438 & 19.2 & 9.5 & 2.6 & 15.52 & 4.73 & 60092.60 & 0.033403 & 28.2 & 1.63 & 193755.1 & $1.63333 \mathrm{E}-06$ \\
\hline 3.5 & 9.5 & $6.31001 \mathrm{E}-05$ & 29.3 & 26.8 & 484 & & 9.5 & 2.5 & 15.52 & 4.73 & 60092.60 & 0.032119 & 28.05 & 1.53 & 192724.5 & $1.53333 \mathrm{E}-06$ \\
\hline 4 & 9.5 & 5.62414E-05 & 29.2 & 26.6 & 525 & 19.6 & 9.5 & 2.6 & 15.52 & 4.73 & 60092.60 & 0.033403 & 27.9 & 1.37 & 191693.9 & 1.36667E-06 \\
\hline 4.5 & 9.5 & $5.34979 \mathrm{E}-05$ & 29 & 26.5 & 564 & 19.4 & 9.5 & 2.5 & 15.52 & 4.73 & 60092.60 & 0.032119 & 27.75 & 1.30 & 190663.3 & 0.0000013 \\
\hline 5 & 9.5 & 4.93827E-05 & 28.9 & 26.3 & 600 & & 9.5 & 2.6 & 15.52 & 4.73 & 60092.60 & 0.033403 & 27.6 & 1.20 & 189632.7 & 0.0000012 \\
\hline
\end{tabular}

Table A.5 - Tube 2, Slurry 


\begin{tabular}{|c|c|c|c|c|c|c|c|c|c|c|c|c|c|c|c|c|}
\hline Time & Flow & Flux & P1 & P2 & Mass & Temperature & $\mathbf{Q}$ & $d P$ & v & v & $\operatorname{Re}$ & $f$ & dP & Qp & TMP & Qp \\
\hline [minutes] & [gpm] & {$[\mathrm{m} / \mathrm{sec}]$} & [psig] & [psig] & [grams] & {$[\mathrm{C}]$} & [gpm] & [psig] & [fps] & {$[\mathrm{m} / \mathrm{s}]$} & & & [psig] & {$[\mathrm{ml} / \mathrm{s}]$} & {$[\mathrm{Pa}]$} & {$\left[\mathrm{m}^{\wedge} 3 / \mathrm{s}\right]$} \\
\hline 0 & 9.9 & & 24.4 & 20 & 0 & & 9.9 & 4.4 & & & & & 22.2 & & 152530.6 & \\
\hline 0.5 & 9.9 & 0.000249657 & 24.5 & 20.6 & 182 & 36 & 9.9 & 3.9 & 16.18 & 4.93 & 62622.82 & 0.046138 & 22.55 & 6.07 & 154935.4 & $6.06667 \mathrm{E}-06$ \\
\hline 1 & 9.9 & 0.000200274 & 25.2 & 21.4 & 328 & 36 & 9.9 & 3.8 & 16.18 & 4.93 & 62622.82 & 0.044955 & 23.3 & 4.87 & 160088.4 & 4.86667E-06 \\
\hline 1.5 & 9.9 & 0.000148148 & 25.4 & 21.4 & 436 & 36 & 9.9 & 4 & 16.18 & 4.93 & 62622.82 & 0.047321 & 23.4 & 3.60 & 160775.5 & 0.0000036 \\
\hline 2 & 9.9 & 0.000127572 & 25.3 & 21.3 & 529 & 37.2 & 9.9 & 4 & 16.18 & 4.93 & 62622.82 & 0.047321 & 23.3 & 3.10 & 160088.4 & 0.0000031 \\
\hline 2.5 & 9.9 & 0.000106996 & 25.4 & 21.4 & 607 & 37.2 & 9.9 & 4 & 16.18 & 4.93 & 62622.82 & 0.047321 & 23.4 & 2.60 & 160775.5 & 0.0000026 \\
\hline 3 & 9.9 & $8.91632 \mathrm{E}-05$ & 25.2 & 21.3 & 672 & 38.1 & 9.9 & 3.9 & 16.18 & 4.93 & 62622.82 & 0.046138 & 23.25 & 2.17 & 159744.9 & 2.16667E-06 \\
\hline 3.5 & 9.9 & $7.54458 \mathrm{E}-05$ & 25.2 & 21.2 & 727 & 38.1 & 9.9 & 4 & 16.18 & 4.93 & 62622.82 & 0.047321 & 23.2 & 1.83 & 159401.4 & $1.83333 \mathrm{E}-06$ \\
\hline 4 & 9.9 & $6.72154 \mathrm{E}-05$ & 25 & 20.9 & 776 & 38.9 & 9.9 & 4.1 & 16.18 & 4.93 & 62622.82 & 0.048504 & 22.95 & 1.63 & 157683.7 & $1.63333 \mathrm{E}-06$ \\
\hline 4.5 & 9.9 & 5.48697E-05 & 24.9 & 21.1 & 816 & 38.9 & 9.9 & 3.8 & 16.18 & 4.93 & 62622.82 & 0.044955 & 23 & 1.33 & 158027.2 & $1.33333 \mathrm{E}-06$ \\
\hline 5 & 9.9 & $5.21262 \mathrm{E}-05$ & 24.8 & 20.9 & 854 & 39.7 & 9.9 & 3.9 & 16.18 & 4.93 & 62622.82 & 0.046138 & 22.85 & 1.27 & 156996.6 & $1.26667 \mathrm{E}-06$ \\
\hline 5.5 & 9.9 & 4.66392E-05 & 24.9 & 21 & 888 & 39.7 & 9.9 & 3.9 & 16.18 & 4.93 & 62622.82 & 0.046138 & 22.95 & 1.13 & 157683.7 & $1.13333 \mathrm{E}-06$ \\
\hline 6 & 9.9 & 4.38957E-05 & 24.9 & 21.1 & 920 & 40.4 & 9.9 & 3.8 & 16.18 & 4.93 & 62622.82 & 0.044955 & 23 & 1.07 & 158027.2 & $1.06667 \mathrm{E}-06$ \\
\hline 6.5 & 9.9 & 4.11523E-05 & 24.8 & 21 & 950 & 40.4 & 9.9 & 3.8 & 16.18 & 4.93 & 62622.82 & 0.044955 & 22.9 & 1.00 & 157340.1 & 0.000001 \\
\hline 7 & 9.9 & 4.11523E-05 & 24.8 & 21 & 980 & 41.4 & 9.9 & 3.8 & 16.18 & 4.93 & 62622.82 & 0.044955 & 22.9 & 1.00 & 157340.1 & 0.000001 \\
\hline 7.5 & 9.9 & $3.97805 \mathrm{E}-05$ & 24.9 & 20.9 & 1009 & 41.4 & 9.9 & 4 & 16.18 & 4.93 & 62622.82 & 0.047321 & 22.9 & 0.97 & 157340.1 & $9.66667 \mathrm{E}-07$ \\
\hline 8 & 9.9 & $3.84088 \mathrm{E}-05$ & 24.9 & 20.8 & 1037 & 41.8 & 9.9 & 4.1 & 16.18 & 4.93 & 62622.82 & 0.048504 & 22.85 & 0.93 & 156996.6 & $9.33333 \mathrm{E}-07$ \\
\hline 8.5 & 9.9 & 3.7037E-05 & 24.8 & 20.8 & 1064 & 41.8 & 9.9 & 4 & 16.18 & 4.93 & 62622.82 & 0.047321 & 22.8 & 0.90 & 156653.1 & 0.0000009 \\
\hline 9 & 9.9 & 3.56653E-05 & 24.7 & 20.9 & 1090 & 42.4 & 9.9 & 3.8 & 16.18 & 4.93 & 62622.82 & 0.044955 & 22.8 & 0.87 & 156653.1 & 8.66667E-07 \\
\hline 9.5 & 9.9 & 3.7037E-05 & 24.7 & 20.8 & 1117 & 42.4 & 9.9 & 3.9 & 16.18 & 4.93 & 62622.82 & 0.046138 & 22.75 & 0.90 & 156309.5 & 0.0000009 \\
\hline 10 & 9.9 & 3.7037E-05 & 24.6 & 20.8 & 1144 & 43 & 9.9 & 3.8 & 16.18 & 4.93 & 62622.82 & 0.044955 & 22.7 & 0.90 & 155966 & 0.0000009 \\
\hline 10.5 & 9.9 & 3.56653E-05 & 24.6 & 20.7 & 1170 & 43 & 9.9 & 3.9 & 16.18 & 4.93 & 62622.82 & 0.046138 & 22.65 & 0.87 & 155622.4 & $8.66667 \mathrm{E}-07$ \\
\hline 11 & 9.9 & 3.49794E-05 & 24.6 & 20.8 & 1195.5 & 43.6 & 9.9 & 3.8 & 16.18 & 4.93 & 62622.82 & 0.044955 & 22.7 & 0.85 & 155966 & 0.00000085 \\
\hline 11.5 & 9.9 & 3.36077E-05 & 24.6 & 20.7 & 1220 & 43.6 & 9.9 & 3.9 & 16.18 & 4.93 & 62622.82 & 0.046138 & 22.65 & 0.82 & 155622.4 & 8.16667E-07 \\
\hline 12 & 9.9 & 3.64883E-05 & 24.5 & 20.7 & 1246.6 & 44 & 9.9 & 3.8 & 16.18 & 4.93 & 62622.82 & 0.044955 & 22.6 & 0.89 & 155278.9 & 8.86667E-07 \\
\hline 12.5 & 9.9 & $3.48422 \mathrm{E}-05$ & 24.6 & 20.7 & 1272 & 44 & 9.9 & 3.9 & 16.18 & 4.93 & 62622.82 & 0.046138 & 22.65 & 0.85 & 155622.4 & 8.46667E-07 \\
\hline
\end{tabular}




\begin{tabular}{|c|c|c|c|c|c|c|c|c|c|c|c|c|c|c|c|c|c|}
\hline Time & Flow & Flux & $q p[20 \mathrm{C}]$ & P1 & P2 & Mass & Temperature & $\mathbf{Q}$ & $d P$ & v & v & Re & $f$ & dP & Qp & TMP & Qp \\
\hline [minutes] & [gpm] & {$[\mathrm{m} / \mathrm{sec}]$} & {$[\mathrm{m} / \mathrm{s}]$} & [psig] & [psig] & [grams] & {$[C]$} & [gpm] & [psig] & [fps] & {$[\mathrm{m} / \mathrm{s}]$} & & & [psig] & {$[\mathrm{ml} / \mathrm{s}]$} & [Pa] & {$\left[\mathrm{m}^{\wedge} 3 / \mathrm{s}\right]$} \\
\hline 0 & 9.4 & & & 9.6 & 6.7 & 0 & 29.4 & 9.4 & 2.9 & & & & & & & & \\
\hline 0.5 & 9.4 & $8.92 \mathrm{E}-05$ & & 9 & 7.1 & 65 & & 9.4 & 1.9 & 15.36 & 4.68 & 59460.05 & 0.025 & 1.9 & 2.17 & $5.53 E+04$ & 2.17E-06 \\
\hline 1 & 9.4 & $9.60 \mathrm{E}-05$ & & 9.3 & 6.5 & 135 & & 9.4 & 2.8 & 15.36 & 4.68 & 59460.05 & 0.037 & 2.8 & 2.33 & $5.43 E+04$ & $2.33 \mathrm{E}-06$ \\
\hline 1.5 & 9.4 & 9.33E-05 & & 9.6 & 7 & 203 & & 9.4 & 2.6 & 15.36 & 4.68 & 59460.05 & 0.034 & 2.6 & 2.27 & $5.70 E+04$ & $2.27 \mathrm{E}-06$ \\
\hline 2 & 7.9 & $1.12 \mathrm{E}-04$ & & 30.6 & 29 & 285 & 30.9 & 7.9 & 1.6 & 12.91 & 3.93 & 49971.74 & 0.030 & 1.6 & 2.73 & $2.05 E+05$ & $2.73 \mathrm{E}-06$ \\
\hline 2.5 & 7.9 & 2.55E-04 & & 31.6 & 29.9 & 471 & & 7.9 & 1.7 & 12.91 & 3.93 & 49971.74 & 0.032 & 1.7 & 6.20 & $2.11 E+05$ & $6.20 \mathrm{E}-06$ \\
\hline 3 & 7.9 & $1.89 \mathrm{E}-04$ & & 31.6 & 29.7 & 609 & & 7.9 & 1.9 & 12.91 & 3.93 & 49971.74 & 0.035 & 1.9 & 4.60 & $2.11 E+05$ & 4.60E-06 \\
\hline 3.5 & 7.9 & 1.50E-04 & & 31.5 & 29.6 & 718 & 28.4 & 7.9 & 1.9 & 12.91 & 3.93 & 49971.74 & 0.035 & 1.9 & 3.63 & $2.10 \mathrm{E}+05$ & $3.63 \mathrm{E}-06$ \\
\hline 4 & 6.3 & 1.70E-04 & & 38.1 & 36.9 & 842 & 29.1 & 6.3 & 1.2 & 10.29 & 3.14 & 39850.89 & 0.035 & 1.2 & 4.13 & $2.58 \mathrm{E}+05$ & 4.13E-06 \\
\hline 4.5 & 6.3 & $1.43 \mathrm{E}-04$ & & 37.9 & 37 & 946 & & 6.3 & 0.9 & 10.29 & 3.14 & 39850.89 & 0.026 & 0.9 & 3.47 & $2.57 E+05$ & 3.47E-06 \\
\hline 5 & 6.3 & $1.41 \mathrm{E}-04$ & & 37.9 & 36.7 & 1049 & 30 & 6.3 & 1.2 & 10.29 & 3.14 & 39850.89 & 0.035 & 1.2 & 3.43 & $2.56 \mathrm{E}+05$ & $3.43 \mathrm{E}-06$ \\
\hline 5.5 & 6.3 & 1.14E-04 & & 37.9 & 36.6 & 1132 & 30.9 & 6.3 & 1.3 & 10.29 & 3.14 & 39850.89 & 0.038 & 1.3 & 2.77 & $2.56 \mathrm{E}+05$ & 2.77E-06 \\
\hline 6 & 4.2 & $1.34 \mathrm{E}-04$ & & 47.1 & 46.6 & 1230 & & 4.2 & 0.5 & 6.86 & 2.09 & 26567.26 & 0.033 & 0.5 & 3.27 & $3.22 \mathrm{E}+05$ & $3.27 \mathrm{E}-06$ \\
\hline 6.5 & 4.2 & $1.34 \mathrm{E}-04$ & & 47.3 & 46.6 & 1328 & & 4.2 & 0.7 & 6.86 & 2.09 & 26567.26 & 0.046 & 0.7 & 3.27 & $3.23 \mathrm{E}+05$ & 3.27E-06 \\
\hline 7 & 4.2 & $1.22 \mathrm{E}-04$ & & 47 & 46.8 & 1417 & 31.9 & 4.2 & 0.2 & 6.86 & 2.09 & 26567.26 & 0.013 & 0.2 & 2.97 & $3.22 \mathrm{E}+05$ & 2.97E-06 \\
\hline 7.5 & 4.2 & $1.15 \mathrm{E}-04$ & & 47.3 & 46.9 & 1501 & & 4.2 & 0.4 & 6.86 & 2.09 & 26567.26 & 0.026 & 0.4 & 2.80 & $3.24 \mathrm{E}+05$ & $2.80 \mathrm{E}-06$ \\
\hline 8 & 2.4 & $1.14 \mathrm{E}-04$ & & 50.2 & 49.9 & 1584 & 32.9 & 2.4 & 0.3 & 3.92 & 1.20 & 15181.29 & 0.060 & 0.3 & 2.77 & $3.44 E+05$ & $2.77 \mathrm{E}-06$ \\
\hline 8.5 & 2.4 & 1.14E-04 & & 50 & 49.9 & 1667 & & 2.4 & 0.1 & 3.92 & 1.20 & 15181.29 & 0.020 & 0.1 & 2.77 & $3.43 \mathrm{E}+05$ & 2.77E-06 \\
\hline 9 & 2.4 & $1.04 \mathrm{E}-04$ & & 50.3 & 50 & 1743 & & 2.4 & 0.3 & 3.92 & 1.20 & 15181.29 & 0.060 & 0.3 & 2.53 & $3.45 E+05$ & $2.53 \mathrm{E}-06$ \\
\hline 9.5 & 2.4 & $9.60 \mathrm{E}-05$ & & 50.3 & 50.1 & 1813 & & 2.4 & 0.2 & 3.92 & 1.20 & 15181.29 & 0.040 & 0.2 & 2.33 & $3.45 E+05$ & $2.33 \mathrm{E}-06$ \\
\hline 10 & 2.4 & 9.74E-05 & & 50.4 & 50.2 & 1884 & 33.2 & 2.4 & 0.2 & 3.92 & 1.20 & 15181.29 & 0.040 & 0.2 & 2.37 & $3.46 \mathrm{E}+05$ & $2.37 \mathrm{E}-06$ \\
\hline 10.5 & 2.4 & 9.47E-05 & & 50.4 & 50 & 1953 & & 2.4 & 0.4 & 3.92 & 1.20 & 15181.29 & 0.081 & 0.4 & 2.30 & $3.45 E+05$ & $2.30 \mathrm{E}-06$ \\
\hline 11 & 2.4 & 9.33E-05 & & 50.4 & 50.2 & 2021 & 34.2 & 2.4 & 0.2 & 3.92 & 1.20 & 15181.29 & 0.040 & 0.2 & 2.27 & 3.46E+05 & $2.27 \mathrm{E}-06$ \\
\hline 11.5 & 2.4 & $8.92 \mathrm{E}-05$ & & 50.2 & 50.2 & 2086 & & 2.4 & 0 & 3.92 & 1.20 & 15181.29 & 0.000 & 0 & 2.17 & $3.45 E+05$ & 2.17E-06 \\
\hline 12 & 2.4 & $9.19 \mathrm{E}-05$ & & 50.6 & 50.3 & 2153 & 34.6 & 2.4 & 0.3 & 3.92 & 1.20 & 15181.29 & 0.060 & 0.3 & 2.23 & $3.47 E+05$ & $2.23 \mathrm{E}-06$ \\
\hline 12.5 & 2.4 & $8.50 \mathrm{E}-05$ & & 50.4 & 50.2 & 2215 & & 2.4 & 0.2 & 3.92 & 1.20 & 15181.29 & 0.040 & 0.2 & 2.07 & $3.46 \mathrm{E}+05$ & 2.07E-06 \\
\hline 13 & 2.4 & $8.64 \mathrm{E}-05$ & & 50.3 & 50.3 & 2278 & 32.8 & 2.4 & 0 & 3.92 & 1.20 & 15181.29 & 0.000 & 0 & 2.10 & $3.46 \mathrm{E}+05$ & $2.10 \mathrm{E}-06$ \\
\hline 13.5 & 2.4 & 7.96E-05 & & 50.6 & 50.2 & 2336 & & 2.4 & 0.4 & 3.92 & 1.20 & 15181.29 & 0.081 & 0.4 & 1.93 & $3.46 \mathrm{E}+05$ & $1.93 \mathrm{E}-06$ \\
\hline 14 & 2.4 & $8.23 \mathrm{E}-05$ & & 50.3 & 50.2 & 2396 & 31.6 & 2.4 & 0.1 & 3.92 & 1.20 & 15181.29 & 0.020 & 0.1 & 2.00 & $3.45 \mathrm{E}+05$ & $2.00 \mathrm{E}-06$ \\
\hline 14.5 & 2.4 & 7.68E-05 & & 50.4 & 50.2 & 2452 & & 2.4 & 0.2 & 3.92 & 1.20 & 15181.29 & 0.040 & 0.2 & 1.87 & $3.46 \mathrm{E}+05$ & $1.87 \mathrm{E}-06$ \\
\hline 15 & 2.4 & 7.41E-05 & & 50.7 & 50.5 & 2506 & 32.1 & 2.4 & 0.2 & 3.92 & 1.20 & 15181.29 & 0.040 & 0.2 & 1.80 & $3.48 E+05$ & $1.80 \mathrm{E}-06$ \\
\hline 15.5 & 2.4 & 7.27E-05 & & 50.7 & 50.6 & 2559 & & 2.4 & 0.1 & 3.92 & 1.20 & 15181.29 & 0.020 & 0.1 & 1.77 & $3.48 E+05$ & $1.77 \mathrm{E}-06$ \\
\hline 16 & 2.4 & 7.41E-05 & & 50.8 & 50.6 & 2613 & 32.8 & 2.4 & 0.2 & 3.92 & 1.20 & 15181.29 & 0.040 & 0.2 & 1.80 & $3.48 \mathrm{E}+05$ & $1.80 \mathrm{E}-06$ \\
\hline 16.5 & 2.4 & $7.13 \mathrm{E}-05$ & & 50.7 & 50.5 & 2665 & & 2.4 & 0.2 & 3.92 & 1.20 & 15181.29 & 0.040 & 0.2 & 1.73 & $3.48 E+05$ & $1.73 \mathrm{E}-06$ \\
\hline 17 & 2.4 & 7.27E-05 & & 50.5 & 50.5 & 2718 & 33.6 & 2.4 & 0 & 3.92 & 1.20 & 15181.29 & 0.000 & 0 & 1.77 & $3.47 E+05$ & $1.77 \mathrm{E}-06$ \\
\hline 17.5 & 2.4 & 7.13E-05 & & 50.4 & 50.4 & 2770 & & 2.4 & 0 & 3.92 & 1.20 & 15181.29 & 0.000 & 0 & 1.73 & $3.46 \mathrm{E}+05$ & $1.73 \mathrm{E}-06$ \\
\hline 18 & 2.4 & $6.86 \mathrm{E}-05$ & & 50.5 & 50.5 & 2820 & 34.5 & 2.4 & 0 & 3.92 & 1.20 & 15181.29 & 0.000 & 0 & 1.67 & $3.47 E+05$ & $1.67 \mathrm{E}-06$ \\
\hline 18.5 & 2.4 & 7.00E-05 & & 50.4 & 50.4 & 2871 & & 2.4 & 0 & 3.92 & 1.20 & 15181.29 & 0.000 & 0 & 1.70 & $3.46 \mathrm{E}+05$ & $1.70 \mathrm{E}-06$ \\
\hline 19 & 2.4 & $6.86 \mathrm{E}-05$ & & 50.6 & 50.6 & 2921 & 36.2 & 2.4 & 0 & 3.92 & 1.20 & 15181.29 & 0.000 & 0 & 1.67 & $3.48 \mathrm{E}+05$ & 1.67E-06 \\
\hline 19.5 & 2.4 & 7.13E-05 & & 50.7 & 50.5 & 2973 & & 2.4 & 0.2 & 3.92 & 1.20 & 15181.29 & 0.040 & 0.2 & 1.73 & $3.48 \mathrm{E}+05$ & $1.73 \mathrm{E}-06$ \\
\hline 20 & 2.4 & 7.00E-05 & & 50.8 & 50.6 & 3024 & 37.5 & 2.4 & 0.2 & 3.92 & 1.20 & 15181.29 & 0.040 & 0.2 & 1.70 & $3.48 \mathrm{E}+05$ & $1.70 \mathrm{E}-06$ \\
\hline
\end{tabular}

Table A.7 - Tube 4, Slurry 


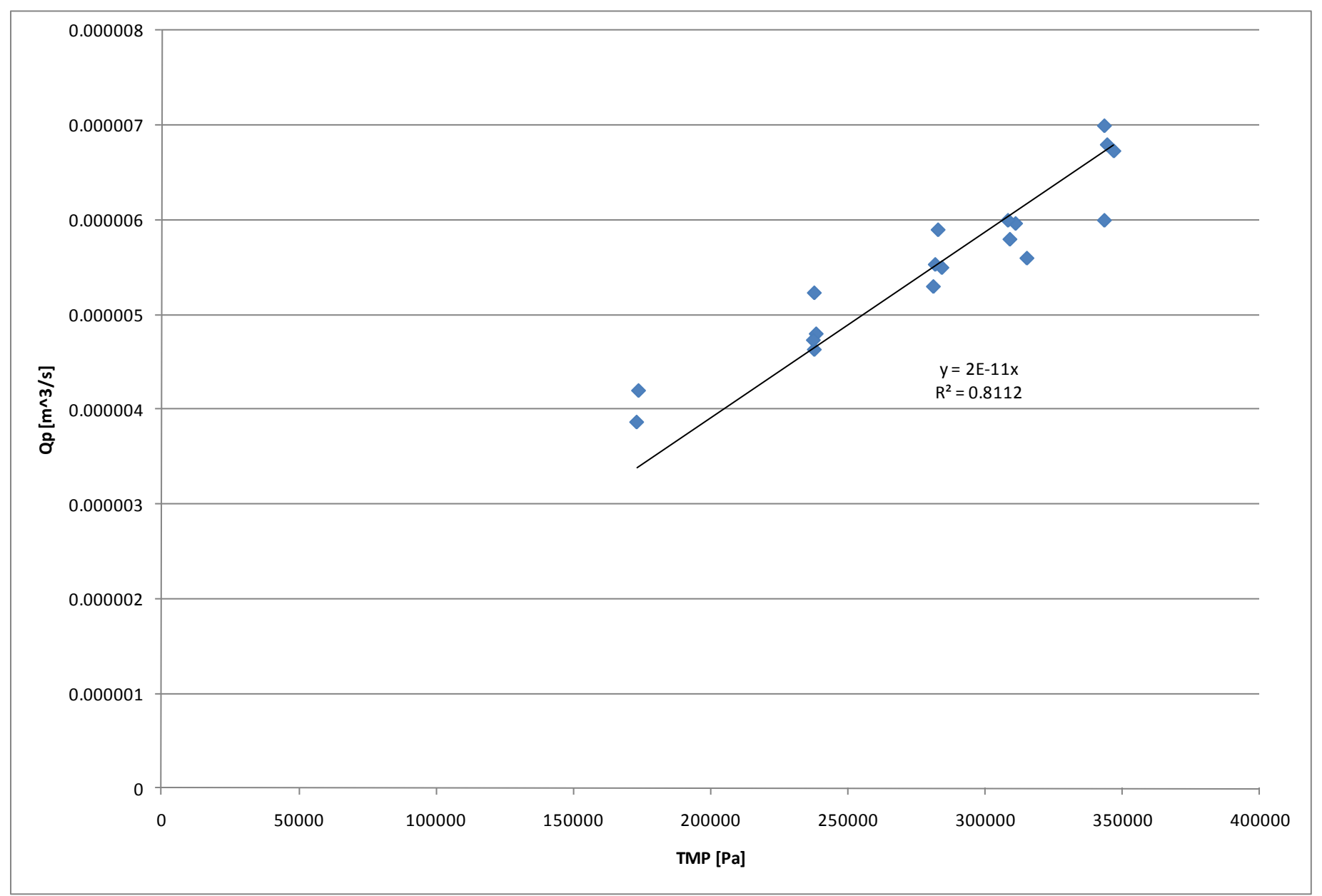

Figure A.5 - Permeate flux versus trans-membrane pressure differential. $\mathbf{R m}$ is determined by taking the slope of the trend line. 


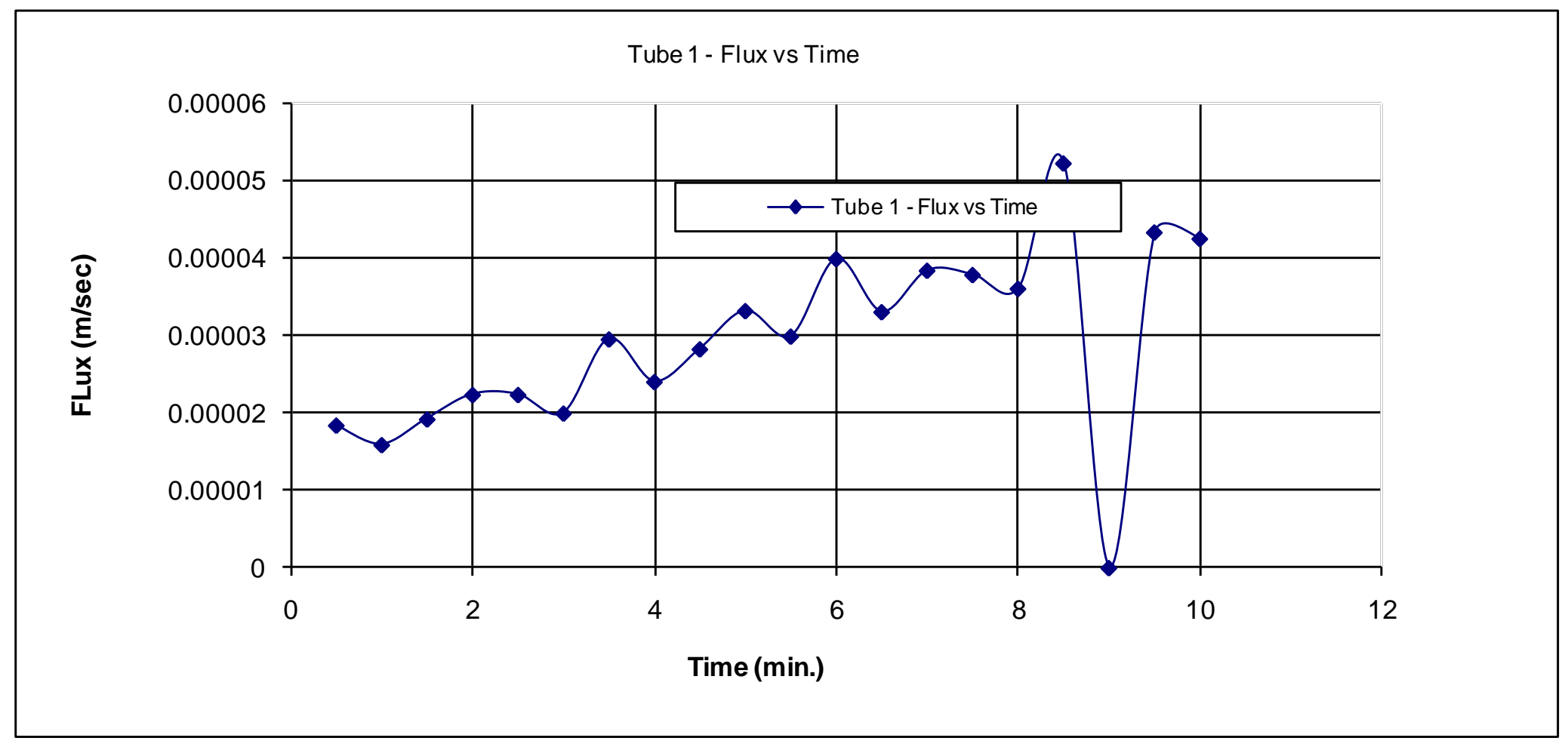

Figure A.6 - Tube 1, Slurry, Time vs. Permeate Flux 


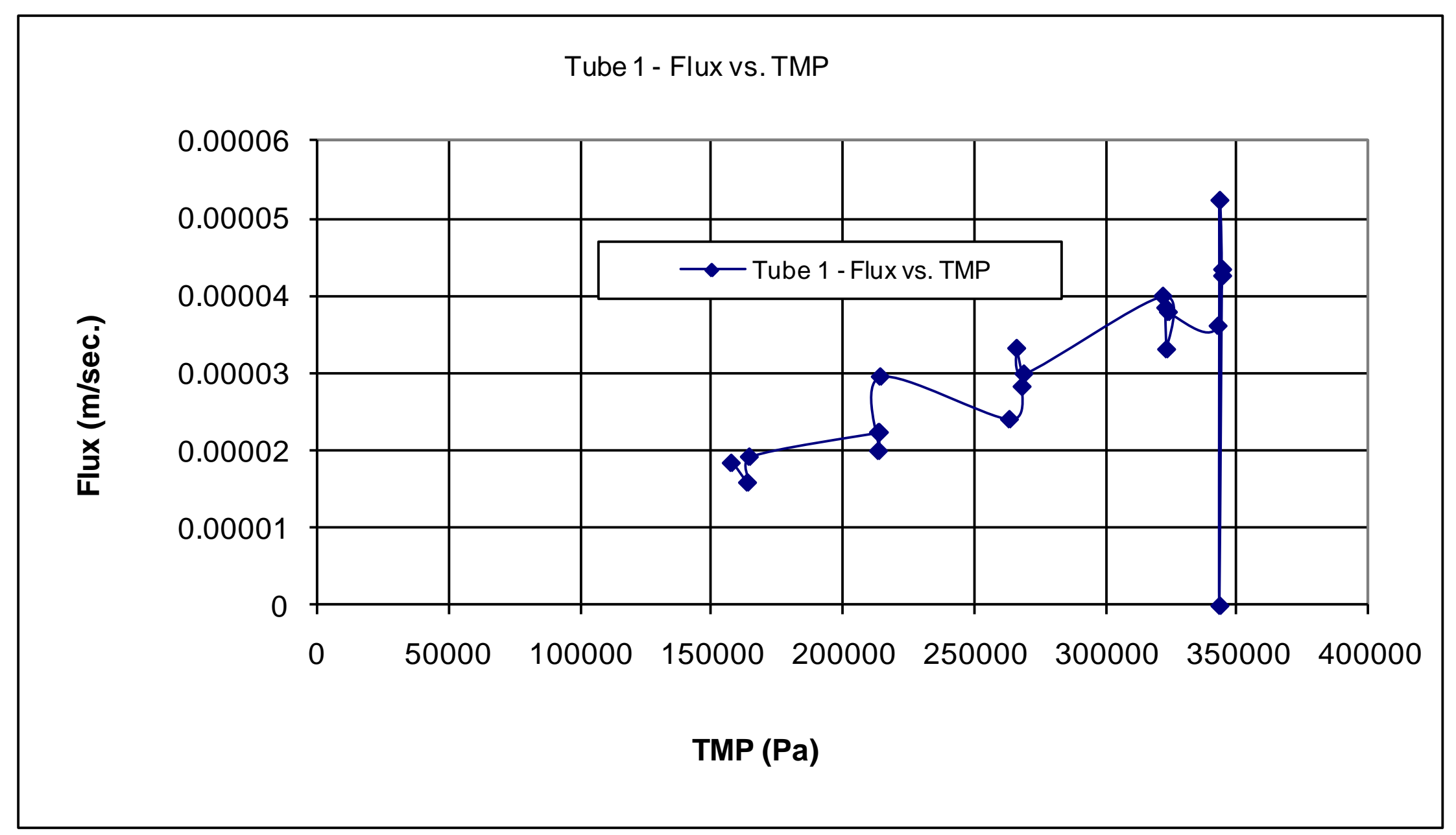

Figure A.7 - Tube 1, Slurry permeate flux versus trans-membrane pressure differential. 


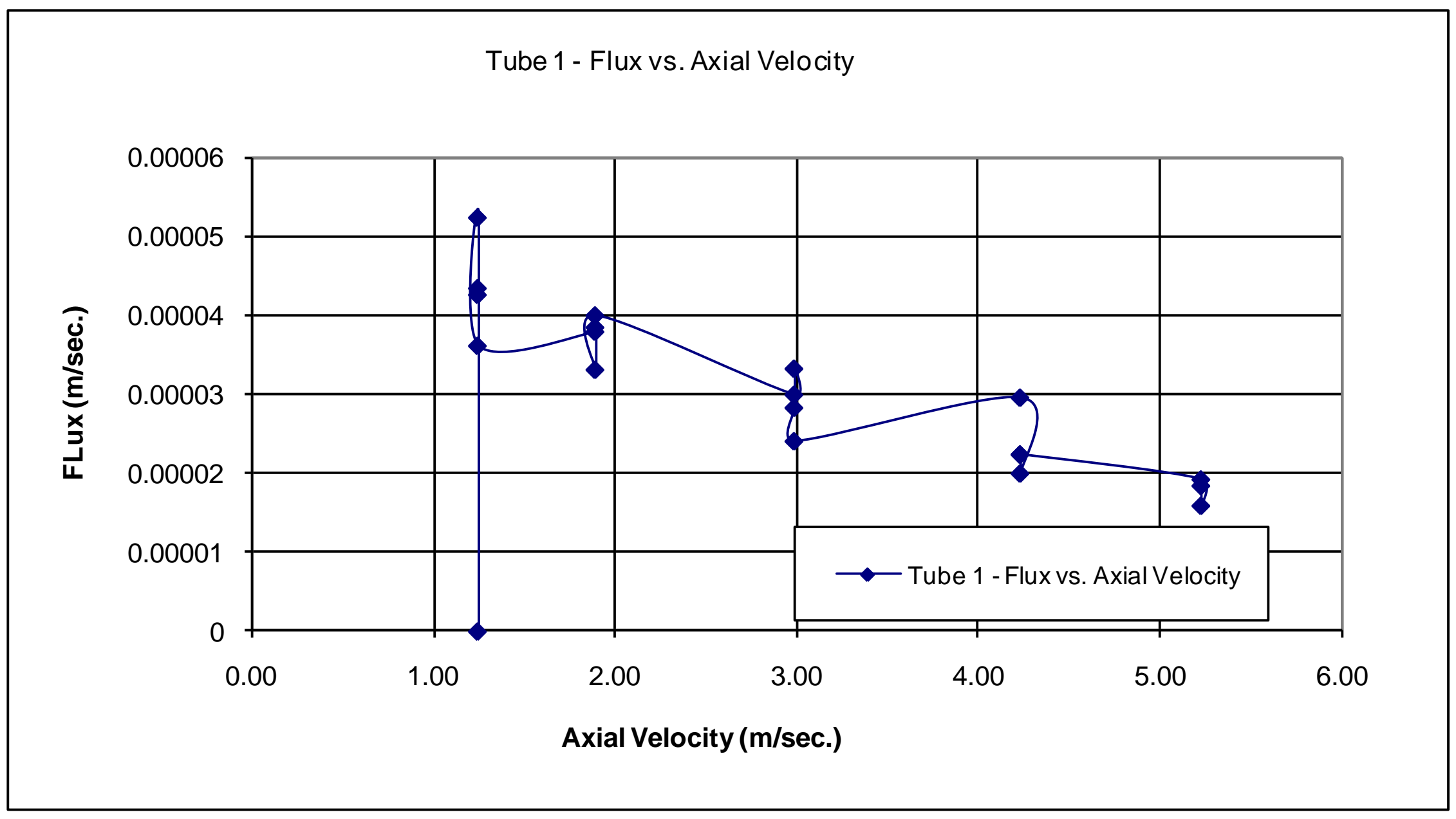

Figure A.8 - Tube 1, Slurry permeate flux versus axial velocity 


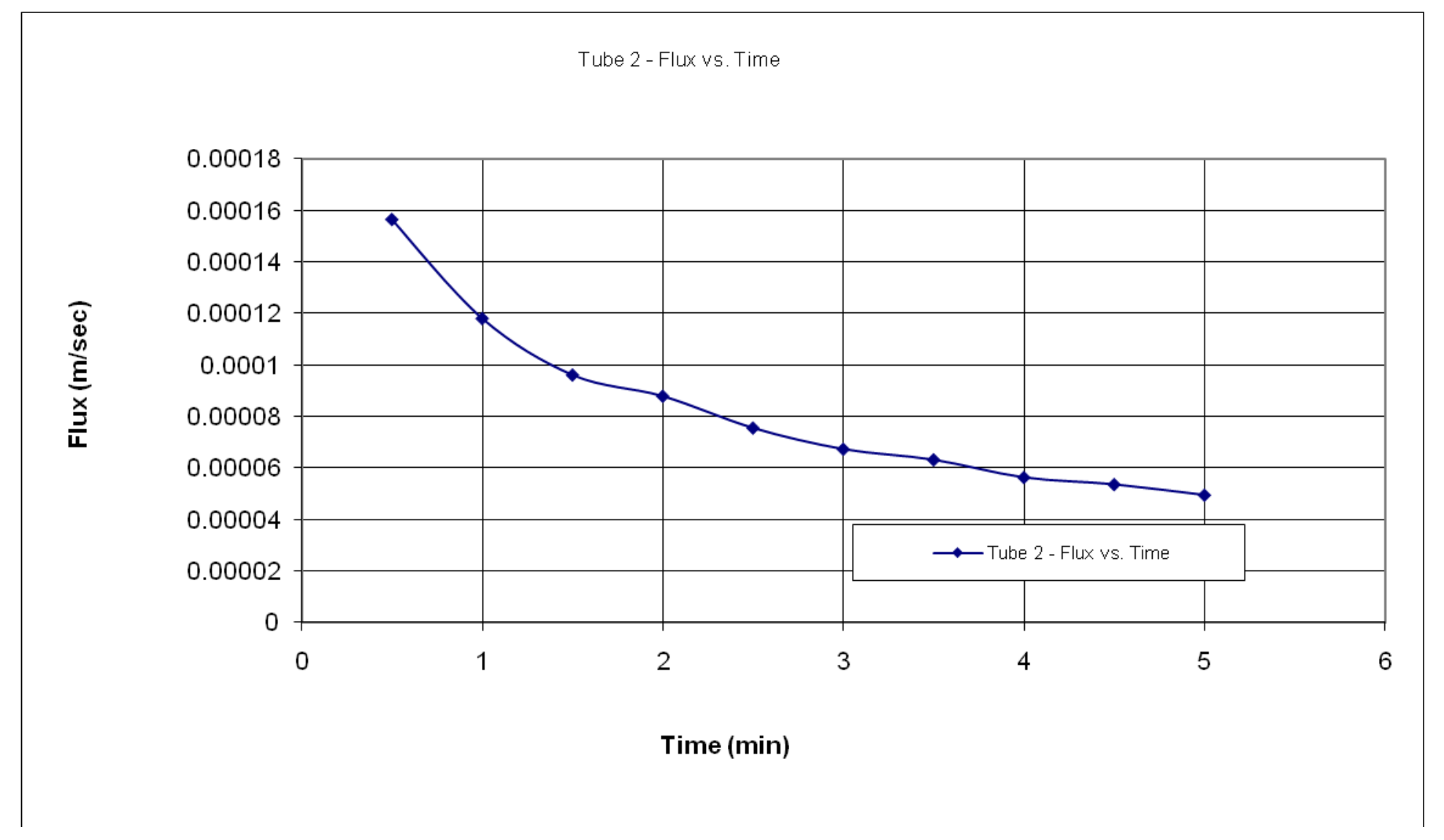

Figure A.9 - Tube 2, Slurry permeate flux versus time. 


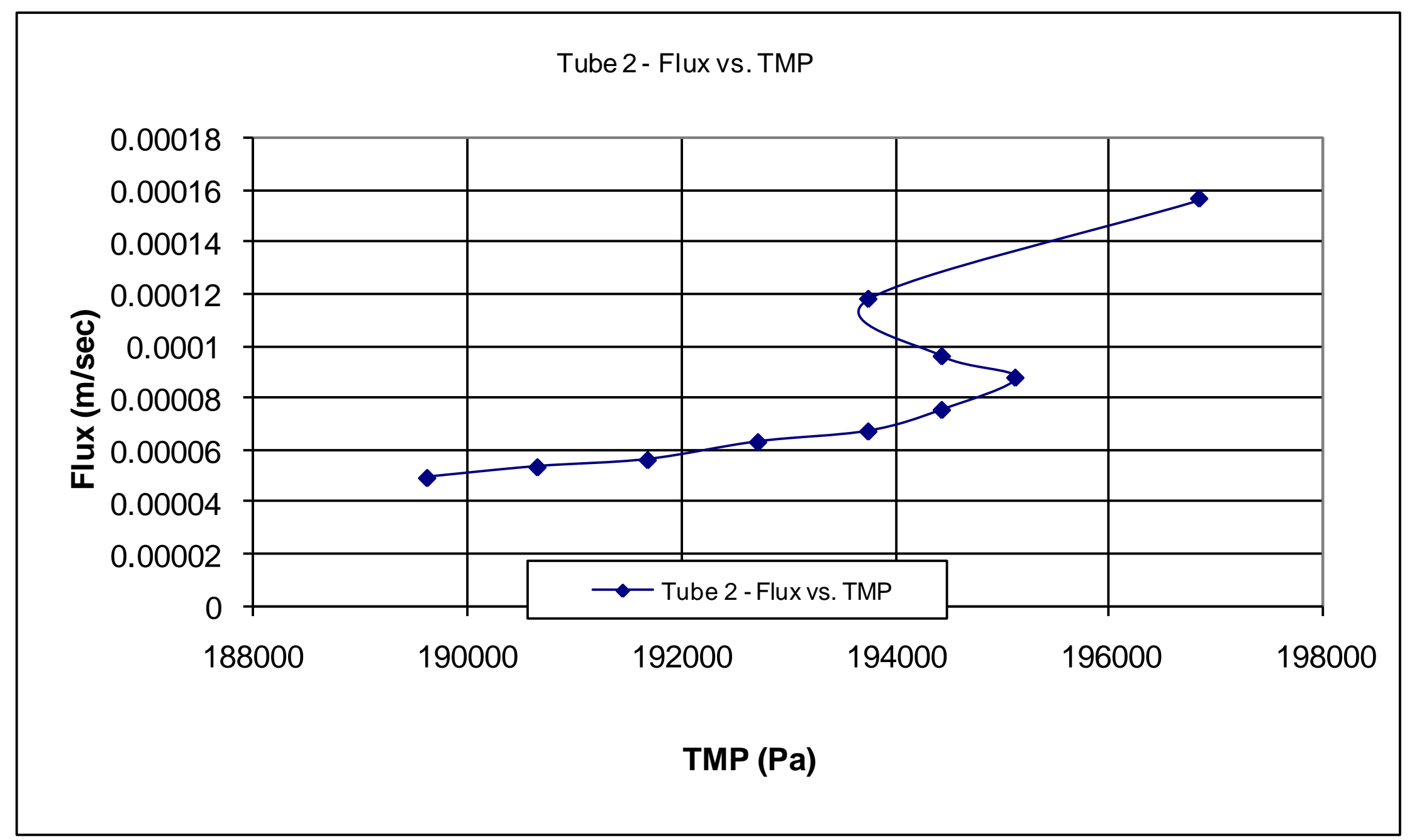

Figure A.10 - Tube 2, Slurry permeate flux versus trans-membrane pressure differential. 


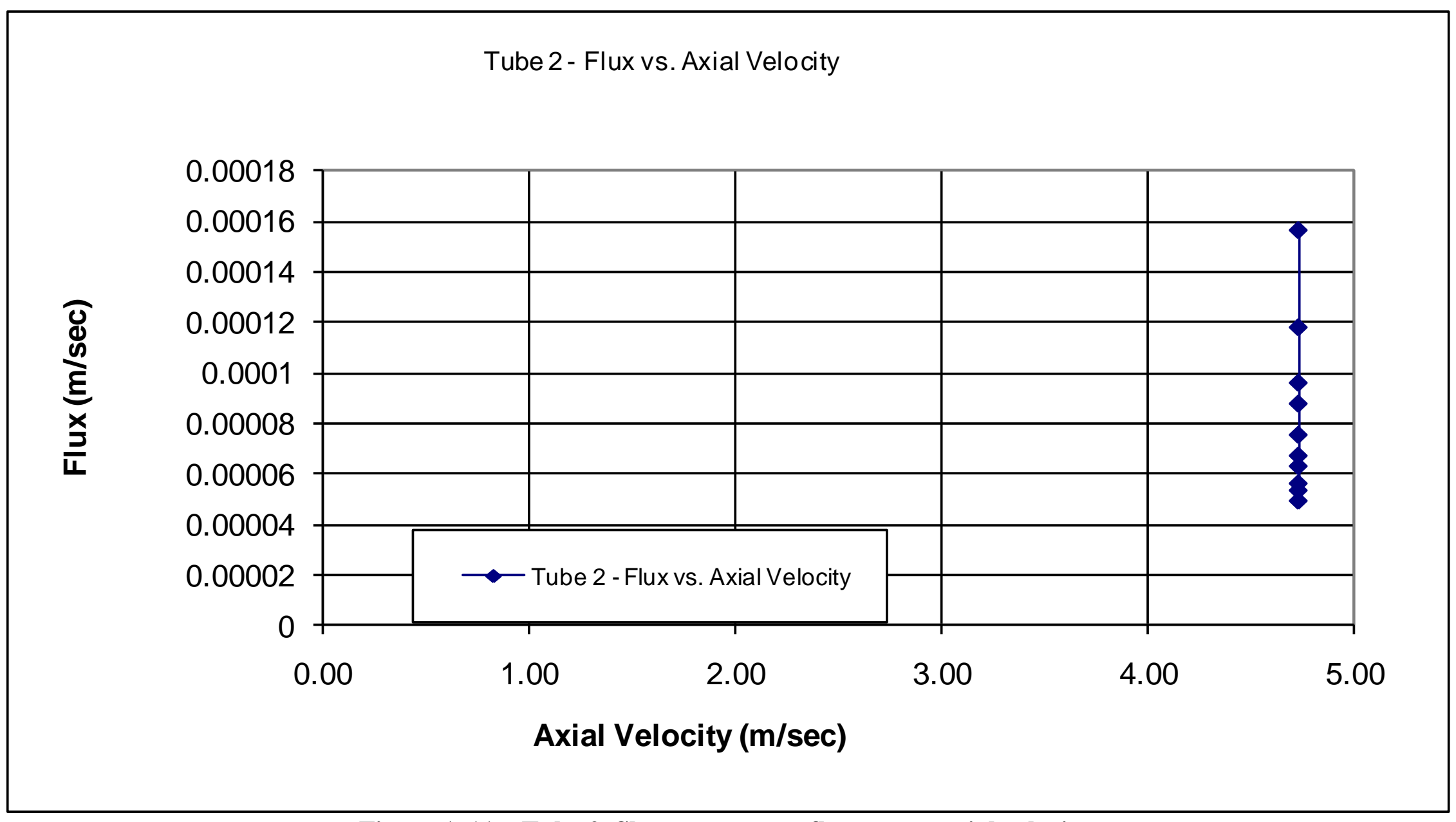

Figure A.11 - Tube 2, Slurry permeate flux versus axial velocity. 


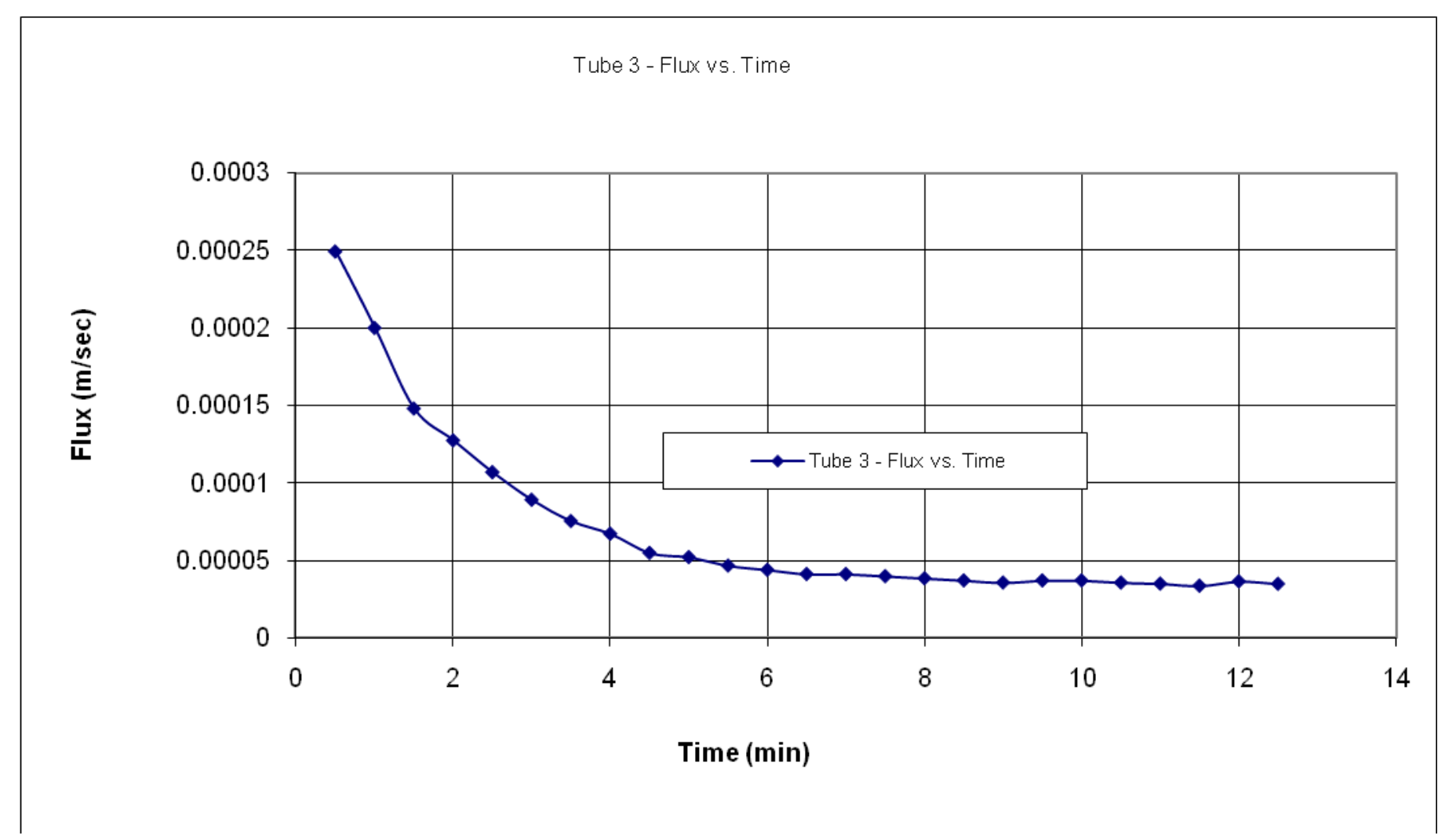

Figure A.12 - Tube 3, Slurry permeate flux versus time. 


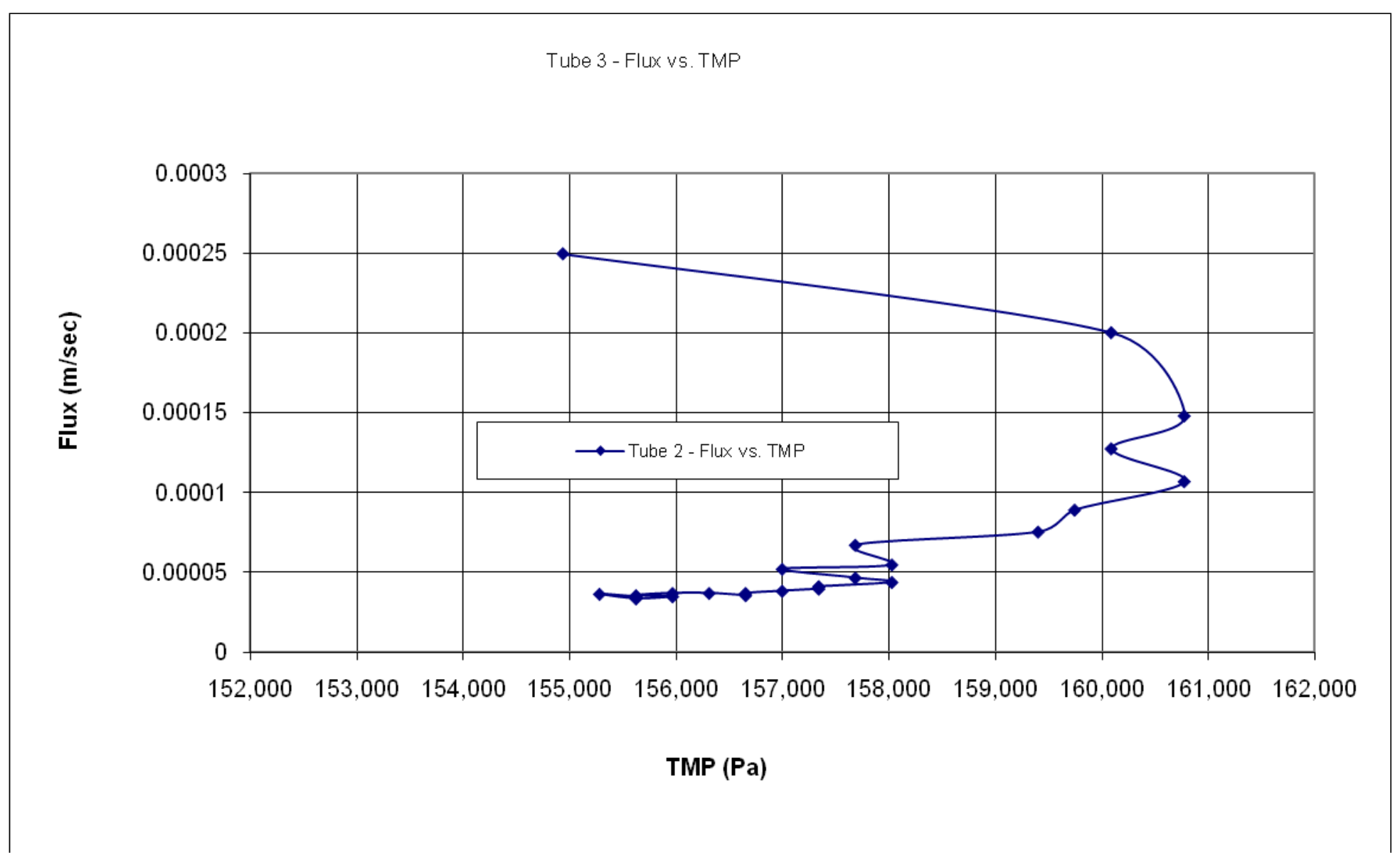

Figure A.13 - Tube 3 Trans-membrane differential pressure versus permeate flux. 


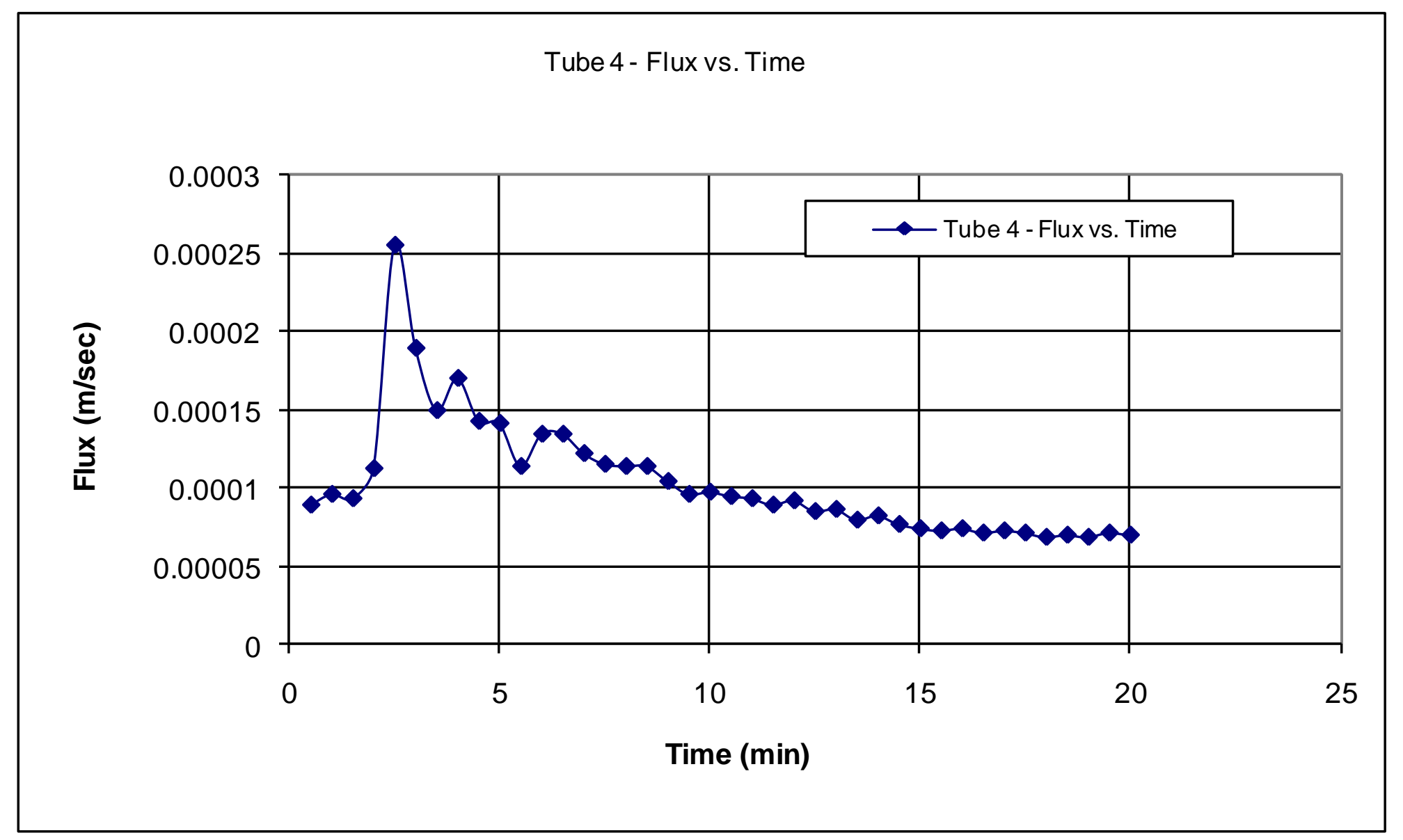

Figure A.14 - Tube 4, Slurry permeate flux versus time. 


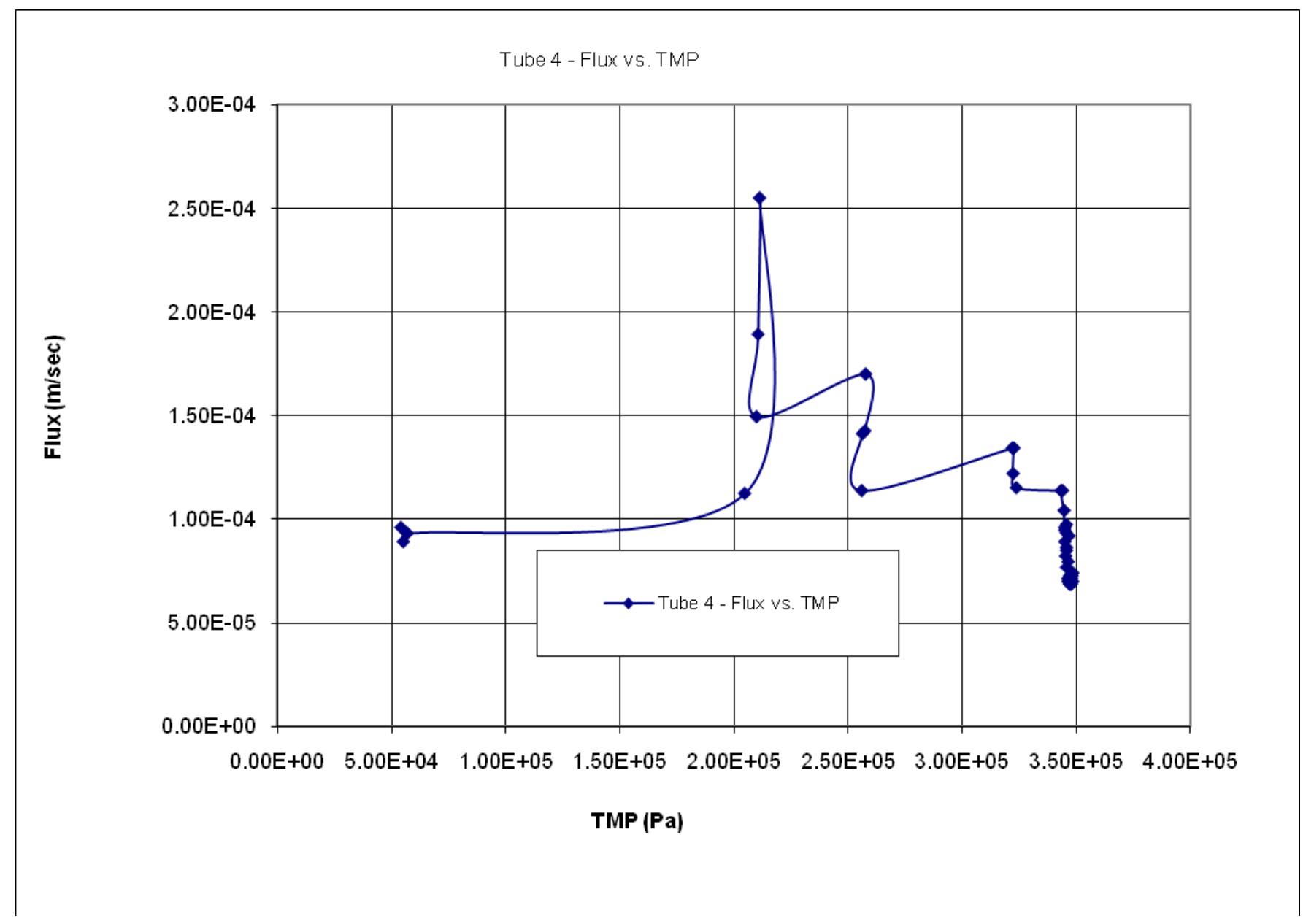

Figure A.15 - Tube 4, Slurry permeate flux versus trans-membrane pressure differential. 


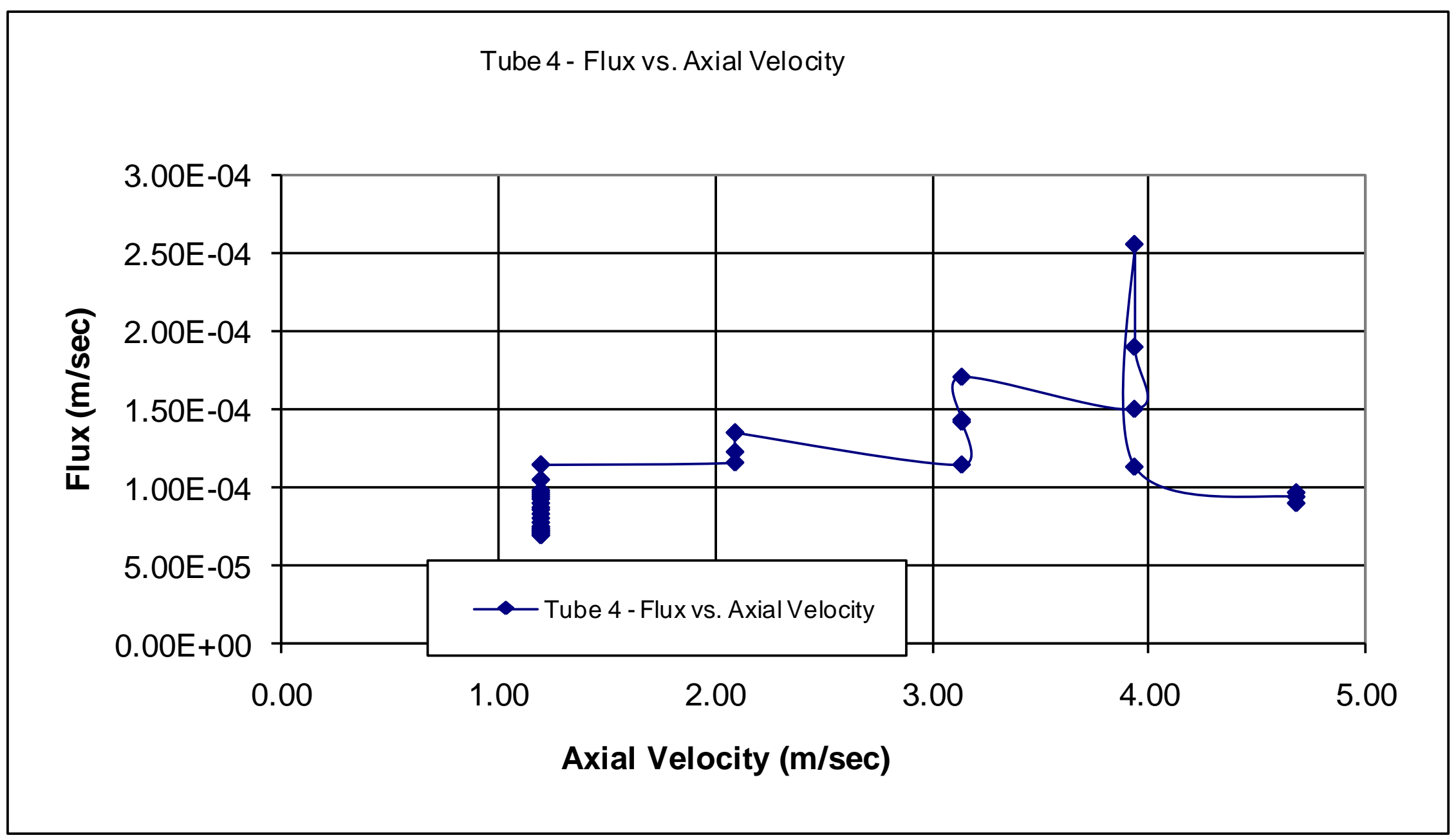

Figure A.16 - Tube 4, slurry Permeate flux versus slurry axial velocity. 
Appendix B - Critical parameter estimation 


$$
\begin{aligned}
& \text { Diterrinotion of } \\
& -R_{m} \\
& -\phi_{B} \\
& -\theta \\
& -\theta_{C}
\end{aligned}
$$

$$
\text { A-28 }
$$




$$
\begin{aligned}
& \text { Dotermination of } R_{m} \\
& Q_{p}\left[m^{3} / s\right] \mid \frac{y=2 \times 10^{-11} x}{\Delta P\left[l_{\sigma}\right]} \\
& \theta_{p}=\frac{\Delta D A}{\left.\mu R_{n}\right)} \quad m=\frac{A}{\mu R_{n}} \\
& A=\pi D L=\pi\left(\frac{1 / 2}{12}\right) 2 \times\left(\frac{.3048 m}{1 P t}\right)^{2} \\
& =.0243 \mathrm{~m}^{2} \\
& \mu \simeq 10^{-3} \frac{\mathrm{kg}}{\mathrm{m}-\mathrm{s}} \\
& 2 \times 10^{-11}=\frac{.0243}{10^{-3} R_{m}} \\
& R_{n}=8.2 \times 10^{+13}
\end{aligned}
$$




$$
\begin{aligned}
& \text { Determinotion of } \mathscr{B}_{3} \text { (lorger MS) } \\
& C\left[\frac{8 n}{a}\right]=40 \\
& \phi_{B}=\frac{v_{i} N_{i}}{v_{T}} \\
& N i[\mathrm{~N} / \mathrm{rr}] * 200 \text { proms } \\
& =1.169 \times 10^{12} \\
& v_{i}=\frac{\pi}{6} \bar{D}^{3}, \bar{D}=6.5 \mathrm{\mu m} \\
& =\frac{143.8 \mathrm{~mm}^{3}}{\text { pootide }} \\
& V_{T}=5 Q=5 \times 10^{-3} \mathrm{n}^{3} \\
& \phi_{B}=\frac{1.68 \times 10^{-4} \mathrm{n}^{3}}{5 \times 10^{-3} \mathrm{~m}^{3}}=.034
\end{aligned}
$$




$$
\begin{aligned}
& 7 \times 10^{-5}=\frac{.425(.04) 1.20^{2}-4 \times 10^{-6}}{183\left(10^{-6}\right) \tan (\theta)} \\
& 1.31=\frac{1}{\operatorname{Tan}(\theta)} \\
& \operatorname{Ton}(\theta)=.76
\end{aligned}
$$

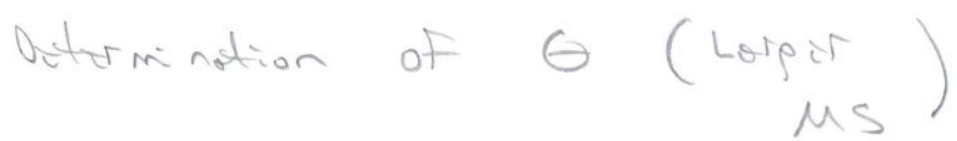

$$
\begin{aligned}
& d p^{\min }=2 \text { microns } \\
& f=.046, u=4.93 \mathrm{~m} / \mathrm{s} \\
& \phi=511 \\
& \theta_{p}(s s)=4 \times 10^{-5} \mathrm{~m} / \mathrm{s} \\
& 4 \times 10^{-5}=\frac{.425(.046) 4.93^{2} 2 \times 10^{-6}}{57710^{-6} \tan \theta}
\end{aligned}
$$




$$
\begin{aligned}
2.43 \times 10^{-2} & =\frac{1}{\operatorname{Tan} \theta} \\
\operatorname{Tan}_{\tan \theta} & =41
\end{aligned}
$$

$$
\text { A-32 }
$$




$$
\begin{aligned}
& \text { Ditimination of } \theta \text { (Smaller }) \\
& \text { At Stiaby-state } \\
& q_{p}=\frac{.425 \mathrm{f} \mathrm{v^{2 }}}{\phi \nu \operatorname{Ton}(\theta)} d p^{\mathrm{min}} \\
& b_{p}^{\min }=.4 \text { micions } \\
& \mathcal{F}=.04, U=1.20 \mathrm{~m} / \mathrm{s} \\
& \nu=10^{-6} \mathrm{~m}^{2} / \mathrm{s}, \phi=183 \\
& Q_{p}=7 \times 10^{-5} \mathrm{~m} / \mathrm{s} \\
& Q_{p}(\phi) \doteq .0003 \mathrm{~m} / \mathrm{s}=\frac{\Delta P}{\mu R_{m}}=\frac{55000 P_{\alpha}}{.00 \frac{50}{m-s} R_{m}} \\
& R_{n}=1.8 \times 10^{11}
\end{aligned}
$$


Ditermination of $\phi_{C}$ (lorpor MS)

$$
\begin{aligned}
& \bar{m}=95 \\
& \bar{m}=1+\frac{(1-c)}{c} \frac{P}{\frac{T}{s}} \\
& 95=1+\frac{(1-c)}{c} \frac{1}{1.2} \\
& 94(1.2)=\frac{1-c}{c} \\
& c=\frac{1}{113.8}=8.8 \times 10^{-3}
\end{aligned}
$$

A-34 


\section{Appendix C - Developed Model}

Appendix C1 - Lu and Ju (1989)

Appendix C2 - Lu, Hwang and Ju (1993)

Appendix C3 - Foust et al. (2010) 
Appendix C1 is a spreadsheet model for Equation 1 and utilizes the experimental results from [9].

Appendix C2 incorporates the model developed from Equations 7 to 15 into a spreadsheet, which included several worksheets. Each worksheet is discussed. The same experimental results were utilized in Appendices C1 and C2.

"Input" - worksheet where inputs to the model were incorporated. These included concentrations, filter parameters, fluid mechanic parameters, particle size distribution parameters, and numerical computation parameters.

“Charts" - worksheet where six charts are displayed and include "dpi vs. PSD”, “dpi vs. f", "dpi vs. dpi_bar", "f vs. time”, "Delta vs. time" and "J vs. time."

"Main Sheet" - where much of the computations occur and numerical integration associated with model for permeate rates.

"dpi" - worksheet calculates the cut-off diameter associated with current conditions and sends this information to "Main Sheet"

" $\mathrm{f}$ " - worksheet based on current conditions determines percent of bulk phase solids that accumulate onto membrane surface and sends this information back to worksheet "Main Sheet"

"dpi_bar" - worksheet determines average dpi for determining cake properties associated with current conditions and uses this in "Alpha"

"Alpha" - determine an average specific resistance of the cake based on information associated with each layer of cake up until current conditions and sends back to "Main Sheet"

"Bench Marking" - worksheet determines the validity of experimental results against model results

Appendix C3 follows much of what was discussed above for Appendix C2, but applied the model to experimental results of work done as part of this project. 


\section{Appendix C1}

$\begin{array}{ccr}\mathrm{V} & {[\mathrm{m} / \mathrm{s}]} & 0.57 \\ \mathrm{H} & {[\mathrm{m}]} & 0.007 \\ \mathrm{mu} & {[\mathrm{kg} / \mathrm{m}-\mathrm{s}]} & 0.001 \\ \text { den(liquid) } & {\left[\mathrm{kg} / \mathrm{m}^{\wedge} 3\right]} & 1000 \\ \text { den(solid) } & {\left[\mathrm{kg} / \mathrm{m}^{\wedge} 3\right]} & 2710 \\ \mathrm{nu} & {\left[\mathrm{m}^{\wedge} 2 / \mathrm{s}\right]} & 0.000001 \\ \mathrm{Phi} & & 258 \\ \mathrm{Rm} & {[1 / \mathrm{m}]} & 1.00 \mathrm{E}+08 \\ \tan \text { (theta) } & & 0.11 \\ \text { flux(clean) } & {[\mathrm{m} / \mathrm{s}]} & 1.52\end{array}$

\begin{tabular}{|c|c|c|c|}
\hline $\begin{array}{c}\mathbf{d p} \\
\text { [micron] }\end{array}$ & $\begin{array}{l}d p \\
{[m]}\end{array}$ & C1 & $\mathrm{C} 2$ \\
\hline 3 & 0.000003 & 37.58099 & 37.53487 \\
\hline 4 & 0.000004 & 37.58099 & 37.53487 \\
\hline 5 & 0.000005 & 37.58099 & 37.53487 \\
\hline 6 & 0.000006 & 37.58099 & 37.53487 \\
\hline 7 & 0.000007 & 37.58099 & 37.53487 \\
\hline 8 & 0.000008 & 37.58099 & 37.53487 \\
\hline 9 & 0.000009 & 37.58099 & 37.53487 \\
\hline 10 & 0.00001 & 37.58099 & 37.53487 \\
\hline 11 & 0.000011 & 37.58099 & 37.53487 \\
\hline 12 & 0.000012 & 37.58099 & 37.53487 \\
\hline 13 & 0.000013 & 37.58099 & 37.53487 \\
\hline 14 & 0.000014 & 37.58099 & 37.53487 \\
\hline 15 & 0.000015 & 37.58099 & 37.53487 \\
\hline 16 & 0.000016 & 37.58099 & 37.53487 \\
\hline 17 & 0.000017 & 37.58099 & 37.53487 \\
\hline $\begin{array}{c}d p \\
\text { [micron] }\end{array}$ & $\begin{array}{c}\mathbf{q} \\
{[\mathrm{cm} / \mathrm{s}]}\end{array}$ & $\begin{array}{c}\mathrm{dp} \\
\text { [micron] }\end{array}$ & $\begin{array}{c}\mathbf{q} \\
{[\mathrm{cm} / \mathrm{s}]}\end{array}$ \\
\hline 3 & 0.0113305 & 9.5 & 0.03 \\
\hline 4 & 0.0151657 & 10 & 0.038 \\
\hline 5 & 0.0190509 & 14 & 0.042 \\
\hline 6 & 0.0229986 & 16 & 0.06 \\
\hline 7 & 0.0270213 & 18 & 0.062 \\
\hline 8 & 0.0311315 & 22 & 0.09 \\
\hline 9 & 0.0353418 & & \\
\hline 10 & 0.0396645 & & \\
\hline 11 & 0.0441123 & & \\
\hline 12 & 0.0486976 & & \\
\hline 13 & 0.053433 & & \\
\hline 14 & 0.0583309 & & \\
\hline 15 & 0.0634038 & & \\
\hline 16 & 0.0686643 & & \\
\hline 17 & 0.0 & & \\
\hline
\end{tabular}

\begin{tabular}{|c|c|c|c|c|}
\hline C3 & $\begin{array}{c}\mathbf{q} \\
{[\mathrm{cm} / \mathrm{s}]}\end{array}$ & $C 1 * d p$ & $\mathrm{C} 2{ }^{*} \mathrm{dp}^{\wedge} 2$ & $\mathrm{C} 3^{*} \mathrm{dp}^{\wedge} 3$ \\
\hline 839122534 & 0.011331 & $1.00 \%$ & $0.00 \%$ & $0.00 \%$ \\
\hline 839122534 & 0.015166 & $0.99 \%$ & $0.00 \%$ & $0.01 \%$ \\
\hline 0839122534 & 0.019051 & $0.99 \%$ & $0.00 \%$ & $0.01 \%$ \\
\hline 0839122534 & 0.022999 & $0.98 \%$ & $0.00 \%$ & $0.02 \%$ \\
\hline 0839122534 & 0.027021 & $0.97 \%$ & $0.00 \%$ & $0.03 \%$ \\
\hline 0839122534 & 0.031132 & $0.97 \%$ & $0.00 \%$ & $0.03 \%$ \\
\hline 839122534 & 0.035342 & $0.96 \%$ & $0.00 \%$ & $0.04 \%$ \\
\hline 839122534 & 0.039665 & $0.95 \%$ & $0.00 \%$ & $0.05 \%$ \\
\hline 839122534 & 0.044112 & $0.94 \%$ & $0.00 \%$ & $0.06 \%$ \\
\hline 839122534 & 0.048698 & $0.93 \%$ & $0.00 \%$ & $0.07 \%$ \\
\hline 839122534 & 0.053433 & $0.91 \%$ & $0.00 \%$ & $0.09 \%$ \\
\hline 339122534 & 0.058331 & $0.90 \%$ & $0.00 \%$ & $0.10 \%$ \\
\hline 39122534 & 0.063404 & $0.89 \%$ & $0.00 \%$ & $0.11 \%$ \\
\hline 39122534 & 0.068664 & $0.88 \%$ & $0.00 \%$ & $0.12 \%$ \\
\hline & & & & \\
\hline
\end{tabular}

$17 \quad 0.0741249$

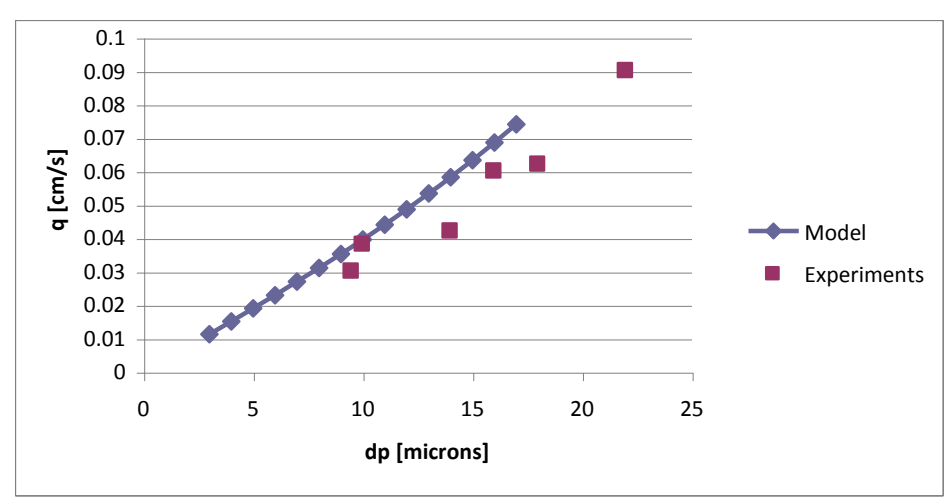




\section{Appendix C2 - Inputs}

\section{Inputs}

Concentrations

Phi@ 4.00E-01

Phi(b) 1.00E-01

Filter Parameters

$\mathrm{Rm}$

Height

Tan(theta)

Phi

Width

Area

Fluid Mechanics

$\begin{array}{lr}\mathrm{mu} & 0.001 \\ \mathrm{dP} & 26,700 \\ \mathrm{rho}(\mathrm{I}) & 1,000 \\ \mathrm{rho}(\mathrm{s}) & 2,710 \\ \mathrm{nu} & 1 . \mathrm{E}-06 \\ \mathrm{u} & 0.612245\end{array}$

\section{PSD Parameters}

dmin
dmax
dp(ave)
a1
a2
a3

Numerical

$$
\text { dT }
$$

$d p(0)$

$1.20 \mathrm{E}+10$

0.007

0.11

$2.58 \mathrm{E}+02$

7.00E-02

4.90E-04

0.612245

$[1 / \mathrm{m}]$

[m]

[m]

$\left[\mathrm{m}^{\wedge} 2\right]$

.0003

$$
\begin{gathered}
{[\mathrm{kg} / \mathrm{m}-\mathrm{s}]} \\
{[\mathrm{Pa}]} \\
{\left[\mathrm{Kg} / \mathrm{m}^{\wedge} 3\right]} \\
{\left[\mathrm{Kg} / \mathrm{m}^{\wedge} 3\right]} \\
{\left[\mathrm{m}^{\wedge} 2 / \mathrm{s}\right]} \\
{[\mathrm{m} / \mathrm{s}]}
\end{gathered}
$$

Determine Experimentally 


\section{Appendix C2 - Charts}

\section{Figure 1 - dpi vs. PSD $\quad$ Figure 4 - $\mathrm{fvs}$. $\mathrm{t}$}

Figure 2 - dpi vs. $f \quad$ Figure 5 - Delta vs.

Figure 3 - dpi vs. dpi_bar $\quad$ Figure 6 - J vs. $t$
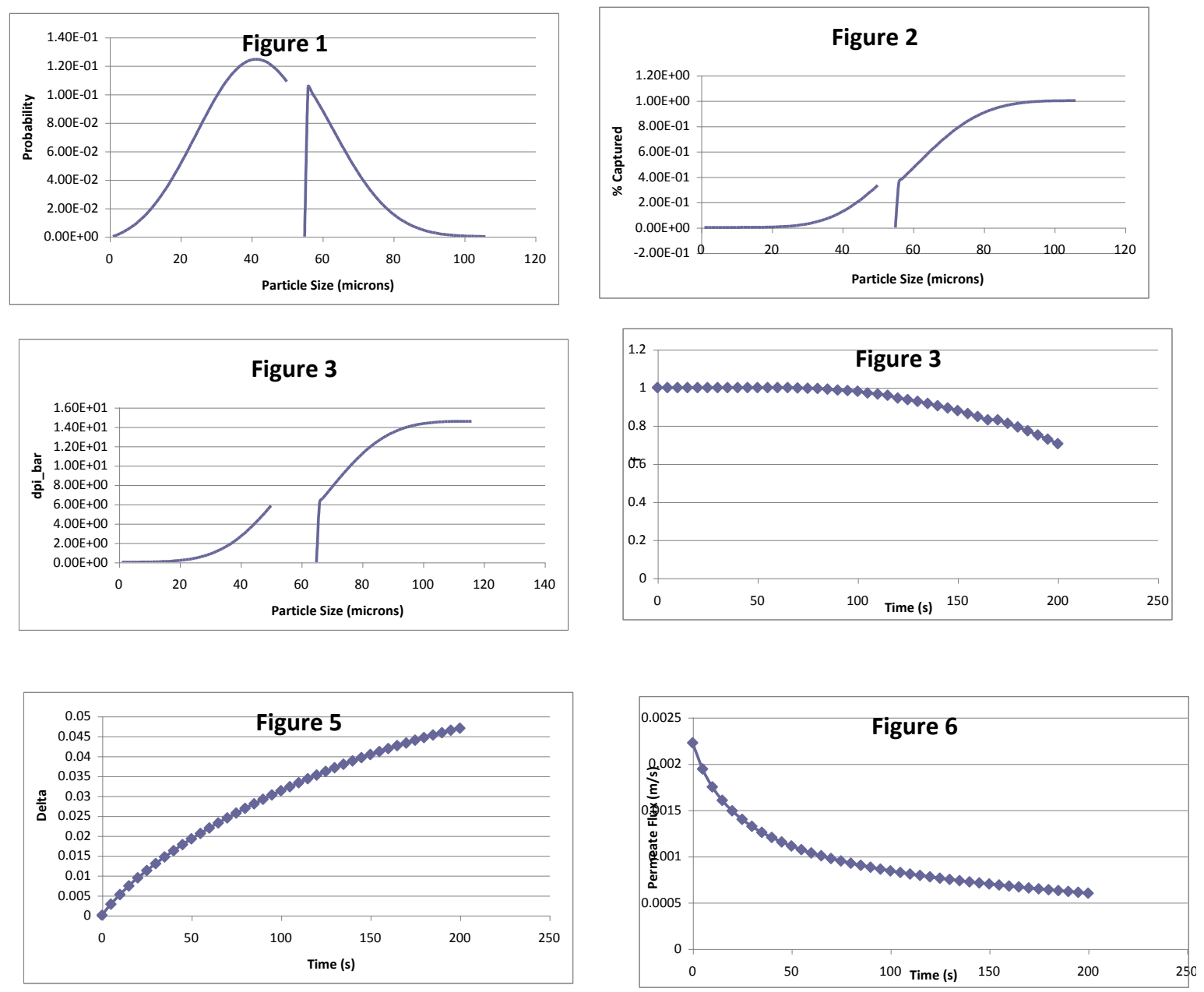


\section{Appendix C2 - Main Sheet}

$\begin{array}{rrrr}\begin{array}{r}\text { Time } \\ \text { [s] }\end{array} & \begin{array}{c}\text { dp } \\ \text { [m] }\end{array} & \text { f } & \text { dpi_bar } \\ 0 & 3.191 \mathrm{E}-05 & 1 & 1.45664 \mathrm{E}-05 \\ 5 & 2.95158 \mathrm{E}-05 & 1 & 1.45664 \mathrm{E}-05 \\ 10 & 2.77225 \mathrm{E}-05 & 1 & 1.45664 \mathrm{E}-05 \\ 15 & 2.62944 \mathrm{E}-05 & 1 & 1.45664 \mathrm{E}-05 \\ 20 & 2.51121 \mathrm{E}-05 & 1 & 1.45664 \mathrm{E}-05 \\ 25 & 2.41067 \mathrm{E}-05 & 1 & 1.45664 \mathrm{E}-05 \\ 30 & 2.32343 \mathrm{E}-05 & 1 & 1.45664 \mathrm{E}-05 \\ 35 & 2.24657 \mathrm{E}-05 & 1 & 1.45664 \mathrm{E}-05 \\ 40 & 2.17803 \mathrm{E}-05 & 1 & 1.45664 \mathrm{E}-05 \\ 45 & 2.11628 \mathrm{E}-05 & 1 & 1.45664 \mathrm{E}-05 \\ 50 & 2.0602 \mathrm{E}-05 & 1 & 1.45664 \mathrm{E}-05 \\ 55 & 2.0089 \mathrm{E}-05 & 1 & 1.45664 \mathrm{E}-05 \\ 60 & 1.9617 \mathrm{E}-05 & 0.99994 & 1.45638 \mathrm{E}-05 \\ 65 & 1.91803 \mathrm{E}-05 & 0.99925 & 1.45567 \mathrm{E}-05 \\ 70 & 1.87744 \mathrm{E}-05 & 0.998168 & 1.45429 \mathrm{E}-05 \\ 75 & 1.83955 \mathrm{E}-05 & 0.996358 & 1.45199 \mathrm{E}-05 \\ 80 & 1.80403 \mathrm{E}-05 & 0.995103 & 1.44849 \mathrm{E}-05 \\ 85 & 1.77055 \mathrm{E}-05 & 0.991713 & 1.44342 \mathrm{E}-05 \\ 90 & 1.73891 \mathrm{E}-05 & 0.986874 & 1.44016 \mathrm{E}-05 \\ 95 & 1.70906 \mathrm{E}-05 & 0.983798 & 1.43192 \mathrm{E}-05 \\ 100 & 1.68058 \mathrm{E}-05 & 0.980218 & 1.42682 \mathrm{E}-05 \\ 105 & 1.65348 \mathrm{E}-05 & 0.971335 & 1.41432 \mathrm{E}-05 \\ 110 & 1.62753 \mathrm{E}-05 & 0.965925 & 1.40678 \mathrm{E}-05 \\ 115 & 1.60272 \mathrm{E}-05 & 0.959794 & 1.3983 \mathrm{E}-05 \\ 120 & 1.57895 \mathrm{E}-05 & 0.945152 & 1.37821 \mathrm{E}-05 \\ 125 & 1.55596 \mathrm{E}-05 & 0.936533 & 1.36647 \mathrm{E}-05 \\ 130 & 1.53384 \mathrm{E}-05 & 0.926982 & 1.35352 \mathrm{E}-05 \\ 135 & 1.5125 \mathrm{E}-05 & 0.916451 & 1.33929 \mathrm{E}-05 \\ 140 & 1.49188 \mathrm{E}-05 & 0.904899 & 1.32374 \mathrm{E}-05 \\ 145 & 1.47191 \mathrm{E}-05 & 0.892288 & 1.3068 \mathrm{E}-05 \\ 150 & 1.45254 \mathrm{E}-05 & 0.878588 & 1.28845 \mathrm{E}-05 \\ 155 & 1.43372 \mathrm{E}-05 & 0.863776 & 1.26865 \mathrm{E}-05 \\ 160 & 1.41539 \mathrm{E}-05 & 0.847836 & 1.24738 \mathrm{E}-05 \\ 165 & 1.39751 \mathrm{E}-05 & 0.830764 & 1.22461 \mathrm{E}-05 \\ 170 & 1.38003 \mathrm{E}-05 & 0.830764 & 1.20036 \mathrm{E}-05 \\ 175 & 1.36255 \mathrm{E}-05 & 0.812561 & 1.17463 \mathrm{E}-05 \\ 180 & 1.34538 \mathrm{E}-05 & 0.793243 & 1.14744 \mathrm{E}-05 \\ 185 & 1.3285 \mathrm{E}-05 & 0.772834 & 1.11883 \mathrm{E}-05 \\ 190 & 1.31186 \mathrm{E}-05 & 0.751369 & 1.08884 \mathrm{E}-05 \\ 195 & 1.29544 \mathrm{E}-05 & 0.728897 & 1.05754 \mathrm{E}-05 \\ 200 & 1.27919 \mathrm{E}-05 & 0.705476 & 1.05754 \mathrm{E}-05\end{array}$

\section{alpha(i) \\ Alpha}

$6 . \mathrm{E}+11$

$[\mathrm{m} / \mathrm{s}$

\section{Delta(i)}

0.00278125

[m]

$\begin{array}{lllllll}6.28 \mathrm{E}+11 & 6.28 \mathrm{E}+11 & 0.001748 & 0.002185187 & 0.005208922 & 3.27 \mathrm{E}+09\end{array}$ $\begin{array}{lllllll}6.28 \mathrm{E}+11 & 6.28 \mathrm{E}+11 & 0.001604 & 0.00200493 & 0.007394108 & 4.65 \mathrm{E}+09\end{array}$ $\begin{array}{llllllll}6.28 \mathrm{E}+11 & 6.28 \mathrm{E}+11 & 0.001491 & 0.001863862 & 0.009399038 & 5.91 \mathrm{E}+09\end{array}$ $\begin{array}{lllllll}6.28 \mathrm{E}+11 & 6.28 \mathrm{E}+11 & 0.0014 & 0.001749432 & 0.0112629 & 7.08 \mathrm{E}+09\end{array}$ $\begin{array}{lllllll}6.28 \mathrm{E}+11 & 6.28 \mathrm{E}+11 & 0.001323 & 0.001654114 & 0.013012332 & 8.18 \mathrm{E}+09\end{array}$ $\begin{array}{lllllll}6.28 \mathrm{E}+11 & 6.28 \mathrm{E}+11 & 0.001258 & 0.001573075 & 0.014666446 & 9.22 \mathrm{E}+09\end{array}$ $\begin{array}{lllllll}6.28 \mathrm{E}+11 & 6.28 \mathrm{E}+11 & 0.001202 & 0.001503044 & 0.016239521 & 1.02 \mathrm{E}+10\end{array}$ $\begin{array}{llllllll}6.28 \mathrm{E}+11 & 6.28 \mathrm{E}+11 & 0.001153 & 0.001441719 & 0.017742565 & 1.11 \mathrm{E}+10\end{array}$ $\begin{array}{llllllll}6.28 \mathrm{E}+11 & 6.28 \mathrm{E}+11 & 0.00111 & 0.001387421 & 0.019184284 & 1.21 \mathrm{E}+10\end{array}$ $\begin{array}{lllllll}6.28 \mathrm{E}+11 & 6.28 \mathrm{E}+11 & 0.001071 & 0.001338894 & 0.020571705 & 1.29 \mathrm{E}+10\end{array}$ $\begin{array}{lllllll}6.29 \mathrm{E}+11 & 6.28 \mathrm{E}+11 & 0.001036 & 0.001295101 & 0.021910599 & 1.38 \mathrm{E}+10\end{array}$ $\begin{array}{lllllll}6.29 \mathrm{E}+11 & 6.28 \mathrm{E}+11 & 0.001004 & 0.001254571 & 0.0232057 & 1.46 \mathrm{E}+10\end{array}$ $\begin{array}{lllllll}6.30 \mathrm{E}+11 & 6.28 \mathrm{E}+11 & 0.000975 & 0.00121707 & 0.024460271 & 1.54 \mathrm{E}+10\end{array}$ $\begin{array}{lllllll}6.32 \mathrm{E}+11 & 6.29 \mathrm{E}+11 & 0.000949 & 0.001181736 & 0.02567734 & 1.61 \mathrm{E}+10\end{array}$ $\begin{array}{lllllll}6.35 \mathrm{E}+11 & 6.29 \mathrm{E}+11 & 0.000924 & 0.001149712 & 0.026859077 & 1.69 \mathrm{E}+10\end{array}$ $\begin{array}{lllllll}6.40 \mathrm{E}+11 & 6.29 \mathrm{E}+11 & 0.000901 & 0.00111753 & 0.028008789 & 1.76 \mathrm{E}+10\end{array}$ $\begin{array}{lllllll}6.43 \mathrm{E}+11 & 6.29 \mathrm{E}+11 & 0.00088 & 0.001085857 & 0.029126319 & 1.83 \mathrm{E}+10\end{array}$ $\begin{array}{llllllll}6.50 \mathrm{E}+11 & 6.3 \mathrm{E}+11 & 0.00086 & 0.001058121 & 0.030212176 & 1.90 \mathrm{E}+10\end{array}$ $\begin{array}{lllllll}6.55 \mathrm{E}+11 & 6.31 \mathrm{E}+11 & 0.000842 & 0.001031401 & 0.031270298 & 1.97 \mathrm{E}+10\end{array}$ $\begin{array}{lllllll}6.67 \mathrm{E}+11 & 6.31 \mathrm{E}+11 & 0.000824 & 0.001000742 & 0.032301698 & 2.04 \mathrm{E}+10\end{array}$ $\begin{array}{lllllll}6.74 \mathrm{E}+11 & 6.32 \mathrm{E}+11 & 0.000808 & 0.000975089 & 0.03330244 & 2.11 \mathrm{E}+10\end{array}$ $\begin{array}{llllllll}6.82 \mathrm{E}+11 & 6.34 \mathrm{E}+11 & 0.000792 & 0.000950022 & 0.034277529 & 2.17 \mathrm{E}+10\end{array}$ $\begin{array}{llllllll}7.02 \mathrm{E}+11 & 6.35 \mathrm{E}+11 & 0.000777 & 0.000917893 & 0.035227551 & 2.24 \mathrm{E}+10\end{array}$ $\begin{array}{lllllll}7.14 E+11 & 6.37 E+11 & 0.000763 & 0.000892785 & 0.036145444 & 2.30 E+10\end{array}$ $\begin{array}{llllllll}7.28 \mathrm{E}+11 & 6.38 \mathrm{E}+11 & 0.000749 & 0.000867877 & 0.037038229 & 2.36 \mathrm{E}+10\end{array}$ $\begin{array}{llllllll}7.43 \mathrm{E}+11 & 6.41 \mathrm{E}+11 & 0.000736 & 0.000843079 & 0.037906106 & 2.43 \mathrm{E}+10\end{array}$ $\begin{array}{llllllll}7.61 \mathrm{E}+11 & 6.43 \mathrm{E}+11 & 0.000723 & 0.000818316 & 0.038749185 & 2.49 \mathrm{E}+10\end{array}$ $\begin{array}{llllllll}7.81 \mathrm{E}+11 & 6.45 \mathrm{E}+11 & 0.000711 & 0.000793524 & 0.039567501 & 2.55 \mathrm{E}+10\end{array}$ $\begin{array}{lllllll}8.03 \mathrm{E}+11 & 6.48 \mathrm{E}+11 & 0.0007 & 0.000768651 & 0.040361025 & 2.61 \mathrm{E}+10\end{array}$ $\begin{array}{lllllll}8.28 \mathrm{E}+11 & 6.51 \mathrm{E}+11 & 0.000689 & 0.000743658 & 0.041129675 & 2.68 \mathrm{E}+10\end{array}$ $\begin{array}{llllllll}8.57 \mathrm{E}+11 & 6.54 \mathrm{E}+11 & 0.000678 & 0.000718516 & 0.041873333 & 2.74 \mathrm{E}+10\end{array}$ $\begin{array}{llllllll}8.89 \mathrm{E}+11 & 6.57 \mathrm{E}+11 & 0.000668 & 0.000693209 & 0.042591849 & 2.80 \mathrm{E}+10\end{array}$ $\begin{array}{lllllll}9.25 \mathrm{E}+11 & 6.61 \mathrm{E}+11 & 0.000657 & 0.00068269 & 0.043285058 & 2.86 \mathrm{E}+10\end{array}$ $\begin{array}{lllllll}9.66 \mathrm{E}+11 & 6.65 \mathrm{E}+11 & 0.000647 & 0.000657504 & 0.043967748 & 2.92 \mathrm{E}+10\end{array}$ $\begin{array}{llllllll}1.01 \mathrm{E}+12 & 6.7 \mathrm{E}+11 & 0.000638 & 0.000632135 & 0.044625253 & 2.99 \mathrm{E}+10\end{array}$ $\begin{array}{llllllll}1.07 \mathrm{E}+12 & 6.74 \mathrm{E}+11 & 0.000628 & 0.000606599 & 0.045257387 & 3.05 \mathrm{E}+10\end{array}$ $\begin{array}{lllllll}1.12 \mathrm{E}+12 & 6.8 \mathrm{E}+11 & 0.000619 & 0.000580924 & 0.045863986 & 3.12 \mathrm{E}+10\end{array}$ $\begin{array}{lllllll}1.19 \mathrm{E}+12 & 6.85 \mathrm{E}+11 & 0.000609 & 0.000555148 & 0.04644491 & 3.18 \mathrm{E}+10\end{array}$ $\begin{array}{lllllll}1.19 \mathrm{E}+12 & 6.91 \mathrm{E}+11 & 0.0006 & 0.000529315 & 0.047000058 & 3.25 \mathrm{E}+10\end{array}$ 


\section{Appendix C2 -dpi}

\begin{tabular}{|c|c|c|c|c|c|c|c|c|c|c|}
\hline ne & $d p(i)$ & $d p(i)$ & C1 & C2 & C3 & q & $q$ & & & Diff \\
\hline 0 & 31.91 & $3.191 \mathrm{E}-05$ & 42.58986 & 3612.209 & 26764278780 & 0.002225 & 0.002225 & 2225 & 2225 & $-4.3449 \mathrm{E}-05$ \\
\hline 5 & .52 & $2.95158 \mathrm{E}-05$ & 42.58986 & 3612.209 & 26764278780 & 0.001942 & 0.001942 & 1942.137 & 1942.137 & $2.2868 \mathrm{E}-05$ \\
\hline 10 & .72 & $2.77225 \mathrm{E}-05$ & 42.58986 & 3612.209 & 26764278780 & 0.001748 & 0.001748 & 748.15 & 1748.15 & -0.00037399 \\
\hline 15 & 9 & $2.62944 \mathrm{E}-05$ & 2.58986 & 36 & 2676 & 0.001604 & 0.001604 & 1603.944 & 1603.944 & $6 \mathrm{E}-07$ \\
\hline 20 & 1 & 2.511 & 42.58986 & & 78780 & 0.001491 & 0.001491 & 1491.09 & 1491.09 & $4 \mathrm{E}-07$ \\
\hline 25 & 1 & $2.41067 \mathrm{E}-05$ & 42.58986 & 3612.209 & 26764278780 & 0.0014 & 0.0014 & 1399.546 & 1399.546 & $-1.0922 \mathrm{E}-06$ \\
\hline 30 & 3 & $.32343 \mathrm{E}-05$ & 42.58986 & 3612.209 & 26764278780 & 0.001323 & 0.001323 & 1323.291 & 1323.291 & $-1.7907 \mathrm{E}-05$ \\
\hline 35 & .47 & $.24657 \mathrm{E}-05$ & 42.58986 & 3612.209 & 26764278780 & 0.001258 & 0.001258 & 1258.46 & 1258.46 & $-6.5248 \mathrm{E}-05$ \\
\hline 40 & 78 & $2.17803 \mathrm{E}-05$ & 42.58986 & 3612.209 & 26764278780 & 0.001202 & 0.001202 & 1202.435 & 1202.436 & 14199 \\
\hline 45 & 16 & $2.11628 \mathrm{E}-05$ & 42.58986 & 3612.209 & 26764278780 & 0.001153 & 0.001153 & 1153.375 & 1153.375 & 24072 \\
\hline 50 & 20.60 & $2.0602 \mathrm{E}-05$ & 42.58986 & 3612.209 & 26764278780 & 111 & 0.00111 & 1109.937 & 1109.937 & 35275 \\
\hline 55 & 20.09 & $2.0089 \mathrm{E}-05$ & 42.58986 & 3612.209 & 3780 & 0.001071 & 0.001071 & 1071.115 & 1071.116 & 7034 \\
\hline 60 & 19.62 & 1.9617E-05 & 42.58986 & 3612.209 & 3780 & 036 & 0.001036 & 1036.143 & 1036.143 & 58743 \\
\hline 65 & 18 & $1.91803 \mathrm{E}-05$ & 986 & 3612.209 & 267 & 04 & 004 & 1004.41 & 1004.411 & 9986 \\
\hline 70 & 77 & $1.87744 \mathrm{E}-05$ & 986 & 3612.209 & 267 & 975 & 975 & 975.4423 & 975.4431 & 3476 \\
\hline 75 & 18.40 & $1.83955 \mathrm{E}-05$ & 42.58986 & 3612.209 & 8780 & 949 & 0.000949 & 948.8449 & 948.8458 & 0077 \\
\hline 80 & 18.04 & $1.80403 \mathrm{E}-05$ & 42.58986 & 3612.209 & 78780 & 0924 & 0.000924 & 924.2964 & 924.2974 & 18736 \\
\hline 85 & 17.71 & $1.77055 \mathrm{E}-05$ & 42.58986 & 3612.209 & 2676 & 0.000901 & 0.000901 & 901.4951 & 901.4951 & 7E-07 \\
\hline 90 & 17.39 & $1.73891 \mathrm{E}-05$ & 42.58986 & 3612.209 & 2676 & 0.00088 & 0.00088 & 880.2397 & 880.2397 & $6 \mathrm{E}-07$ \\
\hline 95 & 17.09 & $1.70906 \mathrm{E}-05$ & 42.58986 & 3612.209 & $267 €$ & 886 & 086 & 860.4381 & 860.4381 & E- 07 \\
\hline 100 & 16.81 & $1.68058 \mathrm{E}-05$ & 42.58986 & 3612.209 & 267 & 842 & 0.000842 & 841.7727 & 841.7727 & $\mathrm{E}-07$ \\
\hline 10 & 16.53 & 1.6534 & 42.5 & 3612.209 & 267 & 0.0 & 824 & 824.2197 & 824.2197 & $\mathrm{E}-05$ \\
\hline $11 c$ & 16.28 & $1.62753 \mathrm{E}-05$ & 42.5 & 3612.209 & 267 & 808 & 0.000808 & 807.5898 & 807.5907 & 2618 \\
\hline $11:$ & 16.03 & $1.60272 \mathrm{E}-05$ & 42.58986 & 3612.209 & 2676 & 0.000792 & 0.000792 & 791.8553 & 791.8553 & $5 \mathrm{E}-07$ \\
\hline 12 & 15.79 & $1.57895 \mathrm{E}-05$ & 42.58986 & 3612.209 & 2676 & 0.000777 & 0.000777 & 776.9278 & 776.9278 & $3 \mathrm{E}-07$ \\
\hline 125 & 15.56 & $1.555966 \mathrm{E}-05$ & 42.58986 & 3612.209 & 78780 & 0.000763 & 0.000763 & 762.6296 & 762.6296 & $1 \mathrm{E}-07$ \\
\hline 13 & 15.34 & $1.53384 \mathrm{E}-05$ & 42.58986 & 3612.209 & 78780 & 0.000749 & 0.000749 & 748.9913 & 748.9913 & $1 \mathrm{E}-07$ \\
\hline 13 & 15.12 & $1.5125 \mathrm{E}-05$ & 42.58986 & 3612.209 & 8780 & 0.000736 & 0.000736 & 735.9512 & 735.9512 & $\mathrm{E}-07$ \\
\hline 14 & 14.92 & $1.49188 \mathrm{E}-05$ & 42.58986 & 3612.209 & 78780 & 0.000723 & 0.000723 & 723.4542 & 723.4552 & 99169 \\
\hline 14 & .72 & $1.47191 \mathrm{E}-05$ & 42.58986 & 3612.209 & 26764278780 & 0.000711 & 0.000711 & 711.4509 & 711.4518 & -0.00092132 \\
\hline 15 & 53 & $1.45254 \mathrm{E}-05$ & 42.58986 & 3612.209 & 78780 & .0007 & 0.0007 & 699.8965 & 699.8974 & -0.0008569 \\
\hline 15 & 14.34 & $1.43372 \mathrm{E}-05$ & 42.58986 & 3612.209 & 26764278780 & 0689 & 0.000689 & 688.7506 & 688.7514 & 79787 \\
\hline 16 & 15 & 1.415 & 42.58986 & 3612.209 & 780 & 678 & 678 & 677.9762 & 677.9769 & 4369 \\
\hline 16 & 8 & -05 & 886 & 209 & 780 & 0.000668 & 000668 & .5395 & 667.5402 & -0.00069393 \\
\hline 17 & 80 & $1.38003 \mathrm{E}-05$ & 42.58986 & 3612.209 & 26764278780 & 0.000657 & 0.000657 & 657.4096 & 657.4103 & -0.00064816 \\
\hline 175 & 13.63 & $1.36255 \mathrm{E}-05$ & 42.58986 & 3612.209 & 26764278780 & 0.000647 & 0.000647 & 647.3404 & 647.341 & 06067 \\
\hline 180 & 13.45 & $1.34538 \mathrm{E}-05$ & 42.58986 & 3612.209 & 26764278780 & 0.000638 & 0.000638 & 637.5195 & 637.5201 & -0.00056845 \\
\hline 185 & 13.28 & $1.3285 \mathrm{E}-05$ & 42.58986 & 3612.209 & 26764278780 & 0.000628 & 0.000628 & 627.9216 & 627.9221 & -0.00053314 \\
\hline 190 & 13.12 & $1.31186 \mathrm{E}-05$ & 42.58986 & 3612.209 & 26764278780 & 0.000619 & 0.000619 & 618.5229 & 618.5234 & -0.0005005 \\
\hline 19 & 12.95 & $1.29544 \mathrm{E}-05$ & 42.58986 & 3612.209 & 26764278780 & 0.000609 & 0.000609 & 609.3013 & 609.3018 & -0.00047031 \\
\hline 20 & 12.79 & $27919 \mathrm{E}-05$ & 42.58986 & 3612.209 & 26764278780 & 0.0006 & 0.0006 & 600.2357 & 600.2362 & -0.00044234 \\
\hline
\end{tabular}

C1*dp

$61.08 \%$

$64.73 \%$

$67.54 \%$

$69.82 \%$

$71.73 \%$

$73.36 \%$

$74.78 \%$

$76.03 \%$

$77.14 \%$

$78.15 \%$

$79.05 \%$

$79.88 \%$

$80.63 \%$

$81.33 \%$

$81.97 \%$

$82.57 \%$

$83.13 \%$

$83.65 \%$

$84.14 \%$

$85.03 \%$

$85.44 \%$

$85.83 \%$

$86.20 \%$

$86.56 \%$

$86.89 \%$

$87.22 \%$

$87.53 \%$

$87.83 \%$

$88.11 \%$

$88.39 \%$

$88.66 \%$

$88.91 \%$

$89.16 \%$

$89.40 \%$

$89.64 \%$

$90.11 \%$

$90.33 \%$

$90.55 \%$

$90.77 \%$
C2* $\mathrm{dp}^{\wedge}$

$0.17 \%$

$0.16 \%$

$0.16 \%$

$0.16 \%$

$0.15 \%$

$0.15 \%$

$0.14 \%$

$0.14 \%$

$0.14 \%$

$0.13 \%$

$0.13 \%$

$0.13 \%$

$0.13 \%$

$0.13 \%$

$0.13 \%$

$0.12 \%$

$0.12 \%$

$0.12 \%$

$0.12 \%$

$0.12 \%$

$0.12 \%$

$0.12 \%$

$0.11 \%$

$0.11 \%$

$0.11 \%$

$0.11 \%$

$0.11 \%$

$0.11 \%$

$0.11 \%$

$0.11 \%$

$0.11 \%$

$0.10 \%$

$0.10 \%$

$0.10 \%$

$0.10 \%$

$0.10 \%$

$0.10 \%$
C3* ${ }^{\wedge} 3$

$39.08 \%$

$35.44 \%$

$32.62 \%$

$30.34 \%$

$28.43 \%$

$26.79 \%$

$5.37 \%$

$24.11 \%$

$23.00 \%$

$21.99 \%$

$21.09 \%$

$20.26 \%$

$19.50 \%$

$18.80 \%$

$18.16 \%$

$17.56 \%$

$17.00 \%$

$16.48 \%$

$15.99 \%$

$15.53 \%$

$15.09 \%$

$14.68 \%$

$14.29 \%$

$13.92 \%$

$13.56 \%$

$13.22 \%$

$12.89 \%$

$2.58 \%$

$12.28 \%$

$12.00 \%$

$11.72 \%$

$11.45 \%$

$11.19 \%$

$10.94 \%$

$10.70 \%$

$10.46 \%$

$10.22 \%$

$9.99 \%$

$9.77 \%$

$9.55 \%$

$9.33 \%$ 


\section{Appendix C2 -f} $\begin{array}{llllll}0.4 & 0.00803727 & 0.002354 & 0.002045\end{array}$ $\begin{array}{lllllll}0.6 & 0.012958958 & 0.004946 & 0.003298\end{array}$ $\begin{array}{llllll}0.8 & 0.018545892 & 0.008655 & 0.004719 \\ 1 & 0.024842969 & 0.013624 & 0.006322\end{array}$ $\begin{array}{lllll}1 & 0.024842969 & 0.013624 & 0.006322\end{array}$ $\begin{array}{lllll}1.2 & 0.031892058 & 0.020002 & 0.008115\end{array}$ $\begin{array}{lllll}1.4 & 0.039731081 & 0.027948 & 0.01011\end{array}$ $\begin{array}{llllll}1.6 & 0.048393046 & 0.037627 & 0.012314\end{array}$ $\begin{array}{lllll}1.8 & 0.057905047 & 0.049208 & 0.014735\end{array}$ $\begin{array}{lllll}2 & 0.068287268 & 0.062865 & 0.017376\end{array}$ $\begin{array}{lllll}2.2 & 0.079551988 & 0.078776 & 0.020243\end{array}$ $\begin{array}{lllll}2.4 & 0.091702638 & 0.097116 & 0.023335\end{array}$ $\begin{array}{lllll}2.6 & 0.104732909 & 0.118063 & 0.02665\end{array}$ $\begin{array}{lllll}2.8 & 0.118625955 & 0.141788 & 0.030186\end{array}$ $\begin{array}{lllll}3 & 0.13335371 & 0.168459 & 0.033933\end{array}$ $\begin{array}{llllll}3.2 & 0.14887634 & 0.198234 & 0.037883\end{array}$ $\begin{array}{lllll}3.4 & 0.165141859 & 0.231263 & 0.042022\end{array}$ $\begin{array}{llllll}3.6 & 0.18208593 & 0.26768 & 0.046334\end{array}$ $\begin{array}{llllll}3.8 & 0.199631865 & 0.307606 & 0.050799\end{array}$ $\begin{array}{lllll}4 & 0.217690849 & 0.351144 & 0.055394\end{array}$ $\begin{array}{llllll}4.2 & 0.236162382 & 0.398377 & 0.060094\end{array}$ $\begin{array}{llllll}4.4 & 0.254934964 & 0.449364 & 0.064871\end{array}$ $\begin{array}{llllll}4.6 & 0.273887009 & 0.504141 & 0.069694\end{array}$ $\begin{array}{llllll}4.8 & 0.292887996 & 0.562719 & 0.074529\end{array}$ $\begin{array}{lllll}5 & 0.311799832 & 0.625079 & 0.079341\end{array}$ $\begin{array}{lllll}5.2 & 0.330478422 & 0.691174 & 0.084094 \\ 5.4 & 0.348775417 & 0.760929 & 0.08875\end{array}$ $\begin{array}{rrrrr}5.4 & 0.348775417 & 0.760929 & 0.08875 \\ 5.6 & 0.36654012 & 0.834238 & 0.09327\end{array}$ $\begin{array}{llllll}5.8 & 0.383621506 & 0.910962 & 0.097617\end{array}$ $\begin{array}{ccccc}5.8 & 0.383621506 & 0.910962 & 0.097617 \\ 6 & 0.39987033 & 0.990936 & 0.101752\end{array}$ $\begin{array}{lllll}6.2 & 0.415141275 & 1.073964 & 0.105637\end{array}$ $\begin{array}{llllll}6.4 & 0.429295101 & 1.159823 & 0.109239\end{array}$ $\begin{array}{lllllll}6 & 0.429200757 & 0.4248263 & 0.112523\end{array}$ $\begin{array}{lllll}6.4 & 0.429295101 & 1.159823 & 0.109239 \\ 6.8 & 0.453737395 & 1.243963 & 0.112523\end{array}$ $\begin{array}{llllll}7 & 0.453793958 & 1.339011 & 0.115459\end{array}$ $\begin{array}{lllllll}7.2 & 0.472282403 & 1.426227 & 0.118018\end{array}$ $\begin{array}{llllll}7.2 & 0.472282403 & 1.526227 & 0.120178\end{array}$ $\begin{array}{llllll}7.4 & 0.47282403 & 1.526227 & 0.120178 \\ 7.6 & 0.484234596 & 1.6205 & 0.121917\end{array}$ $\begin{array}{llllll}7.6 & 0.484234596 & 1.718897 & 0.123219 \\ 7.8 & 0.487592116 & 1.816415 & 0.124073\end{array}$ $\begin{array}{lllllllllllllll}7.8 & 0.487592116 & 1.816415 & 0.124073\end{array}$ $\begin{array}{llllll}8 & 0.489101554 & 1.914247 & 0.124473\end{array}$ $\begin{array}{llllll}8.2 & 0.488934363 & 2.012034 & 0.124415\end{array}$ $\begin{array}{lllll}8.4 & 0.486920732 & 2.109418 & 0.123902\end{array}$ $\begin{array}{lllll}8.6 & 0.483149344 & 2.206048 & 0.122943 \\ 8.8 & 0.47766819 & 2.301582 & 0.121548\end{array}$ $\begin{array}{lllll}8.8 & 0.477668819 & 2.301582 & 0.121548\end{array}$ $\begin{array}{llll}9 & 0.470336863 & 2.395689 & 0.119733\end{array}$ $\begin{array}{lllll}9.2 & 0.461839146 & 2.388057 & 0.11752\end{array}$ $\begin{array}{lllll}9.4 & 0.451667922 & 2.57839 & 0.114932\end{array}$ $\begin{array}{lrrrr}9.6 & 0.44013044 & 2.666417 & 0.111996 \\ 9.8 & 0.427345166 & 2.751886 & 0.108743\end{array}$
$\begin{array}{cc} & \mathbf{f}(\mathbf{x}) \\ 0 & 1.00 \mathrm{E}-1\end{array}$

$\begin{array}{llll}7.600131 & 1.52016 \mathrm{E}-06 & 1.52016 \mathrm{E}-06 & 1.88 \mathrm{E}-09\end{array}$ $\begin{array}{lllll}0.000712 & 0.000170153 & 0.000170153 \quad 2.1 E-07\end{array}$ $\begin{array}{lllll}0.002416 & 0.0006534 & 0.0006534 & 8.06 \mathrm{E}-07\end{array}$ $\begin{array}{lllll}0.006322 & 0.001917715 & 0.001917715 & 2.37 \mathrm{E}-06 \\ 0.014023 & 0.00472236 & 0.0047236 & 5.83 \mathrm{E}\end{array}$ $\begin{array}{llll}0.014023 & 0.00472236 & 0.00472236 & 5.83 \mathrm{E}-06\end{array}$ $\begin{array}{lllll}0.027742 & 0.01027074 & 0.01027074 & 1.27 E-05\end{array}$ $\begin{array}{lllll}0.050439 & 0.020358496 & 0.020358496 & 2.51 \mathrm{E}-05\end{array}$ $\begin{array}{lllll}0.085932 & 0.037544925 & 0.037544925 & 4.63 \mathrm{E}-05\end{array}$ $\begin{array}{lllll}0.139012 & 0.065347269 & 0.065347269 & 8.06 \mathrm{E}-05\end{array}$ $\begin{array}{llll}0.215546 & 0.108456549 & 0.108456549 & 0.000134\end{array}$ $\begin{array}{lllll}0.32258 & 0.172972521 & 0.172972521 & 0.000213\end{array}$ $\begin{array}{lllll}0.468409 & 0.266654251 & 0.266654251 & 0.000329\end{array}$ $\begin{array}{llllll}0.662637 & 0.399181599 & 0.399181599 & 0.000493\end{array}$ $\begin{array}{lllll}0.916201 & 0.582421716 & 0.582421716 & 0.000719\end{array}$ $\begin{array}{llllll}1.241359 & 0.830693469 & 0.830693469 & 0.001025\end{array}$ $\begin{array}{llllll}1.651641 & 1.16102164 & 1.16102164 & 0.001433\end{array}$ $\begin{array}{llllll}2.161751 & 1.593371758 & 1.593371758 & 0.001966\end{array}$ $\begin{array}{lllll}2.78742 & 2.15085568 & 2.15085568 & 0.002654\end{array}$ $\begin{array}{lllll}3.545209 & 2.859897482 & 2.859897482 & 0.003529\end{array}$ $\begin{array}{lllll}4.452258 & 3.750349012 & 3.750349012 & 0.004628\end{array}$ $\begin{array}{llllll}5.525978 & 4.855544552 & 4.855544552 & 0.005991\end{array}$

$\begin{array}{lllll}6.7837 & 6.212284524 & 6.212284524 & 0.007665\end{array}$ $\begin{array}{lllll}8.242273 & 7.860739072 & 7.860739072 & 0.009699\end{array}$ $\begin{array}{llllll}9.917623 & 9.844263632 & 9.844263632 & 0.012147\end{array}$ $\begin{array}{lllll}11.82428 & 12.20912034 & 12.20912034 & 0.015065\end{array}$ $\begin{array}{lllll}13.9749 & 15.00410119 & 15.00410119 & 0.018513\end{array}$ $\begin{array}{lllll}16.37975 & 18.28005139 & 18.28005139 & 0.022556\end{array}$ $\begin{array}{lllll}19.04621 & 22.08929387 & 22.08929387 & 0.027256\end{array}$ $\begin{array}{lllll}21.97833 & 26.48495925 & 26.48495925 & 0.03268\end{array}$ $\begin{array}{llllll}25.17634 & 31.52022823 & 31.52022823 & 0.038893\end{array}$ $\begin{array}{lllll}28.63634 & 37.24749677 & 37.24749677 & 0.04596\end{array}$ $\begin{array}{llllll}32.3499 & 43.7174774 & 43.7174774 & 0.053943\end{array}$ $\begin{array}{llll}36.30388 & 50.97825281 & 50.97825281 & 0.062902\end{array}$ $\begin{array}{llllll}40.48024 & 59.0743004 \quad 59.0743004 \quad 0.072891\end{array}$ $\begin{array}{lllll}44.85604 & 68.0455088 \quad 68.0455088 \quad 0.083961\end{array}$ $\begin{array}{lllll}49.4035 & 77.92620862 & 77.02620862 & 0.0896153\end{array}$ $\begin{array}{lllll}49.4035 & 77.92620862 & 77.02620862 & 0.096153\end{array}$ $\begin{array}{lllll}54.03014 & 88.7420114 & 88.74424114 & 0.109501\end{array}$

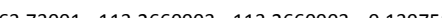
$\begin{array}{lllll}68.730837 & 113.260503 & 113.26057030 & 0.139758\end{array}$ $\begin{array}{llllll}73.43749 & 141.6732627 & 141.6732627 & 0.17481\end{array}$ $\begin{array}{llllll}73.43749 & 141.6732627 & 141.6732627 & 0.17481\end{array}$ $\begin{array}{rlll}78.1985 & 157.3129635 & 157.3129635 & 0.194108 \\ 82.83136 & 173.8792353 & 1738792353 & 0.214549\end{array}$ $\begin{array}{llllllll}82.83136 & 173.8792353 & 173.8792353 & 0.214549\end{array}$ $\begin{array}{llllll}87.28566 & 191.3363664 & 191.3363664 & 0.236089\end{array}$ $\begin{array}{llllll}91.51155 & 209.6386768 & 209.6386768 & 0.258672\end{array}$ $\begin{array}{lllll}95.46068 & 228.7308119 & 228.7308119 & 0.28223\end{array}$ $\begin{array}{lllll}99.08703 & 248.5482175 & 248.5482175 & 0.306682\end{array}$ $\begin{array}{lllll}102.3478 & 269.0177873 & 269.0177873 & 0.33194\end{array}$ 


\section{Appendix C2 - f}

$\begin{array}{lllll}\text { dpi } & & \text { Top } & \text { Bottom } & \mathbf{p}(\mathbf{x}) \\ & 10 & 0.413439875 & 2.834574 & 0.105504\end{array}$ $\begin{array}{llll}10 & 0.413439875 & 2.834574 & 0.1\end{array}$ $\begin{array}{lllll}10.2 & 0.398549632 & 2.914283 & 0.101415 \\ 10.4 & 0.38281473 & 2.990846 & 0.097412\end{array}$ $\begin{array}{lllll}10.4 & 0.38281473 & 2.990846 & 0.097412 \\ 10.6 & 0.3663786 & 3.064122 & 0.093229\end{array}$ $\begin{array}{lllll}10.6 & 0.36385767 & 3.013392 & 0.093229\end{array}$ $\begin{array}{llllll}11 & 0.349385767 & 3.133909 & 0.088905\end{array}$ $\begin{array}{lllll}11 & 0.33197986 & 3.200395 & 0.084476\end{array}$ $\begin{array}{lllll}11.2 & 0.314301733 & 3.263256 & 0.079978 \\ 11.4 & 0.29487722 & 3.322553 & 0.075445\end{array}$ $\begin{array}{lllll}11.4 & 0.296487722 & 3.322553 & 0.075445 \\ 11.6 & 0.278668065 & 3.378287 & 0.07091\end{array}$ $\begin{array}{llllll}11.6 & 0.278698055 & 3.378287 & 0.07091\end{array}$ $\begin{array}{llllll}12 & 0.243494124 & 3.479179 & 0.06196\end{array}$ $\begin{array}{lllll}12 & 0.243494124 & 3.479179 & 0.06196\end{array}$ $\begin{array}{llllll}12.2 & 0.22635832 & 3.52445 & 0.057599 \\ 12.4 & 0.2096521 & 3.565381 & 0.053348\end{array}$ $\begin{array}{lllllllllllll}12.4 & 12.2 & 0.209521 & 3.566381 & 0.053348\end{array}$ $\begin{array}{lllllllllllllllll}12.4 & 0.193458526 & 3.605072 & 0.049228\end{array}$ $\begin{array}{lllll}13 & 0.162885151 & 3.673219 & 0.045256\end{array}$ $\begin{array}{lllll}13 & 0.162885151 & 3.673219 & 0.041448\end{array}$ $\begin{array}{lllllll}13.2 & 0.148614931 & 3.702942 & 0.037817\end{array}$ $\begin{array}{llllll}13.4 & 0.135076864 & 3.729558 & 0.034372\end{array}$ $\begin{array}{llllll}13.6 & 0.122298474 & 3.754417 & 0.03112\end{array}$ $\begin{array}{lllll}14.8 & 0.110297238 & 3.776477 & 0.028066\end{array}$ $\begin{array}{lllll}14.2 & 0.09868126 & 3.796293 & 0.025212 \\ 14.2 & 0.088650033 & 3.814023 & 0.022558\end{array}$ $\begin{array}{lllll}14.2 & 0.088650033 & 3.814023 & 0.022558 \\ 14.4 & 0.07899527 & 3.829822 & 0.020101\end{array}$ $\begin{array}{lllll}14.4 & 0.079101782 & 3.843843 & 0.017838\end{array}$ $\begin{array}{lllll}14.6 & 0.070101782 & 3.843843 & 0.017838 \\ 14.8 & 0.061948374 & 3.856232 & 0.015763\end{array}$ $\begin{array}{rrrrr}15 & 0.05450876 & 3.867134 & 0.01387\end{array}$ $\begin{array}{lllll}15.2 & 0.047752445 & 3.876684 & 0.012151\end{array}$ $\begin{array}{lllllll}15.4 & 0.041645597 & 3.885014 & 0.010597 \\ 15.6 & 0.03151863 & 3.892244 & 0.009199\end{array}$ $\begin{array}{lllllll}15.6 & 0.036151863 & 3.892244 & 0.009199\end{array}$ $\begin{array}{lllll}16 & 0.026350272 & 3.903861 \quad 0.006832\end{array}$ $\begin{array}{llllll}16 & 0.026850272 & 3.903861 & 0.006832\end{array}$ $\begin{array}{lllllll}16.2 & 0.022963707 & 3.908453 & 0.005843\end{array}$ $\begin{array}{llllll}16.4 & 0.019534043 & 3.91236 & 0.004971\end{array}$ $\begin{array}{llllll}16.6 & 0.016522529 & 3.915665 & 0.004204\end{array}$ $\begin{array}{llllll}16.8 & 0.013891485 & 3.918443 & 0.003535 \\ 17 & 0.01604641 & 3.920764 & 0.002953\end{array}$ $\begin{array}{llllll}17 & 0.011604641 & 3.920764 & 0.002953\end{array}$ $\begin{array}{llllll}17.2 & 0.00962742 & 3.922689 & 0.00245 \\ 17.4 & 0.007927148 & 3.924275 & 0.002017\end{array}$ $\begin{array}{lllll}17.4 & 0.007927148 & 3.924275 & 0.002017\end{array}$ $\begin{array}{lllllll}17.6 & 0.006473204 & 3.925569 & 0.001647\end{array}$ $\begin{array}{llllll}17.8 & 0.005237115 & 3.926617 & 0.001333\end{array}$ $\begin{array}{lllll}18 & 0.004192609 & 3.927455 & 0.001067\end{array}$ $\begin{array}{lllllll}18.2 & 0.00331562 & 3.928119 & 0.000844\end{array}$ $\begin{array}{llllll}18.4 & 0.002584252 & 3.928635 & 0.000658\end{array}$ $\begin{array}{lllllll}18.6 & 0.001978727 & 3.929031 & 0.000504\end{array}$ $\begin{array}{lllll}18.8 & 0.001481295 & 3.929327 & 0.000377\end{array}$ $\begin{array}{lllll}19 & 0.001076134 & 3.929543 & 0.000274\end{array}$ $\begin{array}{llllll}19.2 & 0.000749228 & 3.929692 & 0.000191\end{array}$ $\begin{array}{llllllll}19.4 & 0.000488248 & 3.92979 & 0.000124\end{array}$ $\begin{array}{lllll}19.6 & 0.000282411 & 3.929847 \quad 7.19 E-05\end{array}$ $\begin{array}{cccc}19.8 & 0.000122356 & 3.929871 & 3.11 \mathrm{E}-05 \\ 20 & 2.10699 \mathrm{E}-17 & 3.929871 & 5.36 \mathrm{E}-18\end{array}$ $\begin{array}{ccccc}\text { dinteg } & \text { Top } & \text { Bottom } & \mathbf{f}(\mathbf{x}) \\ 105.2044 & 290.0586747 & 290.0586747 & 0.357902\end{array}$ $\begin{array}{lllll}105.2044 & 290.0586747 & 290.0586747 & 0.357902\end{array}$ $\begin{array}{llllll}107.6229 & 311.5832514 & 311.5832514 & 0.384461\end{array}$ $\begin{array}{llllll}109.5747 & 333.4981946 & 33.58981946 & 0.411502\end{array}$ $\begin{array}{lllll}1111.094 & 3781046562 & 378.1046562 & 0.436541\end{array}$ $\begin{array}{lllll}11.12939 & 378.1046562 & 378.1046562 & 0.436541\end{array}$ $\begin{array}{llllll}112.4376 & 40.5921722 & 300.5921722 & 0.494289\end{array}$ $\begin{array}{lllll}112.4368 & 400.5921722 & 400.5921722 & 0.494289\end{array}$ $\begin{array}{lllll}111.7746 & 425.4196432 & 425.4196432 & 0.549601 \\ 110.6835 & 467.5563423 & 467.5563423 & 0.576915\end{array}$ $\begin{array}{lllll}111.7746 & 445.4196432 & 445.4196432 & 0.549601\end{array}$ $\begin{array}{llll}107.0666 & 510.7909682 & 510.7909682 & 0.630262\end{array}$

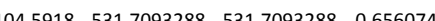
$\begin{array}{lllllll}10.79152 & 552.0523741 & 552.05323741 & 0.65807475\end{array}$ \begin{tabular}{lllllll}
\hline & 101.7132 & 552.0723741 & 552.0523741 & 0.681175 \\
\hline
\end{tabular} $\begin{array}{llll}98.4792 & 571.74715715 & 571.7471571 & 0.705476\end{array}$

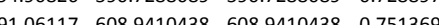
$\begin{array}{lll}86.0773 & 6263365043 \quad 6263365043 & 0.772834\end{array}$ $86.9773 \quad 626.337504026 .33650430 .772834$ $\begin{array}{lllllll}82.7022 & 642.87 & 86943 & 642.8769443 & 0.793243\end{array}$ \begin{tabular}{lllllll}
78.28156 & 658.5332558 & 658.5332558 & 0.812561 \\
\hline
\end{tabular} $\begin{array}{lllllll}73.7606 & 673.285347 & 673.285347 & 0.830764\end{array}$ $\begin{array}{llllll}69.18267 & 687.1218811 & 687.1218811 & 0.837836 \\ 64.59005 & 700.0398915 & 700.0398915 & 0.863776\end{array}$ $\begin{array}{llllll}64.59005 & 70.039895 & 700.0398915 & 0.863776\end{array}$ $\begin{array}{llll}60.02197 & 712.0442859 & 712.0442859 & 0.838588\end{array}$ $\begin{array}{lllll}5 & 50.51487 & 723.1472598 & 723.1472598 & 0.892288\end{array}$

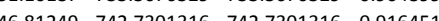
$\begin{array}{lllll}46.81249 & 742.7301316 & 742.7301316 & 0.916451 \\ 42.6725 & 751.2646313 & 751.2646313 & 0.926982\end{array}$ 38.6725751 .2646313751 .26463130 .926982 $\begin{array}{llllll}38.70374 & 75.0053736 & 759.0053796 & 0.936533\end{array}$ $\begin{array}{llllll}34.92418 & 765.9002148 & 765.9002148 & 0.945152\end{array}$ $\begin{array}{llllllll}31.34791 & 772.259765 & 772.2597965 & 0.952888\end{array}$ $\begin{array}{lllllll}27.98532 & 777.8568611 & 77.8568611 & 0.959794\end{array}$ $\begin{array}{lllll}24.84327 & 782.8255148 & 782.8255148 & 0.965925 \\ 21.92529 & 787.210573 & 787.210573 & 0.971335\end{array}$ $\begin{array}{llllll}24.92529 & 787.210573 & 787.210573 & 0.971335 \\ 19.23191 & 791.0569557 & 791.0569557 & 0.976081\end{array}$ $\begin{array}{lllllll}19.23191 & 791.0569557 & 791.0569557 & 0.976081\end{array}$ \begin{tabular}{llllll}
16.76093 & 794.4091424 & 794.4091424 & 0.980218 \\
\hline
\end{tabular} $\begin{array}{lllllll}14.50775 & 797.310693 & 797.310693 & 0.983798\end{array}$ $\begin{array}{lllllll}12.46571 & 799.8038347 & 799.8038347 & 0.986874\end{array}$ $\begin{array}{lllll}12.46571 & 9.62641 & 801.929116 & 801.929116 & 0.989496\end{array}$ $\begin{array}{llllll}8.980055 & 803.7251269 & 803.7251269 & 0.991713 \\ 7.515776 & 805.2282821 & 805.2282821 & 0.993567\end{array}$ $\begin{array}{lllll}7.515776 & 805.2282821 & 805.2282821 & 0.993567\end{array}$ \begin{tabular}{lllllll}
7.215776 & 805.2282821 & 805.2282821 & 0.993567 \\
5.086284 & 806.4726638 & 806.4726638 & 0.995103 \\
\hline
\end{tabular} $\begin{array}{llllll}5.086284 & 807.4899205 & 807.4899205 & 0.996358\end{array}$ $\begin{array}{llllll}4.096472 & 808.309215 & 808.309215 & 0.997369\end{array}$ $\begin{array}{lllllll}3.240011 & 808.9572171 & 808.9572171 & 0.998168 \\ 2.504592 & 809.4581354 & 809.4581354 & 0.998786\end{array}$ $\begin{array}{lllllll}2.504592 & 809.4581354 & 809.4581354 & 0.998786\end{array}$ $\begin{array}{lllll}1.87823 & 809.8337814 & 809.8337814 & 0.99925 \\ 1.34936 & 810.1036607 & 810.1036607 & 0.999583\end{array}$ $\begin{array}{lllll}1.349396 & 810.1036607 & 810.1036607 & 0.999583 \\ 0.907125 & 810.2850856 & 810.2850856 & 0.999807\end{array}$ $\begin{array}{lllll}0.907125 & 810.2850856 & 810.2850856 & 0.999807\end{array}$ $\begin{array}{lllllll}0.541093 & 810.3933042 & 810.3933042 & 0.99994\end{array}$ $\begin{array}{llll}0.24168 & 810.4416403 & 810.4416403\end{array}$ 
Appendix C2 - dpi_bar

dpi $\begin{array}{ccc}\text { Top Bottom } & \mathbf{p}(\mathbf{x})\end{array}$

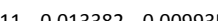
$\begin{array}{lllll}157 & 0.04704 & 0.0232 & 0.012011\end{array}$ $\begin{array}{lllll}1.76 & 0.055934 & 0.032947 & 0.014282\end{array}$ $\begin{array}{llll}1.95 & 0.065609 & 0.045413 & 0.01675\end{array}$ $\begin{array}{lllll}2.14 & 0.07608 & 0.059868 & 0.01942\end{array}$ $\begin{array}{lllll}2.33 & 0.087349 & 0.076464 & 0.022304\end{array}$ $\begin{array}{lllll}2.52 & 0.099416 & 0.095353 & 0.025385\end{array}$ $\begin{array}{llllll}2.71 & 0.112269 & 0.116684 & 0.028666\end{array}$ $\begin{array}{lllll}2.9 & 0.125888 & 0.140603 & 0.032144\end{array}$ $\begin{array}{lllll}3.09 & 0.140243 & 0.167249 & 0.035809\end{array}$ $\begin{array}{llllll}3.28 & 0.155297 & 0.196756 & 0.039653\end{array}$ $\begin{array}{lllll}3.47 & 0.170999 & 0.229245 & 0.04366\end{array}$ $\begin{array}{lllll}3.66 & 0.18729 & 0.264831 & 0.047822\end{array}$ $\begin{array}{lllll}3.85 & 0.204102 & 0.30361 & 0.05211\end{array}$ $\begin{array}{lllll}4.04 & 0.221356 & 0.345668 & 0.0565\end{array}$ $\begin{array}{lllll}4.23 & 0.238962 & 0.39107 & 0.06101\end{array}$ $\begin{array}{lllll}4.42 & 0.256824 & 0.439867 & 0.065577\end{array}$ $\begin{array}{lllll}4.61 & 0.274837 & 0.492086 & 0.070176\end{array}$ $\begin{array}{lllll}4.8 & 0.292888 & 0.547735 & 0.074785\end{array}$ $\begin{array}{lllll}4.99 & 0.310859 & 0.606798 & 0.079374\end{array}$ $\begin{array}{lllll}5.18 & 0.328625 & 0.669237 & 0.08391\end{array}$ $\begin{array}{lllll}5.37 & 0.346061 & 0.734988 & 0.088362\end{array}$ $\begin{array}{lllll}5.56 & 0.363037 & 0.803965 & 0.092697\end{array}$ $\begin{array}{lllll}5.75 & 0.379423 & 0.876056 & 0.09688\end{array}$ $\begin{array}{lllll}5.94 & 0.395092 & 0.951123 & 0.100882\end{array}$ $\begin{array}{lllll}6.13 & 0.409917 & 1.029007 & 0.104667\end{array}$ $\begin{array}{lllll}6.32 & 0.423776 & 1.109525 & 0.108206\end{array}$ $\begin{array}{lllll}6.51 & 0.436556 & 1.19247 & 0.111469\end{array}$ $\begin{array}{rrrrr}6.7 & 0.448147 & 1.277618 & 0.114429\end{array}$ $\begin{array}{rrrrr}6.7 & 0.448147 & 1.277618 & 0.114429 \\ 6.89 & 0.458453 & 1.364724 & 0.11706\end{array}$ $\begin{array}{llllll}7.08 & 0.467384 & 1.453527 & 0.119341\end{array}$ $\begin{array}{lllll}7.27 & 0.474866 & 1.543752 & 0.121251\end{array}$ $\begin{array}{lllll}7.27 & 0.474866 & 1.543752 & 0.121251\end{array}$ $\begin{array}{lllll}7.65 & 0.48524 & 1.727306 & 0.1239\end{array}$ $\begin{array}{lllll}7.46 & 0.480834 & 1.63511 & 0.122775 \\ 7.85 & 0.48524 & 1.727306 & 0.1239\end{array}$ $\begin{array}{llll}7.84 & 0.48805 & 1.820036 & 0.124617\end{array}$ $\begin{array}{lllll}8.03 & 0.489242 & 1.912992 & 0.124922\end{array}$ $\begin{array}{lllll}8.22 & 0.488813 & 2.005866 & 0.124812\end{array}$ $\begin{array}{lllll}8.6 & 0.483149 & 2.190151 & 0.123366\end{array}$ $\begin{array}{llll}8.69 & 0.483149 & 2.190151 & 0.123346\end{array}$ $\begin{array}{lll}8.79 & 0.477981 & 2.280968 \quad 0.122046\end{array}$ $\begin{array}{lllll}8.98 & 0.471322 & 2.370519 & 0.120346\end{array}$ $\begin{array}{lllll}9.17 & 0.46324 & 2.458534 & 0.118283\end{array}$ $\begin{array}{lllll}9.36 & 0.453815 & 2.544759 & 0.115876\end{array}$ $\begin{array}{lllll}9.55 & 0.443137 & 2.628955 & 0.113149\end{array}$ $\begin{array}{llllllll}9.74 & 0.431304 & 2.710903 & 0.110128\end{array}$ $\begin{array}{lllll}9.93 & 0.418426 & 2.790404 & 0.1068\end{array}$ $\begin{array}{llll}10.12 & 0.404615 & 2.867281 & 0.103313 \\ 10.31 & 0.389991 & 2.941379 & 0.099579\end{array}$

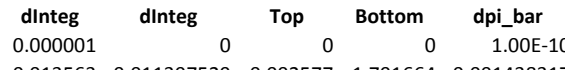

$\begin{array}{llllll}0.013563 & 0.011397529 & 0.002577 & 1.791664 & 0.001438317\end{array}$ $\begin{array}{llllll}0.026111 & 0.018920889 & 0.007538 & 3.63557 & 0.002073413\end{array}$ $\begin{array}{llllll}0.046482 & 0.029606216 & 0.01637 & 5.525359 & 0.002962626\end{array}$ $\begin{array}{lllll}0.077862 & 0.044239759 & 0.031163 & 7.454212 & 0.004180636\end{array}$ $\begin{array}{llllll}0.124218 & 0.063701493 & 0.054765 & 9.41492 & 0.005816805\end{array}$ $\begin{array}{llllll}0.190381 & 0.088963167 & 0.090937 & 11.3956 & 0.00798697\end{array}$ $\begin{array}{llllll}0.282125 & 0.121083857 & 0.144541 & 13.4016 & 0.010785352\end{array}$ $\begin{array}{lllllll}0.406231 & 0.161202811 & 0.221725 & 15.41195 & 0.014386556 \\ 0.570535 & 0.210529386 & 0.330126 & 17.4230 & 0.018947652\end{array}$ $\begin{array}{lllllll}0.570535 & 0.210529386 & 0.330126 & 17.42308 & 0.018947652 \\ 0.783957 & 0.270329972 & 0.479078 & 19.427 & 0.0246307\end{array}$ $\begin{array}{rrrrrr}0.783957 & 0.270329972 & 0.479078 & 19.4271 & 0.024660307\end{array}$ $\begin{array}{llllll}1.056508 & 0.34191184 & 0.679815 & 21.41625 & 0.031742942\end{array}$ $\begin{array}{llllll}1.399261 & 0.426603961 & 0.945674 & 23.38297 & 0.04044286\end{array}$ $\begin{array}{llllll}1.8243 & 0.525734911 & 1.292291 & 25.32 & 0.051038364\end{array}$ $\begin{array}{lllllll}2.344626 & 0.640608073 & 1.73777 & 27.22045 & 0.063840622\end{array}$ $\begin{array}{lllllll}2.974027 & 0.772474467 & 2.302835 & 29.07784 & 0.079195535\end{array}$ $\begin{array}{lllllll}3.726915 & 0.92250361 & 3.010949 & 30.88621 & 0.097485209\end{array}$ $\begin{array}{llllll}4.618115 & 1.091752929 & 3.888391 & 32.64013 & 0.119129152\end{array}$ $\begin{array}{lllllll}5.662623 & 1.281136324 & 4.964289 & 34.33473 & 0.144585044\end{array}$ $\begin{array}{lllllll}6.87532 & 1.491392554 & 6.2706 & 35.96579 & 0.174348993\end{array}$ $\begin{array}{lllllll}8.27066 & 1.723054218 & 7.842025 & 37.5297 & 0.208955176\end{array}$ $\begin{array}{llllll}9.862326 & 1.976418091 & 9.715867 & 39.0235 & 0.248974785\end{array}$ $\begin{array}{lllllll}11.66286 & 2.251517672 & 11.93181 & 40.44488 & 0.295014149\end{array}$ $\begin{array}{lllllll}13.68329 & 2.548098761 & 14.53164 & 41.79216 & 0.347711976\end{array}$ $\begin{array}{lllllll}15.93273 & 2.865598868 & 17.55885 & 43.06432 & 0.407735594\end{array}$ $\begin{array}{lllllll}18.418 & 3.203131248 & 21.05828 & 44.26089 & 0.475776152\end{array}$ $\begin{array}{lllllll}21.14328 & 3.559474232 & 25.0755 & 45.38201 & 0.552542705\end{array}$ $\begin{array}{lllllll}24.1097 & 3.933066489 & 29.65634 & 46.42834 & 0.638755165\end{array}$ $\begin{array}{lllllll}27.31509 & 4.322008678 & 34.84621 & 47.40103 & 0.735136115\end{array}$ $\begin{array}{lllllll}30.75371 & 4.724071863 & 40.68941 & 48.30169 & 0.842401517\end{array}$ $\begin{array}{lllllll}34.41598 & 5.136712866 & 47.22845 & 49.13231 & 0.961250384\end{array}$ $\begin{array}{lllllll}38.2884 & 5.557096587 & 54.50324 & 49.89524 & 1.092353526\end{array}$ $\begin{array}{llllll}42.35345 & 5.982125132 & 62.5504 & 50.59314 & 1.23634152\end{array}$ $\begin{array}{llllll}46.5896 & 6.408473408 & 71.40242 & 51.22889 & 1.393792102\end{array}$ $\begin{array}{rrrrrr}46.5896 & 6.408473408 & 71.40242 & 51.22889 & 1.393792102 \\ 50.97142 & 6.832630675 & 81.08699 & 51.80559 & 1.565217216\end{array}$ $\begin{array}{lllllll}55.46975 & 7.250947341 & 91.62625 & 52.32646 & 1.751049993\end{array}$ $\begin{array}{lllllll}60.05194 & 7.659686183 & 103.0361 & 52.79485 & 1.951631961\end{array}$ $\begin{array}{lllllll}04.68227 & 8.055076972 & 115.3257 & 53.21415 & 2.167200824\end{array}$ $\begin{array}{llllll}69.632233 & 8.033373427 & 128.497 & 53.21475 & 2.167200824\end{array}$

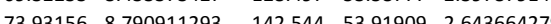
$\begin{array}{lll}78.46783 & 9.124166304 \quad 157.4529 & 54.21147 \quad 2.904410907\end{array}$ $8288804 \quad 9.42981076 \quad 173.201654 .46815 \quad 3.179869451$ $82.88804 \quad 9.42481046173 .201654 .468153 .17989151$ $\begin{array}{llllll}87.14881 & 9.704767487 & 189.7599 & 54.69228 & 3.469591689\end{array}$ $\begin{array}{llllll}91.2072 & 9.946259448 & 207.0892 & 54.88688 & 3.773018759\end{array}$ $\begin{array}{lllll}95.02139 & 10.15185742 & 225.143 & 55.05484 & 4.089436756\end{array}$ $\begin{array}{llllll}101.7596 & 10.44760202 & 263.2024 & 55.32156 & 4.757681978\end{array}$ $\begin{array}{llllll}104.6119 & 10.53493494 & 283.0787 & 55.42526 & 5.107394036\end{array}$ $\begin{array}{rrrrr}107.0776 & 10.58078622 & 303.4234 & 55.5122 & 5.465886468 \\ 109.1303 & 10.58489691 & 324.1581 & 55.58442 & 5.831817026\end{array}$ 


\section{Appendix C2 - dpi_bar}

$\begin{array}{cccc}\text { dpi } & \text { Top } & \text { Bottom } & \mathbf{p}(\mathbf{x}) \\ 10.5 & 0.374675 & 3.012567 & 0.095669\end{array}$ $\begin{array}{lllll}10.5 & 0.374675 & 3.012567 & 0.09566\end{array}$ $\begin{array}{lllll}10.69 & 0.374675 & 3.012567 & 0.09569\end{array}$ $\begin{array}{lllll}10.88 & 0.342465 & 3.145806 & 0.087444\end{array}$ $\begin{array}{llllll}11.07 & 0.325816 & 3.207711 & 0.083193\end{array}$ $\begin{array}{lllll}11.26 & 0.308966 & 3.20711 & 0.083193 & 0.07889\end{array}$ $\begin{array}{rrrrr}11.45 & 0.292028 & 3.3219 & 0.07456 \\ 11.64 & 0.275114 & 3.374172 & 0.070247\end{array}$ $\begin{array}{llll}11.64 & 0.275114 & 3.374172 & 0.070247\end{array}$ $\begin{array}{lllll}11.83 & 0.258327 & 3.423254 & 0.065961\end{array}$ $\begin{array}{llllll}12.02 & 0.241764 & 3.469189 & 0.061731\end{array}$ $\begin{array}{llll}12.4 & 0.2250652 & 3.51251871 & 0.05352\end{array}$ $\begin{array}{llllll}12.4 & 0.209652 & 3.551871 & 0.053532\end{array}$ $\begin{array}{llll}12.59 & 0.194255 & 3.58871 & 0.05352\end{array}$ $\begin{array}{lllll}12.78 & 0.179382 & 3.622862 & 0.045803\end{array}$ $\begin{array}{llllll}12.97 & 0.165087 & 3.654228 & 0.042153\end{array}$ $\begin{array}{llllll}13.16 & 0.151411 & 3.682986 & 0.038651\end{array}$ $\begin{array}{lllll}3.35 & 0.138391 & 3.709291 & 0.035336\end{array}$ $\begin{array}{llllll}13.54 & 0.126051 & 3.73324 & 0.032186\end{array}$ $\begin{array}{llllll}13.73 & 0.114409 & 3.754978 & 0.029213\end{array}$ $\begin{array}{lllll}13.92 & 0.103473 & 3.774638 & 0.026421\end{array}$ $\begin{array}{lllll}14.11 & 0.093247 & 3.792355 & 0.02381\end{array}$ $\begin{array}{llllll}14.3 & 0.083726 & 3.808263 & 0.021379\end{array}$ $\begin{array}{llllll}14.49 & 0.0749 & 3.822494 & 0.019125\end{array}$ $\begin{array}{llllll}14.68 & 0.066753 & 3.835177 & 0.017045 \\ 14.87 & 0.059265 & 3.846437 & 0.015133\end{array}$ $\begin{array}{lllll}14.87 & 0.059265 & 3.83643 & 0.015133\end{array}$ $\begin{array}{llllll}15.06 & 0.052412 & 3.856395 & 0.013383\end{array}$ $\begin{array}{lllll}15.25 & 0.046166 & 3.865167 & 0.011788\end{array}$ $\begin{array}{lllll}15.44 & 0.040499 & 3.872862 & 0.010341\end{array}$ $\begin{array}{lllll}15.63 & 0.035378 & 3.879584 & 0.009033\end{array}$ $\begin{array}{lllll}16.82 & 0.0307714 & 3.885430 & 0.007857\end{array}$ 16.20 .02296438989560 .005863 $\begin{array}{lllll}16.2 & 0.022964 & 3.894856 & 0.005863\end{array}$ $\begin{array}{llllll}16.39 & 0.019695 & 3.898598 & 0.005029\end{array}$ $\begin{array}{lllll}16.58 & 0.016806 & 3.901791 & 0.004291\end{array}$ $\begin{array}{lllll}16.77 & 0.014263 & 3.904501 & 0.003642\end{array}$ $\begin{array}{lllll}16.96 & 0.012036 & 3.906788 & 0.003073\end{array}$ $\begin{array}{llllll}17.15 & 0.010095 & 3.908706 & 0.002578\end{array}$ $\begin{array}{lllll}17.34 & 0.00841 & 3.910304 & 0.002147 \\ 17.53 & 0.006956 & 3.911625 & 0.001776\end{array}$ $\begin{array}{lllll}17.53 & 0.006956 & 3.911625 & 0.001776\end{array}$ $\begin{array}{llllll}17.72 & 0.005707 & 3.91271 & 0.001457\end{array}$ $\begin{array}{lllll}17.91 & 0.004641 & 3.913591 & 0.001185\end{array}$ $\begin{array}{lllll}18.1 & 0.003735 & 3.914301 & 0.000954\end{array}$ $\begin{array}{lllll}18.29 & 0.00297 & 3.914865 & 0.000758\end{array}$ $\begin{array}{lllll}18.48 & 0.002328 & 3.915308 & 0.000594\end{array}$ $\begin{array}{lllll}18.67 & 0.001793 & 3.915648 & 0.000458\end{array}$ $\begin{array}{lllll}18.86 & 0.001351 & 3.915905 & 0.000345\end{array}$ $\begin{array}{llllll}19.05 & 0.000988 & 3.916093 & 0.000252\end{array}$ $\begin{array}{lllll}19.24 & 0.000692 & 3.916224 & 0.000177\end{array}$ $\begin{array}{llllll}19.43 & 0.000454 & 3.91631 & 0.000116\end{array}$ $\begin{array}{lllll}19.62 & 0.000264 & 3.916361 & 6.75 \mathrm{E}-05\end{array}$

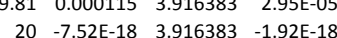

dinteg dinteg Top Bottom dpi_bar

$\begin{array}{llllll}111.9157 & 10.46919185 & 366.4643 & 55.69197 & 6.580200744\end{array}$

$\begin{array}{llllll}112.6206 & 10.35115672 & 387.8622 & 55.73054 & 6.959599757\end{array}$

$\begin{array}{llllll}112.8576 & 10.19490222 & 409.3052 & 55.76086 & 7.340366775 \\ 112.6264 & 10.00234896 & 430.7042 & 55.78417 & 7.720903569\end{array}$

$\begin{array}{llllll}112.6264 & 10.00234896 & 430.7042 & 55.7817 & 7.720903569\end{array}$

$\begin{array}{lllllll}111.9326 & 9.775769751 & 451.9714 & 55.80156 & 8.099619542 \\ 110.7866 & 9.517747631 & 473.0209 & 55.81399 & 8.474951509\end{array}$

$\begin{array}{lllllll}110.7866 & 9.517747631 & 473.0209 & 55.81399 & 8.474951509\end{array}$

$\begin{array}{llllll}109.2043 & 9.231129806 & 43.0209 & 5581399 & 8.474951509 \\ 107.2061 & 8.918978521 & 514.1388 & 55.82325 & 9.845382718\end{array}$

$\begin{array}{llllll}107.2061 & 8.918978521 & 514.1388 & 55.82725 & 9.209460727 \\ 104.817 & 8584519988 & 534.0541 & 55.82944 & 9.565813797\end{array}$ $\begin{array}{lllllll}104.817 & 8.584519988 & 534.0541 & 55.82944 & 9.565813797\end{array}$ $\begin{array}{lllllll}102.0655 & 8.231092516 & 553.4465 & 55.82944 & 9.913165536 \\ 98.98377 & 7.862094907 & 572.2534 & 55.82944 & 10.25002932\end{array}$ $\begin{array}{llllllll}98.98377 & 7.862094007 & 572.2534 & 55.8294 & 10.25002932\end{array}$ $\begin{array}{lllllll}95.60636 & 7.48093617 & 500.4186 & 55.82944 & 10.57539902\end{array}$ $\begin{array}{llllllll}91.97011 & 7.090587506 & 607.893 & 55.82944 & 10.88839374\end{array}$ $\begin{array}{lllllll}88.11327 & 6.655537416 & 624.6345 & 55.82944 & 11.18826279\end{array}$ $\begin{array}{llllllll}84.07497 & 6.297750609 & 640.6087 & 55.82944 & 11.4743886\end{array}$ $\begin{array}{llll}75.61102 & 5.506993153 \quad 670.1578 & 55.82944 & 11.74628752\end{array}$ $\begin{array}{lllllll}75.61102 & 5.506993153 & 670.1548 & 55.82944 & 12.00360861\end{array}$ $\begin{array}{lllllll}71.26245 & 5.11942914 & 683.698 & 55.8294 & 12.24613057\end{array}$ $\begin{array}{lllllll}66.88556 & 4.740294646 & 60.4029 & 55.82944 & 12.47375699\end{array}$ $\begin{array}{lllllll}52.51517 & 4.37168988 & 708.2808 & 55.82944 & 12.68650999\end{array}$ $\begin{array}{lllllll}58.18387 & 4.0134023 & 719.3357 & 55.82944 & 12.88452264\end{array}$ $\begin{array}{llllll}53.92172 & 3.673141369 & 729.5808 & 55.8294 & 13.06803022\end{array}$ $\begin{array}{lllllll}49.7459 & 3.346059255 & 739.0345 & 55.82944 & 13.23736061\end{array}$ $\begin{array}{llllll}45.71063 & 3.035234619 & 747.7195 & 55.82944 & 13.39292405\end{array}$ $\begin{array}{lllllll}41.80698 & 2.741441486 & 755.6628 & 55.82944 & 13.53520251 \\ 3806283 & 2.465209224 & 762.8947 & 5582944 & 13.66473878\end{array}$ $\begin{array}{lllllll}38.06283 & 2.465209224 & 762.8947 & 55.82944 & 13.66473878 \\ 34.49287 & 2.206837551 & 769.4484 & 55.82944 & 13.78212568\end{array}$ $\begin{array}{llllll}34.49287 & 2.206837551 & 769.4484 & 55.82944 & 13.78212568\end{array}$ $\begin{array}{lllllll}31.10867 & 1.966413567 & 775.359 & 55.82944 & 13.8879954\end{array}$ $\begin{array}{lllllll}24.92883 & 1.538816785 & 785.4001 & 55.82944 & 13.98300916\end{array}$ $\begin{array}{llllll}24.92883 & 1.538816785 & 785.4001 & 55.82944 & 14.06784752 \\ 22.14185 & 1350936327 & 789.607 & 55.82944 & 14.14320114\end{array}$ $\begin{array}{lllllll}22.14185 & 1.350936327 & 789.607 & 55.82944 & 14.14320114 \\ 19.55832 & 1.179633119 & 793.3231 & 55.82944 & 14.20976244\end{array}$ $\begin{array}{llllll}19.55832 & 1.179633119 & 793.3231 & 55.82944 & 14.20976244 \\ 17.17651 & 1.02424052 & 796.5867 & 55.82944 & 14.26821793\end{array}$ $\begin{array}{llllll}17.17651 & 1.02424052 & 796.5867 & 55.82944 & 14.26821793 \\ 14.99272 & 0.884004588 & 799.4353 & 55.82944 & 14.31924148\end{array}$ $\begin{array}{lllllll}14.99272 & 0.884004588 & 79.4353 & 55.82944 & 14.31924148\end{array}$ $\begin{array}{llllll}13.00148 & 0.758103993 & 801.9056 & 55.82944 & 14.36348842\end{array}$ $\begin{array}{rrrrrrr}11.1959 & 0.645668748 & 804.0328 & 55.82944 & 14.40159054 \\ 9.567831 & 0.545797522 & 805.8507 & 55.82944 & 14.434152\end{array}$ $\begin{array}{rrrrrr}9.567831 & 0.545797522 & 805.8507 & 55.82944 & 14.434152 \\ 8.1082 & 0.457573381 & 807.3912 & 55.82944 & 14.46174601\end{array}$ \begin{tabular}{lllllll}
8.1082 & 0.457573381 & 807.3912 & 55.82944 & 14.46174601 \\
\hline
\end{tabular} $\begin{array}{lllllll}6.807194 & 0.380077838 & 808.6846 & 55.82944 & 14.4849124\end{array}$ $\begin{array}{lllllll}5.654497 & 0.312403167 & 809.7589 & 55.82944 & 14.50415591\end{array}$ $\begin{array}{lllllll}4.639495 & 0.25366295 & 810.6404 & 55.82944 & 14.51994514\end{array}$ $\begin{array}{lllllll}3.751457 & 0.203000895 & 811.3532 & 55.82944 & 14.53271218\end{array}$ $\begin{array}{lllllll}2.979694 & 0.159597986 & 811.9194 & 55.82944 & 14.54285275 \\ 2.313708 & 0.122678046 & 812.359 & 55.82944 & 14.55072681\end{array}$ $\begin{array}{rrrrr}2.313708 & 0.122678046 & 812.359 & 55.82944 & 14.55072681\end{array}$ $\begin{array}{lllllll}1.7433 & 0.091511837 & 812.6902 & 55.82944 & 14.55665965\end{array}$ $\begin{array}{lllllll}1.258677 & 0.06541981 & 812.9293 & 55.82944 & 14.56094321 \\ 0.850522 & 0.043773657 & 813.0909 & 55.82944 & 14.56383772\end{array}$ $\begin{array}{llllll}0.850522 & 0.043773657 & 813.0909 & 55.82944 & 14.56383772 \\ 0.510057 & 0.025996801 & 813.1879 & 55.82944 & 14.56557356\end{array}$ $\begin{array}{lllllll}0.510057 & 0.025996801 & 813.1879 & 55.82944 & 14.56557356\end{array}$ $\begin{array}{llllll}0.229082 & 0.011563969 & 813.2314 & 55.82944 & 14.56635318 \\ -1.54 \mathrm{E}-14 & -7.6856 \mathrm{E}-16 & 813.2314 & 55.82944 & 14.56635318\end{array}$ 


\section{Appendix C2 - Alpha}

$\begin{array}{lllllll}5 & 6.28 \mathrm{E}+11 & 0.002427672 & 1.53 \mathrm{E}+09 & 1.75 \mathrm{E}+09 & 0.002781 & 6.28 \mathrm{E}+11\end{array}$

$\begin{array}{llllllll}10 & 6.28 \mathrm{E}+11 & 0.002185187 & 1.37 \mathrm{E}+09 & 3.27 \mathrm{E}+09 & 0.005209 & 6.28 \mathrm{E}+11\end{array}$

$\begin{array}{llllllll}15 & 6.28 \mathrm{E}+11 & 0.00200493 & 1.26 \mathrm{E}+09 & 4.65 \mathrm{E}+09 & 0.007394 & 6.28 \mathrm{E}+11\end{array}$

$\begin{array}{llllllll}20 & 6.28 \mathrm{E}+11 & 0.001863862 & 1.17 \mathrm{E}+09 & 5.91 \mathrm{E}+09 & 0.009399 & 6.28 \mathrm{E}+11\end{array}$

$\begin{array}{lllllll}25 & 6.28 \mathrm{E}+11 & 0.001749432 & 1.1 \mathrm{E}+09 & 7.08 \mathrm{E}+09 & 0.011263 & 6.28 \mathrm{E}+11\end{array}$

$\begin{array}{llllllll}30 & 6.28 \mathrm{E}+11 & 0.001654114 & 1.04 \mathrm{E}+09 & 8.18 \mathrm{E}+09 & 0.013012 & 6.28 \mathrm{E}+11\end{array}$

$\begin{array}{llllllll}35 & 6.28 \mathrm{E}+11 & 0.001573075 & 9.89 \mathrm{E}+08 & 9.22 \mathrm{E}+09 & 0.014666 & 6.28 \mathrm{E}+11\end{array}$

$\begin{array}{llllllll}40 & 6.28 \mathrm{E}+11 & 0.001503044 & 9.45 \mathrm{E}+08 & 1.02 \mathrm{E}+10 & 0.01624 & 6.28 \mathrm{E}+11\end{array}$

$\begin{array}{llllllll}45 & 6.28 \mathrm{E}+11 & 0.001441719 & 9.06 \mathrm{E}+08 & 1.11 \mathrm{E}+10 & 0.017743 & 6.28 \mathrm{E}+11\end{array}$

$\begin{array}{llllllll}50 & 6.28 \mathrm{E}+11 & 0.001387421 & 8.72 \mathrm{E}+08 & 1.21 \mathrm{E}+10 & 0.019184 & 6.28 \mathrm{E}+11\end{array}$

$\begin{array}{lllllll}55 & 6.28 \mathrm{E}+11 & 0.001338894 & 8.41 \mathrm{E}+08 & 1.29 \mathrm{E}+10 & 0.020572 & 6.28 \mathrm{E}+11\end{array}$

$\begin{array}{llllllll}60 & 6.29 \mathrm{E}+11 & 0.001295101 & 8.14 \mathrm{E}+08 & 1.38 \mathrm{E}+10 & 0.021911 & 6.28 \mathrm{E}+11\end{array}$

$\begin{array}{lllllll}65 & 6.29 \mathrm{E}+11 & 0.001254571 & 7.89 \mathrm{E}+08 & 1.46 \mathrm{E}+10 & 0.023206 & 6.28 \mathrm{E}+11\end{array}$

$\begin{array}{llllllll}70 & 6.3 \mathrm{E}+11 & 0.00121707 & 7.67 \mathrm{E}+08 & 1.54 \mathrm{E}+10 & 0.02446 & 6.28 \mathrm{E}+11\end{array}$

$\begin{array}{llllllll}75 & 6.32 \mathrm{E}+11 & 0.001181736 & 7.47 \mathrm{E}+08 & 1.61 \mathrm{E}+10 & 0.025677 & 6.29 \mathrm{E}+11\end{array}$

$\begin{array}{lllllll}80 & 6.35 \mathrm{E}+11 & 0.001149712 & 7.31 \mathrm{E}+08 & 1.69 \mathrm{E}+10 & 0.026859 & 6.29 \mathrm{E}+11\end{array}$

$\begin{array}{lllllll}85 & 6.4 \mathrm{E}+11 & 0.00111753 & 7.15 \mathrm{E}+08 & 1.76 \mathrm{E}+10 & 0.028009 & 6.29 \mathrm{E}+11\end{array}$

$\begin{array}{llllllll}90 & 6.43 \mathrm{E}+11 & 0.001085857 & 6.98 \mathrm{E}+08 & 1.83 \mathrm{E}+10 & 0.029126 & 6.29 \mathrm{E}+11\end{array}$

$\begin{array}{llllllll}95 & 6.5 \mathrm{E}+11 & 0.001058121 & 6.88 \mathrm{E}+08 & 1.9 \mathrm{E}+10 & 0.030212 & 6.3 \mathrm{E}+11\end{array}$

$\begin{array}{lllllll}100 & 6.55 \mathrm{E}+11 & 0.001031401 & 6.76 \mathrm{E}+08 & 1.97 \mathrm{E}+10 & 0.03127 & 6.31 \mathrm{E}+11\end{array}$

$\begin{array}{lllllll}105 & 6.67 \mathrm{E}+11 & 0.001000742 & 6.67 \mathrm{E}+08 & 2.04 \mathrm{E}+10 & 0.032302 & 6.31 \mathrm{E}+11\end{array}$

$\begin{array}{llllllll}110 & 6.74 \mathrm{E}+11 & 0.000975089 & 6.57 \mathrm{E}+08 & 2.11 \mathrm{E}+10 & 0.033302 & 6.32 \mathrm{E}+11\end{array}$

$\begin{array}{llllllll}115 & 6.82 \mathrm{E}+11 & 0.000950022 & 6.48 \mathrm{E}+08 & 2.17 \mathrm{E}+10 & 0.034278 & 6.34 \mathrm{E}+11\end{array}$

$\begin{array}{llllllll}120 & 7.02 \mathrm{E}+11 & 0.000917893 & 6.44 \mathrm{E}+08 & 2.24 \mathrm{E}+10 & 0.035228 & 6.35 \mathrm{E}+11\end{array}$

$\begin{array}{llllllll}125 & 7.14 \mathrm{E}+11 & 0.000892785 & 6.38 \mathrm{E}+08 & 2.3 \mathrm{E}+10 & 0.036145 & 6.37 \mathrm{E}+11\end{array}$

$\begin{array}{llllllll}130 & 7.28 \mathrm{E}+11 & 0.000867877 & 6.32 \mathrm{E}+08 & 2.36 \mathrm{E}+10 & 0.037038 & 6.38 \mathrm{E}+11\end{array}$

$\begin{array}{llllllll}135 & 7.43 \mathrm{E}+11 & 0.000843079 & 6.27 \mathrm{E}+08 & 2.43 \mathrm{E}+10 & 0.037906 & 6.41 \mathrm{E}+11\end{array}$

$\begin{array}{llllllll}140 & 7.61 \mathrm{E}+11 & 0.000818316 & 6.23 \mathrm{E}+08 & 2.49 \mathrm{E}+10 & 0.038749 & 6.43 \mathrm{E}+11\end{array}$

$\begin{array}{llllllll}145 & 7.81 \mathrm{E}+11 & 0.000793524 & 6.2 \mathrm{E}+08 & 2.55 \mathrm{E}+10 & 0.039568 & 6.45 \mathrm{E}+11\end{array}$

$\begin{array}{llllllll}150 & 8.03 \mathrm{E}+11 & 0.000768651 & 6.17 \mathrm{E}+08 & 2.61 \mathrm{E}+10 & 0.040361 & 6.48 \mathrm{E}+11\end{array}$

$\begin{array}{llllllll}155 & 8.28 \mathrm{E}+11 & 0.000743658 & 6.16 \mathrm{E}+08 & 2.68 \mathrm{E}+10 & 0.04113 & 6.51 \mathrm{E}+11\end{array}$

$\begin{array}{lllllll}160 & 8.57 \mathrm{E}+11 & 0.000718516 & 6.16 \mathrm{E}+08 & 2.74 \mathrm{E}+10 & 0.041873 & 6.54 \mathrm{E}+11\end{array}$

$\begin{array}{llllllll}165 & 8.89 \mathrm{E}+11 & 0.000693209 & 6.16 \mathrm{E}+08 & 2.8 \mathrm{E}+10 & 0.042592 & 6.57 \mathrm{E}+11\end{array}$

$\begin{array}{llllllll}170 & 9.25 \mathrm{E}+11 & 0.00068269 & 6.32 \mathrm{E}+08 & 2.86 \mathrm{E}+10 & 0.043285 & 6.61 \mathrm{E}+11\end{array}$

$\begin{array}{llllllll}175 & 9.66 \mathrm{E}+11 & 0.000657504 & 6.35 \mathrm{E}+08 & 2.92 \mathrm{E}+10 & 0.043968 & 6.65 \mathrm{E}+11\end{array}$

$\begin{array}{llllllll}180 & 1.01 \mathrm{E}+12 & 0.000632135 & 6.4 \mathrm{E}+08 & 2.99 \mathrm{E}+10 & 0.044625 & 6.7 \mathrm{E}+11\end{array}$

$\begin{array}{llllllll}185 & 1.07 \mathrm{E}+12 & 0.000606599 & 6.46 \mathrm{E}+08 & 3.05 \mathrm{E}+10 & 0.045257 & 6.74 \mathrm{E}+11\end{array}$

$\begin{array}{llllllll}190 & 1.12 \mathrm{E}+12 & 0.000580924 & 6.53 \mathrm{E}+08 & 3.12 \mathrm{E}+10 & 0.045864 & 6.8 \mathrm{E}+11\end{array}$

$\begin{array}{lllllll}195 & 1.19 \mathrm{E}+12 & 0.000555148 & 6.62 \mathrm{E}+08 & 3.18 \mathrm{E}+10 & 0.046445 & 6.85 \mathrm{E}+11\end{array}$

$\begin{array}{lllllll}200 & 1.19 \mathrm{E}+12 & 0.000529315 & 6.31 \mathrm{E}+08 & 3.25 \mathrm{E}+10 & 0.047 & 6.91 \mathrm{E}+11\end{array}$ 
Appendix C2 - Bench Marking

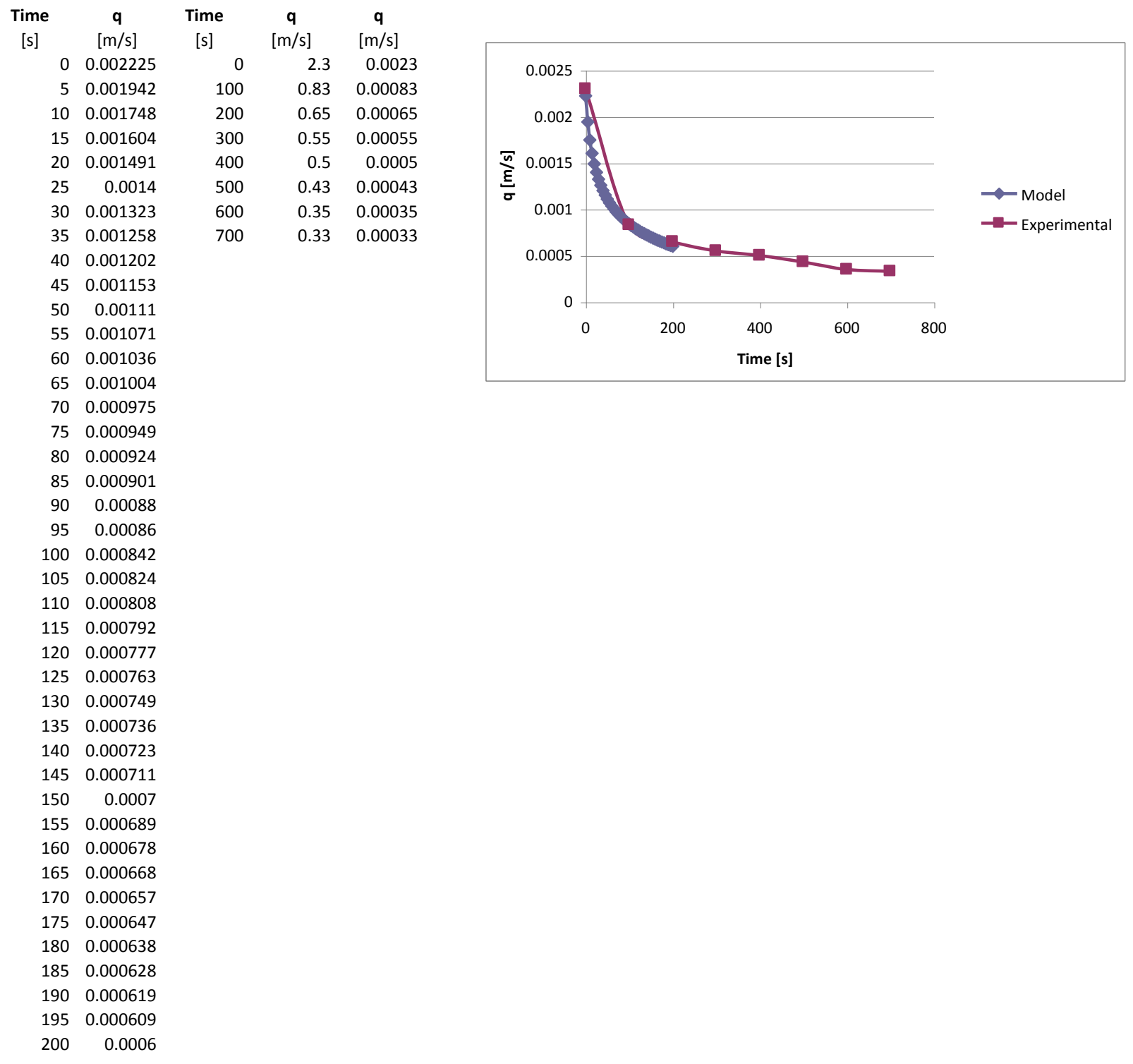




\section{Appendix C3 - Inputs}

\section{Inputs}

\section{Concentrations}

Phi@

Phi(b)

\section{Filter Parameters}

$\mathrm{Rm}$

Diameter

Tan(theta)

Phi

Fluid Mechanics

$\mathrm{mu}$
$\mathrm{dP}$
rho(l)
rho(s)
$\mathrm{nu}$
$\mathrm{u}$
$\mathrm{Re}$
$\mathrm{f}$
PSD Parameters

\section{PSD Parameters}

dmin

dmax

dp(ave)

a1

a2

a3

Numerical
0.01

1.00E-04

$6.00 \mathrm{E}+11$

0.0127

41

$1.00 \mathrm{E}+03$

0.001

156,653

1,000

1,200

1.E-06

4.93

62611

0.045
$[1 / \mathrm{m}]$

[m]

$$
\begin{gathered}
{[\mathrm{kg} / \mathrm{m}-\mathrm{s}]} \\
{[\mathrm{Pa}]} \\
{\left[\mathrm{Kg} / \mathrm{m}^{\wedge} 3\right]} \\
{\left[\mathrm{Kg} / \mathrm{m}^{\wedge} 3\right]} \\
{\left[\mathrm{m}^{\wedge} 2 / \mathrm{s}\right]} \\
{[\mathrm{m} / \mathrm{s}]}
\end{gathered}
$$

Determine Experimentally

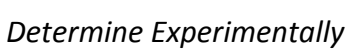

Determine Experimentally 


\section{Appendix C3 - Charts}

\section{Figure 1 - dpi vs. PSD $\quad$ Figure 4 - $\mathrm{f}$ vs. $\mathrm{t}$}

Figure 2 - dpi vs.

Figure 5 - Delta vs. $t$

Figure 3 - dpi vs. dpi_bar

Figure 6 - J vs. t
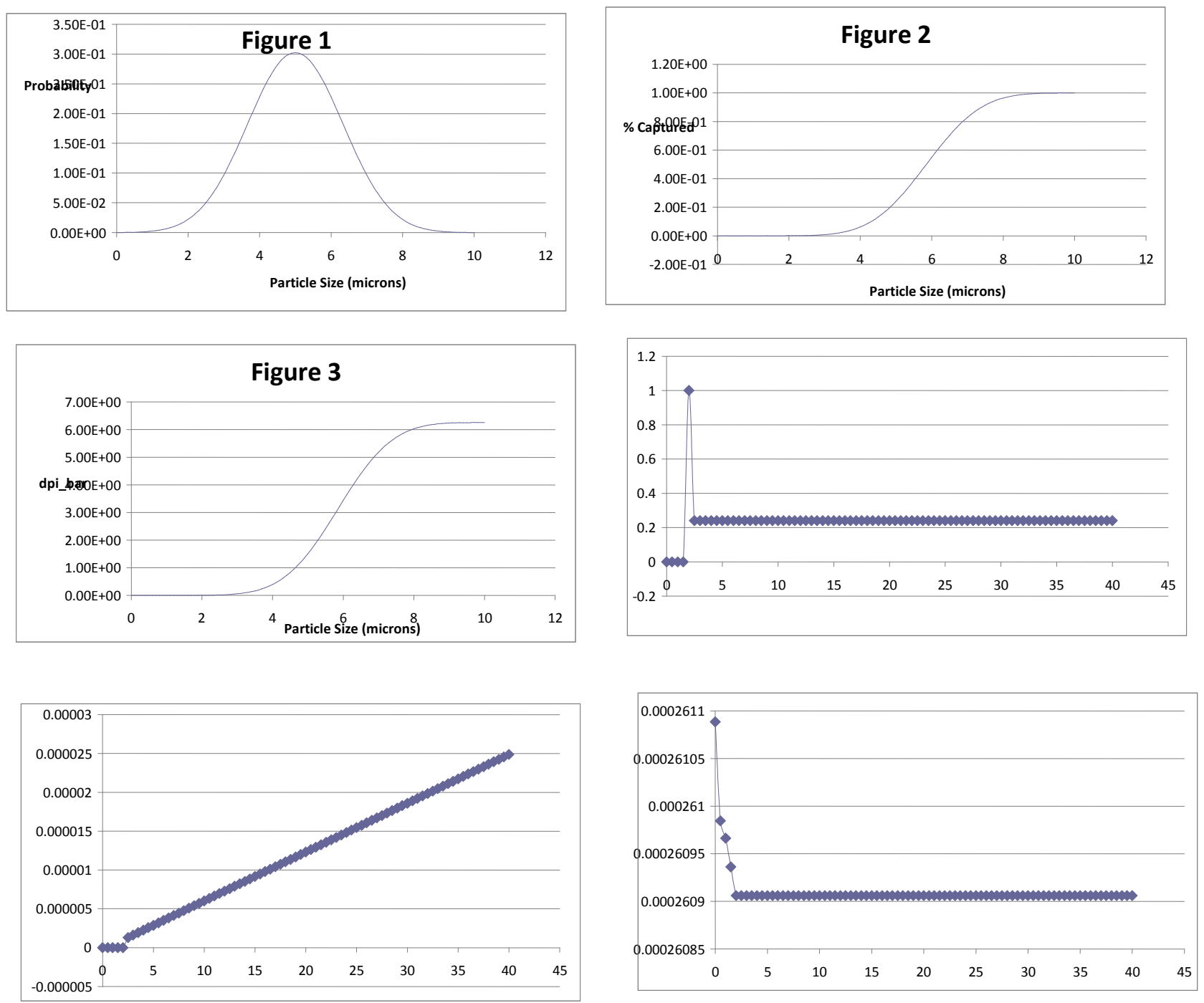

A-49 


\section{Appendix C3 - Main Sheet}

\begin{tabular}{|c|c|c|c|c|c|c|c|c|c|}
\hline $\begin{array}{c}\text { Time } \\
{[s]}\end{array}$ & $\begin{array}{l}d p \\
{[m]}\end{array}$ & $f$ & $\begin{array}{c}\text { dpi_bar } \\
{[\mathrm{m}]}\end{array}$ & alpha(i) & Ipha & $\begin{array}{c}\mathrm{J} \\
{[\mathrm{m} / \mathrm{s}]}\end{array}$ & Delta(i) & $\begin{array}{c}\text { Delta } \\
\text { [m] }\end{array}$ & $\begin{array}{c}\mathrm{Rc} \\
{[1 / \mathrm{m}]}\end{array}$ \\
\hline 0 & 4.0166E-07 & $.56 \mathrm{E}-08$ & $1.25578 \mathrm{E}-12$ & $1.17635 \mathrm{E}+22$ & 0 & 0.000261 & 2.03243E-14 & 0 & 0 \\
\hline 0.5 & $7.2953 \mathrm{E}-07$ & $3.5 \mathrm{E}-07$ & $1.42499 \mathrm{E}-11$ & $9.1357 E+19$ & $E+22$ & 0.000261 & $4.5715 \mathrm{E}-13$ & 14 & 08 \\
\hline 1 & $6.85204 \mathrm{E}-07$ & $1.43 \mathrm{E}-07$ & $7.0726 \mathrm{E}-12$ & $3.70858 E+20$ & $88 \mathrm{E}+20$ & 0.000261 & $1.86933 \mathrm{E}-13$ & 77475E-13 & $81 E+08$ \\
\hline 1.5 & $6.48101 \mathrm{E}-07$ & $1.43 \mathrm{E}-07$ & $7.0726 \mathrm{E}-12$ & $3.70858 \mathrm{E}+20$ & $5.27 \mathrm{E}+20$ & 0.000261 & $1.86911 \mathrm{E}-13$ & $6.64407 \mathrm{E}-13$ & $3.5 \mathrm{E}+08$ \\
\hline 2 & 1.1017E-05 & 1 & $6.25431 \mathrm{E}-06$ & 474251188 & $4.93 E+20$ & 0.000261 & $1.30453 \mathrm{E}-06$ & $8.51318 \mathrm{E}-13$ & $19 E+08$ \\
\hline 2.5 & 0.000005 & 0.240843 & 1.5093E-06 & 8143606911 & $3.22 E+14$ & 0.000261 & 3.14187E-07 & $.30453 \mathrm{E}-06$ & $4.19 \mathrm{E}+08$ \\
\hline 3 & 0.000005 & 0.240843 & $1.5093 \mathrm{E}-06$ & 8143606911 & $2.59 E+14$ & 0.000261 & 3.14187E-07 & $1.61872 \mathrm{E}-06$ & $4.19 E+08$ \\
\hline 3.5 & 0.000005 & 0.240843 & $1.5093 \mathrm{E}-06$ & 8143606911 & $2.17 E+14$ & 0.000261 & $3.14187 \mathrm{E}-07$ & $1.9329 \mathrm{E}-06$ & 4.19E+08 \\
\hline 4 & 0.000005 & 0.240843 & $1.5093 \mathrm{E}-06$ & 8143606911 & $1.87 \mathrm{E}+14$ & 0.000261 & 3.14187E-07 & 2.24709E-06 & $4.2 \mathrm{E}+08$ \\
\hline 4.5 & 0.000005 & 0.240843 & 1.5093E-06 & 8143606911 & $1.64 \mathrm{E}+14$ & 0.000261 & 3.14187E-07 & 2.56128E-06 & $4.2 \mathrm{E}+08$ \\
\hline 5 & 0.000005 & 0.240843 & $1.5093 \mathrm{E}-06$ & 8143606911 & $1.46 \mathrm{E}+14$ & 0.000261 & $3.14187 \mathrm{E}-07$ & $2.87546 \mathrm{E}-06$ & $4.2 \mathrm{E}+08$ \\
\hline 5.5 & 0.000005 & 0.240843 & 1.5093E-06 & 8143606911 & $1.32 E+14$ & 0.00 & 3.14187E-07 & 3.18965E-06 & $4.2 \mathrm{E}+08$ \\
\hline 6 & 0.000005 & 0.240843 & $1.5093 \mathrm{E}-06$ & 814 & $E+14$ & 0.0 & 3.14 & $384 E-06$ & $E+08$ \\
\hline 6.5 & 0.000005 & 0.240843 & 1.5093E-06 & 8143606911 & $1.1 \mathrm{E}+14$ & 0.000261 & 3.14187E-07 & 3.81803E-06 & $4.2 \mathrm{E}+08$ \\
\hline 7 & 0.000005 & 0.240843 & 1.5093E-06 & 8143606911 & $1.02 E+14$ & 0.000261 & 3.14187E-07 & 4.13221E-06 & $4.2 \mathrm{E}+08$ \\
\hline 7.5 & 0.000005 & 0.240843 & $E-06$ & 11 & 13 & 0.0 & 07 & .06 & $E+08$ \\
\hline 8 & 0.000005 & 0.240843 & $1.5093 \mathrm{E}-06$ & 8143606911 & $=+13$ & 0.0 & 3.14187E-07 & 06 & $4.2 \mathrm{E}+08$ \\
\hline 8.5 & 0.000005 & 0.240843 & $1.5093 \mathrm{E}-06$ & 8143606911 & $8.27 E+13$ & 0.00 & $3.14187 \mathrm{E}-07$ & 5.07477 & $4.2 \mathrm{E}+08$ \\
\hline 9 & 0.000005 & 0.240843 & 1.5093E-06 & 8143606911 & $7.78 \mathrm{E}+13$ & 0.000261 & 3.14187E-07 & 5.38896E-06 & $4.2 \mathrm{E}+08$ \\
\hline 9.5 & 0.000005 & 0.240843 & 1.5093E-06 & 8143606911 & $7.36 E+13$ & 0.000261 & 3.14187E-07 & $5.70315 E-06$ & $4.2 \mathrm{E}+08$ \\
\hline 10 & 0.000005 & 0.240843 & 1.509 & 8143606911 & 6.97 & 0.00 & $3.14187 \mathrm{E}-07$ & 06 & $4.2 \mathrm{E}+08$ \\
\hline 10.5 & 0.000005 & 0.240843 & $1.5093 \mathrm{E}-06$ & 8143606911 & $6.63 E+13$ & 0.00 & 3.14187E-07 & 6.33152E-06 & $4.2 \mathrm{E}+08$ \\
\hline 11 & 0.000005 & 0.240843 & $1.5093 \mathrm{E}-06$ & 8143606911 & $6.31 E+13$ & 0.0 & $3.14187 \mathrm{E}-07$ & 6.64571E-06 & $2 \mathrm{E}+08$ \\
\hline 11.5 & 0.000005 & 0.240843 & 1.50 & 6911 & 6.0 & 0.0 & 3.141 & 06 & $E+08$ \\
\hline 12 & 0.000005 & 0.240843 & 1.5093E-06 & 8143606911 & $5.77 E+13$ & 0.000261 & 3.14187E-07 & $7.27408 \mathrm{E}-06$ & $4.2 \mathrm{E}+08$ \\
\hline 12.5 & 0.000005 & 0.240843 & $E-06$ & 06911 & $5.53 E+13$ & 0.0 & $3.14187 \mathrm{E}-07$ & -06 & $E+08$ \\
\hline 13 & 0.000005 & 0.240843 & 1.509 & 606911 & 5.3 & 0.00 & 3.141 & 06 & $4.2 \mathrm{E}+08$ \\
\hline 13.5 & 0.000005 & 0.240843 & 1.5093E-06 & 8143606911 & $5.11 E+13$ & 0.000261 & 3.14187E-07 & 8.21664E-06 & $4.2 \mathrm{E}+08$ \\
\hline 14 & 0.000005 & 0.240843 & 1.5093E-06 & 8143606911 & $4.92 E+13$ & 0.000261 & 3.14187E-07 & 8.53083E-06 & $2 \mathrm{E}+08$ \\
\hline 14.5 & 0.000005 & 0.240843 & $1.5093 \mathrm{E}-06$ & 8143606911 & $4.74 \mathrm{E}+13$ & 0.000261 & 3.14187E-07 & 8.84501E-06 & $4.2 \mathrm{E}+08$ \\
\hline 15 & 0.000005 & 0.240843 & 1.5093E-06 & 8143606911 & $4.58 \mathrm{E}+13$ & 0.000261 & 3.14187E-07 & $9.1592 \mathrm{E}-06$ & $4.2 \mathrm{E}+08$ \\
\hline 15.5 & 0.000005 & 0.240843 & 1.5093E-06 & 8143606911 & $4.43 E+13$ & 0.000261 & 3.14187E-07 & $9.47339 \mathrm{E}-06$ & $4.2 \mathrm{E}+08$ \\
\hline 16 & 0.000005 & 0.240843 & 1.5093E-06 & 8143606911 & $4.29 E+13$ & 0.000261 & 3.14187E-07 & $9.78757 \mathrm{E}-06$ & $4.2 \mathrm{E}+08$ \\
\hline 16.5 & 0.000005 & 0.240843 & $1.5093 \mathrm{E}-06$ & 8143606911 & $4.15 E+13$ & 0.000261 & $3.14187 \mathrm{E}-07$ & $1.01018 \mathrm{E}-05$ & $4.2 \mathrm{E}+08$ \\
\hline 17 & 0.000005 & 0.240843 & $1.5093 \mathrm{E}-06$ & 8143606911 & $4.03 E+13$ & 0.000261 & 3.14187E-07 & 1.04159E-05 & $4.2 \mathrm{E}+08$ \\
\hline 17.5 & 0.000005 & 0.240843 & $1.5093 \mathrm{E}-06$ & 8143606911 & $3.91 E+13$ & 0.000261 & 3.14187E-07 & 1.07301E-05 & $4.2 \mathrm{E}+08$ \\
\hline 18 & 0.000005 & 0.240843 & 1.5093E-06 & 8143606911 & $3.8 \mathrm{E}+13$ & 0.000261 & 3.14187E-07 & 1.10443E-05 & $4.2 \mathrm{E}+08$ \\
\hline 18.5 & 0.000005 & 0.240843 & 1.5093E-06 & 8143606911 & $3.69 E+13$ & 0.000261 & 3.14187E-07 & $1.13585 \mathrm{E}-05$ & $4.2 \mathrm{E}+08$ \\
\hline 19 & 0.000005 & 0.240843 & 1.5093E-06 & 8143606911 & $3.59 E+13$ & 0.000261 & 3.14187E-07 & 1.16727E-05 & $4.2 \mathrm{E}+08$ \\
\hline 19.5 & 0.000005 & 0.240843 & 1.5093E-06 & 8143606911 & $3.5 E+13$ & 0.000261 & 3.14187E-07 & 1.19869E-05 & $4.2 \mathrm{E}+08$ \\
\hline
\end{tabular}




\section{Appendix C3 - Main Sheet}

\begin{tabular}{|c|c|c|c|c|c|c|c|c|c|}
\hline ne & $d p$ & $f$ & dpi_bar & alpha(i) & Alpha & J & Delta(i) & Delta & Rc \\
\hline 20 & 000005 & 240843 & 1.5093E-06 & 143606911 & $3.41 E+13$ & 00261 & 3.14187E-07 & $1.23011 \mathrm{E}-05$ & $.2 \mathrm{E}+08$ \\
\hline 20.5 & 000005 & 0.240843 & 1.5093E-06 & 8143606911 & $3.33 E+13$ & 0.000261 & 3.14187E-07 & $1.26153 \mathrm{E}-05$ & $4.2 \mathrm{E}+08$ \\
\hline 21 & 0.000005 & 0.240843 & 1.5093E-06 & 8143606911 & $3.25 E+13$ & 0.000261 & 3.14187E-07 & 1.29294E-05 & $4.2 \mathrm{E}+08$ \\
\hline 21.5 & 0.000005 & 0.240843 & $1.5093 \mathrm{E}-06$ & 8143606911 & $3.17 E+13$ & 0.000261 & 3.14187E-07 & $1.32436 \mathrm{E}-05$ & $4.2 \mathrm{E}+08$ \\
\hline 22 & 0.000005 & 0.240843 & $1.5093 \mathrm{E}-06$ & 8143606911 & $3.09 E+13$ & 0.000261 & $3.14187 \mathrm{E}-07$ & $1.35578 \mathrm{E}-05$ & $4.2 \mathrm{E}+08$ \\
\hline 22.5 & 0.000005 & 0.240843 & 1.5093E-06 & 8143606911 & $3.02 E+13$ & 0.000261 & 3.14187E-07 & $1.3872 \mathrm{E}-05$ & $4.2 \mathrm{E}+08$ \\
\hline 23 & 0.000005 & 0.240843 & 1.5093E-06 & 8143606911 & $2.96 E+13$ & 0.000261 & 3.14187E-07 & 1.41862E-05 & $4.2 \mathrm{E}+08$ \\
\hline 23.5 & 0.000005 & 0.240843 & $1.5093 \mathrm{E}-06$ & 8143606911 & $2.89 E+13$ & 0.000261 & $3.14187 \mathrm{E}-07$ & 1.45004E-05 & $4.2 \mathrm{E}+08$ \\
\hline 24 & 0.000005 & 0.240843 & $1.5093 \mathrm{E}-06$ & 8143606911 & $2.83 E+13$ & 0.000261 & 3.14187E-07 & $1.48146 \mathrm{E}-05$ & $4.2 \mathrm{E}+08$ \\
\hline 24.5 & 0.000005 & 0.240843 & 1.5093E-06 & 8143606911 & $2.77 E+13$ & 0.000261 & 3.14187E-07 & $1.51287 \mathrm{E}-05$ & $4.2 \mathrm{E}+08$ \\
\hline 25 & 0.000005 & 0.240843 & 1.5093E-06 & 8143606911 & $2.72 E+13$ & 0.000261 & $37 E-07$ & $1.54429 \mathrm{E}-05$ & $4.2 \mathrm{E}+08$ \\
\hline 25.5 & 0.000005 & 0.240843 & $1.5093 \mathrm{E}-06$ & 8143606911 & $2.66 \mathrm{E}+13$ & 0.000261 & 3.14187E-07 & $1.57571 \mathrm{E}-05$ & $4.2 \mathrm{E}+08$ \\
\hline 26 & 0.000005 & 0.240843 & $1.5093 \mathrm{E}-06$ & 8143606911 & $2.61 E+13$ & 0.000261 & $3.14187 \mathrm{E}-07$ & 1.60713E-05 & $4.2 \mathrm{E}+08$ \\
\hline 26.5 & 0.000005 & 0.240843 & $1.5093 \mathrm{E}-06$ & 8143606911 & $2.56 \mathrm{E}+13$ & 0.000261 & 3.14187E-07 & $1.63855 \mathrm{E}-05$ & $4.2 \mathrm{E}+08$ \\
\hline 27 & 0.000005 & 0.240843 & 1.5093E-06 & 8143606911 & $2.51 E+13$ & 0.000261 & 3.14187E-07 & $1.66997 \mathrm{E}-05$ & $4.2 \mathrm{E}+08$ \\
\hline 27.5 & 0.000005 & 0.240843 & $1.5093 \mathrm{E}-06$ & 8143606911 & $2.47 \mathrm{E}+13$ & 0.000261 & 7E-07 & $1.70139 \mathrm{E}-05$ & $4.2 \mathrm{E}+08$ \\
\hline 28 & 0.000005 & 0.240843 & 1.5093E-06 & 8143606911 & $2.42 E+13$ & 0.000261 & 3.14 & $1.73281 \mathrm{E}-05$ & $4.2 \mathrm{E}+08$ \\
\hline 28.5 & 0.000005 & 0.240843 & 1.5093E-06 & 8143606911 & $2.38 \mathrm{E}+13$ & 0.000261 & $37 E-07$ & $1.76422 \mathrm{E}-05$ & $4.2 \mathrm{E}+08$ \\
\hline 29 & 0.000005 & 0.240843 & 1.5093E-06 & 8143606911 & $2.34 \mathrm{E}+13$ & 0.000261 & $7 \mathrm{E}-07$ & $1.79564 \mathrm{E}-05$ & $4.2 \mathrm{E}+08$ \\
\hline 29.5 & 0.000005 & 0.240843 & 1.5093E-06 & 81436 & $2.3 E+13$ & 0.000261 & 3.141 & 1.8270 & $4.2 \mathrm{E}+08$ \\
\hline 30 & 0.000005 & 0.240843 & 1.5093E-06 & 8143606911 & $2.26 E+13$ & 0.000261 & 7E-07 & $1.85848 \mathrm{E}-05$ & $2 \mathrm{E}+08$ \\
\hline 30.5 & 0.000005 & 0.240843 & 1.5093E-06 & 8143606911 & $2.22 \mathrm{E}+13$ & 0.000261 & $7 \mathrm{E}-07$ & 1.8899E-05 & $4.2 \mathrm{E}+08$ \\
\hline 31 & 0.000005 & 0.240843 & $1.5093 \mathrm{E}-06$ & 8143606911 & $2.18 \mathrm{E}+13$ & 0.000261 & $3.14187 \mathrm{E}-07$ & $1.92132 \mathrm{E}-05$ & $4.2 \mathrm{E}+08$ \\
\hline 31.5 & 0.000005 & 0.240843 & 1.5093E-06 & 814360 & $2.15 E+13$ & 0.000261 & E-07 & $1.95274 \mathrm{E}-05$ & $4.2 \mathrm{E}+08$ \\
\hline 32 & 0.000005 & 0.240843 & 1.5093 & 6911 & $2.11 E+13$ & 0.000261 & -07 & 1.984 & $4.2 \mathrm{E}+08$ \\
\hline 32.5 & 0.000005 & 0.240843 & $1.5093 \mathrm{E}-06$ & 8143606911 & $2.08 \mathrm{E}+13$ & 0.000261 & $3.14187 \mathrm{E}-07$ & 2.01557E-05 & $4.2 \mathrm{E}+08$ \\
\hline 33 & 0.000005 & 0.240843 & 1.5093E-06 & 8143606911 & $2.05 E+13$ & 0.000261 & 3.14187E-07 & 2.04699E-05 & $4.2 \mathrm{E}+08$ \\
\hline 33.5 & 0.000005 & 0.240843 & 1.5093E-06 & 8143606911 & $2.02 E+13$ & 0.000261 & 3.14187E-07 & $2.07841 \mathrm{E}-05$ & $4.2 \mathrm{E}+08$ \\
\hline 34 & 0.000005 & 0.240843 & $1.5093 \mathrm{E}-06$ & 8143606911 & $1.99 \mathrm{E}+13$ & 0.000261 & 3.14187E-07 & 2.10983E-05 & $4.2 \mathrm{E}+08$ \\
\hline 34.5 & 0.000005 & 0.240843 & 1.5093E-06 & 8143606911 & $1.96 \mathrm{E}+13$ & 0.000261 & 3.14187E-07 & $2.14125 \mathrm{E}-05$ & $4.2 \mathrm{E}+08$ \\
\hline 35 & 0.000005 & 0.240843 & 1.5093E-06 & 8143606911 & $1.93 E+13$ & 0.000261 & $3.14187 \mathrm{E}-07$ & 2.17267E-05 & 4. $2 \mathrm{E}+08$ \\
\hline 35.5 & 0.000005 & 0.240843 & 1.5093E-06 & 8143606911 & $1.9 \mathrm{E}+13$ & 0.000261 & 3.14187E-07 & 2.20409E-05 & $4.2 \mathrm{E}+08$ \\
\hline 36 & 0.000005 & 0.240843 & 1.5093E-06 & 8143606911 & $1.88 \mathrm{E}+13$ & 0.000261 & 3.14187E-07 & $2.2355 \mathrm{E}-05$ & $4.2 \mathrm{E}+08$ \\
\hline 36.5 & 0.000005 & 0.240843 & 1.5093E-06 & 8143606911 & $1.85 \mathrm{E}+13$ & 0.000261 & 3.14187E-07 & $2.26692 \mathrm{E}-05$ & $4.2 \mathrm{E}+08$ \\
\hline 37 & 0.000005 & 0.240843 & $1.5093 \mathrm{E}-06$ & 8143606911 & $1.83 E+13$ & 0.000261 & 3.14187E-07 & $2.29834 \mathrm{E}-05$ & 4. $2 \mathrm{E}+08$ \\
\hline 37.5 & 0.000005 & 0.240843 & 1.5093E-06 & 8143606911 & $1.8 \mathrm{E}+13$ & 0.000261 & 3.14187E-07 & 2.32976E-05 & $4.2 \mathrm{E}+08$ \\
\hline 38 & 0.000005 & 0.240843 & 1.5093E-06 & 8143606911 & $1.78 \mathrm{E}+13$ & 0.000261 & 3.14187E-07 & $2.36118 \mathrm{E}-05$ & $4.2 \mathrm{E}+08$ \\
\hline 38.5 & 0.000005 & 0.240843 & $1.5093 \mathrm{E}-06$ & 8143606911 & $1.75 \mathrm{E}+13$ & 0.000261 & 3.14187E-07 & $2.3926 \mathrm{E}-05$ & $4.2 \mathrm{E}+08$ \\
\hline 39 & 0.000005 & 0.240843 & $1.5093 \mathrm{E}-06$ & 8143606911 & $1.73 \mathrm{E}+13$ & 0.000261 & 3.14187E-07 & $2.42402 \mathrm{E}-05$ & $4.2 \mathrm{E}+08$ \\
\hline 39.5 & 0.000005 & 0.240843 & 1.5093E-06 & 8143606911 & $1.71 \mathrm{E}+13$ & 0.000261 & 3.14187E-07 & $2.45544 \mathrm{E}-05$ & $4.2 \mathrm{E}+08$ \\
\hline 40 & 0.000005 & 0.240843 & 1.5093E-06 & $8143606 \mathrm{~A}^{11}-5$ & $1.69 E+13$ & 0.000261 & 3.14187E-07 & 2.48685E-05 & $4.2 \mathrm{E}+08$ \\
\hline
\end{tabular}




\section{Appendix C3 - dpi}

\begin{tabular}{|c|c|c|c|c|c|c|c|c|c|c|c|}
\hline Time & $d p(i)$ & $d p(i)$ & C1 & C2 & C3 & $q$ & $q$ & Diff & $C 1 * d p$ & $\mathrm{C} 2 * \mathrm{dp}^{\wedge} 2$ & $\mathrm{C} 3 * \mathrm{dp}^{\wedge} 3$ \\
\hline 0 & 0.40 & 4.0166E-07 & 11.33734 & 108.9999 & $3.95886 E+15$ & 0.000261 & 0.000261 & 3.77429E-07 & $1.74 \%$ & $0.00 \%$ & $98.26 \%$ \\
\hline 0.5 & 0.73 & 7.2953E-07 & 11.33734 & 108.9999 & $3.95886 \mathrm{E}+15$ & 0.000261 & 0.001545 & -1284.37784 & $0.54 \%$ & $0.00 \%$ & $99.46 \%$ \\
\hline 1 & 0.69 & $6.85204 \mathrm{E}-07$ & 11.33734 & 108.9999 & $3.95886 \mathrm{E}+15$ & 0.000261 & 0.001281 & -1020.39489 & $0.61 \%$ & $0.00 \%$ & $99.39 \%$ \\
\hline 1.5 & 0.65 & $6.48101 \mathrm{E}-07$ & 11.33734 & 108.9999 & $3.95886 \mathrm{E}+15$ & 0.000261 & 0.001085 & -824.111471 & $0.68 \%$ & $0.00 \%$ & $99.32 \%$ \\
\hline 2 & 11.02 & 1.1017E-05 & 11.33734 & 108.9999 & $3.95886 \mathrm{E}+15$ & 0.000261 & 5.293767 & -5293506 & $0.00 \%$ & $0.00 \%$ & $100.00 \%$ \\
\hline 2.5 & 5.00 & 0.000005 & 11.33734 & 108.9999 & $3.95886 \mathrm{E}+15$ & 0.000261 & 0.494914 & -494653.203 & $0.01 \%$ & $0.00 \%$ & $99.99 \%$ \\
\hline 3 & 5.00 & 0.000005 & 11.33734 & 108.9999 & $3.95886 \mathrm{E}+15$ & 0.000261 & 0.494914 & -494653.203 & $0.01 \%$ & $0.00 \%$ & $99.99 \%$ \\
\hline 3.5 & 5.00 & 0.000005 & 11.33734 & 108.9999 & $3.95886 E+15$ & 0.000261 & 0.494914 & -494653.203 & $0.01 \%$ & $0.00 \%$ & 99.99\% \\
\hline 4 & 5.00 & 0.000005 & 11.33734 & 108.9999 & $3.95886 \mathrm{E}+15$ & 0.000261 & 0.494914 & -494653.203 & $0.01 \%$ & $0.00 \%$ & $99.99 \%$ \\
\hline 4.5 & 5.00 & 0.000005 & 11.33734 & 108.9999 & $3.95886 \mathrm{E}+15$ & 0.000261 & 0.494914 & -494653.203 & $0.01 \%$ & $0.00 \%$ & $99.99 \%$ \\
\hline 5 & 5.00 & 0.000005 & 11.33734 & 108.9999 & $3.95886 \mathrm{E}+15$ & 0.000261 & 0.494914 & -494653.203 & $0.01 \%$ & $0.00 \%$ & $99.99 \%$ \\
\hline 5.5 & 5.00 & 0.000005 & 11.33734 & 108.9999 & $3.95886 \mathrm{E}+15$ & 0.000261 & 0.494914 & -494653.203 & $0.01 \%$ & $0.00 \%$ & $99.99 \%$ \\
\hline 6 & 5.00 & 0.000005 & 11.33734 & 108.9999 & $3.95886 \mathrm{E}+15$ & 0.000261 & 0.494914 & -494653.203 & $0.01 \%$ & $0.00 \%$ & $99.99 \%$ \\
\hline 6.5 & 5.00 & 0.000005 & 11.33734 & 108.9999 & $3.95886 \mathrm{E}+15$ & 0.000261 & 0.494914 & -494653.203 & $0.01 \%$ & $0.00 \%$ & $99.99 \%$ \\
\hline 7 & 5.00 & 0.000005 & 11.33734 & 108.9999 & $3.95886 \mathrm{E}+15$ & 0.000261 & 0.494914 & -494653.203 & $0.01 \%$ & $0.00 \%$ & $99.99 \%$ \\
\hline 7.5 & 5.00 & 0.000005 & 11.33734 & 108.9999 & $3.95886 \mathrm{E}+15$ & 0.000261 & 0.494914 & -494653.203 & $0.01 \%$ & $0.00 \%$ & $99.99 \%$ \\
\hline 8 & 5.00 & 0.000005 & 11.33734 & 108.9999 & $3.95886 \mathrm{E}+15$ & 0.000261 & 0.494914 & -494653.203 & $0.01 \%$ & $0.00 \%$ & $99.99 \%$ \\
\hline 8.5 & 5.00 & 0.000005 & 11.33734 & 108.9999 & $3.95886 \mathrm{E}+15$ & 0.000261 & 0.494914 & -494653.203 & $0.01 \%$ & $0.00 \%$ & 99.99\% \\
\hline 9 & 5.00 & 0.000005 & 11.33734 & 108.9999 & $3.95886 \mathrm{E}+15$ & 0.000261 & 0.494914 & -494653.203 & $0.01 \%$ & $0.00 \%$ & $99.99 \%$ \\
\hline 9.5 & 5.00 & 0.000005 & 11.33734 & 108.9999 & $3.95886 \mathrm{E}+15$ & 0.000261 & 0.494914 & -494653.203 & $0.01 \%$ & $0.00 \%$ & $99.99 \%$ \\
\hline 10 & 5.00 & 0.000005 & 11.33734 & 108.9999 & $3.95886 E+15$ & 0.000261 & 0.494914 & -494653.203 & $0.01 \%$ & $0.00 \%$ & 99.99\% \\
\hline 10.5 & 5.00 & 0.000005 & 11.33734 & 108.9999 & $3.95886 \mathrm{E}+15$ & 0.000261 & 0.494914 & -494653.203 & $0.01 \%$ & $0.00 \%$ & $99.99 \%$ \\
\hline 11 & 5.00 & 0.000005 & 11.33734 & 108.9999 & $3.95886 \mathrm{E}+15$ & 0.000261 & 0.494914 & -494653.203 & $0.01 \%$ & $0.00 \%$ & $99.99 \%$ \\
\hline 11.5 & 5.00 & 0.000005 & 11.33734 & 108.9999 & $3.95886 \mathrm{E}+15$ & 0.000261 & 0.494914 & -494653.203 & $0.01 \%$ & $0.00 \%$ & $99.99 \%$ \\
\hline 12 & 5.00 & 0.000005 & 11.33734 & 108.9999 & $3.95886 \mathrm{E}+15$ & 0.000261 & 0.494914 & -494653.203 & $0.01 \%$ & $0.00 \%$ & $99.99 \%$ \\
\hline 12.5 & 5.00 & 0.000005 & 11.33734 & 108.9999 & $3.95886 E+15$ & 0.000261 & 0.494914 & -494653.203 & $0.01 \%$ & $0.00 \%$ & $99.99 \%$ \\
\hline 13 & 5.00 & 0.000005 & 11.33734 & 108.9999 & $3.95886 \mathrm{E}+15$ & 0.000261 & 0.494914 & -494653.203 & $0.01 \%$ & $0.00 \%$ & $99.99 \%$ \\
\hline 13.5 & 5.00 & 0.000005 & 11.33734 & 108.9999 & $3.95886 \mathrm{E}+15$ & 0.000261 & 0.494914 & -494653.203 & $0.01 \%$ & $0.00 \%$ & $99.99 \%$ \\
\hline 14 & 5.00 & 0.000005 & 11.33734 & 108.9999 & $3.95886 \mathrm{E}+15$ & 0.000261 & 0.494914 & -494653.203 & $0.01 \%$ & $0.00 \%$ & $99.99 \%$ \\
\hline 14.5 & 5.00 & 0.000005 & 11.33734 & 108.9999 & $3.95886 \mathrm{E}+15$ & 0.000261 & 0.494914 & -494653.203 & $0.01 \%$ & $0.00 \%$ & $99.99 \%$ \\
\hline 15 & 5.00 & 0.000005 & 11.33734 & 108.9999 & $3.95886 \mathrm{E}+15$ & 0.000261 & 0.494914 & -494653.203 & $0.01 \%$ & $0.00 \%$ & $99.99 \%$ \\
\hline 15.5 & 5.00 & 0.000005 & 11.33734 & 108.9999 & $3.95886 \mathrm{E}+15$ & 0.000261 & 0.494914 & -494653.203 & $0.01 \%$ & $0.00 \%$ & $99.99 \%$ \\
\hline 16 & 5.00 & 0.000005 & 11.33734 & 108.9999 & $3.95886 \mathrm{E}+15$ & 0.000261 & 0.494914 & -494653.203 & $0.01 \%$ & $0.00 \%$ & $99.99 \%$ \\
\hline 16.5 & 5.00 & 0.000005 & 11.33734 & 108.9999 & $3.95886 \mathrm{E}+15$ & 0.000261 & 0.494914 & -494653.203 & $0.01 \%$ & $0.00 \%$ & $99.99 \%$ \\
\hline 17 & 5.00 & 0.000005 & 11.33734 & 108.9999 & $3.95886 \mathrm{E}+15$ & 0.000261 & 0.494914 & -494653.203 & $0.01 \%$ & $0.00 \%$ & $99.99 \%$ \\
\hline 17.5 & 5.00 & 0.000005 & 11.33734 & 108.9999 & $3.95886 \mathrm{E}+15$ & 0.000261 & 0.494914 & -494653.203 & $0.01 \%$ & $0.00 \%$ & $99.99 \%$ \\
\hline 18 & 5.00 & 0.000005 & 11.33734 & 108.9999 & $3.95886 \mathrm{E}+15$ & 0.000261 & 0.494914 & -494653.203 & $0.01 \%$ & $0.00 \%$ & $99.99 \%$ \\
\hline 18.5 & 5.00 & 0.000005 & 11.33734 & 108.9999 & $3.95886 \mathrm{E}+15$ & 0.000261 & 0.494914 & -494653.203 & $0.01 \%$ & $0.00 \%$ & $99.99 \%$ \\
\hline 19 & 5.00 & 0.000005 & 11.33734 & 108.9999 & $3.95886 E+15$ & 0.000261 & 0.494914 & -494653.203 & $0.01 \%$ & $0.00 \%$ & $99.99 \%$ \\
\hline 19.5 & 5.00 & 0.000005 & 11.33734 & 108.9999 & $3.95886 \mathrm{E}+15$ & 0.000261 & 0.494914 & -494653.203 & $0.01 \%$ & $0.00 \%$ & $99.99 \%$ \\
\hline 20 & 5.00 & 0.000005 & 11.33734 & 108.9999 & $3.95886 \mathrm{E}+15$ & 0.000267 & 0.494914 & -494653.203 & $0.01 \%$ & $0.00 \%$ & $99.99 \%$ \\
\hline
\end{tabular}




\section{Appendix C3 - dpi}

$\begin{array}{rr}\text { Time } & \text { dp(i) } \\ 20.5 & 5.00 \\ 21 & 5.00 \\ 21.5 & 5.00 \\ 22 & 5.00 \\ 22.5 & 5.00 \\ 23 & 5.00 \\ 23.5 & 5.00 \\ 24 & 5.00 \\ 24.5 & 5.00 \\ 25 & 5.00 \\ 25.5 & 5.00 \\ 26 & 5.00 \\ 26.5 & 5.00 \\ 27 & 5.00 \\ 27.5 & 5.00 \\ 28 & 5.00 \\ 28.5 & 5.00 \\ 29 & 5.00 \\ 29.5 & 5.00 \\ 30 & 5.00 \\ 30.5 & 5.00 \\ 31 & 5.00 \\ 31.5 & 5.00 \\ 32 & 5.00 \\ 32.5 & 5.00 \\ 33 & 5.00 \\ 33.5 & 5.00 \\ 34 & 5.00 \\ 34.5 & 5.00 \\ 35 & 5.00 \\ 35.5 & 5.00 \\ 36 & 5.00 \\ 36.5 & 5.00 \\ 37 & 5.00 \\ 37.5 & 5.00 \\ 38 & 5.00 \\ 38.5 & 5.00 \\ 39 & 5.00 \\ 39.5 & 5.00 \\ 40 & 5.00\end{array}$

\begin{tabular}{|c|c|c|c|c|c|c|}
\hline$d p(i)$ & C1 & C2 & C3 & q & $q$ & Diff \\
\hline 000005 & 11.33734 & 108.9999 & $3.95886 \mathrm{E}+15$ & 0.000261 & 94914 & -494653.203 \\
\hline 00005 & 11.33734 & 108.9999 & $3.95886 \mathrm{E}+15$ & 0.000261 & 0.494914 & -494653.203 \\
\hline 000005 & 11.33734 & 108.9999 & $3.95886 \mathrm{E}+15$ & 0.000261 & 0.494914 & -494653.203 \\
\hline 000005 & 11.33734 & 108.9999 & $3.95886 \mathrm{E}+15$ & 0.000261 & 0.494914 & -494653.203 \\
\hline 0.000005 & 11.33734 & 108.9999 & $3.95886 \mathrm{E}+15$ & 0.000261 & 0.494914 & -494653.203 \\
\hline 000005 & 11.33734 & 108.9999 & $3.95886 \mathrm{E}+15$ & 0.000261 & 0.494914 & -494653.203 \\
\hline 0.000005 & 11.33734 & 108.9999 & $3.95886 \mathrm{E}+15$ & 0.000261 & 0.494914 & -494653.203 \\
\hline 0.000005 & 11.33734 & 108.9999 & $3.95886 \mathrm{E}+15$ & 0.000261 & 0.494914 & -494653.203 \\
\hline 0.000005 & 11.33734 & 108.9999 & $3.95886 \mathrm{E}+15$ & 0.000261 & 0.494914 & -494653.203 \\
\hline 0.000005 & 11.33734 & 108.9999 & $3.95886 \mathrm{E}+15$ & 0.000261 & 0.494914 & -494653.203 \\
\hline 0.000005 & 11.33734 & 108.9999 & $3.95886 \mathrm{E}+15$ & 0.000261 & 0.494914 & -494653.203 \\
\hline 0.000005 & 11.33734 & 108.9999 & $3.95886 \mathrm{E}+15$ & 0.000261 & 0.494914 & -494653.203 \\
\hline 0.000005 & 11.33734 & 108.9999 & $3.95886 \mathrm{E}+15$ & 0.000261 & 0.494914 & -494653.203 \\
\hline 0.000005 & 11.33734 & 108.9999 & $3.95886 \mathrm{E}+15$ & 0.000261 & 0.494914 & -494653.203 \\
\hline 0.000005 & 11.33734 & 108.9999 & $3.95886 \mathrm{E}+15$ & 0.000261 & 0.494914 & -494653.203 \\
\hline 0.000005 & 11.33734 & 108.9999 & $3.95886 \mathrm{E}+15$ & 0.000261 & 0.494914 & -494653.203 \\
\hline 0.000005 & 11.33734 & 108.9999 & $3.95886 \mathrm{E}+15$ & 0.000261 & 0.494914 & -494653.203 \\
\hline 0.000005 & 11.33734 & 108.9999 & $3.95886 \mathrm{E}+15$ & 0.000261 & 0.494914 & -494653.203 \\
\hline 0.000005 & 11.33734 & 108.9999 & $3.95886 \mathrm{E}+15$ & 0.000261 & 0.494914 & -494653.203 \\
\hline 0.000005 & 11.33734 & 108.9999 & $3.95886 \mathrm{E}+15$ & 0.000261 & 0.494914 & -494653.203 \\
\hline 0.000005 & 11.33734 & 108.9999 & $3.95886 \mathrm{E}+15$ & 0.000261 & 0.494914 & -494653.203 \\
\hline 0.000005 & 11.33734 & 108.9999 & $3.95886 \mathrm{E}+15$ & 0.000261 & 0.494914 & -494653.203 \\
\hline 0.000005 & 11.33734 & 108.9999 & $3.95886 \mathrm{E}+15$ & 0.000261 & 0.494914 & -494653.203 \\
\hline 0.000005 & 11.33734 & 108.9999 & $3.95886 \mathrm{E}+15$ & 0.000261 & 0.494914 & -494653.203 \\
\hline 0.000005 & 11.33734 & 108.9999 & $3.95886 \mathrm{E}+15$ & 0.000261 & 0.494914 & -494653.203 \\
\hline 0.000005 & 11.33734 & 108.9999 & $3.95886 \mathrm{E}+15$ & 0.000261 & 0.494914 & -494653.203 \\
\hline 0.000005 & 11.33734 & 108.9999 & $3.95886 \mathrm{E}+15$ & 0.000261 & 0.494914 & -494653.203 \\
\hline 0.000005 & 11.33734 & 108.9999 & $3.95886 \mathrm{E}+15$ & 0.000261 & 0.494914 & -494653.203 \\
\hline 0.000005 & 11.33734 & 108.9999 & $3.95886 \mathrm{E}+15$ & 0.000261 & 0.494914 & -494653.203 \\
\hline 0.000005 & 11.33734 & 108.9999 & $3.95886 \mathrm{E}+15$ & 0.000261 & 0.494914 & -494653.203 \\
\hline 0.000005 & 11.33734 & 108.9999 & $3.95886 \mathrm{E}+15$ & 0.000261 & 0.494914 & -494653.203 \\
\hline 0.000005 & 11.33734 & 108.9999 & $3.95886 \mathrm{E}+15$ & 0.000261 & 0.494914 & -494653.203 \\
\hline 0.000005 & 11.33734 & 108.9999 & $3.95886 \mathrm{E}+15$ & 0.000261 & 0.494914 & -494653.203 \\
\hline 0.000005 & 11.33734 & 108.9999 & $3.95886 \mathrm{E}+15$ & 0.000261 & 0.494914 & -494653.203 \\
\hline 0.000005 & 11.33734 & 108.9999 & $3.95886 \mathrm{E}+15$ & 0.000261 & 0.494914 & -494653.203 \\
\hline 0.000005 & 11.33734 & 108.9999 & $3.95886 \mathrm{E}+15$ & 0.000261 & 0.494914 & -494653.203 \\
\hline 0.000005 & 11.33734 & 108.9999 & $3.95886 \mathrm{E}+15$ & 0.000261 & 0.494914 & -494653.203 \\
\hline 0.000005 & 11.33734 & 108.9999 & $3.95886 \mathrm{E}+15$ & 0.000261 & 0.494914 & -494653.203 \\
\hline 0.000005 & 11.33734 & 108.9999 & $3.95886 \mathrm{E}+15$ & 0.000261 & 0.494914 & -494653.203 \\
\hline 0.000005 & 11.33734 & 108.9999 & $3.95886 \mathrm{E}+15$ & 0.000261 & 0.494914 & -494653.203 \\
\hline
\end{tabular}

\begin{tabular}{cr} 
C1*dp & C2*dp^2 \\
$0.01 \%$ & $0.00 \%$ \\
$0.01 \%$ & $0.00 \%$ \\
$0.01 \%$ & $0.00 \%$ \\
$0.01 \%$ & $0.00 \%$ \\
$0.01 \%$ & $0.00 \%$ \\
$0.01 \%$ & $0.00 \%$ \\
$0.01 \%$ & $0.00 \%$ \\
$0.01 \%$ & $0.00 \%$ \\
$0.01 \%$ & $0.00 \%$ \\
$0.01 \%$ & $0.00 \%$ \\
$0.01 \%$ & $0.00 \%$ \\
$0.01 \%$ & $0.00 \%$ \\
$0.01 \%$ & $0.00 \%$ \\
$0.01 \%$ & $0.00 \%$ \\
$0.01 \%$ & $0.00 \%$ \\
$0.01 \%$ & $0.00 \%$ \\
$0.01 \%$ & $0.00 \%$ \\
$0.01 \%$ & $0.00 \%$ \\
$0.01 \%$ & $0.00 \%$ \\
$0.01 \%$ & $0.00 \%$ \\
$0.01 \%$ & $0.00 \%$ \\
$0.01 \%$ & $0.00 \%$ \\
$0.01 \%$ & $0.00 \%$ \\
$0.01 \%$ & $0.00 \%$ \\
$0.01 \%$ & $0.00 \%$ \\
$0.01 \%$ & $0.00 \%$ \\
$0.01 \%$ & $0.00 \%$ \\
$0.01 \%$ & $0.00 \%$ \\
$0.01 \%$ & $0.00 \%$ \\
$0.01 \%$ & $0.00 \%$ \\
$0.01 \%$ & $0.00 \%$ \\
$0.01 \%$ & $0.00 \%$ \\
$0.01 \%$ & $0.00 \%$ \\
$0.01 \%$ & $0.00 \%$ \\
$0.01 \%$ & $0.00 \%$ \\
$0.01 \%$ & $0.00 \%$ \\
$0.01 \%$ & $0.00 \%$ \\
$0.01 \%$ & $0.00 \%$ \\
$0.01 \%$ & $0.00 \%$ \\
$0.01 \%$ & $0.00 \%$ \\
\hline
\end{tabular}

$\mathrm{C3}^{*} \mathrm{dp}^{\wedge} 3$

99.99\%

$99.99 \%$

$99.99 \%$

$99.99 \%$

$99.99 \%$

$99.99 \%$

$99.99 \%$

$99.99 \%$

$99.99 \%$

$99.99 \%$

$99.99 \%$

$99.99 \%$

$99.99 \%$

$99.99 \%$

$99.99 \%$

$99.99 \%$

99.99\%

$99.99 \%$

$99.99 \%$

$99.99 \%$

$99.99 \%$

99.99\%

$99.99 \%$

$99.99 \%$

99.99\%

$99.99 \%$

99.99\%

$99.99 \%$

$99.99 \%$

$99.99 \%$

$99.99 \%$

$99.99 \%$

$99.99 \%$

$99.99 \%$

$99.99 \%$

$99.99 \%$

$99.99 \%$

$99.99 \%$

$99.99 \%$

$99.99 \%$ 


\section{Appendix C3 - f}

dpi $\begin{array}{llll}0.2 & 6.05745 \mathrm{E}-05 & 8.48 \mathrm{E}-06 & 9.16 \mathrm{E}-05\end{array}$ $\begin{array}{lllll}0.3 & 0.000112991 & 1.98 \mathrm{E}-05 & 0.000171\end{array}$ $\begin{array}{lllll}0.4 & 0.000186444 & 3.84 \mathrm{E}-05 & 0.000282\end{array}$ $\begin{array}{lllll}0.5 & 0.000287028 & 6.71 \mathrm{E}-05 & 0.000434\end{array}$ $\begin{array}{llllll}0.6 & 0.000422149 & 0.000109 & 0.000638\end{array}$ $\begin{array}{lllll}0.7 & 0.000600709 & 0.000169 & 0.000908\end{array}$ $\begin{array}{lllll}0.8 & 0.000833291 & 0.000253 & 0.00126\end{array}$ $\begin{array}{llllll}0.9 & 0.001132333 & 0.000366 & 0.001712\end{array}$ $\begin{array}{lllll}1 & 0.0015123 & 0.000517 & 0.002287\end{array}$ $\begin{array}{lllll}1.1 & 0.001989826 & 0.000716 & 0.003009\end{array}$ $\begin{array}{lllll}1.2 & 0.002583823 & 0.000975 & 0.003907\end{array}$ $\begin{array}{lllll}1.3 & 0.00331555 & 0.001306 & 0.005014\end{array}$ $\begin{array}{lllll}1.4 & 0.004208616 & 0.001727 & 0.006364 \\ 1.5 & 0.005288917 & 0.002256 & 0.007998\end{array}$ $\begin{array}{lllll}1.6 & 0.006584488 & 0.002914 & 0.009957\end{array}$ $\begin{array}{llllll}1.6 & 0.006584488 & 0.002914 & 0.009557\end{array}$ $\begin{array}{lllll}1.8 & 0.009942645 & 0.004721 & 0.015035\end{array}$ $\begin{array}{lllll}1.9 & 0.012069185 & 0.005928 & 0.018251\end{array}$ $\begin{array}{lllll}2 & 0.014537824 & 0.007382 & 0.021984\end{array}$ $\begin{array}{lllll}2.1 & 0.017381247 & 0.00912 & 0.026284\end{array}$ $\begin{array}{lllll}2.2 & 0.020631022 & 0.011183 & 0.031198\end{array}$ $\begin{array}{lllll}2.3 & 0.024316637 & 0.013615 & 0.036772\end{array}$ $\begin{array}{lllll}2.4 & 0.028464446 & 0.016461 & 0.043044\end{array}$ $\begin{array}{lllll}2.5 & 0.033096535 & 0.019771 & 0.050048\end{array}$ $\begin{array}{lllll}2.6 & 0.038229538 & 0.023594 & 0.057811\end{array}$ $\begin{array}{lllll}2.7 & 0.043873445 & 0.027981 & 0.066345\end{array}$ $\begin{array}{lllll}2.8 & 0.050030436 & 0.032984 & 0.075656\end{array}$ $\begin{array}{lllll}2.9 & 0.056693776 & 0.038654 & 0.085732\end{array}$ $\begin{array}{lllll}3 & 0.063846845 & 0.045038 & 0.096549\end{array}$ $\begin{array}{lllll}3.1 & 0.071462319 & 0.052184 & 0.108065\end{array}$ $\begin{array}{lllll}3.2 & 0.079501573 & 0.060135 & 0.120222 \\ 3.3 & 0.087914346 & 0.068926 & 0.132944\end{array}$ $\begin{array}{lllll}3.3 & 0.087914346 & 0.068926 & 0.132944\end{array}$ $\begin{array}{lllll}3.4 & 0.096638696 & 0.07859 & 0.146137 \\ 3.5 & 0.105601297 & 0.08915 & 0.15969\end{array}$ $\begin{array}{lllll}3.5 & 0.105601297 & 0.08915 & 0.15969\end{array}$ $\begin{array}{llll}3.6 & 0.114718076 & 0.100622 & 0.173476 \\ 3.7 & 0.123895222 & 0.113011 & 0.187354\end{array}$ $\begin{array}{lllll}3.8 & 0.133030546 & 0.126314 & 0.201168\end{array}$ $\begin{array}{lllll}3.9 & 0.14201519 & 0.140516 & 0.214755\end{array}$ $\begin{array}{lllll}4 & 0.150735635 & 0.15559 & 0.227942\end{array}$ $\begin{array}{llllll}4.1 & 0.15907598 & 0.171497 & 0.240554\end{array}$ $\begin{array}{lllll}4.2 & 0.166920414 & 0.188189 & 0.252416\end{array}$ $\begin{array}{lllll}4.3 & 0.174155825 & 0.205605 & 0.263358\end{array}$ $\begin{array}{lllll}4.4 & 0.180674458 & 0.223672 & 0.273215\end{array}$ $\begin{array}{lllll}4.5 & 0.18637654 & 0.24231 & 0.281838\end{array}$ $\begin{array}{lllll}4.6 & 0.191172779 & 0.261427 & 0.289091\end{array}$ $\begin{array}{lllll}4.7 & 0.194986657 & 0.280926 & 0.294858\end{array}$ $\begin{array}{lllll}4.8 & 0.197756433 & 0.300701 & 0.299046\end{array}$ $\begin{array}{lllll}4.9 & 0.199436779 & 0.320645 & 0.301587\end{array}$

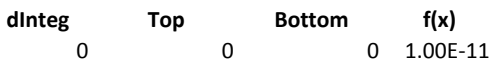
3.67E-08 3.66532E-09 3.66532E-09 $\quad 2.44 \mathrm{E}-11$ 7.33E-07 7.69457E-08 7.69457E-08 $\quad 5.11 \mathrm{E}-10$ 4.61E-06 $\quad 5.3828 \mathrm{E}-07 \quad 5.3828 \mathrm{E}-07 \quad 3.58 \mathrm{E}-09$ $1.8 \mathrm{E}-05 \quad 2.3427 \mathrm{E}-06 \quad 2.3427 \mathrm{E}-06 \quad 1.56 \mathrm{E}-08$ $\begin{array}{llll}5.43 \mathrm{E}-05 & 7.76822 \mathrm{E}-06 & 7.76822 \mathrm{E}-06 & 5.16 \mathrm{E}-08\end{array}$ $\begin{array}{llll}5.000138 & 2.1557 \mathrm{E}-05 & 2.1557 \mathrm{E}-05 & 1.43 \mathrm{E}-07\end{array}$ $\begin{array}{llll}0.000312 & 5.27148 E-05 & 5.27148 E-05 & 3.5 E-07\end{array}$ $\begin{array}{llll}0.000312 & 5.27148 E-05 & 5.27148 E-05 & 3.5 \mathrm{E}-07 \\ 0.000645 & 0.000117232 & 0.000117232 & 7.79 E-07\end{array}$ $\begin{array}{lllll}0.000645 & 0.000117232 & 0.000117232 & 7.79 E-07\end{array}$ $\begin{array}{llllll}0.001248 & 0.000242059 & 0.000242059 & 1.61 \mathrm{E}-06\end{array}$ $\begin{array}{lllll}0.002287 & 0.000470749 & 0.000470749 & 3.13 \mathrm{E}-06\end{array}$ $\begin{array}{lllll}0.004005 & 0.000871247 & 0.000871247 & 5.79 E-06\end{array}$ $\begin{array}{llll}0.006752 & 0.001546419 & 0.001546419 & 1.03 \mathrm{E}-05\end{array}$ $\begin{array}{llll}0.011015 & 0.002647942 & 0.002647942 & 1.76 E-05\end{array}$ $\begin{array}{lllll}0.017464 & 0.004394292 & 0.004394292 & 2.92 \mathrm{E}-05\end{array}$ $\begin{array}{lllll}0.026993 & 0.007093576 & 0.007093576 & 4.71 \mathrm{E}-05\end{array}$ $\begin{array}{lllll}0.040784 & 0.011171976 & 0.011171976 & 7.42 E-05\end{array}$ $\begin{array}{llllllll}0.000784 & 0.011171976 & 0.011171976 & 7.42 \mathrm{E}-05\end{array}$ $\begin{array}{llllll}0.060366 & 0.017208561 & 0.017208561 & 0.000114\end{array}$ 0.0876850 .025977 $\begin{array}{lllll}0.125183 & 0.038495441 & 0.038495441 & 0.000256\end{array}$ $\begin{array}{lllll}0.175872 & 0.056082666 & 0.056082666 & 0.000373\end{array}$ $\begin{array}{lllll}0.243415 & 0.080424134 & 0.080424134 & 0.000534\end{array}$ $\begin{array}{lllll}0.332198 & 0.11364391 & 0.11364391 & 0.000755\end{array}$ $\begin{array}{lllll}0.447399 & 0.158383804 & 0.158383804 & 0.001053\end{array}$ $\begin{array}{llllll}0.595038 & 0.217887562 & 0.217887562 & 0.001448\end{array}$ $\begin{array}{lllllll}0.592007 & 0.21788752 & 0.217887562 & 0.001448\end{array}$ $\begin{array}{llllll}0.782007 & 0.296088233 & 0.296088233 & 0.001968\end{array}$ $\begin{array}{llllll}1.016078 & 0.397696027 & 0.397696027 & 0.0002643\end{array}$ $\begin{array}{llllll}1.305873 & 0.528283333 & 0.528283333 & 0.003511\end{array}$ $\begin{array}{lllll}1.660796 & 0.69436294 & 0.69436294 & 0.004615\end{array}$ $\begin{array}{lllll}2.090919 & 0.903454888 & 0.903454888 & 0.006004\end{array}$ $\begin{array}{lllll}2.606821 & 1.164136944 & 1.164136944 & 0.007737\end{array}$ $\begin{array}{llllll}3.219364 & 1.486073367 & 1.486073367 & 0.009876\end{array}$ $\begin{array}{llllll}3.939432 & 1.880016547 & 1.880016547 & 0.012494\end{array}$ $\begin{array}{llllll}4.777597 & 2.357776231 & 2.357776231 & 0.015669\end{array}$ $\begin{array}{llllll}5.743753 & 2.3577151516 \quad 2.932151516 \quad 0.019486\end{array}$ $\begin{array}{lllllll}4.743753 & 2.932151516 & 2.932151516 & 0.019486\end{array}$ $\begin{array}{lllll}6.8467 & 3.616821545 & 3.616821545 & 0.024036\end{array}$ $\begin{array}{lllllll}8.093703 & 4.426191891 & 4.426191891 & 0.029415\end{array}$ $\begin{array}{lllll}9.490032 & 5.375195053 & 5.375195053 & 0.035722\end{array}$ $\begin{array}{llllll}11.0385 & 6.479045132 & 6.479045132 & 0.043058\end{array}$ $\begin{array}{lllll}12.73904 & 7.752948687 & 7.752948687 & 0.051524\end{array}$ $\begin{array}{lllll}14.58827 & 9.211775847 & 9.211775847 & 0.061219\end{array}$ $\begin{array}{lllll}16.57922 & 10.8696979 & 10.8696979 & 0.072237\end{array}$ $\begin{array}{lllll}18.70102 & 12.73979973 & 12.73979973 & 0.084665\end{array}$ $\begin{array}{lllll}20.93878 & 14.83367738 & 14.83367738 & 0.09858\end{array}$ $\begin{array}{lllll}23.27355 & 17.16103284 & 17.16103284 & 0.114047\end{array}$ $\begin{array}{lllll}25.68247 & 19.72927941 & 19.72927941 & 0.131115\end{array}$ $\begin{array}{lllll}28.13892 & 22.54317175 & 22.54317175 & 0.149816\end{array}$ $\begin{array}{llll}30.61304 & 25.60447531 & 25.60447531 & 0.17016\end{array}$ $\begin{array}{lllll}33.07214 & 28.91168904 & 28.91168904 & 0.192139\end{array}$ $\begin{array}{lllll}35.48146 & 32.45983455 & 32.45983455 & 0.215719\end{array}$ A-54 


\section{Appendix C3 - f}

dpi 5.10 .199 $\begin{array}{lllll}5.2 & 0.197756433 & 0.380364 & 0.299046\end{array}$ $\begin{array}{llllll}5.3 & 0.194986657 & 0.399863 & 0.294858\end{array}$ $\begin{array}{lllll}5.4 & 0.191172779 & 0.41898 & 0.289091\end{array}$ $\begin{array}{lllll}5.5 & 0.18637654 & 0.437618 & 0.281838\end{array}$ $\begin{array}{lllll}5.6 & 0.180674458 & 0.455685 & 0.273215\end{array}$ $\begin{array}{llllll}5.7 & 0.174155825 & 0.473101 & 0.263358\end{array}$ $\begin{array}{lllll}5.8 & 0.166920414 & 0.489793 & 0.252416\end{array}$ $\begin{array}{llllll}5.9 & 0.15907598 & 0.505701 & 0.240554\end{array}$ $\begin{array}{lllll}6 & 0.150735635 & 0.520774 & 0.227942\end{array}$ $\begin{array}{lllll}6.1 & 0.14201519 & 0.534976 & 0.214755\end{array}$ $\begin{array}{lllll}6.2 & 0.133030546 & 0.548279 & 0.201168\end{array}$ $\begin{array}{llllll}6.3 & 0.123895222 & 0.560668 & 0.187354\end{array}$ $\begin{array}{lllll}6.4 & 0.114718076 & 0.57214 & 0.173476\end{array}$ $\begin{array}{rrrrr}6.5 & 0.105601297 & 0.5827 & 0.15969\end{array}$ $\begin{array}{lllll}6.6 & 0.096638696 & 0.592364 & 0.146137\end{array}$ $\begin{array}{lllll}6.7 & 0.087914346 & 0.601156 & 0.132944\end{array}$ $\begin{array}{lllll}6.8 & 0.079501573 & 0.609106 & 0.120222\end{array}$ $\begin{array}{lllll}6.9 & 0.071462319 & 0.616252 & 0.108065\end{array}$

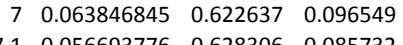
$\begin{array}{lllll}7.1 & 0.056693776 & 0.628306 & 0.085732\end{array}$ $\begin{array}{llllll}7.2 & 0.050030436 & 0.633309 & 0.075656\end{array}$ $\begin{array}{lllll}7.3 & 0.043873445 & 0.637696 & 0.066345\end{array}$ $\begin{array}{lllll}7.4 & 0.038229538 & 0.641519 & 0.057811\end{array}$ $\begin{array}{lllll}7.5 & 0.033096535 & 0.644829 & 0.050048\end{array}$ $\begin{array}{llllll}7.6 & 0.028464446 & 0.647675 & 0.043044\end{array}$ $\begin{array}{lllll}7.7 & 0.024316637 & 0.650107 & 0.036772\end{array}$ $\begin{array}{llllll}7.8 & 0.020631022 & 0.65217 & 0.031198\end{array}$ $\begin{array}{lllll}7.9 & 0.017381247 & 0.653908 & 0.026284\end{array}$ $\begin{array}{lllll}8 & 0.014537824 & 0.655362 & 0.021984\end{array}$ $\begin{array}{lllll}8.1 & 0.012069185 & 0.656569 & 0.018251\end{array}$ $\begin{array}{lllll}8.2 & 0.009942645 & 0.657563 & 0.015035\end{array}$ $\begin{array}{llllll}8.3 & 0.008125247 & 0.658376 & 0.012287\end{array}$ $\begin{array}{lllll}8.4 & 0.006584488 & 0.659034 & 0.009957\end{array}$ $\begin{array}{lllll}8.5 & 0.005288917 & 0.659563 & 0.007998\end{array}$ $\begin{array}{llllll}8.6 & 0.004208616 & 0.659984 & 0.006364\end{array}$ $\begin{array}{lllll}8.7 & 0.00331555 & 0.660316 & 0.005014\end{array}$ $\begin{array}{lllll}8.8 & 0.002583823 & 0.660574 & 0.003907\end{array}$ $\begin{array}{lllll}8.9 & 0.001989826 & 0.660773 & 0.003009\end{array}$ $\begin{array}{lllll}9 & 0.0015123 & 0.660924 & 0.002287\end{array}$ $\begin{array}{lllll}9.1 & 0.001132333 & 0.661037 & 0.001712\end{array}$ $\begin{array}{lllll}9.2 & 0.000833291 & 0.661121 & 0.00126\end{array}$ $\begin{array}{lllll}9.3 & 0.000600709 & 0.661181 & 0.000908\end{array}$ $\begin{array}{lllll}9.4 & 0.000422149 & 0.661223 & 0.000638\end{array}$ $\begin{array}{lllll}9.5 & 0.000287028 & 0.661252 & 0.000434\end{array}$ $\begin{array}{lllll}9.6 & 0.000186444 & 0.66127 & 0.000282\end{array}$ $\begin{array}{lllll}9.7 & 0.000112991 & 0.661282 & 0.000171\end{array}$ $\begin{array}{cccc}9.8 & 6.05745 \mathrm{E}-05 & 0.661288 & 9.16 \mathrm{E}-05\end{array}$ $9.9 \quad 2.42384 \mathrm{E}-05 \quad 0.66129 \quad 3.67 \mathrm{E}-05$ $10 \quad 3.84068 \mathrm{E}-18 \quad 0.66129 \quad 5.81 \mathrm{E}-18$ $\begin{array}{llll}\text { dinteg } & \text { Top } & \text { Bottom } & \mathbf{f}(\mathbf{x})\end{array}$

$\begin{array}{lllll}40.00587 & 40.24091012 & 40.24091012 & 0.26743\end{array}$ $\begin{array}{lllll}42.04831 & 44.44574146 & 44.44574146 & 0.295374\end{array}$ $\begin{array}{llllll}43.89757 & 48.83549798 & 48.83549798 & 0.324547\end{array}$ $\begin{array}{llllll}45.52136 & 53.38763433 & 53.38763433 & 0.354799\end{array}$ $\begin{array}{llllll}46.89076 & 58.07671001 & 58.07671001 & 0.385961\end{array}$ $\begin{array}{llllll}47.98094 & 62.87480422 & 62.87480422 & 0.417848\end{array}$ $\begin{array}{lllll}48.77199 & 67.75200351 & 67.75200351 & 0.450261\end{array}$ $\begin{array}{lllll}49.24945 & 72.67694827 & 72.67694827 & 0.48299\end{array}$ $\begin{array}{llllll}49.40473 & 77.61742177 & 77.61742177 & 0.515823\end{array}$ $\begin{array}{llllll}49.23542 & 82.54096343 & 82.54096343 & 0.548544\end{array}$ $\begin{array}{lllll}48.74524 & 87.41548767 & 87.41548767 & 0.580938\end{array}$ $\begin{array}{lllll}47.94401 & 92.20988885 & 92.20988885 & 0.612801\end{array}$ $\begin{array}{llllll}46.84725 & 96.89461421 & 96.89461421 & 0.643934\end{array}$ $\begin{array}{lllll}45.47573 & 101.4421875 & 101.4421875 & 0.674156\end{array}$ $\begin{array}{llllll}43.85481 & 105.8276687 & 105.8276687 & 0.703301\end{array}$ $\begin{array}{llllll}42.01369 & 110.0290375 & 110.0290375 & 0.731222\end{array}$ $\begin{array}{lllll}39.98454 & 114.0274913 & 114.0274913 & 0.757794\end{array}$ $\begin{array}{lllll}37.80162 & 117.8076531 & 117.8076531 & 0.782916\end{array}$ $\begin{array}{lllll}35.50032 & 121.3576854 & 121.3576854 & 0.806509\end{array}$ $\begin{array}{lllll}33.11628 & 124.669313 & 124.669313 & 0.828517\end{array}$ $\begin{array}{lllll}30.68445 & 127.7377581 & 127.7377581 & 0.848909\end{array}$ $\begin{array}{lllll}28.23838 & 130.5615957 & 130.5615957 & 0.867675\end{array}$ $\begin{array}{lllll}25.80942 & 133.1425377 & 133.1425377 & 0.884827\end{array}$ $\begin{array}{lllll}23.42622 & 135.4851593 & 135.4851593 & 0.900396\end{array}$ $\begin{array}{lllll}21.11418 & 137.5965774 & 137.5965774 & 0.914428\end{array}$ $\begin{array}{lllll}18.8952 & 139.4860972 & 139.4860972 & 0.926985\end{array}$ $\begin{array}{lllll}16.78741 & 141.1648379 & 141.1648379 & 0.938141\end{array}$ $\begin{array}{lllll}14.80514 & 142.6453517 & 142.6453517 & 0.94798\end{array}$ $\begin{array}{lllll}12.95896 & 143.9412477 & 143.9412477 & 0.956593\end{array}$ $\begin{array}{lllll}11.25582 & 145.0668301 & 145.0668301 & 0.964073\end{array}$ $\begin{array}{lllll}9.699312 & 146.0367613 & 146.0367613 & 0.970519\end{array}$ $\begin{array}{lllll}8.289941 & 146.8657554 & 146.8657554 & 0.976028\end{array}$ $\begin{array}{lllll}7.025525 & 147.5683079 & 147.5683079 & 0.980697\end{array}$ $\begin{array}{lllll}5.901573 & 148.1584652 & 148.1584652 & 0.984619\end{array}$ $\begin{array}{lllll}4.911696 & 148.6496348 & 148.6496348 & 0.987883\end{array}$ $\begin{array}{llllll}4.048019 & 149.0544367 & 149.0544367 & 0.990573\end{array}$ $\begin{array}{lllll}3.301576 & 149.3845943 & 149.3845943 & 0.992768\end{array}$ $\begin{array}{lllll}2.662679 & 149.6508622 & 149.6508622 & 0.994537\end{array}$ $\begin{array}{lllll}2.121256 & 149.8629878 & 149.8629878 & 0.995947\end{array}$ $\begin{array}{lllll}1.667146 & 150.0297023 & 150.0297023 & 0.997055\end{array}$ $\begin{array}{lllll}1.290346 & 150.158737 & 150.158737 & 0.997912\end{array}$ $\begin{array}{lllll}0.981224 & 150.2568593 & 150.2568593 & 0.998564\end{array}$ $\begin{array}{llll}0.73067 & 150.3299263 & 150.3299263 & 0.99905\end{array}$ $\begin{array}{lllll}0.530221 & 150.3829484 & 150.3829484 & 0.999402\end{array}$ $\begin{array}{lllll}0.372137 & 150.4201621 & 150.4201621 & 0.99965\end{array}$ $\begin{array}{lllll}0.249442 & 150.4451063 & 150.4451063 & 0.999815\end{array}$ $\begin{array}{lllll}0.155943 & 150.4607007 & 150.4607007 & 0.999919\end{array}$ $\begin{array}{lllll}0.086214 & 150.4693221 & 150.4693221 & 0.999976\end{array}$ $\begin{array}{lll}0.035565 & 150.4728785 & 150.4728785\end{array}$ 


\section{Appendix C3 - dpi_bar}

Top Bottom $p(\mathbf{x})$

$\begin{array}{rrrr}0.1 & 2.42 \mathrm{E}-05 & 2.42 \mathrm{E}-06 & 3.67 \mathrm{E}-05 \\ 0.2 & 6.06 \mathrm{E}-05 & 8.48 \mathrm{E}-06 & 9.16 \mathrm{E}-05\end{array}$ $\begin{array}{llll}0.2 & 6.06 \mathrm{E}-05 & 8.48 \mathrm{E}-06 & 9.16 \mathrm{E}-05 \\ 0.3 & 0.000113 & 1.98 \mathrm{E}-05 & 0.000171\end{array}$ $\begin{array}{lllll}0.3 & 0.000113 & 1.98 \mathrm{E}-05 & 0.000171\end{array}$ $\begin{array}{lllll}0.4 & 0.000186 & 3.84 \mathrm{E}-05 & 0.000282\end{array}$ $\begin{array}{lllll}0.5 & 0.000287 & 6.71 \mathrm{E}-05 & 0.000434\end{array}$ $\begin{array}{lllll}0.6 & 0.000422 & 0.000109 & 0.000638\end{array}$ $\begin{array}{llllll}0.7 & 0.000422 & 0.0001090 & 0.000638\end{array}$ $\begin{array}{lllll}0.7 & 0.000601 & 0.000169 & 0.000908\end{array}$ $\begin{array}{llllll}0.8 & 0.000833 & 0.000253 & 0.00126\end{array}$ $\begin{array}{lllll}0.9 & 0.001132 & 0.000366 & 0.001712\end{array}$ $\begin{array}{llllll}1 & 0.001512 & 0.000517 & 0.002287\end{array}$ $\begin{array}{lllll}1.1 & 0.00199 & 0.000716 & 0.003009\end{array}$ $\begin{array}{lllll}1.2 & 0.002584 & 0.000975 & 0.003907\end{array}$ $\begin{array}{lllll}1.3 & 0.003316 & 0.001306 & 0.005014\end{array}$ $\begin{array}{lllll}1.4 & 0.004209 & 0.001727 & 0.006364\end{array}$ $\begin{array}{llllll}1.5 & 0.005289 & 0.002256 & 0.007998\end{array}$ $\begin{array}{lllll}1.5 & 0.005289 & 0.002256 & 0.007998\end{array}$ $\begin{array}{lllllll}1.6 & 0.006584 & 0.002914 & 0.009957\end{array}$ $\begin{array}{llllll}1.7 & 0.008125 & 0.003727 & 0.012287\end{array}$ $\begin{array}{lllll}1.8 & 0.009943 & 0.004721 & 0.015035\end{array}$ $\begin{array}{lllll}19 & 0.012069 & 0.005928 & 0.018251\end{array}$ $\begin{array}{lllll}2 & 0.014538 & 0.007382 & 0.021984\end{array}$ $\begin{array}{lllll}2.1 & 0.017381 & 0.00912 & 0.026284\end{array}$ $\begin{array}{lllll}2.2 & 0.020631 & 0.011183 & 0.031198\end{array}$ $\begin{array}{lllll}2.3 & 0.024317 & 0.013615 & 0.036772\end{array}$ $\begin{array}{lllll}2.4 & 0.028464 & 0.016461 & 0.043044\end{array}$ $\begin{array}{lllll}2.5 & 0.033097 & 0.019771 & 0.050048\end{array}$ $\begin{array}{lllll}2.6 & 0.03823 & 0.023594 & 0.057811\end{array}$ $\begin{array}{lllll}2.7 & 0.043873 & 0.027981 & 0.066345\end{array}$ $\begin{array}{lllll}2.8 & 0.05003 & 0.032984 & 0.075656\end{array}$ $\begin{array}{lllll}2.9 & 0.056694 & 0.038654 & 0.085732\end{array}$ $\begin{array}{lllll}3 & 0.063847 & 0.045038 & 0.096549\end{array}$ $\begin{array}{lllll}3.1 & 0.071462 & 0.052184 & 0.108065\end{array}$ $\begin{array}{lllll}3.2 & 0.079502 & 0.060135 & 0.120222\end{array}$ $\begin{array}{lllll}3.3 & 0.087914 & 0.068926 & 0.132944\end{array}$ $\begin{array}{llll}3.4 & 0.096639 & 0.07859 & 0.146137\end{array}$ $\begin{array}{llll}3.5 & 0.105601 & 0.08915 & 0.15969\end{array}$ $\begin{array}{llll}3.6 & 0.114718 & 0.100622 & 0.173476\end{array}$ $\begin{array}{llll}3.7 & 0.123895 & 0.113011 & 0.187354\end{array}$ $\begin{array}{lllll}3.8 & 0.133031 & 0.126314 & 0.201168\end{array}$ $\begin{array}{lllll}3.9 & 0.142015 & 0.140516 & 0.214755\end{array}$ $\begin{array}{lllll}4 & 0.150736 & 0.15559 & 0.227942\end{array}$ $\begin{array}{lllll}4.1 & 0.159076 & 0.171497 & 0.240554\end{array}$ $\begin{array}{lllll}4.2 & 0.16692 & 0.188189 & 0.252416\end{array}$ $\begin{array}{lllll}4.3 & 0.174156 & 0.205605 & 0.263358\end{array}$ $\begin{array}{lllll}4.4 & 0.180674 & 0.223672 & 0.273215\end{array}$ $\begin{array}{lllll}4.5 & 0.186377 & 0.24231 & 0.281838\end{array}$ $\begin{array}{llll}4.6 & 0.191173 & 0.261427 & 0.289091\end{array}$ $\begin{array}{lllll}4.7 & 0.194987 & 0.280926 & 0.294858\end{array}$ $\begin{array}{lllll}4.8 & 0.197756 & 0.300701 & 0.299046\end{array}$ $\begin{array}{lllll}4.9 & 0.199437 & 0.320645 & 0.301587\end{array}$

$\begin{array}{lllll}5 & 0.2 & 0.340645 & 0.302439\end{array}$
dinteg

(1)
0
Top 0
Bottom dpi_bar
$1.00 \mathrm{E}-10$

$\begin{array}{llllll}3.67 E-08 & 3.66532 E-07 & 3.67 E-09 & 0.404371 & 9.06425 E-09\end{array}$ $\begin{array}{llllll}7.33 E-07 & 3.66402 E-06 & 7.69 E-08 & 0.849634 & 9.05634 \mathrm{E}-08\end{array}$ $\begin{array}{llllll}4.61 \mathrm{E}-06 & 1.53778 \mathrm{E}-05 & 5.38 \mathrm{E}-07 & 1.336582 & 4.02729 \mathrm{E}-07\end{array}$ $\begin{array}{llllll}1.8 \mathrm{E}-05 & 4.51104 \mathrm{E}-05 & 2.34 \mathrm{E}-06 & 1.865526 & 1.25578 \mathrm{E}-06\end{array}$ $\begin{array}{lllll}5.43 \mathrm{E}-05 & 0.00010851 & 7.77 \mathrm{E}-06 & 2.436248 & 3.1886 \mathrm{E}-06\end{array}$ $\begin{array}{llllll}0.000138 & 0.000229814 & 2.16 \mathrm{E}-05 & 3.047963 & 7.0726 \mathrm{E}-06\end{array}$ $\begin{array}{llllll}0.000312 & 0.000445111 & 5.27 E-05 & 3.699305 & 1.42499 E-05\end{array}$ $\begin{array}{lllllll}0.000312 & 0.000445111 & 5.27 \mathrm{E}-05 & 3.699305 & 1.42499 \mathrm{E}-05\end{array}$ $\begin{array}{lllllll}0.000645 & 0.000806463 & 0.000117 & 4.388308 & 2.67146 \mathrm{E}-05 \\ 0.001248 & 0.00138697 & 0.000242 & 5.122819 & 4.73473 \mathrm{E}\end{array}$ $\begin{array}{llllll}0.001248 & 0.00138697 & 0.000242 & 5.112419 & 4.73473 \mathrm{E}-05\end{array}$ $\begin{array}{llllll}0.002287 & 0.002286894 & 0.000471 & 5.868517 & 8.02159 \mathrm{E}-05\end{array}$ $\begin{array}{lllllll}0.004005 & 0.003640897 & 0.000871 & 6.652945 & 0.000130957\end{array}$ $\begin{array}{lllllll}0.006752 & 0.005626434 & 0.001546 & 7.461567 & 0.000207251\end{array}$ $\begin{array}{llllll}0.011015 & 0.008473253 & 0.002648 & 8.289823 & 0.000319421\end{array}$ $\begin{array}{llllll}0.017464 & 0.012473929 & 0.004394 & 9.132811 & 0.000481154\end{array}$ $\begin{array}{llllll}0.026993 & 0.017995223 & 0.007094 & 9.98537 & 0.000710397\end{array}$ $\begin{array}{llllll}0.040784 & 0.025490003 & 0.011172 & 10.84217 & 0.001030419\end{array}$ $\begin{array}{lllllll}0.060366 & 0.03550932 & 0.017209 & 11.69782 & 0.001471091\end{array}$ $\begin{array}{llllll}0.087685 & 0.048714123 & 0.025977 & 12.54695 & 0.002070392\end{array}$ $\begin{array}{llllll}0.125183 & 0.065885991 & 0.038495 & 13.38432 & 0.00287616\end{array}$ $\begin{array}{llllll}0.175872 & 0.087936126 & 0.056083 & 14.20491 & 0.003948119\end{array}$ $\begin{array}{llllll}0.243415 & 0.115911748 & 0.080424 & 15.00401 & 0.005360176\end{array}$ $\begin{array}{llllll}0.332198 & 0.150998985 & 0.113644 & 15.7773 & 0.007203\end{array}$ $\begin{array}{llllll}0.447399 & 0.194521276 & 0.158384 & 16.52091 & 0.00958687\end{array}$ $\begin{array}{lllllll}0.595038 & 0.247932324 & 0.217888 & 17.23147 & 0.012644748\end{array}$ $\begin{array}{lllllll}0.592007 & 0.31282324 & 0.217888 & 17.23147 & 0.012640748\end{array}$ $\begin{array}{llllllll}0.782007 & 0.312802686 & 0.296088 & 17.90616 & 0.016535555\end{array}$ $\begin{array}{llllllll}1.016078 & 0.390799206 & 0.397696 & 18.54273 & 0.021447547\end{array}$ $\begin{array}{lllllll}1.305873 & 0.48365669 & 0.528283 & 19.13951 & 0.027601714\end{array}$ $\begin{array}{llllll}1.660796 & 0.593141455 & 0.694363 & 19.69542 & 0.03525505\end{array}$ $\begin{array}{llllll}2.090919 & 0.721006718 & 0.903455 & 20.20992 & 0.044703546\end{array}$ $\begin{array}{llllll}2.606821 & 0.868940185 & 1.164137 & 20.683 & 0.05628471\end{array}$ $\begin{array}{llllll}3.219364 & 1.038504592 & 1.486073 & 21.11518 & 0.070379383\end{array}$ $\begin{array}{lllllll}3.939432 & 1.231072438 & 1.880017 & 21.50738 & 0.087412625\end{array}$ $\begin{array}{lllllll}4.777597 & 1.447756615 & 2.357776 & 21.86093 & 0.107853409\end{array}$ $\begin{array}{lllrll}5.743753 & 1.689339075 & 2.932152 & 22.1775 & 0.132212872\end{array}$ $\begin{array}{llllll}6.8467 & 1.956200083 & 3.616822 & 22.45903 & 0.161040886\end{array}$ $\begin{array}{lllllll}8.093703 & 2.248250962 & 4.426192 & 22.70765 & 0.194920758\end{array}$ $\begin{array}{llllll}9.490032 & 2.564873411 & 5.375195 & 22.92567 & 0.234461894\end{array}$ $\begin{array}{lllllll}11.0385 & 2.904868629 & 6.479045 & 23.11548 & 0.280290369\end{array}$ $\begin{array}{lllllll}12.73904 & 3.266419372 & 7.752949 & 23.27951 & 0.333037411\end{array}$ $\begin{array}{lllllll}14.58827 & 3.6470679 & 9.211776 & 23.42021 & 0.393325918\end{array}$ $\begin{array}{llllll}16.57922 & 4.04371233 & 10.8697 & 23.53996 & 0.461755249\end{array}$ $\begin{array}{lllllll}18.70102 & 4.452623401 & 12.7398 & 23.53105 & 0.438884635\end{array}$ $\begin{array}{llllll}18.9302 & 4.452623401 & 12.7398 & 23.64105 & 0.538884635\end{array}$ $\begin{array}{llllllll}20.93878 & 4.869482904 & 14.83368 & 23.7257 & 0.625215664\end{array}$ $\begin{array}{lllllll}23.27355 & 5.289442236 & 17.16103 & 23.79595 & 0.721174406\end{array}$ $\begin{array}{llllll}25.68247 & 5.707214582 & 19.72928 & 23.85374 & 0.82709381\end{array}$ $\begin{array}{llllll}28.13892 & 6.117157264 & 22.54317 & 23.90081 & 0.943197039\end{array}$ $\begin{array}{llllll}30.61304 & 6.513411842 & 25.60448 & 23.93876 & 1.069582464\end{array}$ $\begin{array}{llllll}33.07214 & 6.890028599 & 28.91169 & 23.96902 & 1.206210964\end{array}$ $\begin{array}{lllllll}35.48146 & 7.241113288 & 32.45983 & 23.99285 & 1.352896178\end{array}$ $\mathrm{A}^{37}-5^{8} \mathrm{~b}^{489} \quad 7.560977306 \quad 36.24032 \quad 24.01137 \quad 1.509298219$ 


\section{Appendix C3 - dpi_bar}

dpi Top Bottom $\mathbf{p}(\mathbf{x})$ $\begin{array}{llllll}5.1 & 0.199437 & 0.360589 & 0.301587\end{array}$ $\begin{array}{lllll}5.2 & 0.197756 & 0.380364 & 0.299046\end{array}$ $\begin{array}{lllll}5.3 & 0.194987 & 0.399863 & 0.294858\end{array}$ $\begin{array}{lllll}5.4 & 0.191173 & 0.41898 & 0.289091\end{array}$ $\begin{array}{lllll}5.5 & 0.186377 & 0.437618 & 0.281838\end{array}$ $\begin{array}{lllll}5.6 & 0.180674 & 0.455685 & 0.273215\end{array}$ $\begin{array}{lllll}5.7 & 0.174156 & 0.473101 & 0.263358\end{array}$ $\begin{array}{lllll}5.8 & 0.16692 & 0.489793 & 0.252416\end{array}$ $\begin{array}{lllll}5.9 & 0.159076 & 0.505701 & 0.240554\end{array}$ $\begin{array}{lllll}6 & 0.150736 & 0.520774 & 0.227942\end{array}$ $\begin{array}{lllll}6.1 & 0.142015 & 0.534976 & 0.214755\end{array}$ $\begin{array}{lllll}6.2 & 0.133031 & 0.548279 & 0.201168\end{array}$ $\begin{array}{lllll}6.3 & 0.123895 & 0.560668 & 0.187354\end{array}$ $\begin{array}{lllll}6.4 & 0.114718 & 0.57214 & 0.173476\end{array}$ $\begin{array}{lllll}6.5 & 0.105601 & 0.5827 & 0.15969\end{array}$ $\begin{array}{llll}6.6 & 0.096639 & 0.592364 & 0.146137\end{array}$ $\begin{array}{lllll}6.7 & 0.087914 & 0.601156 & 0.132944\end{array}$ $\begin{array}{lllll}6.8 & 0.079502 & 0.609106 & 0.120222\end{array}$ $\begin{array}{lllll}6.9 & 0.071462 & 0.616252 & 0.108065\end{array}$ $\begin{array}{lllll}7 & 0.063847 & 0.622637 & 0.096549\end{array}$ $\begin{array}{lllll}7.1 & 0.056694 & 0.628306 & 0.085732\end{array}$ $\begin{array}{lllll}7.2 & 0.05003 & 0.633309 & 0.075656\end{array}$ $\begin{array}{lllll}7.3 & 0.043873 & 0.637696 & 0.066345\end{array}$ $\begin{array}{lllll}7.4 & 0.03823 & 0.641519 & 0.057811\end{array}$ $\begin{array}{lllll}7.5 & 0.033097 & 0.644829 & 0.050048\end{array}$ $\begin{array}{lllll}7.6 & 0.028464 & 0.647675 & 0.043044\end{array}$ $\begin{array}{lllll}7.7 & 0.024317 & 0.650107 & 0.036772\end{array}$ $\begin{array}{lllll}7.8 & 0.020631 & 0.65217 & 0.031198\end{array}$ $\begin{array}{lllll}7.9 & 0.017381 & 0.653908 & 0.026284\end{array}$ $\begin{array}{lllll}8 & 0.014538 & 0.655362 & 0.021984\end{array}$ $\begin{array}{lllll}8.1 & 0.012069 & 0.656569 & 0.018251\end{array}$ $\begin{array}{llll}8.2 & 0.009943 & 0.657563 & 0.015035\end{array}$ $\begin{array}{lllll}8.3 & 0.008125 & 0.658376 & 0.012287\end{array}$ $\begin{array}{lllll}8.4 & 0.006584 & 0.659034 & 0.009957\end{array}$ $\begin{array}{lllll}8.5 & 0.005289 & 0.659563 & 0.007998\end{array}$ $\begin{array}{lllll}8.6 & 0.004209 & 0.659984 & 0.006364\end{array}$ $\begin{array}{lllll}8.7 & 0.003316 & 0.660316 & 0.005014\end{array}$ $\begin{array}{lllll}8.8 & 0.002584 & 0.660574 & 0.003907\end{array}$ $\begin{array}{lllll}8.9 & 0.00199 & 0.660773 & 0.003009\end{array}$ $\begin{array}{lllll}9 & 0.001512 & 0.660924 & 0.002287\end{array}$ $\begin{array}{llll}9.1 & 0.001132 & 0.661037 & 0.001712\end{array}$ $\begin{array}{lllll}9.2 & 0.000833 & 0.661121 & 0.00126\end{array}$ $\begin{array}{llll}9.3 & 0.000601 & 0.661181 & 0.000908\end{array}$ $\begin{array}{lllll}9.4 & 0.000422 & 0.661223 & 0.000638\end{array}$ $\begin{array}{lllll}9.5 & 0.000287 & 0.661252 & 0.000434\end{array}$ $\begin{array}{lllll}9.6 & 0.000186 & 0.66127 & 0.000282\end{array}$ $\begin{array}{llll}9.7 & 0.000113 & 0.661282 & 0.000171\end{array}$ $\begin{array}{llll}9.8 & 6.06 \mathrm{E}-05 & 0.661288 & 9.16 \mathrm{E}-05\end{array}$ $9.9 \quad 2.42 \mathrm{E}-05 \quad 0.66129 \quad 3.67 \mathrm{E}-05$ $10 \quad 3.84 \mathrm{E}-18 \quad 0.66129 \quad 5.81 \mathrm{E}-18$ dinteg dinteg Top Bottom dpi_bar

$40.00587 \quad 7.84$ $\begin{array}{lllllll}42.04831 & 8.08621412 & 44.44574 & 24.03622 & 1.84911538\end{array}$ $\begin{array}{lllllll}43.89757 & 8.282559467 & 48.8355 & 24.04408 & 2.031082398\end{array}$ $\begin{array}{lllllll}45.52136 & 8.429882128 & 53.38763 & 24.04972 & 2.21988628\end{array}$ $\begin{array}{lllllll}46.89076 & 8.525592153 & 58.07671 & 24.05363 & 2.414467276\end{array}$ $\begin{array}{llllll}47.98094 & 8.568025374 & 62.8748 & 24.05623 & 2.613659762\end{array}$ $\begin{array}{llllll}48.77199 & 8.55648997 & 67.752 & 24.05784 & 2.816213174\end{array}$ $\begin{array}{llllll}49.24945 & 8.491284083 & 72.67695 & 24.05872 & 3.020815392\end{array}$ $\begin{array}{llllll}49.40473 & 8.373683892 & 77.61742 & 24.05908 & 3.226117868\end{array}$ $\begin{array}{lllllll}49.23542 & 8.205902774 & 82.54096 & 24.05908 & 3.430761689\end{array}$ $\begin{array}{llllll}48.74524 & 7.991023329 & 87.41549 & 24.05908 & 3.633368131\end{array}$ $\begin{array}{llllll}47.94401 & 7.732905131 & 92.20989 & 24.05908 & 3.832644311\end{array}$ $\begin{array}{lllllll}46.84725 & 7.436072001 & 96.89461 & 24.05908 & 4.027361887\end{array}$ $\begin{array}{llllll}45.47573 & 7.105583287 & 101.4422 & 24.05908 & 4.216378826\end{array}$ $\begin{array}{llllll}43.85481 & 6.746894164 & 105.8277 & 24.05908 & 4.398658512\end{array}$ $\begin{array}{llllll}42.01369 & 6.365710216 & 110.029 & 24.05908 & 4.573285683\end{array}$ $\begin{array}{llllll}39.98454 & 5.967841549 & 114.0275 & 24.05908 & 4.739478827\end{array}$ $\begin{array}{llllll}37.80162 & 5.559061477 & 117.8077 & 24.05908 & 4.896598805\end{array}$ $\begin{array}{llllll}35.50032 & 5.144974361 & 121.3577 & 24.05908 & 5.044153598\end{array}$ $\begin{array}{llllll}33.11628 & 4.730896564 & 124.6693 & 24.05908 & 5.181799255\end{array}$ $\begin{array}{llllll}30.68445 & 4.321753703 & 127.7378 & 24.05908 & 5.309337189\end{array}$ $\begin{array}{llllll}28.23838 & 3.921996557 & 130.5616 & 24.05908 & 5.426708167\end{array}$ $\begin{array}{llllll}25.80942 & 3.535537041 & 133.1425 & 24.05908 & 5.533983351\end{array}$ $\begin{array}{llllll}23.42622 & 3.16570481 & 135.4852 & 24.05908 & 5.63135289\end{array}$ $\begin{array}{llllll}21.11418 & 2.815224172 & 137.5966 & 24.05908 & 5.71911262\end{array}$ $\begin{array}{llllll}18.8952 & 2.486210254 & 139.4861 & 24.05908 & 5.797649293\end{array}$ $\begin{array}{llllll}16.78741 & 2.180182698 & 141.1648 & 24.05908 & 5.867425062\end{array}$ $\begin{array}{llllll}14.80514 & 1.898094678 & 142.6454 & 24.05908 & 5.928961661\end{array}$ $\begin{array}{llllll}12.95896 & 1.640374647 & 143.9412 & 24.05908 & 5.982824738\end{array}$ $\begin{array}{llllll}11.25582 & 1.406978021 & 145.0668 & 24.05908 & 6.029608842\end{array}$ $\begin{array}{llllll}9.699312 & 1.197445956 & 146.0368 & 24.05908 & 6.069923405\end{array}$ $\begin{array}{llllll}8.289941 & 1.010968396 & 146.8658 & 24.05908 & 6.10438000\end{array}$ $\begin{array}{lllllll}7.025525 & 0.846448805 & 147.5683 & 24.05908 & 6.133581148\end{array}$ $\begin{array}{llllll}5.901573 & 0.702568219 & 148.1585 & 24.05908 & 6.158110654\end{array}$ $\begin{array}{llllll}4.911696 & 0.577846604 & 148.6496 & 24.05908 & 6.178525801\end{array}$ $\begin{array}{llllll}4.048019 & 0.470699891 & 149.0544 & 24.05908 & 6.19535113\end{array}$ $\begin{array}{llllll}3.301576 & 0.379491448 & 149.3846 & 24.05908 & 6.209073915\end{array}$ $\begin{array}{llllll}2.662679 & 0.302577119 & 149.6509 & 24.05908 & 6.220141166\end{array}$ $\begin{array}{llllll}2.121256 & 0.238343374 & 149.863 & 24.05908 & 6.228958029\end{array}$ $\begin{array}{llllll}1.667146 & 0.185238405 & 150.0297 & 24.05908 & 6.235887412\end{array}$ $\begin{array}{llllll}1.290346 & 0.141796312 & 150.1587 & 24.05908 & 6.241250654\end{array}$ $\begin{array}{llllll}0.981224 & 0.106654757 & 150.2569 & 24.05908 & 6.245329047\end{array}$ $\begin{array}{llllll}0.73067 & 0.078566641 & 150.3299 & 24.05908 & 6.248366028\end{array}$ $\begin{array}{llllll}0.530221 & 0.056406487 & 150.3829 & 24.05908 & 6.250569857\end{array}$ $\begin{array}{llllll}0.372137 & 0.039172285 & 150.4202 & 24.05908 & 6.25211662\end{array}$ $\begin{array}{llllll}0.249442 & 0.025983589 & 150.4451 & 24.05908 & 6.253153411\end{array}$ $\begin{array}{llllll}0.155943 & 0.016076649 & 150.4607 & 24.05908 & 6.25380158\end{array}$ $\begin{array}{llllll}0.086214 & 0.008797314 & 150.4693 & 24.05908 & 6.254159922\end{array}$ $\begin{array}{llllll}0.035565 & 0.003592382 & 150.4729 & 24.05908 & 6.254307744\end{array}$ A-5.51E-15 $\quad 5.80785 E-16 \quad 150.4729 \quad 24.05908 \quad 6.254307744$ 


\section{Appendix C3 - Alpha}

\begin{tabular}{|c|c|c|c|c|c|c|}
\hline me & alpha(i) & delta(i) & Product & Sum & Delta & Alpha \\
\hline 0 & $1.18 \mathrm{E}+22$ & 2.03243E-14 & $2.39 \mathrm{E}+08$ & & 0 & \\
\hline 5 & $9.14 \mathrm{E}+19$ & $4.5715 \mathrm{E}-13$ & 41763880 & $2.39 \mathrm{E}+08$ & $2.03 \mathrm{E}-14$ & $1.18 \mathrm{E}+22$ \\
\hline 10 & $3.71 E+20$ & $1.86933 \mathrm{E}-13$ & 69325575 & $2.81 E+08$ & 4.77E-13 & $5.88 \mathrm{E}+20$ \\
\hline 15 & $3.71 E+20$ & $1.86911 \mathrm{E}-13$ & 69317569 & $3.5 \mathrm{E}+08$ & $6.64 \mathrm{E}-13$ & $5.27 E+20$ \\
\hline 20 & $4.74 \mathrm{E}+08$ & $1.30453 \mathrm{E}-06$ & 618.675 & $4.19 E+08$ & $8.51 \mathrm{E}-13$ & $4.93 E+20$ \\
\hline 25 & $8.14 E+09$ & $3.14187 \mathrm{E}-07$ & 2558.614 & $4.19 E+08$ & $1.3 \mathrm{E}-06$ & $3.22 \mathrm{E}+14$ \\
\hline 30 & $8.14 \mathrm{E}+09$ & 3.14187E-07 & 2558.614 & $4.19 \mathrm{E}+08$ & $1.62 \mathrm{E}-06$ & $2.59 \mathrm{E}+14$ \\
\hline 35 & $8.14 E+09$ & 3.14187E-07 & 2558.614 & $4.19 E+08$ & $1.93 \mathrm{E}-06$ & $2.17 E+14$ \\
\hline 40 & $8.14 \mathrm{E}+09$ & $3.14187 \mathrm{E}-07$ & 2558.614 & $4.2 E+08$ & $2.25 \mathrm{E}-06$ & $1.87 \mathrm{E}+14$ \\
\hline 45 & $8.14 \mathrm{E}+09$ & 3.14187E-07 & 2558.614 & $4.2 \mathrm{E}+08$ & $2.56 \mathrm{E}-06$ & $1.64 \mathrm{E}+14$ \\
\hline 50 & $8.14 \mathrm{E}+09$ & 3.14187E-07 & 2558.614 & $4.2 \mathrm{E}+08$ & $2.88 \mathrm{E}-06$ & $1.46 \mathrm{E}+14$ \\
\hline 55 & $8.14 \mathrm{E}+09$ & $3.14187 \mathrm{E}-07$ & 2558.614 & $4.2 \mathrm{E}+08$ & $3.19 \mathrm{E}-06$ & $1.32 \mathrm{E}+14$ \\
\hline 60 & $8.14 \mathrm{E}+09$ & 3.14187E-07 & 2558.614 & $4.2 E+08$ & $3.5 \mathrm{E}-06$ & $1.2 \mathrm{E}+14$ \\
\hline 65 & $8.14 \mathrm{E}+09$ & 3.14187E-07 & 2558.614 & $4.2 E+08$ & $3.82 \mathrm{E}-06$ & $1.1 \mathrm{E}+14$ \\
\hline 70 & $8.14 \mathrm{E}+09$ & 3.14187E-07 & 2558.614 & $4.2 \mathrm{E}+08$ & 4.13E-06 & $1.02 \mathrm{E}+14$ \\
\hline 75 & $8.14 E+09$ & 3.14187E-07 & 2558.614 & $4.2 E+08$ & 4.45E-06 & $9.44 E+13$ \\
\hline 80 & $8.14 \mathrm{E}+09$ & 3.14187E-07 & 2558.614 & $4.2 \mathrm{E}+08$ & 4.76E-06 & $8.81 \mathrm{E}+13$ \\
\hline 85 & $8.14 \mathrm{E}+09$ & 3.14187E-07 & 2558.614 & $4.2 \mathrm{E}+08$ & 5.07E-06 & $8.27 \mathrm{E}+13$ \\
\hline 90 & $8.14 \mathrm{E}+09$ & 3.14187E-07 & 2558.614 & $4.2 \mathrm{E}+08$ & 5.39E-06 & $7.78 \mathrm{E}+13$ \\
\hline 95 & $8.14 \mathrm{E}+09$ & 3.14187E-07 & 2558.614 & $4.2 \mathrm{E}+08$ & $5.7 \mathrm{E}-06$ & $7.36 \mathrm{E}+13$ \\
\hline 100 & $8.14 E+09$ & 3.14187E-07 & 2558.614 & $4.2 E+08$ & $6.02 \mathrm{E}-06$ & $6.97 E+13$ \\
\hline 105 & $8.14 E+09$ & $3.14187 \mathrm{E}-07$ & 2558.614 & $4.2 E+08$ & $6.33 \mathrm{E}-06$ & $6.63 E+13$ \\
\hline 110 & $8.14 \mathrm{E}+09$ & 3.14187E-07 & 2558.614 & $4.2 \mathrm{E}+08$ & 6.65E-06 & $6.31 \mathrm{E}+13$ \\
\hline 115 & $8.14 E+09$ & 3.14187E-07 & 2558.614 & $4.2 \mathrm{E}+08$ & 6.96E-06 & $6.03 E+13$ \\
\hline 120 & $8.14 \mathrm{E}+09$ & 3.14187E-07 & 2558.614 & $4.2 \mathrm{E}+08$ & 7.27E-06 & $5.77 \mathrm{E}+13$ \\
\hline 125 & $8.14 E+09$ & 3.14187E-07 & 2558.614 & $4.2 E+08$ & 7.59E-06 & $5.53 E+13$ \\
\hline 130 & $8.14 \mathrm{E}+09$ & 3.14187E-07 & 2558.614 & $4.2 \mathrm{E}+08$ & $7.9 \mathrm{E}-06$ & $5.31 \mathrm{E}+13$ \\
\hline 135 & $8.14 \mathrm{E}+09$ & 3.14187E-07 & 2558.614 & $4.2 \mathrm{E}+08$ & $8.22 \mathrm{E}-06$ & $5.11 \mathrm{E}+13$ \\
\hline 140 & $8.14 E+09$ & 3.14187E-07 & 2558.614 & $4.2 E+08$ & $8.53 \mathrm{E}-06$ & $4.92 \mathrm{E}+13$ \\
\hline 145 & $8.14 E+09$ & 3.14187E-07 & 2558.614 & $4.2 E+08$ & $8.85 \mathrm{E}-06$ & $4.74 \mathrm{E}+13$ \\
\hline 150 & $8.14 E+09$ & 3.14187E-07 & 2558.614 & $4.2 E+08$ & $9.16 \mathrm{E}-06$ & $4.58 \mathrm{E}+13$ \\
\hline 155 & $8.14 \mathrm{E}+09$ & 3.14187E-07 & 2558.614 & $4.2 \mathrm{E}+08$ & 9.47E-06 & $4.43 E+13$ \\
\hline 160 & $8.14 \mathrm{E}+09$ & $3.14187 \mathrm{E}-07$ & 2558.614 & $4.2 \mathrm{E}+08$ & $9.79 \mathrm{E}-06$ & $4.29 E+13$ \\
\hline 165 & $8.14 E+09$ & 3.14187E-07 & 2558.614 & $4.2 E+08$ & $1.01 \mathrm{E}-05$ & $4.15 E+13$ \\
\hline 170 & $8.14 E+09$ & 3.14187E-07 & 2558.614 & $4.2 E+08$ & $1.04 \mathrm{E}-05$ & $4.03 E+13$ \\
\hline 175 & $8.14 \mathrm{E}+09$ & 3.14187E-07 & 2558.613 & $4.2 \mathrm{E}+08$ & 1.07E-05 & $3.91 \mathrm{E}+13$ \\
\hline 180 & $8.14 E+09$ & $3.14187 \mathrm{E}-07$ & 2558.613 & $4.2 \mathrm{E}+08$ & $1.1 \mathrm{E}-05$ & $3.8 \mathrm{E}+13$ \\
\hline 185 & $8.14 \mathrm{E}+09$ & 3.14187E-07 & 2558.613 & $4.2 \mathrm{E}+08$ & $1.14 \mathrm{E}-05$ & $3.69 \mathrm{E}+13$ \\
\hline 190 & $8.14 E+09$ & 3.14187E-07 & 2558.613 & $4.2 E+08$ & 1.17E-05 & $3.59 E+13$ \\
\hline 195 & $8.14 E+09$ & 3.14187E-07 & 2558.613 & $4.2 E+08$ & $1.2 \mathrm{E}-05$ & $3.5 \mathrm{E}+13$ \\
\hline 200 & $8.14 E+09$ & 3.14187E-07 & 2558613 & $4.2 \mathrm{E}+08$ & $1.23 \mathrm{E}-05$ & $3.41 E+13$ \\
\hline
\end{tabular}




\section{Appendix C3 - Alpha}

\begin{tabular}{|c|c|c|c|c|c|c|}
\hline ne & alpha(i) & delta(i) & Product & Sum & Delta & Alpha \\
\hline 205 & $8.14 \mathrm{E}+09$ & $3.14187 \mathrm{E}-07$ & 2558.613 & $4.2 \mathrm{E}+08$ & $1.26 \mathrm{E}-05$ & $3.33 E+13$ \\
\hline 210 & $8.14 \mathrm{E}+09$ & 3.14187E-07 & 2558.613 & $4.2 \mathrm{E}+08$ & $1.29 \mathrm{E}-05$ & $3.25 E+13$ \\
\hline 215 & $8.14 \mathrm{E}+09$ & $3.14187 \mathrm{E}-07$ & 2558.613 & $4.2 \mathrm{E}+08$ & $1.32 \mathrm{E}-05$ & $3.17 E+13$ \\
\hline 220 & $8.14 \mathrm{E}+09$ & 3.14187E-07 & 2558.613 & $4.2 \mathrm{E}+08$ & $1.36 \mathrm{E}-05$ & $3.09 \mathrm{E}+13$ \\
\hline 225 & $8.14 \mathrm{E}+09$ & $3.14187 \mathrm{E}-07$ & 2558.613 & $4.2 \mathrm{E}+08$ & 1.39E-05 & $3.02 E+13$ \\
\hline 230 & $8.14 \mathrm{E}+09$ & $3.14187 \mathrm{E}-07$ & 2558.613 & $4.2 \mathrm{E}+08$ & $1.42 \mathrm{E}-05$ & $2.96 E+13$ \\
\hline 235 & $8.14 \mathrm{E}+09$ & 3.14187E-07 & 2558.613 & $4.2 \mathrm{E}+08$ & $1.45 \mathrm{E}-05$ & $2.89 E+13$ \\
\hline 240 & $8.14 \mathrm{E}+09$ & $3.14187 \mathrm{E}-07$ & 2558.613 & $4.2 \mathrm{E}+08$ & $1.48 \mathrm{E}-05$ & $2.83 E+13$ \\
\hline 245 & $8.14 \mathrm{E}+09$ & 3.14187E-07 & 2558.613 & $4.2 \mathrm{E}+08$ & $1.51 \mathrm{E}-05$ & $2.77 E+13$ \\
\hline 250 & $8.14 \mathrm{E}+09$ & $3.14187 \mathrm{E}-07$ & 2558.613 & $4.2 \mathrm{E}+08$ & $1.54 \mathrm{E}-05$ & $2.72 E+13$ \\
\hline 255 & $8.14 \mathrm{E}+09$ & 3.14187E-07 & 2558.613 & $4.2 \mathrm{E}+08$ & $1.58 \mathrm{E}-05$ & $2.66 \mathrm{E}+13$ \\
\hline 260 & $8.14 \mathrm{E}+09$ & 3.14187E-07 & 2558.613 & $4.2 \mathrm{E}+08$ & $1.61 \mathrm{E}-05$ & $2.61 E+13$ \\
\hline 265 & $8.14 \mathrm{E}+09$ & 3.14187E-07 & 2558.613 & $4.2 \mathrm{E}+08$ & $1.64 \mathrm{E}-05$ & $2.56 E+13$ \\
\hline 270 & $8.14 \mathrm{E}+09$ & $3.14187 \mathrm{E}-07$ & 2558.613 & $4.2 \mathrm{E}+08$ & 1.67E-05 & $2.51 E+13$ \\
\hline 275 & $8.14 \mathrm{E}+09$ & 3.14187E-07 & 2558.613 & $4.2 \mathrm{E}+08$ & $1.7 \mathrm{E}-05$ & $2.47 E+13$ \\
\hline 280 & $8.14 \mathrm{E}+09$ & 3.14187E-07 & 2558.613 & $4.2 \mathrm{E}+08$ & $1.73 \mathrm{E}-05$ & $2.42 E+13$ \\
\hline 285 & $8.14 \mathrm{E}+09$ & $3.14187 \mathrm{E}-07$ & 2558.613 & $4.2 \mathrm{E}+08$ & $1.76 \mathrm{E}-05$ & $2.38 \mathrm{E}+13$ \\
\hline 290 & $8.14 \mathrm{E}+09$ & $3.14187 \mathrm{E}-07$ & 2558.613 & $4.2 \mathrm{E}+08$ & 05 & $2.34 \mathrm{E}+13$ \\
\hline 295 & $8.14 \mathrm{E}+09$ & 3.14187E-07 & 2558.613 & $4.2 \mathrm{E}+08$ & $1.83 \mathrm{E}-05$ & $2.3 E+13$ \\
\hline 300 & $8.14 \mathrm{E}+09$ & $3.14187 \mathrm{E}-07$ & 2558.613 & $4.2 \mathrm{E}+08$ & $1.86 \mathrm{E}-05$ & $2.26 \mathrm{E}+13$ \\
\hline 305 & $8.14 \mathrm{E}+09$ & 3.14187E-07 & 2558.613 & $4.2 \mathrm{E}+08$ & 1.89E-05 & $2.22 \mathrm{E}+13$ \\
\hline 310 & $8.14 \mathrm{E}+09$ & 3.14187E-07 & 2558.613 & $4.2 \mathrm{E}+08$ & $1.92 \mathrm{E}-05$ & $2.18 \mathrm{E}+13$ \\
\hline 315 & $8.14 \mathrm{E}+09$ & 3.14187E-07 & 2558.613 & $4.2 \mathrm{E}+08$ & $1.95 \mathrm{E}-05$ & $2.15 E+13$ \\
\hline 320 & $8.14 \mathrm{E}+09$ & 3.14187E-07 & 2558.613 & $4.2 \mathrm{E}+08$ & 1.98 & $2.11 E+13$ \\
\hline 325 & $8.14 \mathrm{E}+09$ & 3.14187E-07 & 2558.613 & $4.2 \mathrm{E}+08$ & $2.02 \mathrm{E}-05$ & $2.08 E+13$ \\
\hline 330 & $8.14 \mathrm{E}+09$ & 3.14187E-07 & 2558.613 & $4.2 \mathrm{E}+08$ & $2.05 \mathrm{E}-05$ & $2.05 E+13$ \\
\hline 335 & $8.14 \mathrm{E}+09$ & 3.14187E-07 & 2558.613 & $4.2 \mathrm{E}+08$ & $2.08 \mathrm{E}-05$ & $2.02 E+13$ \\
\hline 340 & $8.14 \mathrm{E}+09$ & 3.14187E-07 & 2558.613 & $4.2 \mathrm{E}+08$ & 2.11E-05 & $1.99 E+13$ \\
\hline 345 & $8.14 \mathrm{E}+09$ & 3.14187E-07 & 2558.613 & $4.2 \mathrm{E}+08$ & $2.14 \mathrm{E}-05$ & $1.96 \mathrm{E}+13$ \\
\hline 350 & $8.14 \mathrm{E}+09$ & 3.14187E-07 & 2558.613 & $4.2 \mathrm{E}+08$ & 2.17E-05 & $1.93 E+13$ \\
\hline 355 & $8.14 \mathrm{E}+09$ & $3.14187 \mathrm{E}-07$ & 2558.613 & $4.2 \mathrm{E}+08$ & $2.2 \mathrm{E}-05$ & $1.9 \mathrm{E}+13$ \\
\hline 360 & $8.14 \mathrm{E}+09$ & 3.14187E-07 & 2558.613 & $4.2 \mathrm{E}+08$ & $2.24 \mathrm{E}-05$ & $1.88 \mathrm{E}+13$ \\
\hline 365 & $8.14 \mathrm{E}+09$ & 3.14187E-07 & 2558.613 & $4.2 \mathrm{E}+08$ & $2.27 \mathrm{E}-05$ & $1.85 \mathrm{E}+13$ \\
\hline 370 & $8.14 \mathrm{E}+09$ & 3.14187E-07 & 2558.613 & $4.2 \mathrm{E}+08$ & $2.3 \mathrm{E}-05$ & $1.83 E+13$ \\
\hline 375 & $8.14 \mathrm{E}+09$ & 3.14187E-07 & 2558.613 & $4.2 \mathrm{E}+08$ & $2.33 \mathrm{E}-05$ & $1.8 \mathrm{E}+13$ \\
\hline 380 & $8.14 \mathrm{E}+09$ & 3.14187E-07 & 2558.613 & $4.2 \mathrm{E}+08$ & $2.36 \mathrm{E}-05$ & $1.78 \mathrm{E}+13$ \\
\hline 385 & $8.14 \mathrm{E}+09$ & 3.14187E-07 & 2558.613 & $4.2 \mathrm{E}+08$ & 2.39E-05 & $1.75 E+13$ \\
\hline 390 & $8.14 \mathrm{E}+09$ & 3.14187E-07 & 2558.613 & $4.2 \mathrm{E}+08$ & $2.42 \mathrm{E}-05$ & $1.73 E+13$ \\
\hline 395 & $8.14 \mathrm{E}+09$ & 3.14187E-07 & 2558.613 & $4.2 \mathrm{E}+08$ & $2.46 \mathrm{E}-05$ & $1.71 \mathrm{E}+13$ \\
\hline 400 & $8.14 \mathrm{E}+09$ & 3.14187E-07 & $A^{2558}-5913$ & $4.2 \mathrm{E}+08$ & $2.49 \mathrm{E}-05$ & $1.69 E+13$ \\
\hline
\end{tabular}


Appendix C3 - Bench Marking

\begin{tabular}{|c|c|c|c|}
\hline $\begin{array}{l}\text { Time } \\
{[s]}\end{array}$ & $\begin{array}{c}\mathbf{q p} \\
{[\mathrm{m} / \mathrm{s}]}\end{array}$ & $\begin{array}{l}\text { Time } \\
{[s]}\end{array}$ & $\begin{array}{c}\mathbf{q p} \\
{[\mathrm{m} / \mathrm{s}]}\end{array}$ \\
\hline 0 & 0.000261 & 30 & 0.000187 \\
\hline & & 60 & 0.00015 \\
\hline & & 90 & 0.000111 \\
\hline & & 120 & $9.36 \mathrm{E}-05$ \\
\hline & & 150 & 7.85E-05 \\
\hline & & 180 & $6.44 \mathrm{E}-05$ \\
\hline & & 210 & $5.45 \mathrm{E}-05$ \\
\hline & & 240 & 4.78E-05 \\
\hline & & 270 & $3.9 \mathrm{E}-05$ \\
\hline & & 300 & $3.66 \mathrm{E}-05$ \\
\hline & & 330 & 3.27E-05 \\
\hline & & 360 & $3.04 \mathrm{E}-05$ \\
\hline & & 390 & $2.85 \mathrm{E}-05$ \\
\hline & & 420 & $2.8 \mathrm{E}-05$ \\
\hline & & 450 & $2.71 \mathrm{E}-05$ \\
\hline & & 480 & $2.59 \mathrm{E}-05$ \\
\hline & & 510 & $2.5 \mathrm{E}-05$ \\
\hline & & 540 & $2.38 \mathrm{E}-05$ \\
\hline & & 570 & $2.47 \mathrm{E}-05$ \\
\hline & & 600 & $2.45 \mathrm{E}-05$ \\
\hline & & 630 & $2.36 \mathrm{E}-05$ \\
\hline & & 660 & 2.29E-05 \\
\hline & & 690 & $2.2 \mathrm{E}-05$ \\
\hline & & 720 & 2.37E-05 \\
\hline & & 750 & $2.26 \mathrm{E}-05$ \\
\hline
\end{tabular}


Appendix D - Filtration Drawings and Equipment Specifications

Appendix D1 - Filtration Drawings

Appendix D2 - Equipment Specifications 


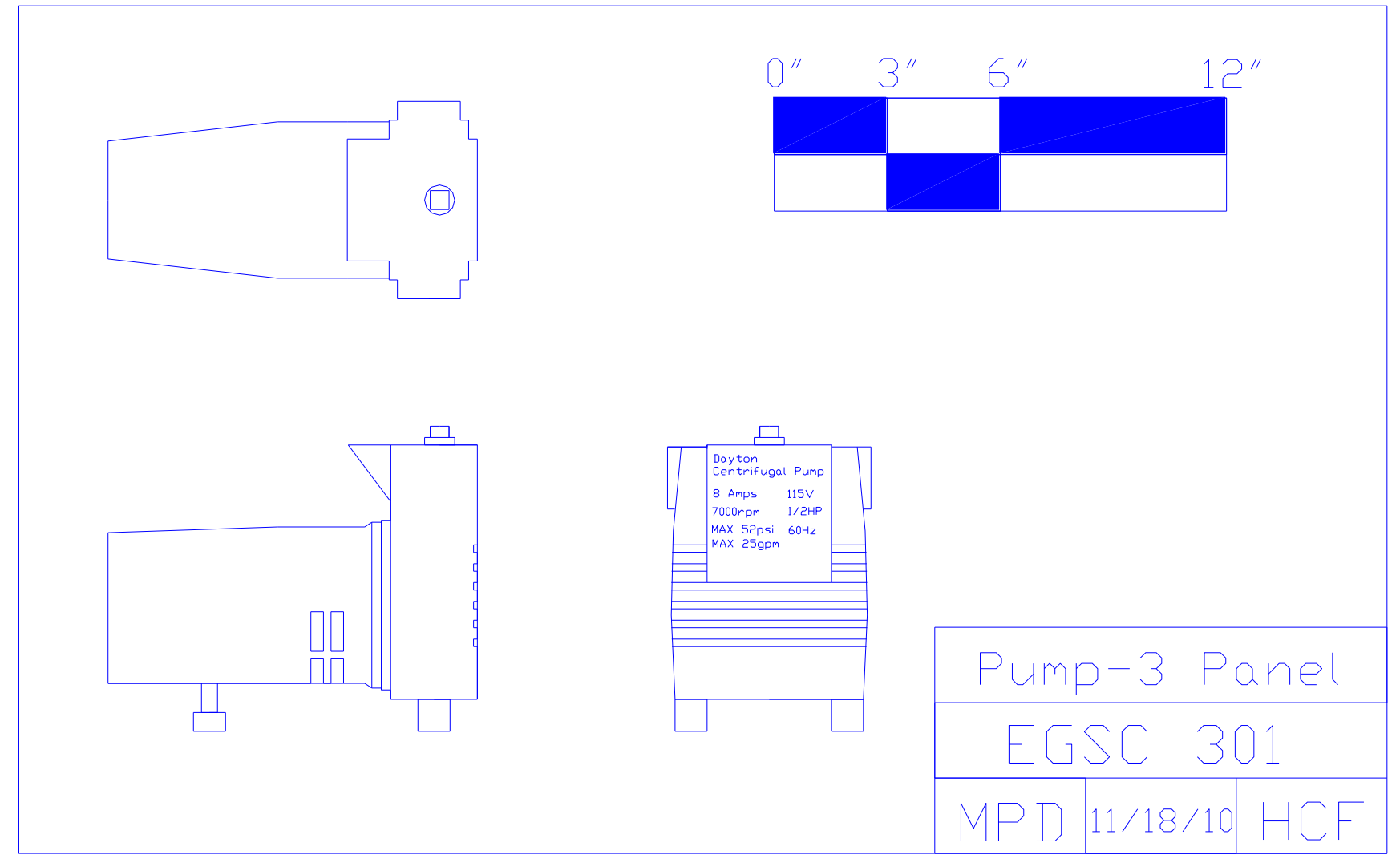

Figure D.1 - Three Panel View of Pump 


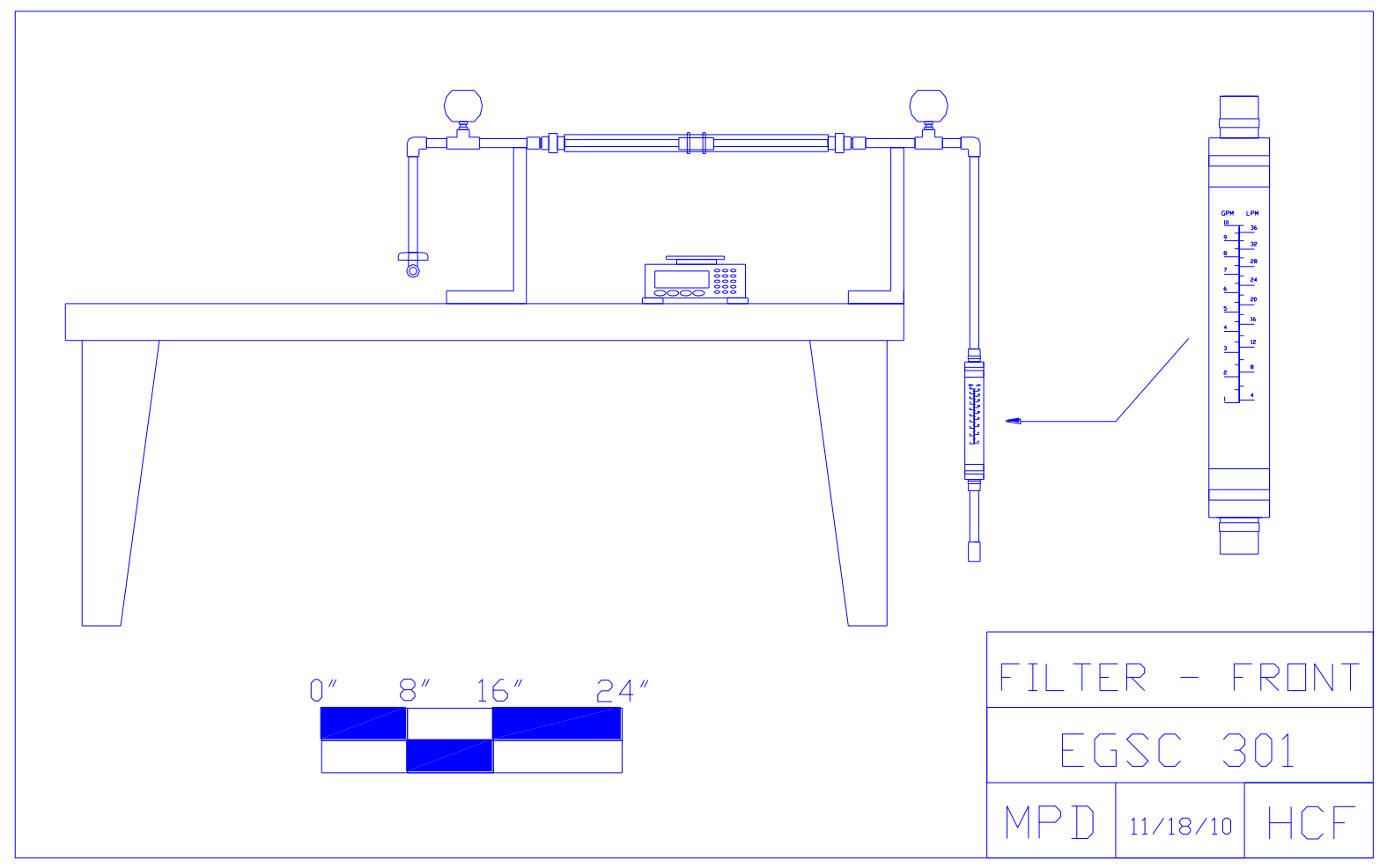

Figure D.2 - Front View of Filtration System 


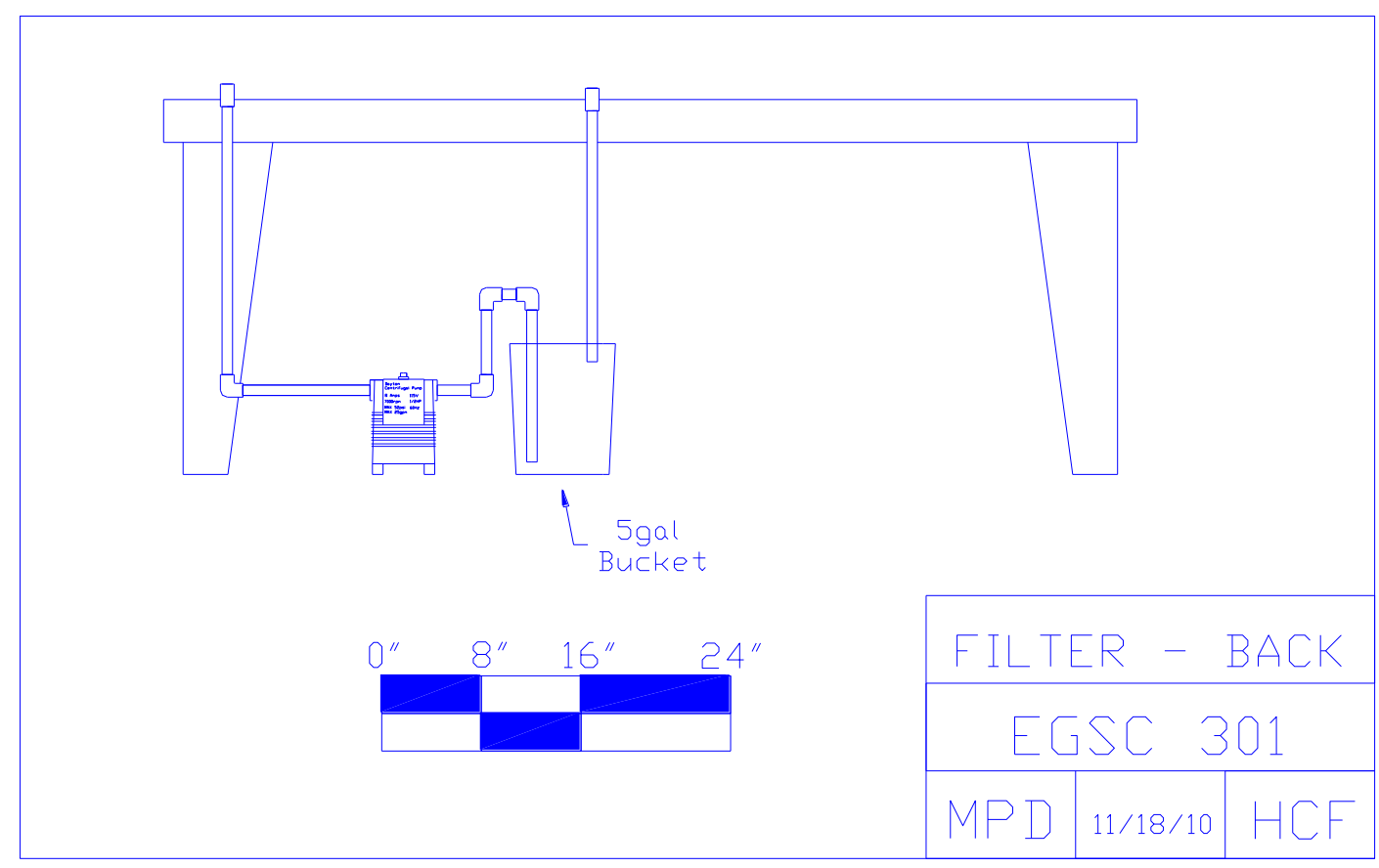

Figure D.3 - Back View of Filtration System 


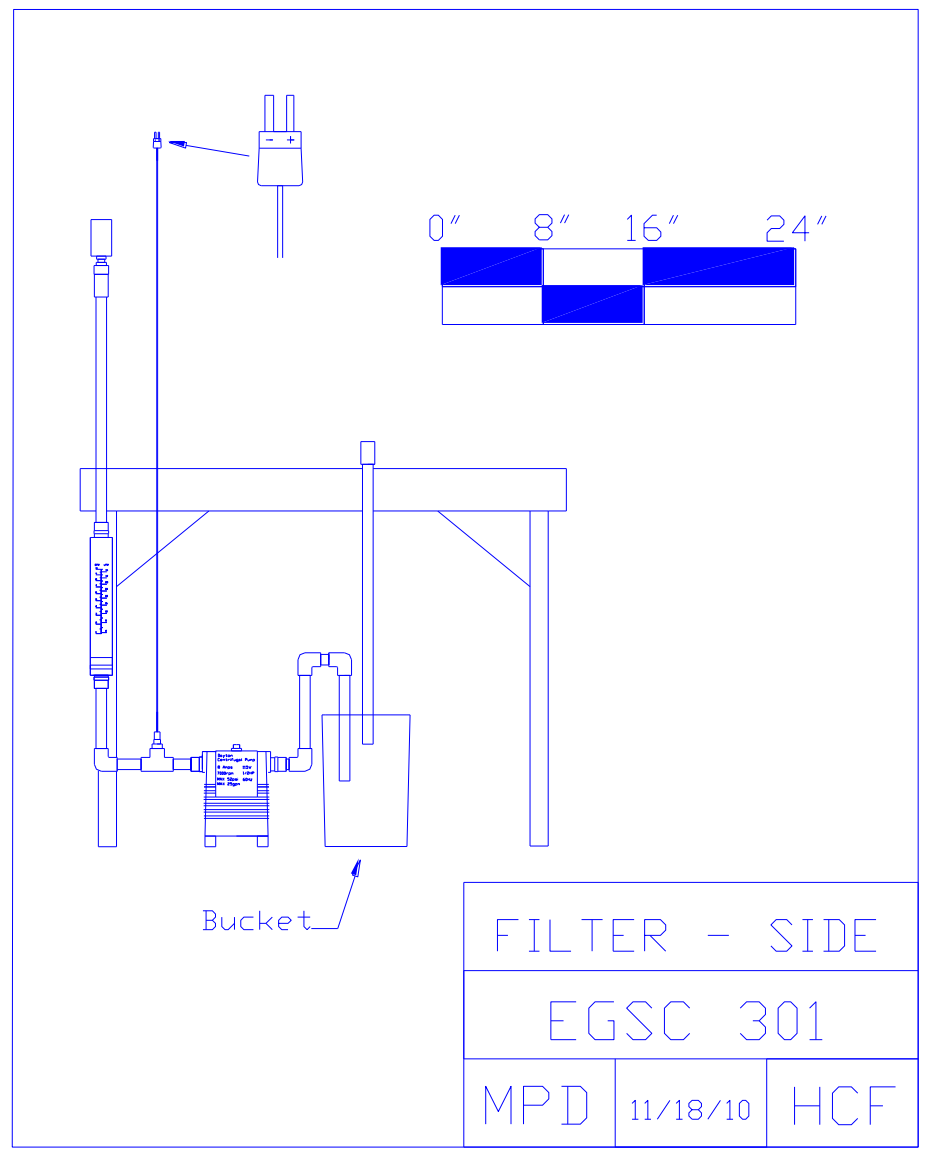

Figure D.4 - Side View of Filtration System 


\section{Appendix D2 - Equipment Specifications}

Filter Unit

\begin{tabular}{|l|l|l|}
\hline \multicolumn{1}{|c|}{ Parameter } & \multicolumn{1}{c|}{ Value } & Comments \\
\hline Manufacturer and Designation & Mott, 1403212-01-001 & \\
\hline Length & $24{ }^{\prime \prime}$ & \\
\hline ID & $0.5{ }^{\prime}$ & \\
\hline OD & $.625{ }^{\prime}$ & \\
\hline Material & Stainless Steel 314 & \\
\hline Nominal Pore Size & 0.1 microns & \\
\hline
\end{tabular}

Table D.1 - Filter Unit Specifications

$\underline{\text { Pump }}$

\begin{tabular}{|l|l|l|}
\hline \multicolumn{1}{|c|}{ Parameter } & \multicolumn{1}{c|}{ Value } & \multicolumn{1}{c|}{ Comments } \\
\hline Manufacturer and Designation & Dayton, 4CB57 & \\
\hline Pump Type & Centrifugal & \\
\hline HP Rating & 0.5 & \\
\hline Flow Range & 0 to 840 gph & \\
\hline Pressure Range & 0 to 44 psi & \\
\hline
\end{tabular}

Table D.2 - Pump Specifications

Flow Meter

\begin{tabular}{|l|l|l|}
\hline \multicolumn{1}{|c|}{ Parameter } & \multicolumn{1}{c|}{ Value } & \multicolumn{1}{c|}{ Comments } \\
\hline Manufacturer and Designation & Omega, FL46300 & \\
\hline Sensor Range & 0 to 20 gpm & \\
\hline Accuracy of Device & $+/-5 \%$ & \\
\hline
\end{tabular}

Table D.3 - Flow Meter Specifications

$\underline{\text { Pressure Gauge }}$

\begin{tabular}{|l|l|l|}
\hline \multicolumn{1}{|c|}{ Parameter } & \multicolumn{1}{c|}{ Value } & \multicolumn{1}{c|}{ Comments } \\
\hline Manufacturer and Designation & Omega, DPG1000B-100G & \\
\hline Sensor Range & 0 to $100 \mathrm{psig}$ & \\
\hline Accuracy of Device & $+/-.25 \%$ & \\
\hline
\end{tabular}

Table D 4 - Pressure Gauge Specifications

Microspheres

The two microsphere sizes utilized are as follows:

Larger Micro-Spheres (L-MS)

Particle Description:

Catalog number: BB01N

Polymer Description: PMMA (Dry)

Characteristics:

Mean Diameter \#1 (microns): 6.50 (Laser Diffraction)

Standard Deviation \#1 (microns): 3 to 10

Solids Content (wt. \%): 100

Calculated Data:

Density of Solid Polymer (g/ml): 1.19 
Number of Microspheres per ml: $6.954 \mathrm{e}+9$

Number of Microspheres/gram: 5.844e+9

Number of Microspheres per ml: $6.954 \mathrm{e}+9$

Surface Area (microns/gram): 7.757e+11

\section{Smaller Micro-Spheres (S-MS)}

Particle Description:

Catalog number: PP02N

Polymer Description: PMMA

Characteristics:

Mean Diameter \#1 (microns): 0.52 (PCS/QELS)

Antimicrobial: $0.1 \%$ NaN3

Solids Content (wt. \%): 10

Buffer: DI Water

Calculated Data:

Density of Solid Polymer (g/ml): 1.19

Number of Microspheres per ml: $1.160 \mathrm{e}+12$

Number of Microspheres/gram: 1.141e+13

Surface Area (microns/gram): 9.696e+12 
Appendix E - Response to Comments 
Notes on: Final Report - Development of Particle Capture Model as the Basis to a Permeate Volume Maximization Study by Foust, Herbert, Prasai, Sever, and Ghosehaja

Response to comments given in the first part of this document

1. No further experimentation was conducted.

2. Measurement uncertainty was largely ignored

3. Additional graphs were added to Appendix A2, Experimental results

4. Permeate flux will be utilized over permeate rates.

5. Additional appendices were added to better describe the system components and microspheres

Henry,

When you do call we need to talk about the final report.

You sent me your final report on 10/20 with accompanying files.

Unfortunately, due to my schedule I am only looking at your work now and of course I have a lot of questions.

However, I notice that while you did experimentation to benchmark your model there is very little in the report about that experimental work.

I would like to see: A picture of the test setup.

You need descriptions of:

1, The filter tubes: type, porosity, material, length, diameter, orientation, etc. etc.

2. Measurement equipment: pressure transducers, temperature sensors, flow meters.

3. Measurement uncertainties.

4. A more detailed operational procedures to obtain data.

5. Physical characteristics of the slurry at each solids concentration: Viscosity (or Consistency), Yield Stress, Density, particle distribution.

6. A micrograph of the particles.

7. Graphs that show for both your slurry and just water:

Filtrate Flux vs. axial velocity

Filtrate Flux vs. TMP

Filtrate Flux vs. Time

8. Explanation why the flow and pressure ranges were chosen, why the particular slurry and solids were chosen, etc.

9. Explanation on how cake parameters were obtained and your level of uncertainty in those parameters.

Is anyone checking your numbers? Your Figure 5 shows Experimental Validations. The values are unbelievably high. Even your lowest value of approximately $0.001 \mathrm{~m} 3 / \mathrm{s}$ is three orders of magnitude too high. I looked back at your Appendix A Excel file and see that you convert from 
$\mathrm{ml} / \mathrm{s}$ to $\mathrm{m} 3 / \mathrm{s}$ by dividing by 1000 . But you should have divided by 1000000 ! What you are showing is Liters/s and there are 1000 Liters in a cubic meter. I would have thought with all your authors things like this would be reviewed and caught. This is the reason why I did not worry about reviewing your work earlier.

Other thoughts.

1. Why were your tests so short? That is 10 to 15 minutes. To let the tubes dry for a week but only run filtration for a few minutes doesn't make sense. Furthermore, during that time period your are changing both axial velocity and TMP. For instance, your Figure 1 shows flow rate versus $\mathrm{dP}$. First off you need to state the $\mathrm{dP}$ is Transmembrane Pressure because there are other pressure drops, like the axial slurry pressure drop. Secondly, the data implies something is held constant, but your Excel file indicates that your are changing axial velocity every 30 seconds or so, therefore, I have no idea what the $\mathrm{dP}$ data are telling me.

2. In my experience the filter cake needs at least 60 minutes to be established. Your are changing both axial velocity, TMP every minute or so and your entire filtrate period is less than 30 minutes. I do not have a lot of confidence that the cakes you developed, obtained, and measured are good representations of cakes developed in the field. Do you have data from another source than your own so a better comparison can be made.

3. After digging through your Excel files I think I found that you used 0.5-inch Inside Diameter tubes and assuming you obtained the standard 2-foot long tubes then your filter area would be $0.261 \mathrm{ft} 2$. If I use your lowest flow rate of $0.000001 \mathrm{~m} 3 / \mathrm{s}=0.001 \mathrm{Liters} / \mathrm{s}=0.06 \mathrm{Liters} / \mathrm{minute}=$ $0.0159 \mathrm{gpm}$, then the flux is $0.0159 / 0.261 \mathrm{ft} 2=0.06 \mathrm{gpm} / \mathrm{t} 2$. This is high, which is typical when just starting to filter, however, if you had let the test rig filter for several hours or days the flux would be closer to $0.03,0.02 \mathrm{gpm} / \mathrm{ft} 2$, or lower.

Regards,

mark

Concerning your revised report, please convert all filtrate (or permeate) flow rates versus time, or axial velocity, or TMP to permeate flux. Flow rate is size dependent and most readers will not relate to your scale. You need to present the information on a filter surface area basis so comparisons can be made, i.e., gpm/ft 2 , or $\mathrm{m} 3 / \mathrm{m} 2$ ? $\mathrm{s}$, or $\mathrm{m} / \mathrm{day}$, or $\mathrm{cm} / \mathrm{hr}$, etc.

Furthermore, give the dimensions of the equipment used.

Example:

I.D. $=0.485$ inch \pm 0.003 inch

Active porous filter length $=22.5$ inches \pm 0.1 inch

Somewhere you state the tubes you used were $1 / 2$ inch inside diameter. How do you know? No tube I have received is exactly the listed dimension. For example, when I received my 1/2-inch tube from Mott I took an inside 
micrometer and measured the ID at different depths into each end of the tube and in several locations along the internal perimeter. My measurements range from 0.480 inch to 0.487 inch, with an average of 0.485 inch and a standard deviation of 0.003 inch. When you discuss hardware and give dimensions as I just discussed it gives the reader a lot of confidence that you were careful about doing things accurately and indicates the level of certainty one can expect from an experiment.

1. Page 3, Introduction, $1^{\text {st }}$ Paragraph, $1^{\text {st }}$ Sentence: Frank Tiller needs a reference. Done

2. Page 3, Introduction, $2^{\text {nd }}$ Paragraph, $3^{\text {rd }}$ Sentence: Reference [7] is out of order. Need to reference 1-6 first. Malay/Firat provide correct sequence of citations

3. Page 3, Introduction, $3^{\text {rd }}$ Paragraph, last Sentence: Does this mean that particles $>10$ microns cannot become part of the filter cake. What evidence is there of this fact? Hank

4. Page 3, Introduction, $4^{\text {th }}$ Paragraph, last Sentence: Do not understand what is meant by "relative" insignificance. How is insignificance determined? Done

\section{a. Compressibility, particle concentration, and cake rheology must be important to filtrate flux and permeability. How can they be insignificant?}

5. Page 4, Lu, Ju, and Hwang, $1^{\text {st }}$ Paragraph, $4^{\text {th }}$ Sentence: How does particle distribution with an average of a diameter of 10 micron be consisted of mostly 1-micron sized particles? Hank

6. Page 4, Lu, Ju, and Hwang, $1^{\text {st }}$ Paragraph, $5^{\text {th }}$ Sentence: This sentence means that the largest particle size retained became smaller with time? Hank

7. Page 4, Lu, Ju, and Hwang, $2^{\text {nd }}$ Paragraph, $3^{\text {rd }}$ Sentence: This sentence implies the researchers, i.e., Foust, et al., did not develop any model, but used the one found in Reference 1. Is this true? This must be clearly stated. Not sure where this statement is.

8. Page 4, Lu, Ju, and Hwang, $2^{\text {nd }}$ Paragraph, $4^{\text {th }}$ Sentence: Doesn't shear stress increase when "bulk" velocity increase? How can you disassociate the two?

9. Page 4, Lu, Ju, and Hwang, $3^{\text {rd }}$ Paragraph, $2^{\text {nd }}$ Sentence: How is Beta sub c measured? Measurement of interparticle forces, friction coefficient between particles, and an equation for the force balance determines Beta $\odot$.

10. Page 4, Lu, Ju, and Hwang, ${ }^{\text {th }}$ Paragraph, ${ }^{1 \text { st }}$ Sentence: Reference for Tiller and for Kozeny are not given in the reference section and the style of references is not consistent with the rest of the report.

11. Page 4, Lu, Ju, and Hwang, $4^{\text {th }}$ Paragraph, Last Sentence: How is it known that smaller particles are in the upper layers?

Typically, filtration starts at a high bulk phase velocity and TMP, which results in a large permeate flux. These conditions for particles that aren't too big results in the first 
layers having a wide PSD and including larger particles. As the process goes on, the permeate flux decreases and with this the size of particles captured decreases (see Figure 1). Eventually, there are no particles small enough and a quasi-steady state begins.

\section{Incorporated}

12. Page 5, Lu, Ju, and Hwang, $5^{\text {th }}$ Paragraph, $2^{\text {nd }}$ Sentence: What are Brownian forces? Brownian motion is understood.

13. Page 5, Lu, Ju, and Hwang, $6^{\text {th }}$ Paragraph, Last Sentence: When the cake is more porous ("higher" porosity) does that lead to a higher filtrate flux? What is meant by a "lower packing porosity?" Utilizing Kozeny's equation for spherical particles and a given average size of particles within the cake, a higher packing porosity results in a lower specific resistance.

\section{Incorporated}

15. Page 5, Lu, Ju, and Hwang, $7^{\text {th }}$ Paragraph, $2^{\text {nd }}$ Sentence: Stated is a range of 0.5 to 10 microns, but previously a range of 1 to 20 microns was stated for the same work. This is inconsistent. These are two different studies.

16. Page 5, Lu, Ju, and Hwang, $7^{\text {th }}$ Paragraph, $3^{\text {rd }}$ Sentence: Stated is the term "filtration pressure," is this axial pressure drop or TMP? Be clear. Done

17. Page 5, Lu, Ju, and Hwang, $5^{\text {th }}$ Paragraph, Last Sentence: Here it is stated that cake compressibility is significant but in the Introduction it was stated to be insignificant. This is inconsistent. Done

18. Page 5, Lu, Ju, and Hwang, $6^{\text {th }}$ Paragraph, Last Sentence: How does higher axial velocities reduce the average particle size?

\section{Given}

20. $Q_{p}=\frac{.425 f u^{2}}{\phi v \tan \theta} d_{p}-\frac{\left(\rho_{p}-\rho_{s}\right)}{18 \mu \phi} g d_{p}^{2}+\frac{15.25 f^{2} u^{4}}{4608 v^{g}} d_{p}^{3}$

21. $Q_{p}=\frac{\Delta \mathrm{P}}{\mu\left(R_{m}+R_{\ell}\right)}=c_{1} d_{p}-c_{2} d_{p}^{2}+c_{3} d_{p}^{3}$

22. For a given permeate flux, increasing $u$, axial velocity, results in lowering dp.

23.

24. Page 6, Song and Elimelech, Last Paragraph, $3^{\text {rd }}$ Sentence: What is the difference between "solid" and "particle?" 
25. Page 6, Song and Elimelech, Last Paragraph, Last Sentence: What are Brownian particles? Particles with a colloidal size range.

26. Page 6, Tien et al., $1^{\text {st }}$ Paragraph, $1^{\text {st }}$ Sentence: “...broad are" should be "...broad area" Done

27. Page 7, Foley, Malone, and MacLoughlin, $1^{\text {st }}$ Paragraph, Last Sentence: Since the paragraph discusses cake layers do your words, "cake thickness" in this last sentence mean a layer of cake or the entire cake (all the layer)? Entire cake.

28. Page 7, Foley, Malone, and MacLoughlin, $1^{\text {st }} \& 2^{\text {nd }}$ Paragraphs, and throughout report: What is the difference among $d_{p}, a_{p}, \alpha_{p}, R_{\max }$ ? Need consistency throughout, independent of what other authors use so the reader can follow the rationale. List of nomenclature will be provided.

29. Page 7, Foley, Malone, and MacLoughlin, $2^{\text {nd }}$ Paragraph: I do not follow the logic. 0 microns is $d_{p}(0)$. How can particle that does not exist have any effect on filtration? $\mathbf{D p}(\mathbf{0})$ simply refers to the cut-off diameter of the first layer of the cake.

30. Page 7, Sharma and Civan, $1^{\text {st }}$ Paragraph, $3^{\text {rd }}$ Sentence: “These equations were..." Only a single equation, Eq. 5, is shown. Done

31. Page 7, Sharma and Civan, $1^{\text {st }}$ Paragraph, Last Sentence: What is meant by“....critical permeability of the membrane?" I assume you are not discussing the cake. The question they were asking is the following: is there a critical permeability of the membrane below which a cake will not form?

32. Page 8 , Implications for filtration..., $1^{\text {st }}$ Paragraph, $1^{\text {st }}$ Sentence: While assuming that "all are at or above 1 micron," may make your problem easier to solve is it realistic? Yes. In Duignan (2003), most of the PSD presented were in the range of 1 to 10 micron.

33. Page 8, Implications for filtration..., $1^{\text {st }}$ Paragraph, $1^{\text {st }}$ Sentence: Reference as (Lu and Ju, 1989; Foley et al., 1995) are not consistent with the rest of the paper [1] [10].

34. Page 8, Implications for filtration..., $1^{\text {st }}$ Paragraph, $1^{\text {st }}$ Sentence: How was Eq. 7 derived. I seems to come from nowhere and therefore not understandable.

35. Page 8, Implications for filtration..., Equation 7: What is $Q_{p}$ ?

\section{Permeate flux, change made. Done}

37. Page 9, Implications for filtration...: All the symbols need defining. Done

38. Page 10, Operating Procedure, Item No. 1: It would be very useful to show a diagram, picture, or both of the experimental test equipment to understand this section. Done

39. Page 10, Operating Procedure, Item No. 2: You previous mentioned about modeling with radioactive waste. Why are your tests with water acceptable? Explain you goal. A 
DI/Microsphere slurry was utilized for safety reasons and to provide accuracy in modeling the specific resistance of each cake layer.

40. Page 10, Operating Procedure, Item No. 2: You can send a sample of your material to many different labs to obtain physical property data. This was not done.

41. Page 10, Operating Procedure, Item No. 3: Mention if the particles can be damage by that action of the pump. It's possible and analysis should have been conducted to visually inspect the particles, but this was not done. It was simply assumed that particles remained spherical.

42. Page 10, Operating Procedure, Item No. 4: Why not directly return the filtrate to the slurry tank instead of having batches? With batches your concentration goes up and then it takes a big drop and the cycle repeats. See Drawings.

43. Page 10, Operating Procedure, Item Nos. 7, 8, and 9: Who is doing the providing and who is doing the receiving? Those performing the experiments, which were myself, Malay, Bijeta Prasai, and one other student notes problems, ran experiments to procedure, and carefully recorded results. There were verbal procedures for cooling, cleaning, and measuring.

44. Page 10, Experimental Design, $2^{\text {nd }}$ Paragraph, $1^{\text {st }}$ Sentence: "Details are given below" of tubes. Table 1 does not give any details of the tubes. The details and pictures would be very informative. Done

45. Page 11, Friction factor experiments, Under Equation 15: What is the Reynolds number based on, the tube diameters or particle sizes? Tube diameter.

46. Page 11, Friction factor experiments, $3^{\text {rd }}$ Paragraph, Only Sentence: You state 200 grams of the larger spheres." Larger than what? You do not talk about specific sizes until Page 14 , therefore you should discuss the size difference for the ready to understand the impact.

47. Two different types of microspheres were utilized

48. .4 to .6 microns

\section{3 to 10 microns}

50. Page 11, Friction factor experiments, $4^{\text {th }}$ Paragraph: included in your burger dots you should describe how TMP is measured, its accuracy and any limitations. Done

51. Page 12, Friction factor experiments, $4^{\text {th }}$ Paragraph, Second to last Sentence: You state ",which have a narrow PSD. That PSD should be shown. Done

52. Page 12, Determination of concentration of solids in cake, $1^{\text {st }}$ Paragraph, $2^{\text {nd }}$ Sentence: You state a mass of solids has the symbol w. A list of symbols in the report will help immensely. Malay/Firat 
53. Page 12, Determination of concentration of solids in cake, $2^{\text {nd }}$ Paragraph, 1 st Sentence: I believe the past tense of tare is tared. Done

54. Page 12, Determination of concentration of solids in cake, Eqs 18 and 19: How is 19 obtained from 18 . Should be clear now.

55. Page 13, Determination of concentration of solids in cake, before Eq. 21: Why are spherical particles used? Done

56. Page 13, Filter Cleaning: Why is a basic and not an acid used to clean the filters. Describe your success with cleaning and a return to clean fluxes. Malay

57. Page 13, Experimental Results: Should this section be called Appendix A?

\section{Page 15, Figure 1: Show the TMP range and temperature, too Firat/Malay}

59. Page 15, Determination of friction factor for filter system + Various Slurries, Equation 22: Isn't this equation actually Equation 15 ? I repeated it.

60. Page 15/16, Figure 2: What is meant by for Tubes 1,4 , and DI? Do you mean Tube 1 with a certain slurry, Tube 4 with a certain slurry, and some unknown tube that just used water?

61. Page 17, Table 2: You should state the measurement uncertainty. I don't know if we can do much with this issue. Ideas?

62. Page 18, Experimental Validation of Permeate Rates, $1^{\text {st }}$ Paragraph: You state that, "When a slightly lower values... brings in question the results." This is unclear and you need to be clear at what you are telling the reader.

63. Page 18, Genetic Algorithms, $1^{\text {st }}$ Paragraph, $1^{\text {st }}$ Sentence, “...genetic algorithms ...was beyond the scope of this project." I thought that was the purpose of your work, to develop a genetice algorithm to better model experimental data. If I am wrong please make this clear in the Introduction of the report. I'll make sure this is stated up front.

64. Page 19, Perspective, Burger Dots. This issues need to be discussed up front in the procedures/experimental portion to give a heads-up to the problems expected/encountered and what was done, if anything about them, and how they could of effected the results. I'll make sure this is stated up front.

65. Page 20, Perspective, $4^{\text {th }}$ Paragraph, $1^{\text {st }}$ Sentence: Why should the physics of existing models "not be questioned?" Science is about questioning at all times and when good answers do not result such models fall to the wayside. Done 
A-76 


\section{Distribution:}
A.B. Barnes, 999-W
D.A. Crowley, 773-43A
S.D. Fink, 773-A
B.J. Giddings, 786-5A
C.C. Herman, 999-W
S.L. Marra, 773-A
A.P. Fellinger, 773-41A
F.M. Pennebaker, 773-42A
W. R. Wilmarth, 773-A
M.E. Stone, 999-W
M.R. Duignan, 786-5A
C.A. Nash, 773-24A
M.R. Poirier, 773-42A 